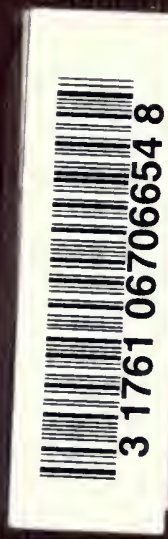

DEO FN NIA PUBLICATIONS OF HE UNIVBRSITY OF CHICAGO

STUDIES IN GENGRAL PHYSIOLOGY

JACQUNS LOEB 


Digitized by the Internet Archive in 2007 with funding from Microsoft Corporation 
THE DECENNIAL PUBLICATIONS OF THE UNIVERSITY OF CHICAGO 


\section{THE DECENNIAL PUBLICATIONS}

ISSUED IN COMMEMORATION OF THE COMPLETION OF THE FIRST TEN YEARS OF THE UNIVERSITY'S EXISTENCE

AUTHORIZED BY THE BOARD OF TRUSTEES ON THE RECOMMENDATION OF THE PRESIDENT AND SENATE

EDITED BY A COMMITTE APPOINTED BY THE SENATE

EDWARD CAPPS

STARR WILLARD CUTTING BOLLIN D. SALISBERX

JAMES ROWLAND ANGELL WILLIAM I. THOMAS SHAILER MATHEWS

CARL DARLING BCCK FREDERIC IVES CARPENTER OSFAR BOLZA

JULIUS STIEGLITZ JACQEES LOEB 


\section{THESE VOLUMES ARE DEDICATED}

TO THE MEN AND WOMEN

OF OUR TIME AND COUNTRY WHO BY WISE AND GENEROU'S GIVING HAVE ENCOURAGED THE SEARCH AFTER TRUTH

IN ALL DEPARTMENTS OF KNOWLEDGE 
STUDIES IN GENERAL PHYSIOLOGY 
. 


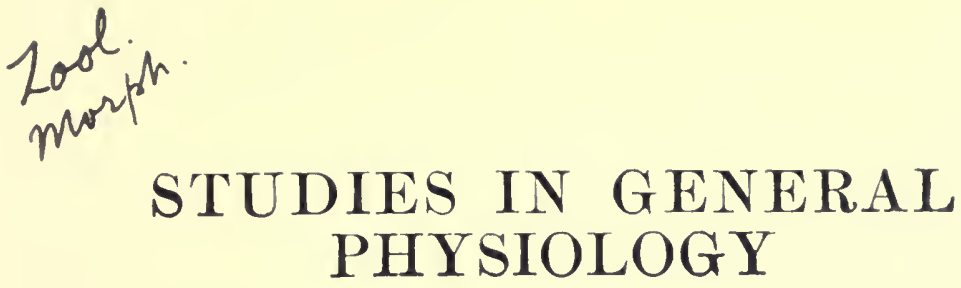

BY

JACQUES LOEB

FORMERLY OF THE DEPARTMENT OF PHYSIOLOGY

NOW PROFESSOR OF PHYSIOLOGY IN THE

DNIVERSITY OF CALIFORNIA

$$
\frac{65640}{19 / 5^{2} / 00^{\circ}}
$$

THE DECENNIAL PUBLICATIONS

SECOND SERIES VOLUME XV

PART II

CHICAGO

THE UNIVERSITY OF CHICAGO PRESS

1905 
Copyright 1905

BY THE UNIVERSITY OF CHICAGO 


\section{TABLE OF CONTENTS}

\section{PART I}

I. The Heliotropism of Animals and its Identity with the Heliotropism of Plants - $\quad$ - $\quad$ - $\quad$ - $\quad$ - 1

II. Further Investigations on the Heliotropism of Animals and its Identity with the Heliotropism of

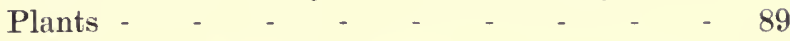

III. On Instinct and Will in Animals - - - 107

IV. Heteromorphosis - $\quad-\quad-\quad-\quad-\quad-\quad-115$

V. Geotropism in Animals - $\quad$ - $\quad$ - $\quad$ - $\quad$ - $\quad-176$

VI. Organization and Growth - $\quad$ - $\quad$ - $\quad$ - $\quad$ - $\quad$ - 191

VII. Experiments on Cleavage - _ _ _ - - 253

VIII. The Artificial Transformation of Positively Heliotropic Animals into Negatively Heliotropic and vice versa - $\quad$ - $\quad$ - $\quad$ - $\quad$ - $\quad$ - $\quad$ - $\quad$ - 265

IX. On the Development of Fish Embryos with Sup-

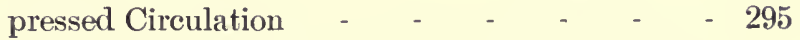

X. On a Simple Method of Producing from One Egg Two or More Embryos Which Are Grown

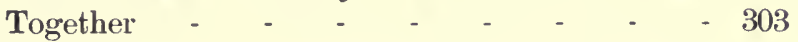

XI. On the Relative Sensitiveness of Fish Embryos in Various Stages of Development to Lack of Oxygen and Loss of Water - $\quad-\quad c_{1} \quad-\quad 309$

XII. On the Limits of Divisibility of Living Matter - 321

XIII. Remarks on Regeneration - - - - - 338

XIV. Contributions to the Brain Physiology of Worms - 345

XV. The Physiological Effects of Lack of Oxygen - - 370 


\section{PART II}

XVI. The Influence of Light on the Development of Organs in Allimals - $\quad$ - $\quad$ - $\quad$ - $\quad$ -

XVII. Has the Central Nervous System Any Influence upon the Metamorphosis of Larve? - - 436

XVIII. On the Theory of Galvanotropism - - - 440

XIX. The Physiological Effects of Ions. I - - $\quad 450$

XX. On the Physiological Effects of Electrical Wares - 482

XXI. The Physiological Problems of Today - _ $\quad$ - 497

XXII. The Physiological Effects of Ious. II - _ - 501

XXIII. Why Is Regeneration of Protoplasmic Fragments without a Nucleus Difficult or Impossible? - 505

XXIV. On the Similarity between the Absorption of Water by Muscles and by Soaps - $\quad$ - $\quad$ - $\quad$ - 510

XXV. On Ions Which Are Capable of Calling Forth Rhythmical Contractions in Skeletal Muscle - 518

XXVI. On the Nature of the Process of Fertilization and the Artificial Production of Normal Larvæ (Plutei) from the Unfertilized Eggs of the SeaUrchin

XXVII. On Ion-Proteid Compounds and Their Rôle in the Mechanies of Life-Phenomena. - The Poisonous Character of a Pure NaCl Solution - - 544

XXVIII. On the Different Effects of Ions upon Myogenic and Neurogenic Rhythmical Contractions and upon Embryonic and Muscular Tissue - -

XXIX. On the Artificial Production of Normal Larvæ from the Unfertilized Eggs of the Sea-Urchin (Arbacia) - - - - $\quad$ - $\quad$ - $\quad$ - 576

XXX. On Artificial Parthenogenesis in Sea-Urchins - 624

XXXI. On the Transformation and Regeneration of Organs

XXXII. Further Experiments on Artificial Parthenogenesis and the Nature of the Process of Fertilization - 
XXXIII. Experiments on Artificial Parthenogenesis in Annelids (Chretopterus) and the Nature of the Process of Fertilization - $\quad$ - $\quad$ - $\quad$ - $\quad 646$

XXXIV. On an Apparently New Form of Muscular Irritability (Contact-Irritability?) Produced by Solutions of Salts (Preferably Sodium Salts) Whose Anions Are Liable to Form Insoluble Calcium

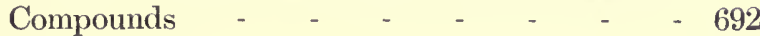

XXXV. The Toxic and the Antitoxic Effects of Ions as a Function of Their Valency and Possibly Their Electrical Charge - $\quad$ - $\quad$ - $\quad$ - $\quad$ - $\quad$ - 708

XXXVI. Maturation, Natural Death, and the Prolongation of the Life of Unfertilized Starfish Eggs (Asterias Forbesii) and Their Significance for the Theory of Fertilization - - _ -

XXXVII. On the Production and Suppression of Muscular Twitchings and Hypersensitiveness of the Skin by Electrolytes - $\quad$ - $\quad$ - $\quad$ - $\quad$ - $\quad$ - 748

XXXVIII. On the Methods and Sources of Error in the Experiments on Artificial Parthenogenesis - 766

INDEX 
- 
PAR'T II 



\section{XVI}

THE INFLUENCE OF LIGHT ON THE DEVELOPMENT OF ORGANS IN ANIMALS ${ }^{1}$

\section{EARLIER EXPERIMENTS}

Two GREAT series of experiments which Nature herself has made are at our disposal for answering the question as to what effect light has on the development of animals; namely, the intra-uterine development, and the development of animals living in caves. The fact that intra-uterine development goes on in complete darkness proves that the formation of the embryo and its organs, histological differentiation, and considerable growth can occur and continue for a long time in the abse ce of light. As far as animals living in caves are concerned, some of them differ from the same forms which live in the light in the development of single organs, such as eyes, antennæ, and pigment. It has not, however, as yet been proved that this peculiarity of the cave inhabitants is a direct effect of the lack of light upon their development; but granting that it is the direct result of lack of light, it follows from a summation of the facts in hand that where light has any direct effect whatsoever on development, it evidently makes itself felt only upon the development of individual organs and not upon the development in general.

It is strange that, notwithstanding the definiteness of these facts, experimental work on the influence of light on the development of organs in animals has been directed mostly to the question whether light promotes or inhibits development and growth of animals in general.

1 Pfiugers Archiv, Vol. LXIII (1895), p. 273. 
It is not to be wondered at that the various investigators arrived at diametrically opposite results.

Edwards states that frogs' eggs do not develop and soon die when inclosed in a dark box, while the development takes place in an open box which is exposed to the light. According to Edwards, even the young larvæ require a longer time to develop in the dark than in the light. Edwards's statements are based on very few experiments. Dutrochef repeated the experiments of Edwards, and found that where the supply of oxygen was sufficient and the temperature was the same in the two boxes, the eggs of Batrachians developed as well and as rapidly in the dark as in the light. These facts indicate that in Edwards's experiments the eggs suffered from lack of oxygen and exposure to a low temperature.

Béclard published a short communication on the influence of light on the development of the eggs and the larvæ of flies. He placed the eggs under colored bell-jars, and found that after four or five days development was most advanced under the violet and blue jars, and least under the green. I cannot understand the experiments of Béclard, as fly larvæ hatch in about two days in summer, and up to this time their size depends on the size of the eggs, since further growth takes place only when the larvæ find food in which to bury themselves. The statements of Beclard regarding the influence of light on the production of carbon dioxide in animals are also doubtful.

It is rather strange, though characteristic, that in the scientific literature of our subject one frequently finds serious mention of the investigations of General Pleasanton, made on six pigs. The general put three pigs into a stall with violet windows, and three into a stall with ordinary windows. While the three pigs exposed to violet light gained 398 pounds in four months, the others gained during the same 
time 386 pounds in weight. From this observation Pleasanton concluded that violet light is favorable to the growth of pigs. General Pleasanton's book is printed in blue type, and gives an explanation of all natural phenomena, from love down to the activity of a volcano.

Emil Young made a series of experiments on the influence of colored light on development. He concluded that violet light hastens to a certain degree the development of frogs' eggs, and the growth of embryos, while green light is fatal to or greatly retards development. Young's results are incomprehensible. The larvæ of frogs develop naturally in daylight, and the latter contains more green light than light which has passed through a green screen, and should according to Young be fatal. We might, perhaps, assume that some other light counteracts the effect of the green light sufficiently to do away with this fatal effect. From Young's experiments, however, this does not seem to be the case. It is quite possible that other conditions (such as the development of micro-organisms) affected the results of Young's experiments, which lasted through several weeks.

Driesch used monochromatic light and carried out the same experiments as Young on freshly fertilized eggs of Rana, Echinus, and Planorbis, and found, in all cases, that light "has no influence on the segmentation or the formation of organs; under otherwise similar conditions these phenomena occur with the same velocity in darkness, in white, in green, in violet, or in other lights."

In my experiments on heteromorphosis in Naples, I observed that the polyps of Eudendrium racemosum are positively heliotropic, and that the number of polyps which develop is apparently dependent on the intensity of the light. It seemed that fewer polyps were developed in weak light than in strong light. This accidental observation led me to study the influence of light on the development of organs 
iu Eudendrium racemosum more closely in Woods Hole. The results of these observations are briefly reported in the following pages.

\section{NEW EXPERIMENTS}

1. The species of Eudendrium studied in Woods Hole has the same name as that in Naples-namely, Eudendrium racemosum; it is, however, not certain that the two forms are identical. The following statements hold for the form in Woods Hole. When fresh stems of Eudendrium are put into an aquarium, all the polyps soon fall off, probably due to unavoidable injury in collecting and handling the material. In the course of a few days, however, with a good supply of oxygen and a sufficiently high temperature, new polyps are developed. It was the dependence of this new development on light which was studied.

A large quantity of vigorous colonies was collected each time. Long stems were picked and put in separate vessels, ten being distributed into each vessel, all of which contained an equal quantity of sea-water. Each of the stems usually formed from ten to twenty polyps. The different vessels were exposed to various kinds of light. In each experiment I therefore dealt, not with the development of a single - polyp, but with a large number of them. I thought it necessary, furthermore, to make another set of control experiments by exposing the same stems successively to different kinds of light.

Experiment 1.-On August 8 a number of stems of the same culture of Eudendrium was divided as equally as possible between two vessels, in the manner described above. One of the vessels was exposed to diffuse daylight; the other was placed in a dark box which was ventilated every evening. The supply of oxygen was the same in the light as in the dark, and the temperature was always the same in the two vessels. 
On August 14 over fifty polyps had dereloped in the vessel which was exposed to light, while in the vessel kept in the dark not a single polyp had been formed. The experiment was continued until September 1; the polyps thrived and increased in number in the light, while in the dark not a single polyp had yet been formed. The stems which up to this time had been in the dark were now exposed to the light. On September 6-that is to say, in five days-several polyps developed on each stem. The number of polyps increased from day to day. The same stems, which in three weeks had been unable to form a single polyp in the dark, developed a great number of them in five days when exposed to the light. The control animals in the light had developed polyps from the first.

Experiment 2.-On August 16 the stems of a new colony were divided equally among three vessels, two of which were placed in the dark and one in the light. As usual, numerous polyps were formed in the light in the course of five days; no polyps were formed at first in the dark. This experiment was also continued until September 1. By that time no polyps had yet developed on the stems kept in one of the darkened vessels; two stems in the other darkened vessel had developed six polyps. The animals were then exposed to light; in five days all the stems had produced new polyps.

Experiment 3.--On August 25 one half of a Eudendrium colony was placed in diffuse light, while the other half was put in the dark. On September 1 a large number of polyps had been developed in the light; but in the dark only roots and no polyps had been developed. Conditions remained the same until September 5, when the animals which had been kept in the dark were exposed to the light. On the following day they were accidentally killed.

These experiments show that light favors the development of polyps in Eudendrium; that no polyps, or only very 
few, are developed in the dark; that darkness does not, however, interfere with the development of roots.

2. It was of interest now to establish which rays of the visible spectrum favor the development of polyps. The effect of light on plants is known to be very strikingly a function of the wave-length. Assimilation and in part the formation of chlorophyll are pre-eminently functions of the long wave-lengths. The heliotropic phenomena are essentially a function of the blue rays. According to Sachs, the ultra-violet rays are of special importance in the formation of blossoms in certain plants. I have shown that the short light-waves are most effective heliotropically in animals also. From this, however, no conclusions can be drawn as to which rays influence most especially the formation of polyps. I therefore studied this subject experimentally. Unfortunately, these experiments were hampered because no other means of obtaining monochromatic light were at my disposal than the use of blue and red glass. I had special boxes made for these experiments which were painted black inside and one wall of which was formed by blue or red glass. The dark-red glasses which I employed yielded a light which was fairly monochromatic; the dark-blue glasses allowed some red to pass through. In the case of the light. red and light-blue glasses the light was far from monochromatic.

Experiment 1.-On August 31 a large number of Eudendrium were divided between two vessels, one of which was placed in a box in dark-red light, the other in a box in darkblue light. As nearly as I could judge, the red and blue glasses allowed about equal quantities of light to pass through. The old polyps perished within three days, but somewhat sooner in the red than in the blue lightit. On September 4 I discovered the first new polyp in the blue light. The number of new polyps in the blue light steadily 
increased, but not a single one was formed in the red light. On September 8, seventy new polyps with stems $3-10 \mathrm{~mm}$. long had developed in the blue light. Not a single polyp had developed in the red light, but a few roots had been formed. Conditions did not change during the following days. After nine days not a single polyp had developed in the red light, while over seventy thriving polyps had been formed in the blue light.

In order to test whether the stems in the red light would develop polyps if brought into the blue light, I substituted a blue glass for the red glass on September 9. Two days later, on September 11, indications of new polyps were already apparent, and on the following day thirty-two complete polyps had been formed; on the next day the number had increased to sixty-six. From these experiments it is seen that in the development of polyps red light acts more like darkness, while blue light acts like mixed daylight, just as in heliotropic phenomena.

Experiment 2.-On August 22 a large number of stems of Eudendrium were equally divided, as in the preceding experiments, between two vessels, one of which was placed in blue, the other in red light. After the old polyps had fallen off, the first new polyps appeared in the blue light on August 27. At about the same time roots began to develop in the red light, but no polyps. On August 29 forty vigorously growing polyps had developed in the blue light, while in the red light no polyps but only roots had developed. On August 31 the culture in the blue light had formed a forest of new, well-developed polyps, while the culture in the red light had only developed several roots. The culture in the blue light had also developed a few roots. On August 31 I replaced the red glass by blue. On September 11 the first new polyps began to form, whose number from now on steadily increased. 
This time I also made the reverse experiment. The polyps formed in blue light were exposed to red light (the blue glass was replaced by a red one on September 6 ). After five days all the newly developed polyps had perished. By September 13 only a few diminutive polyps had developed.

Experiment 3.-On August 25 eight stems of Eudendrium culture were placed behind light-red glass (which allowed also some blue light to pass through), and nine stems of the same culture behind blue glass which was not very dark. On August 30 a number of polyps had developed, not only behind the light-blue, but also behind the light-red glass. The light-red screen was then replaced by a dark-red one; while the number of polyps constantly increased in the blue light, development soon ceased behind the dark-red screen. On September 1 the eight stems in the red light had only sixteen small polyps, while the nine in the blue light, which were of the same size and from the same culture, had eighty polyps. On the following day eighteen polyps had developed in the red light, while the stems in the blue light were literally covered with them.

On September 5 the glasses were exchanged; the animals which up to this time had been behind the red screen were now exposed to blue light, while those which had been exposed to blue light were placed behind the dark-red screen. The number of polyps on the stems in the blue light (which had formerly been in the red) increased rapidly; on September 9 the number had grown to 27 , on the 10 th to 40 , and so on. The polyps on the animals in the red light (which had formerly been in the blue) not only did not increase in number, but they began to die, and on the 11th only a few were left which looked sickly.

A fourth experiment corroborated the result that numerous and vigorous polyps are formed behind a dark-blue screen, while in red light only roots are formed. 
We must therefore conclude that not all the rays of diffuse daylight influence the formation of polyps equally, but that only the more refrangible (blue) rays of the visible spectrum favor the development of polyps, while the less refrangible (red) rays act as darkness - a fact similar to that established for heliotropism.

3. We may finally raise the question whether or not light influences the development of Planula larvæ. My studies in this direction are not yet completed, but I found that in isolated cases, in spite of an exposure to darkness for several weeks, during which time no new polyps were formed, the development of the larvæ progressed as under normal conditions; at least they were normal and not retarded in their development. I was able to make some experiments with the larvæ themselves. These larvæ are pear-shaped, and are able to move forward very slowly by means of cilia. They are, as I have already shown, energetically positively heliotropic. The blue rays are in these experiments mole effective than the red. About forty-eight hours after they begin to swim, the larræ attach themselves to some solid base, and within the next twelve hours their pointed ends begin to grow and to form polyps, while their blunt ends form roots. When lighted from one side only the whole organism bends toward the light. The question therefore arose whether the Planula larva can develop a polyp in the dark. This is the case when a larva has developed in the presence of light. When brought into the dark such a larva develops a polyp within twelve to twenty-four hours. In this, however, we need not see any contradiction to the other experiments, as in these the development of the polyps required three to four days. It would be interesting to determine whether Planula larvæ, if their whole development occurs in the dark, can develop polyps in the absence of light.

In conclusion I wish to mention that the polyp-bearing 
and growing stems are energetically positively heliotropic. Only that part of the stem immediately behind the polyp bends heliotropically. While these curvatures are usually produced in less than two hours in blue light, no curvature takes place in dark-red light even after two days; nor do the heliotropic curvatures appear when the polyps are cut off. I shall return later to this and some other facts bearing on the theory of heliotropism. A stem of Eudendrium which is illuminated from one side only develops more polyps on the lighted side than on the shaded side - a thing which explains . itself from the foregoing.

\section{EXPERIMENTS ON FUNDULUS EMBRYOS}

A large number of experiments on Fundulus embryos show that they develop as completely and as quickly in the dark as in the light; only the supply of oxygen must be the same in both cases. In one experiment the eggs were kept in the dark in a small, tightly closed vessel; those exposed to the light were kept in a large vessel; in this case the eggs developed more quickly in the light than in the dark. Car:trol experiments showed very clearly that it was not the light, but the better supply of oxygen to the vessel exposed to the light, which caused this difference in the development of the eggs. Only one constant difference exists between the eggs cultivated in the light and in the dark, and this concerus their color. As I have stated repeatedly, a large number of black and red chromatophores are formed in the membrane of the yolk-sac, which gradually creep upon the blood-vessels and surround them like a sheath. Since the number of these chromatophores progressively increases, the egg, if developed in the light, finally becomes very dark. In contrast to this, the eggs kept in the dark are very light and transparent. This difference may possibly be due to a contraction of the chromatophores in the dark, but I am not cer- 
tain of this. The other possibility is that in the dark a smaller number of pigment cells are formed. In embryos which develop in the light toward the end of development the pigment cells form a sheath around the blood-vessels. When the eggs develop in the dark, only isolated chromatophores are found upon the blood-vessels; the vessels are for the most part free from pigment.

I found no noticeable difference in the development of pigment in the embryo itself. The pigment cells of the retina, for example, developed apparently as numerously and contained the same amount of coloring matter in the dark as in the light. The yolk-sac alone showed the influence of the light. 


\section{XVII}

HAS THE CENTRAL NERYOUS SYSTEM ANY INFLU. ENCE UPON THE METAMORPHOSIS OF LART E?

Gustav Tornier has just published a hypothesis which is to explain how the acquired characteristics of parents are inherited by their offspring. This hypothesis is as follows:

In the more highly organized animals every adaptation of a functioning peripheral end-organ is accompanied by a corresponding and equal adaptation in the central nerrous system; the central nervous system carries the acquired characteristic to the sexual organ, which forms with it a functional and nutritive unit, especially to the sexual cells, in that it compels the latter to undergo similar transformations. If the sexual cells give rise to new individuals, the descendants inherit the acquired characteristics of the parents. ${ }^{2}$

Tornier's paper is very clear, and even though I cannot agree with his hypothesis, I consider it important that Tornier through his precise presentation of his subject has directed the attention of investigators to the question of the significance of the central nervous system in the processes of development.

If Tornier's idea is correct, then every alteration in the central nervous system must be accompanied by a similar change in the end-organs. Before the appearance of Tornier's paper I had already made a series of experiments in which I divided the spinal chord of Amblystoma larve in order to determine whether in the change of the larvæ to the sexually mature form the animals with the divided spinal cord would behave as one or two separate animals; in other words, whether in an animal with a divided spinal cord the metamorphosis of the interior and the posterior portions would occur simultaneously as in the case of the uninjured animal.

1 Archiv für Entwickelungsmechanik der Organismen, Vol. IV (1896), p. 502.

2 "ťber Hy perdaktylie," etc., ibid., Vol. III, p. 180. 
Amblystoma is well adapted to an experiment of this kind. The larva loses an organ at each end in the process of metamorphosis - the three large external gills at the head end of the animal, as well as the so-called tail fin at the tail end. Both disappear simultaneously in normal animals in a few days; at the same time an alteration occurs in the pigmentation and marking of the skin. One could not state a priori how a division of the spinal cord would influence the processes of development, for it is well known that immediately after the division of the spinal cord in dogs severe changes usually occur in the condition of the skin of the posterior portions of the body, which may lead to the formation of abscesses, which later again disappear (Goltz).

Division of the spinal cord (close behind the cervical region) did not have even the slightest effect in a single instance upon the processes of development; metamorphosis occurred just as though the animal were uninjured. This was the more remarkable as in some cases a metamorphosis occurred immediately after the division of the spinal cord, while the wound was still open. I believed at first, on the basis of these experiments, that division of the spinal cord might accelerate the metamorphosis of the larvæ, or cause it directly. I found, however, that this was not the case. One animal, for example, was still in the larval stage six weeks after the operation, while the uninjured control animals had already completed metamorphosis.

Since the experiments showed without exception that division of the spinal cord had no effect upon the metamorphic processes, we must state in detail what evidence we have to show that the cord was indeed severed entirely. First of all the operation was made in such a way that the separation of the two ends of the spinal cord could be seen directly in the bottom of the wound. Secondly, the posterior part of the body was paralyzed, that is to say, it was 
dragged along in the movements of the anterior portion of the animal as though it was an inanimate mass. A peculiarity exists here, of course, which Friedländer ${ }^{1}$ and $\mathrm{I}^{2}$ have observed in worms, in a more pronounced way, namely, that a sort of indirect co-ordination may occur between the anterior and posterior portions of the animals in spite of the division of the cord. Thirdly, that division was perfect was proved through galvanotropic experiments. The constant current brings about associated changes in the position of the anterior and posterior extremities in the normal animal, while these associated changes in position do not occur in an animal in which the spinal cord has been severed. ${ }^{3}$

These observations show without a doubt that, in spite of the division of the spinal cord, metamorphosis occurs as though the central nervous system were intact. If 'Tornier's idea were strictly correct, one would expect that the division of the central nervous system would be followed, not only by a division of the motor and sensory functions of the anterior and posterior part of the animal, but also by a division of the morphogenetic functions. Since this is, however, not the case, this conclusion at least may be drawn, namely, that the morphogenetic functions in animals with a central nervous system do not depend so strictly upon the central nervous system as do the motor and sensory functions.

The objection might be raised that the central nervous system of Amblystoma is not highly enough developed to decide the question of the influence of the spinal cord upon the formative processes. Observations are, however, at hand which leave no room for doubt that conditions are similar in the dog. Goltz has found that all the individual milk-glands in a pregnant bitch develop equally after division of the

1 Biologisches Centralblatt, Vol. VIII.

2 Pflügers Archiv, Vol. LVI.

3 Loeb und Garkey, II, ibid., Vol. LXIV. 
spinal cord or even after the removal of a piece. ${ }^{1}$ In this case also morphogenetic processes are independent of the central nervous system.

This objection may also be raised, however, that Tornier has assumed in the development of the larva a formative influence of the central nervous system only upon the sexual cells, and not upon the body cells. This objection must be granted, but it must also be remembered, on the other side, that it is risky to assume such a formative effect of the central nervous system where we have no means to ascertain the facts, while we can show that such an influence does not exist where the facts can be studied experimentally. That a set of muscles cannot functionate without the corresponding segments of the central nervous system is certain, but it is equally certain from the experiments of Goltz and Ewald that the blood-vessels behave differently. It is, at present, to say the least, just as probable that the central nerrous system does not influence the sexual cells as that the opposite assumption of Tornier is true.

If it be assumed, on the other hand, that the formation of organs, or that morphogenetic processes in general, are determined through chemical substances which are formed in the metabolism of the animal and circulate through the animal, it is clear that, in spite of the division of the central nervous system, metamorphosis must occur simultaneously in both portions of the animal anterior and posterior to the cut. This assumption also does away with the necessity of formulating independent laws for the development of organisms with and without the central nervous system. In various papers I have pointed out that the facts of morphogenesis can be explained on a chemical basis, as Sachs has first suggested.

I will not here discuss the question of the inheritance of acquired characteristics.

1 Goltz dxd Ewald, Pfugers Archiv, Vol.LXIII. 


\section{XVIII}

\section{ON THE THEORY OF GALVANOTROPISM}

ON THE POLAR STIMULATION BY THE CONSTANT CURRENT OF THE GLANDS OF THE SKIN OF AMBLYSTOMA ${ }^{1}$

1. IN experiments on the galvanotropism of adult Amblystomæ I noticed a polar stimulation of the glands of the skin which soon interested me more than the galvanotropic reactions themselves; for I found that the glands were always stimulated on the anodal side of the animal, and that there exists here a similar exception to Pflüger's law as that which Kühnediscovered in Actinosphærium. The phenomena were, however, of great interest in another direction. The activity of the glands of the skin was determined in part through a polar stimulation of the central nervous system by the galvanic current. It could easily be shown that in this case the central nervous system behaves as a homogeneous whole. Both facts, the stimulation at the anode as also the behavior of the central nervous system just mentioned, are, of course, of significance for the theory of galvanotropic phenomena.

The skin of the fully developed Amblystoma contains a large number of glands which give out a mucoid secretion when stimulated in certain ways. The secretion forms a white layer upon the black skin. If a descending constant current of about 3 milliamperes, having a density of about $3 \delta$, is sent through the animal, a secretion is formed upon the anterior half of the head (Fig. 126, $a b$ ). Small white dots appear, which become more distinct the longer the cur-

1 Pflügers Archiv, Vol. LXV (1896), p. 308. This paper was the third in a series of communications on galvanotropism which, however, are not reprinted in these volumes. [1903] 
rent is kept up; finally a tiny mucous plug is noticed in each of the glands.

If the current is sent through the animal in an ascending direction, a profuse secretion occurs upon the tail (Fig. $127, c d)$. The amount of the secretion formed is, with the

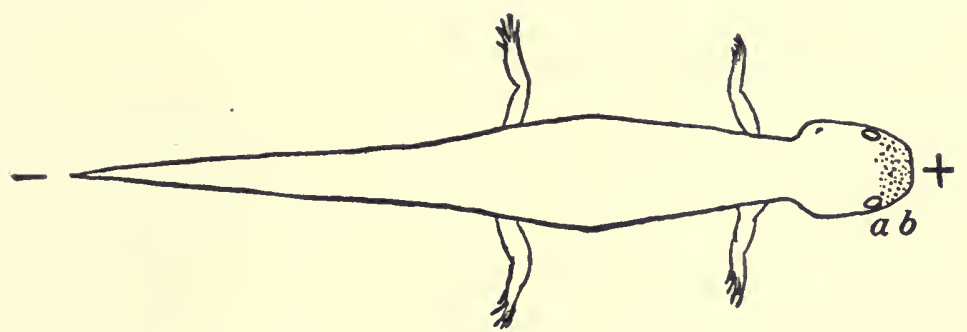

FIG. 126

same density of current, much greater than that formed upon the head, and within a short time a thick white layer is formed which drops off readily when the animal moves. The secretion may be profuse enough to render the water in the trough turbid in a short time.

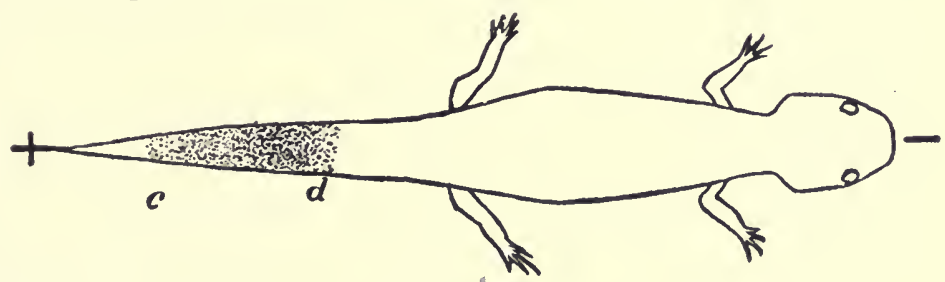

FIG. 127

If the current is passed in a transverse direction through the animal, secretion occurs only upon one-half of the body - upon the half directed toward the anode.

We see, therefore, that in all three cases the glands of the skin upon the anodal side or the anodal end of the animal are always the ones to begin to secrete. The results are the same whether metallic electrodes or unpolarizable electrodes are used. 
That we are, indeed, dealing with the effects of a constant current is shown by the fact, first of all, that the longer the circuit is closed, the longer does secretion last, the greater is the amount of the secretion, and the greater the region in which the secretion occurs; secondly, that the secretory phenomena are brought about when the intensity of the current is raised very slowly. The breaking of the current, on the other hand, has no effect.

2. The next question that presented itself was whether we dealt in this case with the effects of the current upon the skin or the glands themselves, or whether we had to do with a stimulation of the central nervous system. We next investigated the action of the current upon animals in which the spinal cord had been cut. When a current was passed longitudinally through such animals, they behaved as though they consisted of two fully independent pieces. If we call that portion of the animal lying anterior to the cut the anterior animal, and that lying behind it the posterior animal, then the end of both the anterior animal and the posterior animal which was directed toward the anode secreted during the passage of a current longitudinally through the animal. In Figs.128 and $129 S$ marks the position at which the spinal cord was severed. In a descending current not only the piece $a b$ (Fig. 128) at the head end of the animal secretes mucus, as in the case of the normal animal, but also the anterior region $c d$ of the posterior part of the animal, which under otherwise similar conditions never secretes in the uninjured animal. When the current passes in an ascending direction, secretion occurs not only at the tail (cd, Fig. 129), as in the uninjured animal, but secretion occurs also at the posterior end of the anterior part of the animal ( $a b$, Fig. 129). The secretion in the latter case often limits itself to the hindmost edge of the immediate vicinity of the wound, and does not extend forward until the current has passed through the animal for some time: 
This reduplication of the secreting regions after the sectioning of the spinal cord is noticed not only immediately after severance of the cord, but at any time, even eight weeks after the operation - I have not as yet studied these animals for a longer time than this-after the wound has

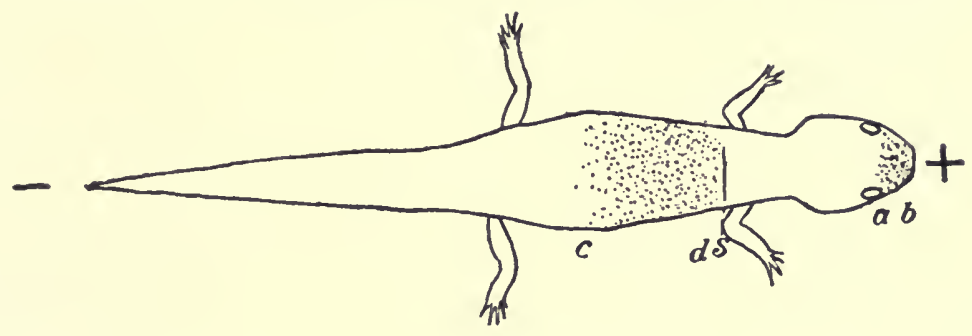

FIG. 128

healed so perfectly that it is impossible to recognize the position of the incision. These experiments render it very probable that the polar secretion of the glands of the skin, when a current is passed longitudinally through the animal, is determined by a stimulation of the central nervous system.

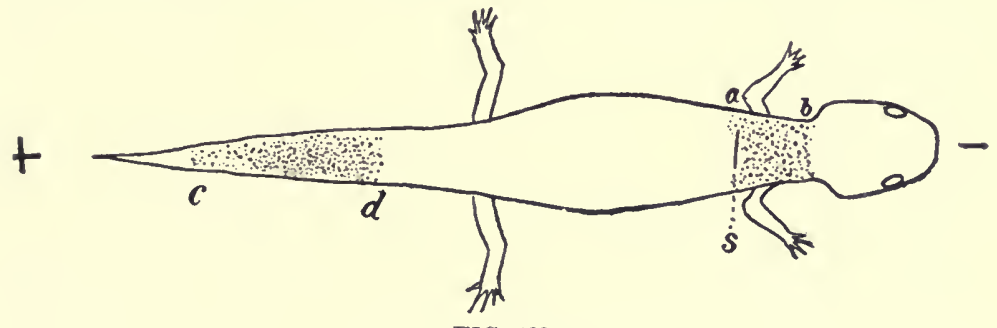

FIG. 129

It also seems as though the entire central nervous system behaves like a homogeneous whole, and as though the stimulation with a constant current occurs at the anode.

3. In order further to test this possibility, I cut a number of Amblystomæ into small pieces. It was, of course, impossible to keep these pieces alive, so they had to be experimented upon immediately. In this way it was found that every piece of the animal which still possesses its correspond- 
ing portion of the central nerrous system shows the polar stimulation of the glands of the skin at the anode end when a current is passed through the piece in a longitudinal direction. Furthermore, an interesting difference was found between the head and the tail end of the animal in regard to the size of

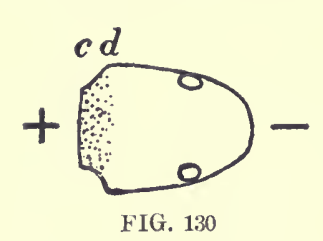

FIG. 130 the secreting region. When an ascending (homodromic) current was sent through an isolated head, the secretion was limited to the outer edge at the anodal side ( $c d$, Fig. 130) - the cut end. If, on the other hand, a descending current was sent through the head, almost the entire head secreted ( $a b$, Fig. 131). When an isolated tail was traversed by a descending current, the glands of only a small region in the neighborhood of the wound secreted ( $a b$, Fig. 132). If an ascending (homodromic) current was sent through the tail, the glands in the whole region ( $c$ d, Fig. 133) secreted. It might be thought that the wound has an inhibiting effect upon the secretion of the glands lying in its neighborhood,

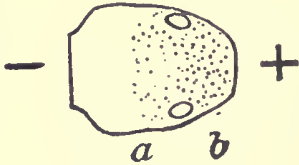

FIG. 131 and that for this reason the isolated head secretes most freely under the influence of a descending current, while an isolated tail secretes most freely under the influence of an ascending current. It can easily be shown, however, that the wound

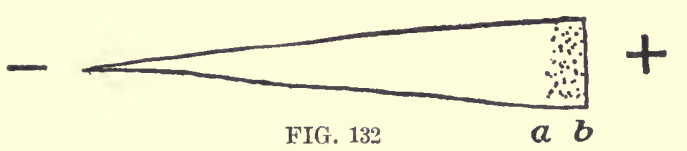
does not play this rôle, but that in general those portions of the animal lying near the head secrete more freely and over a larger region when a descending current is used than when an ascending current is used, while the posterior pieces secrete most strongly under the influence of an ascending current. For when the head of an animal is amputated, and the pos- 
terior portion is cut off at a short distance behind the snterior legs, the remaining piece (Fig. 13t) has a wounded surface at each end. The fragment, howerer, belongs to the anterior end of the animal, and therefore behaves like the head; that is to say, under the influence of a descending cur-

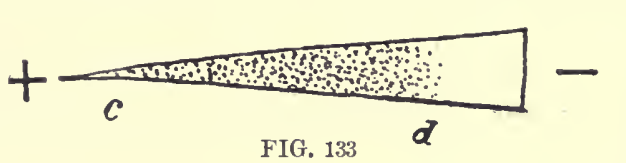
rent the secretion covers the extensive region $a b$ (Fig. 131), while under the influence of an ascending current secretion is limited to the narrow zone cl (Fig. 135). When the corresponding experiment is made upon a piece cut from the posterior half of the animal, a more extensive secretion is obtained when an ascending current is used than when a descending current is employed.

4. What becomes of the galvanic

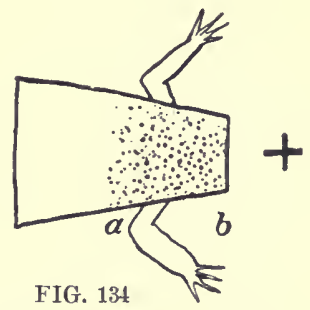
secretion when the spinal cord is destroyed? Pieces cut from the trunk in which $\mathrm{I}$ had destroyed the spinal cord showed no polar excitation of the glands of the skin when the cur-

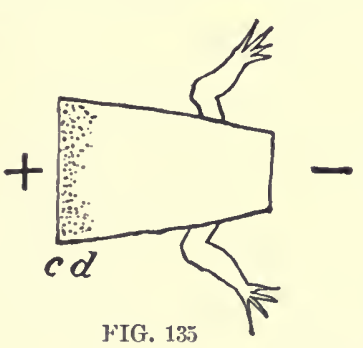
rent was passed in a longitudinal direction. The effect on the central nervous system is shown in a still more striking way when the latter is destroyed only in part. We experimented upon a piece, as shown in Fig. 134. We convinced ourselves first of all of the fact that secretion occurred anteriorly in about the region $a b$ when a descending current was sent through the animal. We then destroyed the anterior part of the spinal cord (Fig. 136) from the point $S$ to $S_{1}$ by means of a needle. When a current was again sent through the piece in a descending direction, 
no secretion occurred at the anterior end (in the region $S S)$; a secretion occurred instead close behind $S$ in the region $a b$, that is to say, in the regions directed toward the anode of the animal, which still possessed a spinal cord.

The destruction of the anterior portion of the spinal cord

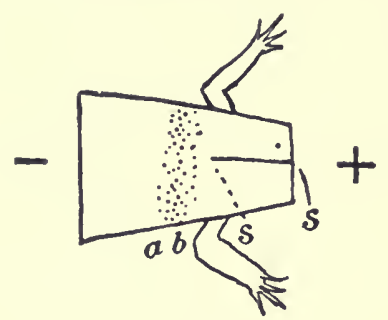

FIG. 136 SS had no effect upon the secretion when the current was sent in a homodromic direction. In both cases secretion occurred in the region $c$ d (Fig. 137). I have often repeated this remarkable experiment, always with the same result. It might be thought that the destruction of the spinal cord had an inhibiting effect upon the secretion of those glands of the skin which are connected with the destroyed portion of the spinal cord, and I was myself inclined to believe this. When I subjected pieces of Amblystomæ, in which the spinal cord had been destroyed either entirely or in part, to a transverse current, I found to my surprise that secretion still occurred at the anode, it mattered not whether the spinal cord was destroyed or not. In view of this fact only one other assumption remains, namely, that two sources exist for the stimulation of the glands of the skin through the galvanic current. One of these is stimulation of the central nervous system; the second, the direct stimulation of peripheral organs, either the peripheral nerve fibers which go to the glands of the skin, or the nerve end-

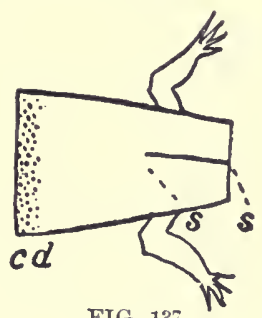

FIG. 137 ings in the skin, or perhaps the glands themselves. In dealing with a current running longitudinally we have to do with only the first source, and polar stimulation of the central nervous system occurs at the anode. In the case of a transverse current we have to deal, in addition to this, or 
entirely, with a stimulation of peripheral elements. That these elements are not excited by a current passing longitudinally may depend upon a fact which Maxwell and I discussed more fully in our paper, "Zur Theorie des Galvanotropismus," namely, the orientation of the elements.

5. In the experiments just described, especially in those in which the central nervous system is traversed by a longitudinal current, the central nervous system behaves like a homogeneous whole, one side of which is entirely in anelectrotonus, the other in catelectrotonus. This result differs from those obtained by Maxwell and myself in Crustaceans. In these it seemed as if the phenomena observed could be explained in a satisfactory way under the assumption that the central nervous system does not go into electrotonus as a homogeneous whole, but that the individual elements (segments?) are each composed of a catelectrotonic and an anelectrotonic portion, and that the effect of the current as a whole is made up of the effects of the current upon the individual elements (segments?). Must we now do away with this assumption, which is most probable in the case of the galvanotropism of Crustaceans, because in another class of phenomena, namely, the excitation of the glands in a different class of animals (salamanders), we find a different behavior of the central nervous system? I think not. I have often convinced myself of the fact that even closely related animals, even different varieties of the same species, may behave absolutely differently heliotropically, geotropically, and stereotropically; not to speak at all of our experience concerning the artificial reversal of tropisms. I also consider it entirely possible or probable that in one class of animals the central nervous system may behave as a homogeneous whole toward the current, while in another class it may behave as though composed of a series of individual

${ }_{1}^{1}$ Pfiugers Archiv, Vol. LXIII (1896), p. 121. 
elements each of which may be considered as in its own state of electrotonus. As a support for the correctness of this idea I quote the interesting observation of Roux, to which this investigator has recently again called attention:

Every cell in an eggo which is dirided into a smaller or larger number of cells (morula or blastula) reacts individually, giving rise to altered electrical fields (special polarization) as long as the eggr is vigorous. If, howerer, the vitality of the egg is reduced by cooling or poisoning (not sufficiently to cause death), the complexus of cells reacts as a whole, in other words, like an egg which is not yet divided into cells.

If these two opposite conditions can occur in one and the same animal (under only different conditions), it is perhaps not extravagant to assume that the central nervous system of Amblystoma may behave like a homogeneous whole when subjected to the constant current, while the central nervous system of Crustaceans may behare as a series of separately irritable elements in its galvanotropic reactions. Whether the central nervous system of Amblystoma behaves in its galvanotropic phenomena as in its secretory processes is a question still to be investigated.

It seems to me that our experiments on the polar excitation of the glands of the skin of salamanders may lead to a different explanation of the liquefaction of protoplasm observed by Kühne at the anodal side of Actinosphærium from that which he has given. ${ }^{2}$ Kühne compares this process with the tetanus of contractile elements. Might we not rather in this case be dealing with processes similar in nature to phenomena of secretion? One can readily understand how violent phenomena of secretion brought about through a strong electrical current might lead to a disintegration of the substance of a tender Protozoon, since the much tougher epidermis of Amblystoma goes to pieces at the anodal side

1 Pfügers Archiv, Vol. LXIII, p. 5 42.

2 Untersuchungen über das Protoplasma (Leipzig, 1864). 
(where the secretion occurs) in such experiments. The fact that the disintegration of Actinosphærium and the secretion in Amblystoma both occur at the anode must also be thrown in to the balance. ${ }^{1}$

It was an entirely unexpected discovery that in these experiments stimulation always occurs at the anodal side of the central nervous system. This is the only exception to Pflüger's law which has, to my knowledge, been found in vertebrates thus far.

1 Birukoff has called attention to the fact that cataphoretic effects of the current form the basis of the anodic disintegration of Actinospherium as well as of the secretion of the glands of Amblystoma. His idea is entirely within the limits of possibility. [1908] 


\section{XIX}

THE PHYSIOLOGICAL EFFECTS OF IONS. I $^{1}$

I. INTRODUCTION

THE works of Tan 't Hoff, Arrhenius, and Ostwald on osmotic pressure and on the dissociation of electrolytes mark the beginning of a new epoch in science. The effects of their work have scarcely made themselves felt as yet in animal physiology. Several years ago I tried to utilize the theory of osmotic pressure in explaining the hypertrophy of muscle through activity. The increase in the volume of the muscle cells during growth demands energy - a fact which has not as yet been considered in animal physiology. Physiologists were satisfied with the statement that the working muscle received more blood, and in consequence assimilated more strongly, than the non-working muscle, although it is well known that the best-nourished muscle does not hypertrophy without work. I have pointed out the fact that the processes of hydrolysis which can be shown to take place in the active muscle must lead to an increase in its osmotic pressure. ${ }^{2} \quad$ Since the muscle substance acts as a semi-permeable wall, a source of energy is demonstrated in this way for furnishing the energy for the work of growth. The increase in the osmotic pressure in active muscle, or rather the increase in the amount of water absorbed by the active muscle, has been proved directly not only by Ranke, but also by Miss Cooke. This theory has received no notice; even the thought that a source of energy is necessary for

1 Pfilgers Archiv, Vol. LXIX (1897), p. 1.

2 It is possible that this is not the only source of energy for the increase of volume in the muscle. Surface energy or other forms of energy may also play a role here. [1903] 
the work done in growth las never once been considered. We need not go far to find the reason for this. Even in the newer text-books of physiology the attraction of salts for water is still spoken of as was the case fifty years ago; the idea of osmotic pressure and the work of Van 't Hoff liave not yet worked their way into this territory. ${ }^{1}$

One of the most fertile results of the theory of dissociation is the idea which has been brought forward, chiefly by Ostwald, that those reactions of acids in aqueous solutions which are common to all acids, and only to these, are dependent upon the activity of the positively charged hydrogen ion, and that in a similar way the universally specific effects of bases are determined by the negatively charged $\mathrm{OH}$ ion. The relative strength of acids and bases is therefore dependent upon the number of $\mathrm{H}$ and $\mathrm{OH}$ ions contained in the unit volume of the solution, and this number is determined by the degree of dissociation of the electrolyte under consideration. A further important result of the theory of dissociation is the fact that in completely dissociated salt solutions the properties of the solution are the sum of the properties of the ions contained in it. The ion itself, however, represents a new species of molecules, namely, atoms or groups of atoms which are charged with a definite amount of electricity. It is the object of this and further papers to determine the physiological effects of individual ions.

Kahlenberg and True were the first to makesuch experiments in physiology. ${ }^{2}$ These authors investigated the toxic properties of acids and salts in dilute aqueous solutions upon growing plants. As a measure of the toxic effects these authors used that concentration of the given electrolyte in water which just allowed germinating beans to grow sixteen

1 Since these lines were written matters have changed. [1903]

2 Botanical Gazette, Vol. XXII (1896), p. 81. 
to twenty-four hours. They found that aqueous solutions of $\mathrm{HBr}, \mathrm{HCl}, \mathrm{HNO}_{3}, \mathrm{H}_{2} \mathrm{SO}_{4}$, and $\mathrm{KHSO}_{4}$ which contained the same number of hydrogen ions in the unit volume were equally toxic; that, in other words, the toxic exect of these acids was determined solely by the hydrogen ious and not by the anions (nor by the molecules which, at the dilution employed, were all dissociated electrolytically). They could show in a similar way that the toxic effects of salt solutions employed in their observations were determined by their ions.

I do not doubt the correctness of the principal conclusions of Kahlenberg and True. But I do not believe that these authors determined the limit of the poisonous action sharply enough. They found, for example, that the acids mentioned above were no longer toxic when 1 gram-molecule (in univalent) or $\frac{1}{2}$ gram-molecule (in bivalent acids) was dissolved in 6,400 liters, but that when this amount was dissolved in 3,200 liters they were poisonous; that is to say, the germinating lupines cease to grow in them after from sixteen to twenty-four hours. More accurate determinations than this they did not make. If someone should say that the acids studied in these experiments acted, not according to the number of hydrogen ions, but according to the percentage of acid, such a criticism could not be overcome by the figures of Kahlenberg and True. These concentrations for $\mathrm{HCl}$, $\frac{1}{2} \mathrm{H}_{2} \mathrm{SO}_{4}$, and $\mathrm{HNO}_{3}$ behaved, for example, as 36.5:49:63; they lie therefore between the values 1:2. Kahlenberg and True have chosen for these purposes a very unsatisfactory physiological reaction. The exact time at which growth ceases cannot be determined accurately; and when, in addition, experiments must be continued through the night, the determination of the exact time becomes so uncertain that, according to my idea, the method is a questionable one for the quantitative determination of the toxicity of different solutions. 
I undertook the determination of the physiological effects of the ions of a series of electrolytes on frog's muscle. It seemed essential to my mind, however, to choose such reactions as are capable of exact quantitative determination. As such reactions I chose first of all the amount of water absorbed by a muscle under the influence of certain electrolytes; for I had found that the gastrocnemius muscle of the frog, which has, as is well known, usually about the osmotic pressure of a 0.7 per cent. $\mathrm{NaCl}$ solution, increases considerably in weight upon the addition of a trace of an acid or an alkali to this sodium-chloride solution. This increase in weight is chiefly due, no doubt, to the absorption of water. The second reaction which I chose was the influence of the electrolyte on the threshold of stimulation. As a source of stimulation I used induction shocks, and as the measure of the threshold of stimulation, the greatest distance at which the secondary coil could be moved away from the primary and just appreciable contractions still take place. I attach less value to the latter method, because it seems to me that the irritability of the individual muscle fibers does not vanish at the same moment. When the electrodes are placed at one point, no effect may be appreciable; when they are moved, however, a slight twitching of individual fibers may yet be brought about. This method can, therefore, not be considered as accurate as the first method.

\section{EXPERIMENTS WITH ACIDS}

1. The normal solutions used in these experiments were made with the greatest care by Dr. Bernhard, assistant in the chemical laboratory. Solutions of the acids and alkalies were made which were one-tenth normal with reference to the $\mathrm{H}$ and $\mathrm{OH}$ contained in them. The $\mathrm{HCl}$ solution, for example, contained 1 gram-molecule $(1 \mathrm{~mol}$. $) \mathrm{HCl}$ in 10 liters of water; the $\mathrm{H}_{2} \mathrm{SO}_{4}$ solution, only $\frac{1}{2}$ mol. $\mathrm{H}_{2} \mathrm{SO}_{4}$ in 10 
liters of water. Of these solutions $5,10,15$, or 20 c.c. were added to 100 c.c. of a 0.7 per cent. $\mathrm{NaCl}$ solution. The gastrocnemius muscle of a frog was laid bare without injuring the muscle, its surface rapidly dried between sheets of filter paper, and the tendon cut. The muscle was placed between two watch crystals, weighed, and then introduced into one of the solutions described above. The muscle remained in the solution for exactly one hour, when it was removed, again carefully dried between filter papers, and again weighed. The method is accurate to within about $5 \mathrm{mg}$. The following circumstances are, lowever, to be considered in using the method. As the exchange between the substances contained in the muscle and in the solution occurs chiefly at the surface of the muscle, it is necessary to use for the same series of experiments only muscles of approximately the same weight, which have, in consequence, about the same surface. A light muscle (with its relatively larger surface) will show a relatively greater difference in weight at the same osmotic difference between the muscle and solution, after remaining one hour in the latter than a heavier muscle (with its relatively smaller surface). Secondly, the fact must be remembered in utilizing this method that the osmotic pressure of the gastrocnemius of the frog is subject to not inconsiderable variations, depending upon whether the animal was previously quiet or active. If the effect of acids is to be compared, care must therefore be taken that frogs are used which have been kept for twenty-four hours under as nearly as possible the same conditions (light, water, temperature, oxygen supply). Even then individual differences continue to exist. This difficulty can be overcome only by making a large number of experiments.

2. I will first give five series of experiments which show that the acid effects of $\mathrm{HNO}_{3}, \mathrm{HCl}$, and $\mathrm{H}_{2} \mathrm{SO}_{4}$ are the same when the same number of hydrogen atoms are contained in 
the same volume of the solvent. In these experiments the solvent was not a 0.7 per cent. $\mathrm{NaCl}$ solution, but a 0.585 per cent. $\mathrm{NaCl}$ solution. To each 100 c.c. of this solution were added 5 c.c. of a 0.365 per cent. $\mathrm{HCl}$, or a 0.49 per cent. $\mathrm{H}_{2} \mathrm{SO}_{4}$, or a 0.63 per cent. $\mathrm{HNO}_{3}$ solution - that is, 5 c.c. of a one-tenth normal solution of these acids. The Roman numerals indicate the series of experiments; the Arabic figures indicate here, as in the following tables, the increase in weight which each muscle shows in percentage of its original weight after remaining for one hour in the solution. The equation $V=210$ means in this case, as in the following tables, that 1 or $\frac{1}{2} \mathrm{~mol}$. of the electrolyte is dissolved in 210 liters of water.

\section{TABLE I}

$(V=210)$

\begin{tabular}{|c|c|c|c|c|c|c|}
\hline & I & II & III & IV & $\mathrm{v}$ & Average \\
\hline $\begin{array}{l}\mathrm{HNO}_{3} \ldots \ldots \\
\mathrm{HCl} \ldots \\
1 / 2 \mathrm{H}_{2} \mathrm{SO}_{4} \ldots\end{array}$ & $\begin{array}{l}8.6 \% \\
8.2 \\
8.4\end{array}$ & $\begin{array}{l}7.6 \% \\
7.8 \\
6.7\end{array}$ & $\begin{array}{l}7.3 \% \\
7.6 \\
7.9\end{array}$ & $\begin{array}{l}7.6 \% \\
7.6 \\
7.9\end{array}$ & $\begin{array}{l}8.0 \% \\
7.6 \\
9.6\end{array}$ & $\begin{array}{l}7.8 \% \\
7.7 \\
8.1\end{array}$ \\
\hline
\end{tabular}

It can easily be seen that the results in each series of experiments harmonize to such an extent that one could easily forget that we are dealing with effects on living tissues. The variations between the values of the individual series of experiments can be explained by the differences in the state of the experimental material. In general, all the results of the same series of experiments show relatively high values ( $\mathrm{I}$ and $\mathrm{V}$ ), or relatively low values (for example, II). The temperature has much to do with these variations, but is not the only circumstance of importance.

From these experiments it can be said that solutions of these three acids, which contain the same number of hydrogen atoms in the same volume, have quantitatively the same effects on the increase in the weight of (the amount of water absorbed by) the muscle. 
3. Can we now say that in these experiments we are dealing only with the effects of the hydrogen ions? In order to decide this question, we must see which fraction of the molecules of acid is dissociated at the dilution employed. If we designate that fraction of the molecules which are dissociated by $a$, then, as is well known, $a=\frac{\mu_{\nu}}{\mu_{\infty}}$, where $\mu_{\nu}$ represents the molecular conductivity of the electrolyte at the dilution $\nu, \mu_{\infty}$ the molecular conductivity at infinite dilution.

- According to Ostwald, ${ }^{1}$ the speed of migration of the $\mathrm{H}$ ions at $25^{\circ}=325$, that of the $\mathrm{Cl}$ ions $=70.2$. According to Kohlrausch's law $\mu_{\infty}$ is for $\mathrm{HCl}$ therefore $=395$. In the same way we find for $\mathrm{HNO}_{3}, \mu_{\infty}=390$. According to Kohlrausch, the speed of migration of $\mathrm{H}$ ions at $18^{\circ}=290$. That of $\mathrm{SO}_{4}$ can be determined indirectly as about $132 .{ }^{2}$ $\mu_{\infty}$ is therefore at this temperature 712 for $\mathrm{H}_{2} \mathrm{SO}_{4}$.

When $V=200, \mu_{v}$ for $\mathrm{HCl}=377$, for $\mathrm{HNO}_{3}=377$. At $18^{\circ}$, and when $V=333, \mu_{\nu}$ for $\mathrm{H}_{2} \mathrm{SO}_{4}$, according to Kohlrausch, $=600.2$. In our experiments $V=400$. For $V=$ $400, \mu_{\nu}$ would lie between 600 and 610 .

In our solutions, therefore

$$
\begin{aligned}
& \alpha=\frac{377}{395}=0.95 \text { for } \mathrm{HCl}\left(25^{\circ}\right) ; \\
& \alpha=\frac{377}{390}=0.96 \text { for } \mathrm{HNO}_{3}\left(25^{\circ}\right) ; \\
& \alpha=\frac{600}{712}=0.8 \text { (inaccurate) for } \mathrm{H}_{2} \mathrm{SO}_{4}\left(18^{\circ}\right) .
\end{aligned}
$$

The effect which the presence of $\mathrm{NaCl}$ has on the dissociation of the acids is neglected in these values.

If we study the figures somewhat more closely, we see that they are not far removed from unity; that, in other words, about 95 , per cent. of the hydrochloric and the nitric acid molecules have dissociated into ions, and something less

1 Ostwald, Lehrbuch, 2d ed., Vol. II, p. 675.

2 KoHLRausch, Wiedemann's Annalen, Vol. L. 
than 5 per cent. of the acids exist in the molecular form. It is therefore only logical to attribute the action of the acids on the absorption of water by the muscle to the dissociated molecules. Furthermore, since $\mathrm{HCl}$ and $\mathrm{HNO}_{3}$ show the same degree of dissociation, and the acid effects upon the muscle are the same, we may further conclude that at the dilution employed only the hydrogen ions are active, while the anions $\mathrm{Cl}$ and $\mathrm{NO}_{3}$ have no physiological action.

The same probably holds also for sulphuric acid, even though the degree of dissociation is somewhat less here. We therefore come to the conclusion that the effect of the acid upon the absorption of water by the muscle is determined by the $\mathrm{H}$ ions and is independent of the anions $\mathrm{SO}_{4}, \mathrm{NO}_{3}$, $\mathrm{Cl}$, and, further, of the undissociated molecules $\mathrm{H}_{2} \mathrm{SO}_{4}$, $\mathrm{HNO}_{3}, \mathrm{HCl}$.

The rest of the experiments in this paper are all made with a 0.7 per cent. $\mathrm{NaCl}$ solution, instead of the 0.585 per cent. $\mathrm{NaCl}$ solution used in the foregoing experiments. An experiment with 0.7 per cent. $\mathrm{NaCl}$ solution when $V=210$ gave the following results:

For $\mathrm{HNO}_{3}, 5.7$ per cent.

For $\mathrm{HCl}, 6.1$ per cent.

For $\frac{1}{2} \mathrm{H}_{2} \mathrm{SO}_{4}, 6.5$ per cent.

I should like to emphasize again how nearly the values are identical. The difference between these values and those obtained with the 0.585 per cent. $\mathrm{NaCl}$ solution is determined by the difference in the osmotic pressures, as we shall see later.

4. The next problem was to determine how the acid effects increase with an increase in the concentration of the acids. In the two experiments of Table II, 10 c.c. of the one-tenth normal solution of the acid was added to each 100 c.c. of the 0.7 per cent. $\mathrm{NaCl}$ solution. $V$ therefore $=110$. 
TABLE II

$(\mathrm{r}=110)$

\begin{tabular}{|c|c|c|c|}
\hline & I & II & Average \\
\hline $\begin{array}{l}\mathrm{HNO}_{3} \ldots \ldots \ldots \\
\mathrm{HCl}_{1 / 2} \mathrm{H}_{2} \mathrm{SO}_{4} \ldots \ldots \ldots\end{array}$ & $\begin{array}{l}9.2 \% \\
9.5 \\
8.0\end{array}$ & $\begin{array}{l}8.8 \% \\
8.6 \\
9.3\end{array}$ & $\begin{array}{l}9.0 \% \\
9.0 \\
8.6\end{array}$ \\
\hline
\end{tabular}

When $I^{r}=110, \mu_{\nu}$ is about 375 for $\mathrm{HCl}$ instead of 377 . The degree of dissociation is therefore only slightly different from that when $V=210$. Nevertheless, the effect of the acid is not doubled when the concentration is doubled, but only increased about 50 per cent. Pronounced toxic effects already show themselves when $V=100$. I need not again point out how well the values agree with each other.

I wish finally to give a series of experiments with $\mathrm{KHSO}_{4}$ and $\mathrm{NaHSO}_{4}$. One-tenth normal solutions of these acids were used of which 10 c.c. were added to 100 c.c. of a 0.7 per cent. $\mathrm{NaCl}$ solution. The amount of water absorbed by the muscle is given in Table III.

TABLE III

$(V=110)$

\begin{tabular}{|c|c|c|c|c|c|}
\hline & I & II & III & IV & Average \\
\hline $\begin{array}{l}\mathrm{KHSO}_{+} \ldots \ldots \ldots \ldots \ldots \\
\mathrm{NaHSO}_{4} \ldots \ldots \ldots \ldots \ldots\end{array}$ & $\begin{array}{l}7.6 \% \\
8.1\end{array}$ & $\begin{array}{l}8.2 \% \\
9.8\end{array}$ & $7.8 \%$ & $\dot{7} .2 \%$ & $\begin{array}{l}7.9 \% \\
8.2\end{array}$ \\
\hline
\end{tabular}

The values are quantitatively almost equal to those of the other acids, especially sulphuric acid. In these concentrations the lesser degree of dissociation of the sulphuric acid when compared with nitric or hydrochloric acid is clearly shown.

If we sum up the results of all these experiments, we can say that the acid effects (when $V=100 \mathrm{or} 200$ ) of $\mathrm{HCl}$, $\mathrm{HNO}_{3}, \frac{1}{2} \mathrm{H}_{2} \mathrm{SO}_{4}, \mathrm{KHSO}_{4}, \mathrm{NaHSO}_{4}$, so far as these effects are expressed in the absorption of water, or, more accurately, in the increase in the weight of the muscle, are chiefly ion 
effects, and that these are the effects of the hydrogen ions. All these acids have quantitatively the same physiological effect when the same number of hydrogen ions are contained in the unit volume of solvent.

5. My experiments on the effects of organic acids have only just been begun. Thus far I have used only four acids, namely, acetic acid, lactic acid, oxalic acid, and malic acid. Ten c.c. of a one-tenth normal solution of one of these acids were added to 100 c.c. of a 0.7 per cent. $\mathrm{NaCl}$ solution. The increase in weight expressed in per cent. of the original weight of the muscle is given in Table IV:

TABLE IV

$(V=110)$

\begin{tabular}{|c|c|c|c|c|c|}
\hline & I & II & III & IV & Average \\
\hline 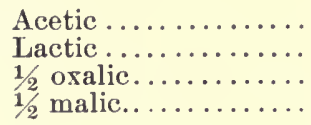 & $\begin{array}{l}4.7 \% \\
6.7 \\
6.4 \\
4.0\end{array}$ & $\begin{array}{l}3.4 \% \\
6.8 \\
6.3 \\
4.4\end{array}$ & $\begin{array}{l}3.3 \% \\
8.0 \\
6.0 \\
5.4\end{array}$ & $\begin{array}{l}4.7 \% \\
8.0 \\
8.8 \\
6.8\end{array}$ & $\begin{array}{l}3.9 \% \\
7.4 \\
6.9 \\
5.1\end{array}$ \\
\hline
\end{tabular}

In order to decide whether we are dealing here with the effects of $\mathrm{H}$ ions, and in how far, we must first determine the degree of dissociation of these solutions. We use for this purpose Ostwald's determinations. ${ }^{1}$

For acetic acid, $\mu 100=15$ (about), $\mu \infty=364$;

For lactic acid, $\mu 100=38$ (about), $\mu \infty=358$;

For oxalic acid, $\mu 200=338$ (about), $\mu \infty=365$;

For malic acid, $\mu 200=85$ (about), $\mu \infty=356$.

If we calculate from these figures the fraction of molecules that are dissociated, the following values are found for $a$ for the concentrations employed:

For acetic acid, $a=\frac{15}{364}=0.04$;

For lactic acid, $a=3 \frac{38}{358}=0.10$;

For oxalic acid, $a=\frac{3}{36} \frac{38}{5}=0.92$;

For malic acid, $a=\frac{85}{356}=0.23$.

1 Abhandlungen der Sächsischen Gesellschaft der Wissenschaften, Vol. XV (1889). 
The relative number of dissociated molecules varies considerably. In the case of oxalic acid it reaches a value which approximates almost that for hydrochloric acid. We find, also, that the acid effect of oxalic acid approximates that of inorganic acids. For $\frac{1}{2} \mathrm{H}_{2} \mathrm{SO}_{4}, \mathrm{KHSO}_{4}$, and $\mathrm{NaHSO}_{4}$, when $V=210$, we obtain increases in weight which average 8.6, 7.9, and 8.2 per cent. (see Tables II and III). For oxalic acid we find an average of 6.9 per cent. The action is somewhat weaker than that of the inorganic acids. We may in this, perhaps, ahready see the effects of the anion. In the main, however, we may yet attribute the absorption of water under the influence of oxalic acid to the hydrogen ions.

In the case of lactic acid, however, this is out of the question. Only one-tenth of all the molecules were dissociated, yet the absorption of water was at least as great as in the case of oxalic acid. It is impossible that we are dealing here with the mere effects of the $\mathrm{H}$ ions of the lactic acid. The lactic-acid molecules bring about secondary effects in this case which add themselves to the effects of the $\mathrm{H}$ ions.

Acetic acid acts more than half as strongly as oxalic acid, and yet only 4 per cent. of all the molecules present are dissociated, while 92 per cent. of the oxalic-acid molecules are dissociated. The molecules of the acetic acid must therefore have secondary effects, and these in even greater degree than in the case of lactic acid, which add themselves to the effects of the few $\mathrm{H}$ ions which are already present. ${ }^{1}$

Malic acid, finally, is six times as strongly dissociated as acetic acid; its activity is, however, only a little greater than that of the latter.

I am not inclined to admit that these apparent irregulari-

1 It is also possible that acetic acid migrates comparatively more rapidly into the muscle fiber than oxalic acid. But it is also possible that these acids undergo or cause chemical changes in the mascle substance which increase their efficiency. [1903] 
ties must compel us to question whether we are indeed dealing with the effects of ions in the case of the inorganic acids and oxalic acid. The idea, which I have already suggested, that we are dealing with secondary effects in these cases, seems to me preferable.

Among these secondary effects the relations to the fermentative processes which are going on at all times in living tissues are the first to be considered. We know from the work of Emil Fischer how much fermentability is a function of the geometric configuration of the molecule. It is possible that the apparent difficulties which these organic acids at present offer to the assumption of the physiological effects of ions may yet become a fruitful support for the theory of ionization.

\section{EXPERIMENTS WITH BASES}

$\mathrm{LiOH}, \mathrm{NaOH}$, and $\mathrm{KOH}$ were especially considered. A few series of experiments were also made with $\frac{1}{2} \mathrm{Ba}(\mathrm{OH})_{2}$ and $\frac{1}{2} \mathrm{Sr}(\mathrm{OH})_{2}$. The experiments again showed that these bases have the same effect upon the absorption of water by the muscle when they are used in such concentrations that the same number of hydroxyl ions are contained in equal volumes of the solutions.

The method was the same as that employed in the case of acid. Solutions of all these bases were prepared which were one-tenth normal with reference to $\mathrm{OH}$. Of these solutions 5, 10, 15 , or 20 c.c. were added to 100 c.c. of a 0.7 per cent. $\mathrm{NaCl}$ solution. The increase in weight which the muscle suffered in these solutions in one hour was determined and is expressed in the following tables in percentage of the original weight of the muscle. We will give first of all the experiments with $\mathrm{LiOH}, \mathrm{NaOH}$, and KOH. $V$ indicates again the concentration of the base; and $V=210$ means that $1 \mathrm{~mol}$. of the alkali is dissolved in 210 liters of water. 
TABLE V

$(V=210)$

\begin{tabular}{|c|c|c|c|c|}
\hline & I & II & III & Average \\
\hline $\mathrm{LiOH}$ & $7.0 \%$ & $9.0 \%$ & $8.8 \%$ & $8.2 \%$ \\
\hline $\mathrm{NaOH} . . . \ldots \ldots \ldots$ & 11.3 & 6.4 & 7.8 & 8.5 \\
\hline КОН........... & 7.6 & 3.7 & 7.1 & 6.5 \\
\hline
\end{tabular}

TABLE VI

$(V=110)$

\begin{tabular}{|c|c|c|c|c|}
\hline & I & II & III & Average \\
\hline $\mathrm{LiOH}$ & $17.6 \%$ & $14.8 \%$ & $14.2 \%$ & $15.5 \%$ \\
\hline $\mathrm{NaOH} .$. & 14.2 & 17.3 & 16.0 & 15.8 \\
\hline $\mathrm{KOH}, \ldots \ldots \ldots \ldots$ & 10.0 & 20.8 & 16.0 & 15.6 \\
\hline
\end{tabular}

TABLE VII

$(V=76.6)$

\begin{tabular}{|c|c|}
\hline $\mathrm{LiOH}$ & $22.0 \%$ \\
\hline $\mathrm{NaOH}$ & 19.1 \\
\hline $\mathrm{KOH}$. & 20.6 \\
\hline
\end{tabular}

TABLE VIII

$(V=60)$

\begin{tabular}{|c|c|c|c|c|c|c|}
\hline & I & II & III & IV & V & Average \\
\hline LiOH & $26.4 \%$ & $27.5 \%$ & $21.3 \%$ & $26.7 \%$ & $25.7 \%$ & $25.5 \%$ \\
\hline $\mathrm{NaOH}$. & 26.7 & 27.4 & 27.3 & 26.7 & 27.5 & 27.1 \\
\hline КОН ... & 20.7 & 28.2 & 22.4 & 23.3 & 22.8 & 23.5 \\
\hline
\end{tabular}

As can also be seen, the effect increases somewhat more slowly with an increase in concentration than does the concentration itself. In Table VIII the concentration is over three times as great as that in Table $\mathrm{V}$; the effect of the alkali, however, only three times as great.

We must now try to answer the question which is of 
greatest importance to us: Do these phenomena rest upon the effect of the $\mathrm{OH}$ ions or the molecules of the bases? The degree of dissociation of the bases at the concentrations employed gives us the information we seek regarding this point.

Without detaining the reader with the mathematical proof, we can show that the dissociation of these alkalies at the concentrations employed is nearly complete. From this it follows that we are dealing with the effects of ions, and that the effect of the alkalies observed by us on the absorption of water by the muscle is determined solely by the negatively charged hydroxyl ions; that the molecules $\mathrm{KOH}$ $\mathrm{NaOH}$, and $\mathrm{LiOH}$, and also the cations $\mathrm{K}, \mathrm{Na}$, and $\mathrm{Li}$, play no part in this effect. For this reason we must obtain quantitatively equal physiological effects as soon as the given bases are used in such concentrations that the same number of hydroxyl ions is present in the same volume of the solution.

These results are well corroborated by the following experiments with $\frac{1}{2} \mathrm{Ba}(\mathrm{OH})_{2}$ and $\frac{1}{2} \mathrm{Sr}(\mathrm{OH})_{2}$.

TABLE IX

$(V=110)$

\begin{tabular}{c|c|c|c|c}
\hline \hline & I & II & III & Average \\
\cline { 2 - 3 } & $\begin{array}{l}16.8 \% \\
1 / 2 \mathrm{Ba}(\mathrm{OH})_{2} \ldots \ldots \ldots\end{array}$ & $\begin{array}{l}18.5 \% \\
17.5\end{array}$ & $\begin{array}{l}19.0 \% \\
14.5\end{array}$ & $\begin{array}{l}18 \text { 1\% } \\
15.4\end{array}$ \\
\hline
\end{tabular}

TABLE X

$(V=60)$

\begin{tabular}{|c|c|c|c|c|}
\hline & I & II & III & A verage \\
\hline $\begin{array}{l}1 / 2 \mathrm{Ba}(\mathrm{OH})_{2} \\
1 / 2 \mathrm{Sr}(\mathrm{OH})_{3}\end{array}$ & $\begin{array}{l}27.8 \% \\
30.6\end{array}$ & $\begin{array}{l}29.5 \% \\
25.6\end{array}$ & $\begin{array}{l}24.3 \% \\
21.2\end{array}$ & $\begin{array}{l}27.2 \% \\
25.8\end{array}$ \\
\hline
\end{tabular}


These are about the same values that we obtained for $\mathrm{NaOH}, \mathrm{LiOH}$, and $\mathrm{KOH}$ when $V=110$ and $V=60$.

The dissociation of $\frac{1}{2} \mathrm{Ba}(\mathrm{OH})_{2}$ and $\frac{1}{2} \mathrm{Sr}(\mathrm{OH})_{2}$ in the concentrations employed here is also so complete that there can be no doubt that we are dealing solely with the effects of ions and exclusively with the effects of the hydroxyl ions. When the effects of acids and alkalies are compared, it is seen that hydroxyl ions have a greater influence on the absorption of water than an equal number of $H$ ions in the same volume of the solvent.

IV. ON THE EFFECTS OF H AND OH IONS ON THE ABSORPTION OF WATER BY MUSCLE IN LONG-CONTINUED EXPERIMENTS

I had next to convince myself whether the experiments above detailed take place in living and irritable muscle or in dead and unirritable muscle. Stimulation experiments showed that the muscle which had remained for one hour in one of the alkali solutions even when $V=60$ was still irritable. Irritability was diminished, but it had not disappeared. So far as the acids were concerned, it seemed that the solution of an inorganic acid when $V=110$ is just as poisonous as that of a base when $V=60$, so far as irritability was concerned. We may therefore perhaps say that the $H$ ion is much more poisonous for the muscle than the hydroxyl ion. Of the organic acids which I employed oxalic acid was the most poisonous, while the remaining acids were much less poisonous. Oxalic acid approached the inorganic acids in toxicity. In oxalic acid we deal with the effects of the hydrogen ions. As I intend to return to this subject in another paper, these remarks may suffice at this time.

It was further necessary to investigate how the absorption of water by muscle is influenced when the muscle is allowed to remain much longer in the acid and alkali solutions than 
given here; so long, indeed, that the muscle may be regarded as dead. It was found that the increase in weight continues, even though less rapidly, with an increase in the time.

The following table shows the amount of water absorbed in twenty-four hours when $V=210$ and $V=110$ :

TABLE XI

\begin{tabular}{|c|c|c|c|}
\hline & $V=210(24 \mathrm{hrs})$. & $V=110(24 \mathrm{hrs})$. & $V=60(18 \mathrm{hrs})$. \\
\hline $\mathrm{LiOH}$ & $47.0 \%$ & $76.0 \%$ & $86.8 \%$ \\
\hline $\mathrm{NaOH} \ldots \ldots \ldots$ & 41.3 & 72.2 & 76.3 \\
\hline КОН ........ & 47.5 & 77.0 & 79.4 \\
\hline
\end{tabular}

One sees again that the quantitative effects of the solutions of the three bases is nearly the same as soon as the same number of $\mathrm{OH}$ ions are contained in the unit volume. In Table XII is given the amount of water absorbed by muscles after a residence of eighteen hours in solutions of acids when $V=110$ (or 210 ):

TABLE XII

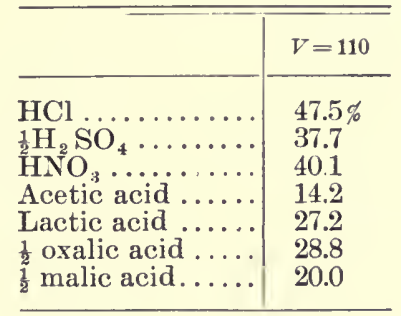

When the muscle is kept for a long time in acids, the muscle substance becomes liquefied. This is especially noticeable in the inorganic acids, and in oxalic and lactic acid. The absorption of water has in itself nothing to do with this process, as nothing of the sort is observed in the alkali solutions, even though the absorption of water is much greater in these.

1I suppose that this liquefaction is due to a hydrolysis which in the prescnce of acid is accelerated by the pepsin in the muscle. [1903] 
A comparison of Tables XII and XI shows again how much stronger the specific effect of the hydroxyl ions is than that of the hydrogen ions for the absorption of water by muscle.

The increase in the weight of the muscle under the influence of dilute acids and alkalies therefore continues even when the muscle has already lost its irritability. As only small amounts of the acids and alkalies are used, one is inclined to imagine the effect of the $\mathrm{H}$ and $\mathrm{OH}$ ions to be of a fermentative character.

V. IN HOW FAR ARE THE CHANGES IN THE WEIGHT OF THE MUSCLE A FUNCTION OF DIFFERENCES IN OSMOTIC PRESSURE BETWEeN THE MUSClE AND THE SURrouNdiNG LIQUID?

1. I have availed myself of more than a hundred experiments to show that in a 0.7 per cent. $\mathrm{NaCl}$ solution the gastrocnemius muscle of the frog generally suffers no important change in weight during the first hour. Often it loses a few milligrams in weight; in rare cases it increases a trifle; in the remaining cases its weight remains absolutely constant. The 0.7 per cent. $\mathrm{NaCl}$ solution can therefore be looked upon as approximately of the same osmotic pressure as the total osmotic pressure of the molecules and ions dissolved in the muscle cells. The fact that the presence of an acid or base in the salt solution compels the muscle to increase in weight shows that we have to deal in living matter with a system which alters its osmotic pressure easily, or in which the permeability of the protoplasmic wall is easily modified ; One might perhaps think at first that the great increase in the weight of the muscle upon the addition of acids or alkalies is simply determined by the fact that the muscle itself

1 It is possible that the absorption of water caused by alkalies and acids belongs to those phenomena of imbibition which have recently been studied by van Bemmelen. [1903] 
takes up these substances. There is no doubt that these substances enter the muscle, but the increase in the weight of the muscle amounts to much more than the weight of all the acid in the solution. I added, for example, 5 c.c. of a onetenth normal solution of $\mathrm{LiOH}$ to 100 c.c. of a 0.7 per cent. $\mathrm{NaCl}$ solution; the muscle increased $60 \mathrm{mg}$. in weight in one hour and $338 \mathrm{mg}$. in twenty-four hours. The total amount of $\mathrm{LiOH}$ in the solution was, however, only $12 \mathrm{mg}$. ! One might further think that the addition of a dilute acid or alkali decreased the osmotic pressure of the "physiological salt solution," and that in consequence its water had to enter the muscle. I have tested this possibility experimentally, and have found that the addition of 20 c.c. distilled water to 100 c.c. of a 0.7 per cent. $\mathrm{NaCl}$ solution brings about an increase in weight of from 1 to 3 per cent. of the original weight of the muscle. The addition of 20 c.c. of a dilute alkali solution, however, brings about an increase in weight of about 26 per cent. in one hour!

2. The next task which presents itself here is, first, to gain an insight into the order of magnitude of the osmotic forces which come into play in these experiments; and, secondly, to see how far equal differences in osmotic pressure bring about equal effects in the muscle.

The concentration of the $\mathrm{NaCl}$ solution in which the muscle of the frog neither increased nor decreased in weight in an hour varies between 0.62 and 0.72 per cent. Through activity this concentration may reach 1 per cent. and even more.

To quarrel over the question as to whether a 0.65 per cent. $\mathrm{NaCl}$ solution or a 0.7 per cent. $\mathrm{NaCl}$ solution is to be designated as a "physiological solution" is absurd, because the osmotic pressure of the muscle varies so greatly with rest and activity, temperature, etc., that at one moment a 0.65 per cent. $\mathrm{NaCl}$ solution may be isotonic, and one hour later 
a 0.73 per cent. $\mathrm{NaCl}$ solution may be isotonic for the same muscle.

If we assume that a 0.7 per cent. solution is isotonic with the muscle, we can easily calculate the osmotic pressure in the muscle, One molecule $\mathrm{NaCl}$ in one liter has an osmotic pressure of 22.3 atmospheres, if no dissociation occurred. A 0.7 per cent. $\mathrm{NaCl}$ solution would therefore have a pressure of 2.67 atmospheres. A certain fraction $a$ of the $\mathrm{NaCl}$ molecules is, however split into ions, and the latter act osmotically like molecules. If the original number of molecules be $N$, then, since each dissociated $\mathrm{NaCl}$ molecule yields 2 ions, the proportion of the molecules + ions present to the number of the original molecules $=[N(1-a)+2 N a]$ : $N$, or $=1+a$.

Because of the dissociation, the osmotic pressure therefore rises from 2.67 atmospheres to $2.67(1+a)$ atmospheres.

$a$ can readily be calculated in this case. A 0.7 per cent $\mathrm{NaCl}$ solution corresponds to a concentration of $V=8.3$. For $V=10$ and $T=18^{\circ}, \mu$, according to Kohlrausch $=86.5$. $\mu_{\infty}$ at $18^{\circ}=103 . \quad a$ therefore $=86.5=0.84$. The osmotic pressure of a muscle which is isotonic with a 0.7 per cent. $\mathrm{NaCl}$ solution therefore amounts to about 4.91 atmospheres. So far as I know, not a single text-book gives this figure, which is of much importance for physiology.

For a muscle which is isotonic with a 0.6 per cent. $\mathrm{NaCl}$ solution the osmotic pressure would amount to 4.2 atmospheres.

One may therefore say that the osmotic pressure of the gastrocnemius muscle of a frog varies between 4.2 and 4.9 atmospheres.

If the muscle is introduced into a solution the osmotic pressure of which is higher or lower than 4 or 5 atmospheres,

I Since this was written, this figure has entered the text-books, but the fact that it was given here for the first time seems to have been overlooked. [1903] 
the muscle must lose or take up water, and this in proportion to the difference in osmotic pressure.

3. Three years ago I induced Miss Cooke to make such experiments. As, however, she weighed the salt without previously drying it, I considered it well to repeat the experiments with more accurately prepared solutions. The solutions which I used were distilled water ( 0 per cent.), 0.35 , $0.7,1.05,1.4,1.75,2.1,2.45$, and 2.8 per cent. $\mathrm{NaCl}$ solutions.

The experiments were made at high temperature, $24^{\circ}$ to $30^{\circ}$ C. Table XIII gives the results. An increase in weight is indicated by + , a decrease by - , and in per cent. of the original weight of the muscles.

TABLE XIII

\begin{tabular}{|c|c|c|c|c|c|}
\hline Concentration & I & II & III & IV & $v$ \\
\hline 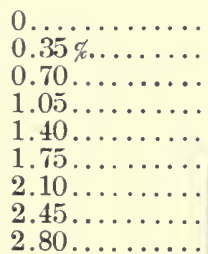 & $\begin{array}{l}+28.2 \% \\
+9.0 \\
-2.0 \\
-4.7 \\
-7.0 \\
-9.0 \\
\cdots \cdots \\
\cdots \cdots\end{array}$ & $\begin{array}{l}+30.7 \% \\
+10.0 \\
-0.7 \\
-3.7 \\
-0.6 \\
-7.8 \\
\cdots \cdots \\
\ldots \ldots\end{array}$ & $\begin{array}{l}+29.6 \% \\
\because 0.5 \\
=3.1 \\
-4.2 \\
-7.6 \\
-7.1 \\
=9.5 \\
-7.8\end{array}$ & $\begin{array}{l}+30.5 \% \\
\cdots 0.5 \\
-3.9 \\
-6.6 \\
-7.2 \\
-8.5 \\
\cdots\end{array}$ & $\begin{array}{l}+29.7 \% \\
+9.5 \\
-0.6 \\
-3.8 \\
-5.9 \\
-7.9 \\
-7.8 \\
-9.5 \\
-7.8\end{array}$ \\
\hline
\end{tabular}

We can at once draw an important conclusion from these results, namely, that the changes in the weight of a muscle in a sodium-chloride solution do not follow proportionally the differences between the osmotic pressure of the muscle and of the solution (when we assume that the osmotic pressure in the muscle is equal to 4 or 5 atmospheres); but that in hypisotonic solutions the increase in weight occurs more rapidly with a decrease in the concentration of the outer solution than the decrease in the concentration of the solution itself; and that in hyperisotonic solutions the decrease 
in weight occurs more slouly than the increase in the concentration of the external solution.

Both results point to the fact that an increase works in the same sense as a decrease in the amount of water contained in the cells, for both lead, apparently, to an increase in the osmotic pressure within the cells.

It is generally stated that muscles always twitch in concentrated salt solutions in consequence of the loss of water which they suffer, and Miss Cooke was inclined to see in these twitchings the cause of the increase in the osmotic pressure in the muscles immersed in hyperisotonic salt solutions. I noticed, however, that these twitchings always occurred in 1.05 and 1.4 per cent. solutions; that they occurred only rarely in 1.7 per cent. solutions, and that they never occurred in 2-2.8 per cent. solutions. It is possible that they occurred in the latter case only during the first few moments after immersion and then ceased. They might in this way have escaped my notice. One cannot, therefore, simply say any longer that the withdrawal of water brings about contractions in the muscle, but one must add that this occurs only when the difference in osmotic pressure between the outer solution and the muscle is not too great, or, perhaps more accurately, when the concentration of the surrounding solution is not too high.

The fact that the loss of water by the muscle increases more slowly than the difference in the osmotic pressures between the outer solution and the muscle is supplemented by the behavior of the muscle when left for a long time in 0.7 per cent. and hyperisotonic sodium-chloride solutions. The decrease in weight soon comes to a standstill, and the muscle begins to take up water so that in eighteen hours its weight is greater than its original weight. This occurs even when the muscle is kept in a 2.8 per cent. $\mathrm{NaCl}$ solution!

This fact that the "injured" muscle is able to take up 
water even from so concentrated a solution as a 2.8 per cent. $\mathrm{NaCl}$ solution is of importance in pathology, namely, in the explanation of adema. These conditions have thus far been attributed in the main to changes in blood-pressure and changes in the vessel walls. I believe, however, that we are dealing in this case with changes in the osmotic forces in the tissue cells or changes in their permeability; these changes are brought about as in our experiments through "injuries" (poisons) and lead, according to their nature, to a swelling of the cells or to a secretion of fluid into the body cavities.

VI. PROOFS OF THE VALIDITY OF VAN 'T HOFF'S THEORY OF OSMOTIC PRESSURE FOR THESE PHENOMENA

If solutions of $\mathrm{LiCl}$ or $\mathrm{KCl}$ are prepared of the same concentration as a 0.7 per cent. $\mathrm{NaCl}$ solution, the muscle behaves in them, so far as its change in weight is concerned, as in a 0.7 per cent. $\mathrm{NaCl}$ solution. The changes in the weight of a muscle are in this case, therefore, a function of the osmotic pressure. The degree of dissociation in all three salts is about the same.

I tested further whether the effect of an addition of 20 c.c. of a one-tenth normal $\mathrm{NaOH}$ solution was the same for "physiological" $\mathrm{LiCl}, \mathrm{NaCl}$, and $\mathrm{KCl}$ solutions. The increase in the amount of water absorbed by the muscle amounted respectively to $26.4,26.7$, and 20.7 per cent. of the original weight of the muscle in one hour. In a second experiment 5 c.c. of a one-tenth normal $\mathrm{KOH}$ solution was added to 100 c.c. of a 0.7 per cent. $\mathrm{NaCl}$ solution and to $\mathrm{LiCl}$ and $\mathrm{KCl}$ solutions isotonic with the $\mathrm{NaCl}$ solution. The absorption of water amounted to 8.2 per cent. in $\mathrm{LiCl}, 8$ per cent. in $\mathrm{NaCl}$, and 7.8 per cent. in $\mathrm{KCl}$. One can scarcely wish that the results should be more nearly identical.

Should anyone wish to interpret the experiments of the 
preceding chapter in such a way as though Van 't Hoff's theory of osmotic pressure did not hold for physiology, these experiments might perhaps teach him better.

This is especially the case with reference to the experiments with $\mathrm{MgCl}_{2}, \mathrm{CaCl}_{2}, \mathrm{SrCl}_{2}$, and $\mathrm{BaCl}_{2}$. One mol. of these compounds was dissolved in one liter of distilled water and then diluted to the same degree as a 0.7 per cent. $\mathrm{NaCl}$ solution. A muscle was introduced into 100 c.c. of each of these solutions. Table XIV gives the weight lost in these solutions in one hour.

Each of the salts mentioned here dissociates into three ions - two electro-negative chlorine ions and one bivalent electro-positive ion. According to this, the relation of thenumber of molecules actually present to those originally present is as $[N(1-a)+3 N a]: N=1+2 a, a$ in this case $=$ $0.6-0.7$.

TABLE XIV

\begin{tabular}{l|c|c|c}
\hline \hline & I & II & Average \\
\cline { 2 - 4 } $\mathrm{MgCl}_{2} \ldots \ldots \ldots \ldots$ & $-3.3 \%$ & $-3.7 \%$ & $-3.5 \%$ \\
$\mathrm{CaCl}_{2} \ldots \ldots \ldots \ldots$ & -3.4 & -3.5 & -3.4 \\
$\mathrm{SrCl}_{2} \ldots \ldots \ldots \ldots$ & -3.3 & -4.7 & -4.0 \\
$\mathrm{BaCl}_{2} \ldots \ldots \ldots \cdots$ & -5.1 & -6.7 & -5.9 \\
\hline
\end{tabular}

Without dissociation the osmotic pressure of each of these salt solutions would have amounted to 2.67 atmospheres. In consequence of the dissociation the osmotic pressure rises to $2.67(1+1.3)=6.14$ atmospheres.

The loss in weight which the muscles suffered in these solutions is nearly equal to the loss in weight which the muscles suffered in a $\mathbf{1 . 0 5}$ per cent. $\mathrm{NaCl}$ solution. In the latter solution this amounted on the average to 3.8 per cent. The osmotic pressure of such a solution is about 7.3 per cent., that is, therefore, a little higher than that of the $\mathrm{MgCl}_{2}$ solution. When we consider, however, that the condition of 
the protoplasm, and consequently its osmotic pressure, is affected differently by the different ions - of which we will say more immediately - the agreement between the values is satisfactory enough for proving the validity of Van 't Hoff's theory of osmotic pressure for the life phenomena of cells. Barium chloride, however, seems to be an exception.

VII. ON THE EFFECT OF POTASSILM CARBONATE AND SODIUYI CARBONATE SOLUTIONS UPON THE MUSCLE

If solutions of $\mathrm{Na}_{2} \mathrm{CO}_{3}$ and $\mathrm{K}_{2} \mathrm{CO}_{3}$ of the same concentration as a 0.7 per cent. $\mathrm{NaCl}$ solution are prepared, muscles immersed in them increase markedly in weight. Table XV gives the increase in weight of the muscles in these solutions after one hour.

\begin{tabular}{c|c|c}
\multicolumn{2}{c}{ TABLE XV } \\
\hline & I & II \\
\hline & & \\
\hline $\mathrm{Na}_{2} \mathrm{CO}_{3} \ldots \ldots \ldots \ldots$ & $\begin{array}{l}7.1 \% \\
\mathrm{~K}_{2} \mathrm{CO}_{3} \ldots \ldots \ldots \ldots\end{array}$ & $\begin{array}{l}7.1 \% \\
6.1\end{array}$ \\
\hline
\end{tabular}

The muscles showed the glassy appearance of a muscle which has been in a weak solution of an alkali. The order of magnitude of the absorption of water also corresponds with the effects of an alkali. According to the theory of dissociation, this effect is brought about in the following way: The potassium carbonate is dissociated in part into potassium and $\mathrm{CO}_{3}$ ions; as carbonic acid is a very weak acid - that is to say is only slightly dissociated-each $\mathrm{CO}_{3}$ ion combines with two $\mathrm{H}$ ions to form carbonic acid. Two negatively charged $\mathrm{OH}$ ions must, in consequence, go into solution, ${ }^{3}$ and these bring about both the alkaline reaction of the solution and the absorption of water by the muscle. We are dealing in this case, therefore, not with potassium or carbonate effects, but with the effects of hydroxyl ions.

1 More correctly form $2 \mathrm{KOH}$, which, however, at this degree of dilution is dissociated to a high degree. [1903] 
It is well known that weak solutions of $\mathrm{Na}_{2} \mathrm{CO}_{3}$ increase the irritability of the muscle. $\mathrm{NaOH}$ in dilute solution acts in the same way. Strange to say, these effects are generally attributed to the Na. We are dealing in both cases, however, with effects which are brought about solely through the hydroxyl ions (see sec. iii) and which have nothing to do with the $\mathrm{Na}$ ions or the $\mathrm{Na}$ compounds. So far as I know, this error goes through the whole literature of physiology and pharmacology. The chapter of chemical stimulation as well as the chapter on pharmacology stand in need of a thorough revision on the basis of the theory of dissociation.

VIII. THE VELOCITY OF MIGRATION AND THE RELATIVE TOXICITY OF DIFFERENT IONS FOR THE MUSCLE

It seems to me to be of the greatest interest to compare the relative toxicities of ions in order to discover if any relations exist between these toxicities and the other properties of the ions.

If I make such a comparison of the toxicity of the ions dealt with in this paper, I do it with two reservations: first, that although the method of determining the toxicity of ions for muscle by determining the threshold of stimulation is superior to the method of Kahlenberg, it is, nevertheless, not as accurate as that of determining the velocity of migration of the ions; secondly, that the observations made thus far refer to only a very limited number of ions. I hope to overcome the latter shortcoming by further experiments. But I do not yet see how the former difficulty is to be overcome.

The most poisonous ion (of the ions which have been discussed in this paper) for muscle is undoubtedly the hydrogen ion, which has the lowest atomic weight, but the greatest velocity of migration. For the strength of current and the induction apparatus employed by us, 10-15 c.c. of a one-tenth normal $\mathrm{HCl}, \mathrm{HNO}_{3}$ or $\frac{1}{2} \mathrm{H}_{2} \mathrm{SO}_{4}$ solution (in 0.7 per cent. $\mathrm{NaCl}$ solution) sufficed to do away with the irritability of the 
muscle in one hour. The hydroxyl ions act much more weakly. When 20 c.c. of a one-tenth normal $\mathrm{LiOH}, \mathrm{NaOH}$, or $\mathrm{KOH}$ solution were added to the $\mathrm{NaCl}$ solution, the irritability was greater or just as great as when 10 c.c. of the acid solution were added. The speed of migration of the hydrogen ions is, according to Ostwald, 325 at $25^{\circ}$, that of the hydroxyl ions 170 .

If we study the monovalent cations $\mathrm{Li}, \mathrm{Na}, \mathrm{K}, \mathrm{Rb}$, and $\mathrm{Cs}$, it is to be remembered that at the concentration which $\mathrm{I}$ employed of $1 \mathrm{~mol}$. in about 8 liters of water the dissociation of the chlorides of these elements is so complete ( 84 per cent.) that we are dealing chiefly with the effects of ions. Of these ions $\mathrm{Li}$ and $\mathrm{Na}$ were not poisonous, so far as the irritability of the muscle was concerned, for the irritability remained unchanged. On the other hand, the ions $\mathrm{K}, \mathrm{Rb}$, and $\mathrm{Cs}$, with their greater atomic weight and greater velocity were decidedly poisonous. The irritability of the muscle in the $\mathrm{KCl}$ solution (of the same concentration as a 0.7 per cent. $\mathrm{NaCl}$ solution) was almost destroyed after one hour, or at any rate greatly decreased. The same is true of $\mathrm{RbCl}$ and $\mathrm{CsCl}$ solutions of the same concentration as a 0.7 per cent. $\mathrm{NaCl}$ solution.

It cannot be concluded from my observations that the toxicity of the $\mathrm{Rb}$ and $\mathrm{Cs}$ ions is greater than that of the $\mathrm{K}$ ions. I am rather inclined to believe that the toxicity of the three last-named ions for the gastrocnemius of the frog is about the same. I thought at first that the toxicity of the ions was a function of their ionic weight. Such a view is, however, untenable when the atomic weights are considered. The atomic weight of $\mathrm{Li}$ is 7 , that of $\mathrm{Na} 23$, that of $\mathrm{K} 39$, that of Rb 85.2, that of Cs 132.7; and yet there is a great jump from the toxicity of the sodium ions to that of the potassium ions. The latter are, however, about as poisonous as $\mathrm{Rb}$ and $\mathrm{Cs}$ ions, in spite of the great differences in their 
atomic weights. On the other hand, we notice a beautiful agreement between the relative toxicity of the individual members of this group and the velocity of the migration of the ions. According to Kohlrausch, the speed of migration of the Li ion at $18^{\circ}$ is 33 , that of the $\mathrm{Na}$ ion 41 , that of the $\mathrm{K}$ ion 60 . The velocities of the ions of $\mathrm{Rb}$ and $\mathrm{Cs}$ are equal to the velocity of $K$, according to Ostwald. A great jump, therefore, occurs from $N$ a to $K$ in the velocity of the migration of the ions, while no such jump occurs from $K$ to $R b$ and to $C s$, just as is the case in their toxicity. It may therefore be said that the relative toxicity for muscle of the ions of this group is rather a function of their velocity of migration than of their atomic weight. The heavier elements are, therefore, more poisonous only becanse their ions have a greater speed of migration than the $\mathrm{Na}$ and Li ions.

On the other hand, the toxicity of $K$ ions is much less than that of the hydroxyl ions. In our experiments with alkalies the addition of 10 c.c. of a one-tenth normal alkali solution to 100 c.c. of a physiological $\mathrm{NaCl}$ solution was sufficient to bring about a decided decrease in irritability. It did not matter, however, whether the alkali used was $\mathrm{KOH}, \mathrm{NaOH}$, or $\mathrm{LiOH}$. At this concentration only the $\mathrm{OH}$ ions were poisonous, while the toxicity of the $\mathrm{K}$ ions did not appear.

The investigation of the relative toxicity of the bivalent ions $\mathrm{Be}, \mathrm{Mg}, \mathrm{Ca}, \mathrm{Sr}$, and $\mathrm{Ba}$ is rendered difficult by the fact that a solution of the chlorides of these elements of the same concentration as a 0.7 per cent. $\mathrm{NaCl}$ solution has a greater osmotic pressure than the sodium-chloride solution. The muscle, therefore, loses water (as we have seen) in such a solution, and the loss in water must also decrease the irritability. We are, however, in a position to estimate the influence of the loss of water on the irritability. The loss of water in these solutions was about equal to that in a 1.05 
per cent. $\mathrm{NaCl}$ solution. While the irritability of the muscle was decreased but little after remaining one hour in such a sodium-chloride solution-it fell in one hour from 420 to 380 - it had decreased in a $\mathrm{BeCl}_{2}$ solution, for example, to 220 in one hour. In the remaining solutions $\mathrm{MgCl}_{2}, \mathrm{CaCl}_{2}, \mathrm{SrCl}_{2}$, and $\mathrm{BaCl}_{2}$ the decrease in irritability was still greater. In one experiment, for example, the muscle just responded, after remaining for one hour in a $\mathrm{MgCl}_{2}$ solution, when the secondary coil was pushed out $110 \mathrm{~mm}$., while the muscle in the $\mathrm{CaCl}_{2}$ solution could just be stimulated when the coil was at 0 . The muscles which had been in $\mathrm{SrCl}_{2}$ and $\mathrm{BaCl}_{2}$ did not respond at all to stimuli after an hour. In another experiment a contraction could be obtained in a muscle which had been for one hour in the $\mathrm{MgCl}_{2}$ solution when the secondary coil was at 100 ; for the muscle which had been in $\mathrm{CaCl}_{2}$ when the secondary coil was at 150 ; for the $\mathrm{SrCl}_{2}$ solution when the secondary coil was at 50 to 60 ; while the muscle which had been for one hour in $\mathrm{BaCl}_{2}$ was absolutely unirritable. These figures show at the same time that this method of determining the irritability leaves much to be desired. The following conclusion call, however, certainly be drawn from these experiments: The $\mathrm{Be}$ ions are decidedly more poisonous than the $\mathrm{Li}$ ions, even though their atomic weights are almost the same; in the same way $\mathrm{Mg}$ ions are decidedly more poisonous than $\mathrm{Na}$ ions, although their atomic weights are nearly the same. This fact must also be considered, that the dissociation of the chlorides of these bivalent elements is less than that of the chlorides of the Li group, and that, in consequence, the number of the cations in the Be group is smaller than in the Li group. Furthermore, since the $\mathrm{SrCl}_{2}$ and $\mathrm{BaCl}_{2}$ solutions are at least just as poisonous as the equally concentrated $\mathrm{RbCl}$ and $\mathrm{CsCl}$ solutions, it is perhaps right to ask whether the toxicity does not in these 
cases increase simultaneously with the valency. To say that the toxicity increases in proportion to the increase in atomic weight would be entirely wrong. The atomic weights are 9.08 for $\mathrm{Be}, 24.3$ for $\mathrm{Mg}, 39.9$ for $\mathrm{Ca}, 87.3$ for $\mathrm{Sr}$, and 136.9 for $\mathrm{Ba}$. If the toxicity of the ions were proportional to their atomic weights, this would show itself clearly in our experiments. The velocities of migration correspond much more perfectly with the relative toxicities of these ions. According to Kohlrausch, the velocities of the ions at $18^{\circ}$ are about as follows: $\frac{1}{2} \mathrm{Mg}=42, \frac{1}{2} \mathrm{Ca}=49, \frac{1}{2} \mathrm{Ba}=53$. $\mathrm{Sr}$ is not given, but the velocity of its ion might stand close to that of $\mathrm{Ba}$. One sees that this series of velocities does not show the jump which occurred in the former series from $\mathrm{Na}$ to $\mathbf{K}$, and which corresponded to a similar jump in the relative toxicities. The difference in the velocity of migration of $\mathrm{Mg}$ and $\mathrm{Ca}$ is only 10 per cent., while that between the corresponding members of the Li series, namely, Na and $\mathbf{K}$, is 50 per cent. We see also that no such jump exists from the toxicity of $\mathrm{Mg}$ to that of $\mathrm{Ca}$. The conclusion seems justified, therefore, that the relative toxicities of the series of ions $\mathrm{Be}, \mathrm{Mg}, \mathrm{Ca}, \mathrm{Sr}$, and $\mathrm{Ba}$ correspond more nearly to the velocities of these ions than to their atomic weights.

We have yet to discuss the toxicity of the anions. $\mathrm{OH}$, with its enormously high velocity of migration, is, as we have seen, a relatively strong poison for muscle. On the other hand, the $\mathrm{Cl}$ ion, with a speed of migration which is equal to that of the $\mathrm{K}$ ion, is as harmless as the $\mathrm{Li}$ and $\mathrm{Na}$ ions, as is shown by the behavior of the 0.7 per cent. $\mathrm{NaCl}$ solution, which contains just as many $\mathrm{Cl}$ ions as $\mathrm{Na}$ ions. The speed of migration of the $\mathrm{NO}_{3}$ ion is, according to Kohlrausch, 60 at $18^{\circ}$; that of $\frac{1}{2} \mathrm{SO}_{4}, 66$; that of $\mathrm{Cl}, 62$. The fact that $\frac{1}{2} \mathrm{H}_{2} \mathrm{SO}_{4}, \mathrm{HNO}_{3}$, and $\mathrm{HCl}$ show themselves to be equally poisonous at the same concentration indicates that in the concentrations which we employed the effect of the 
$\mathrm{NO}_{3}$ and the $\mathrm{SO}_{4}$ ion does not come into consideration. I shall return to this point as soon as I have made further experiments.

It is self-evident, of course, that so close a relation as proportionality between the velocity of migration and the relative toxicity of the ions is to be expected only in those ions which belong to the same narrow group; a group in which the remaining characteristics of the ions are almost identical and in which importrunt differences exist only with reference to atomic weight and velocity of migration. What has been said thus far holds only for the members of the Li series or the Be series among themselves; it would be wrong to judge the relative toxicity of $\mathrm{K}$ and $\mathrm{Ca}$ on the basis of the velocities of migration of their ions, because in doing this new differences come into consideration; for example, the difference in their valencies. It would be entirely absurd to judge the toxicity of the alkaloids by the velocity of the ions.

This further fact is to be considered in judging toxicity, that all our evidence is of a negative character - the cessation of life or of individual functions, especially irritability. The most widely differing circumstances may, however, bring about this result. One poison may act by rendering impossible processes of oxidation (for example, HCN, according to Geppert); another may bring about molecular changes which influence the transformations of energy in the cell, etc. It is to be expected that different groups of poisons bring about their toxic effects in different ways. This is a further warning against a too sweeping generalization of the relation between velocity of migration and toxicity. We must finally not overlook the apparent inequality in the permeability of the protoplasm for different ions, a subject concerning which special experiments are yet to be made. 


\section{SUMMARY OF RESULTS}

1. The addition of small amounts of a very dilute acid or alkali brings about a great increase in weight (absorption of water?) in a muscle contained in a physiological sodium chloride solution.

2. For the inorganic acids, $\mathrm{HNO}_{3}, \mathrm{HCl}, \mathrm{H}_{2} \mathrm{SO}_{4}$, $\mathrm{KaHSO}_{4}, \mathrm{NaHSO}_{4}$ (in a high degree of dilution) this increase in weight is solely a function of the number of hydrogen ions contained in the unit of volume of the physiological salt solution. Solutions of these different acids which contain the same number of $\mathrm{H}$ ions in the unit of volume bring about a quantitatively equal increase in weight.

3. This simple relation does not hold for organic acids (acetic acid, lactic acid, malic acid). In these the effect of the anion or of the undissociated molecules makes itself felt.

4. For the bases $\mathrm{LiOH}, \mathrm{NaOH}, \mathrm{KOH}, \mathrm{Sr}(\mathrm{OH})_{2}, \mathrm{Ba}(\mathrm{OH})_{2}$, this increase in weight is solely a function of the number of hydroxyl ions contained in the unit of volume of the physiological salt solution. Dilute solutions of these different bases which contain an equal number of hydroxyl ions in the unit of volume bring about an equal increase in weight.

5. If the muscle is introduced into various solutions of $\mathrm{NaCl}$ the osmotic pressure of which is higher or lower than that of the muscle, it is found that the change in the weight of the muscle is not proportional to the difference between the osmotic pressure in the muscle and that of the surrounding solution; in hypisotonic solutions the muscle increases in weight more rapidly; in hyperisotonic solutions it decreases in weight more slowly than corresponds to the differences in osmotic pressure.

6 . The validity of Van 't Hoff's theory of osmotic pressure for these processes is proved by the fact that solutions of $\mathrm{LiCl}, \mathrm{KCl}, \mathrm{RbCl}, \mathrm{CsCl}, \mathrm{MgCl}_{2}, \mathrm{CaCl}_{2}, \mathrm{SrCl}_{2}$, and $\mathrm{BaCl}_{2}$ 
bring about approximately the same change in weight as a $\mathrm{NaCl}$ solution of the same osmotic pressure. ${ }^{1}$

7. Sodium and potassium carbonate bring about an absorption of water by the muscle in consequence of the hydroxyl ions contained in the solution of these salts.

8. The relative toxicity of the group of ions $\mathrm{Li}, \mathrm{Na}, \mathrm{K}$, $\mathrm{Rb}$, Cs for muscle runs parallel with the velocities of the migration of these ions and not with their atomic weights. A similar parallelism exists between the velocity of the ion and its relative toxicity in the group $\mathrm{Be}, \mathrm{Mg}, \mathrm{Ca}, \mathrm{Sr}$, and Ba. Such a relation is, of course, to be expected only between ions which belong to the same narrow group in the periodic system.

1 When the duration of the experiment is short. [1903] 


\section{XX \\ ON THE PHYSIOLOGICAL EFFECTS OF ELECTRICAL WAVES ${ }^{1}$}

1. Is the June number of Pflügers Archiv I published some experiments which were undertaken in the hope of obtaining physiological effects through Hertzian waves. ${ }^{2}$ I have continued my experiments since then, and will in this paper publish some new facts and some further confirmations of the ideas set forth at that time. I will at the same time enter a little more deeply into the theoretical discussion of these phenomena.

In the July number of the Archives de physiologie Danilewsky published a paper on the "Excitation of Nerves through Electrical Rays." The experiments of this author coincide partly, so far as the mere facts are concerned, with the experiments which I have published previously. So far as his explanation of the experiments goes, it is entirely wrong.

If we allow a spark to pass between the spheres of the discharger of an electric machine or a Ruhmkorff coil, we obtain waves all of which are propagated with the velocity of light. The wave-lengths, however, depend upon the number of oscillations per second. If, for example, we separate the two spheres of the spark discharger of a Ruhmkorff until a spark no longer passes between them, the number of oscillations obtained in a second corresponds to the number of oscillations of the interruptor. In this case we deal with waves thousands of kilometers in length, and it is of course

1 Pfügers Archiv, Vol. LXIX (1897), p. 99.

2 "On the Theory of Galvanotropism, V," ibid., Vol. LXVII (1897), p. 483. 
only a façon de parler if we continue to speak of waves in this case, just as we might still designate a circle as an ellipse. If sparks pass across, the length of the waves varies with the capacity and the self-induction of the discharger. With small spheres and a short spark discharge very short waves (a few centimeters in length) can be obtained. The next shortest waves with which we are acquainted are the "heat-rays;" after these come the "light-rays" which act upon the eyes; and finally the ultra-violet rays. The wave-length is of importance in the effect produced by each of these waves, in so far as every wave-motion is most effective when it strikes a body which constitutes a resonator for the given wave-motion. Under such conditions the energy of the waves may suffice to cause the body "to vibrate sympathetically." Definite relations exist between the wave-lengths and the dimensions of a resonator, according to which the resonators for light-waves must have almost molecular dimensions, while the longer waves such as arise in the discharge of a condensator correspond to larger resonators.

This fact becomes especially important for the theory of life-phenomena. The basis of all life-phenomena are chemical and molecular processes. It is therefore probable a prior $i$ that only such wave-motions will be able to call forth immediate life-phenomena, the resonators of which have molecular dimensions. Thus we see, indeed, that lightwaves produce a series of physiological effects. But we also see that certain functions such as the chlorophyll functions or the heliotropic effects, etc., depend on definite wave-lengths. I conclude from this that the heliotropic functions and the chlorophyll functions are dependent upon molecules of different dimensions. The electromagnetic theory of light will perhaps enable us to determine the approximate, and later perhaps the absolute, 
dimensions of the molecules in the living cell which are sensitive to light. With these possibilities in view I have undertaken at this time more accurate experiments on the heliotropic activity of the different rays of the spectrum. My previous experiments in this direction were made in the

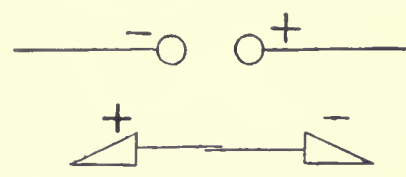

FIG. 138 main with colored screens, which sufficed for the immediate pur. pose before me at that time, namely, to show that the phenomena of animal heliotropism are identical with those of plant heliotropism. The latter had also in the main been analyzed only by the aid of colored screens.

2. The experiments which I described in the paper mentioned in the introduction showed, however, clear physiological effects. In these experiments I dealt with oscillatory discharges, and the nerve-muscle preparation was struck by waves the length of which varied in the different experiments between several centimeters and meters. Yet I maintained that the oscillatory nature of the discharges had nothing to do with these physiological effects, but that the contractions of the muscle were dependent upon the mere disappearance of the electrostatic charge from the two spheres of the discharger. It may perhaps be best to review briefly the chief experiments. We used a ToeplerHoltz machine. As the living tissue or indicator in our experiments we used two frog's legs with exposed nerves. Both legs were laid as nearly as possible in the same straight line, so that the two free ends of the nerves touched each other (Fig. 138). In this way a preparation is obtained in which the capacities are distributed symmetrically upon both sides. Through this fact my preparation has an advantage over Danilewsky's, who used only one nerve, connected on the one side with the leg, on the other 
with the spinal cord. If the nerves are laid parallel to the spark discharge maximal effects are obtained when the muscle preparations lie in a symmetrical position with relation to the two spheres of the discharger (Fig. 138), while every displacement of the preparation toward one side (Fig. 139) diminishes the effects or causes them to cease entirely.

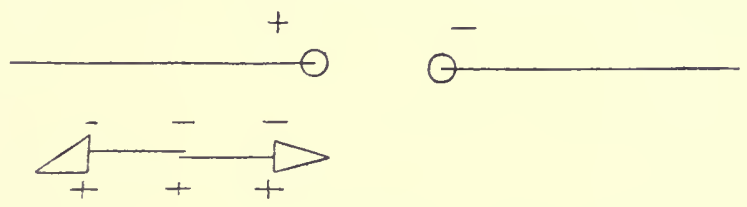

FIG. 139

If, on the other hand, the nerves of the muscle preparations are laid at a right angle to the spark discharge, minimal effects are obtained when the preparation lies in a position symmetrical with the two spheres of the discharger (Fig. 140), while maximal effects are obtained when the muscle preparations are moved laterally a sufficient distance (Fig. 141).
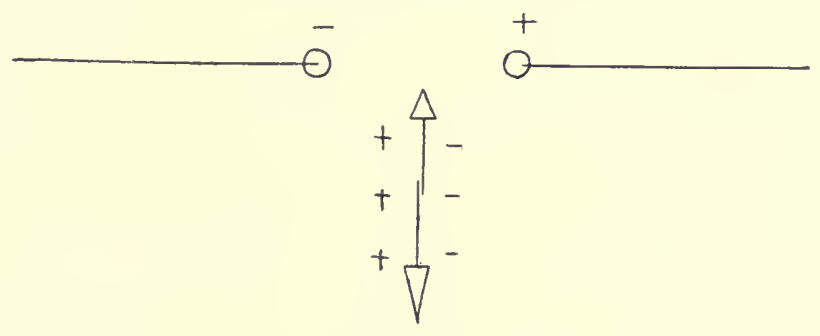

FIG. 140

The explanation which I gave of these phenomena was as follows:

a) Let it be assumed that the two muscle preparations lie parallel to the spark discharge and in a position symmetrical with reference to the discharger (Fig. 138). If at a certain time the one sphere of the discharger is charged positively, the other negatively, a corresponding distribution of the electricities is induced in the nerve-muscle 
preparations. When a spark passes there is nothing to keep the electricities in the muscle preparation apart, and a current consequently passes longitudinally through the nerves and causes the muscles to contract.

b) The muscle preparations lie at a right angle to the path of the spark, but in a position symmetrical with reference to the spheres of the discharger (Fig. 140). The electricities will now be distributed in the preparation in such a way that during the passage of the spark a current must pass

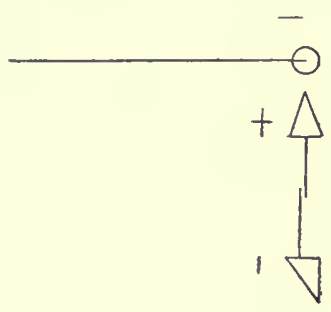

FIG. 141

transversely through the nerve. Since the nerve cannot be stimulated by a current passing transversely through it, the effect is in this case minimal.

c) The nerve-muscle preparations again lie parallel with the spark discharge, but not in a position symmetrical with reference to it, but toward one side of it (Fig. 139). The electricities will now be so distributed that during the discharge a current must pass transversely through the nerve. We must therefore again expect a minimal effect, etc.

The experiment with a mirror which I described in a previous paper, and which at first seemed to contradict our explanation, can also be explained in this way. The nervemuscle preparations were placed at right angles with the spark discharge, but not in a position symmetrical with the discharger, but slightly to one side of it (Fig. 142). Under such circumstances only a weak current passes longitudinally through the nerves during the passage of the spark. 
If now the preparation is so placed with reference to the spark discharge that a contraction is just rendered impossible during the passage of the spark, a contraction can again be brought about when a mirror $S S$ (Fig. 142) is so placed that one end of it is near that sphere of the discharger which is farthest away from the preparation, while the other end of the mirror is near that end of the preparation which is directed away from the spark discharge. The explanation of the effect of this mirror is very simple. A distribution of the electricities is

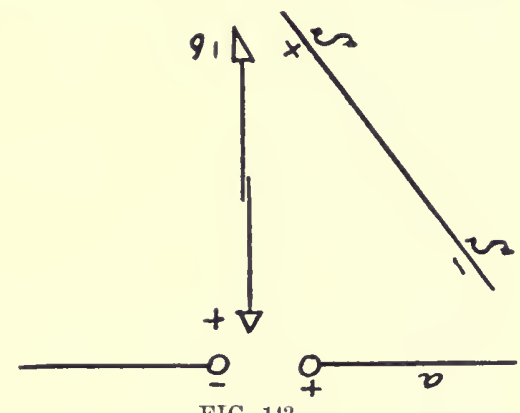

FIG. 142 also induced in the mirror, and this induction must increase the distribution of the electricities in the nerve-muscle preparation.

But it might be imagined that we are in this case dealing with the effects of waves which are reflected by the mirror. That this is not the case, but that we are dealing with the effects of a double induction, is proved by the following experiment. Let everything be left just as in the previous experiment, only the spark discharge be turned through an angle of $90^{\circ}$, so that it is now vertical instead of horizontal as before. The electric waves will now be reflected by the mirror just as before, but the strengthening effect of the induction through the mirror can now no longer exist. Under these circumstances no contractions occur, whereby it is proved that the electric waves are not the cause of the mirror effect. Since my first publication of this experiment I have supplemented it in two directions which make it more interesting as a demonstration experiment, and which bring additional proof of the correctness of our explanation. First of all I have found that it is not necessary to use a metallic 
mirror, but that a moistened glass plate is just as good a mirror as a metallic plate. If we were dealing with the effect of waves, this would not have been the case, as electric waves penetrate a thin layer of water more easily than a metal plate. Secondly, the body of the experimenter can be
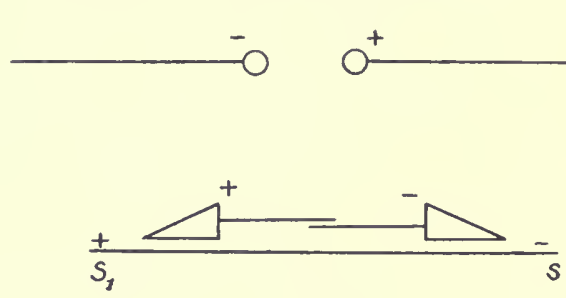

FIG. 143 used in this experiment instead of a mirror. The experimenter needs only to bring one hand into the neighborhood of the sphere $a$ (Fig.

142), the other in the neighborhood of the end $b$ of the muscle preparations. In this way the muscle can be made to contract, and the result might convince any believer in telepathy that his superstition has a scientific foundation. In the latter case the effects of induction are too apparent, the effects of a reflection of waves too improbable, to allow one to think of a wave-effect.

The last series of experiments which I published consisted in the inhibition of the electrical effects through a screen. The preparation lies parallel to the spark discharge and in a position symmetrical with reference to the spheres of the discharger (Fig. 138). The preparation contracted energetically each time the spark passed between the spheres of the discharger. If now a metal screen $S S_{1}$ (Fig. 143) is placed behind the preparation and parallel to it, these effects disappear. This can be explained as the result of induction. A distribution of the electricities will be induced in the mirror by the two spheres in the same sense as in the muscle preparations. Since the same kinds of electricity lie opposite each other in the mirror and in the nerve-muscle preparations, the effect upon the muscle preparations must 
be weakened by the mirror, and in consequence contractions do not occur. The explanation through the assumption of electric waves would be that standing waves are formed, and that a node exists at the mirror. It was a simple matter to show that this explanation is wrong. The mirror needs only to be moved away steadily in order to show that at every other distance contractions again begin. If we were indeed dealing with standing waves, periodic inhibitions of the contractions should have occurred when the mirror was steadily removed from the nerve-muscle preparations.

In this experiment it is also possible to replace the metallic mirror by a moist glass plate or by the experimenter himself. When he stands behind the muscle and brings one hand near each one of the two free ends of the preparation, the contractions can easily be inhibited. I need scarcely mention that this form of demonstration is especially "impressive."

3. The objection might now be raised against this explanation that we ought to give a more modern representation of the changes which occur in the preparations in these experiments. I am glad to fill in this gap in my first publication, since this gives me an opportunity to enter more deeply into the chemical theory of electro-physiological effects, which I have begun to discuss in two previous papers. The question which is of importance to physiologists in this case is the following: What is changed in a nerve-muscle preparation, or any other living substance, when we say that it has a negative or a positive charge of electricity, as has happened repeatedly in this paper? It follows, first of all, from Faraday's law governing conduction in liquids, that electricity can be conducted in living matter only through a migration of ions, since only the liquid portions of a cell are conductors. Ostwald has drawn the further conclusion from Faraday's law that static electricity 
in a liquid conductor can also be conceived of only as an excess of negative or positive ions on the surface of the solution. It seems to me that Ostwald's assumption is a necessary one, and, corresponding with this, I believe that when we assume a distribution of electricities in a nerve-muscle preparation, as shown in Fig. 138, a definite number of positive ions are distributed over the surface of the right half of the preparation, and an equal number of negative ions over the surface of the left half of the preparation. The lines of force which go out from the spheres of the spark discharge to the preparation can be imagined as the connecting lines between the centers of polarized elements. These connecting lines would therefore end at the surface of muscle preparations in the ions. As soon as the charge disappears from the spheres of the discharger, the excess of positive ions on the right side of the preparation and the excess of negative ions on the left side of the muscle preparation can no longer remain separated, and a migration of the ions - a currentmust occur in the nerves. In this case (in consequence of the semi-permeability of certain elements in the preparation?) a collection of ions must occur at certain points in the preparation. The ions are converted into atoms and so bring about chemical effects either directly or indirectly; these chemical effects bring about the contractions which we notice during the passage of the spark. ${ }^{1} \quad$ One can readily understand in this way also why the oscillatory nature of the discharge is of no importance in the physiological effects produced, as the latter are dependent solely upon the migration of ions. If our theory is correct, it is therefore to be expected that the experiments which have been described can also be made successfully, when it is possible to do away with the oscillatory character of the discharge entirely.

1 I am now inclined to believe that no transformation of ions into atoms occurs in this case, and that the mere change in the concentration of ions at the surface of the semipermeable membranes suffices for the result. This harmonizes with a view expressed since by Nernst. [1903] 


\section{II}

My experiments were published in the June number of Pfliigers Archiv. In the July number of the Archives de physiologie B. Danilewsky published two articles under the title, "Excitation des nerfs par les rayons électriques." Danilewsky overlooked the circumstance upon which everything depends in this case-the significance of the orientation of the nerves toward the spark discharge. It will be seen that Danilewsky's experiments are a further proof for my assumption that the effects which he and I observed are

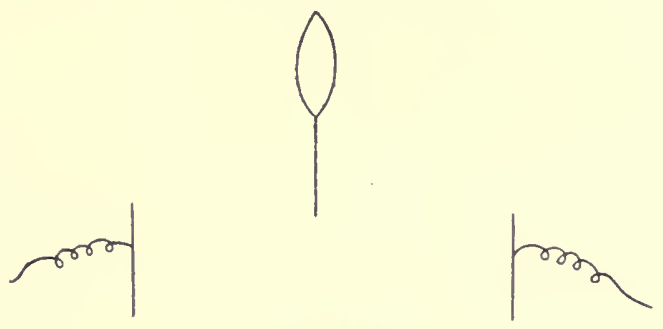

FIG. 144

not determined by the oscillatory nature of the discharge. For his experiments are made in a way which does away with the oscillatory nature of the discharge almost entirely.

The experiments of Danilewsky apparently fall into three groups. In reality, however, we are dealing with one and the same experiment. We will discuss first of all the experiment which he designates as the "interference experiment" (p. 524). Each of the poles of the Ruhmkorff coil is connected with a smooth metal plate. These metal plates are set up parallel to each other some 50 to $100 \mathrm{~cm}$. apart. "If the nerve is placed in a position symmetrical with the two metal plates, one obtains no effect. . . . The symmetry needs to be altered only slightly, that is to say, the preparation needs to approximate one of the metal plates only slightly, in order to bring about induced contractions." If we study the drawing (Fig. 14t, according to Danilewsky) 
somewhat closely, we find that in this experiment the nerve accidentally lay parallel to the metal plates and somewhat outside the area inclosed by the metal plates. This is no other experiment than that which $I$ have described under $b$ ), and which is shown in Fig. 140. In order to convince

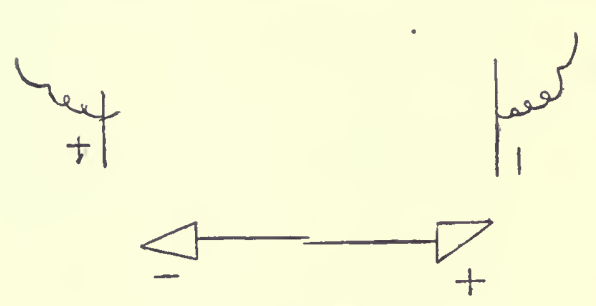

FIG. 145 oneself of this fact one needs only to turn the nerve through an angle of $90^{\circ}$, as $\mathrm{I}$ have done, and lay it parallel to the line connecting the electrodes (Fig. 145); one then obtains maximal effects when the nerve lies symmetrically with reference to the metal plates. We do not deal, therefore, with interference in Danilewsky's experiment, but (as I had already shown in my first publication) with the well-known fact that the nerve is insensitive, or only slightly sensitive, to a current which passes through it transversely. I convinced myself of the correctness of this interpretation in yet another way. One can also obtain minimal effects when the nerves lie at right angles to the electrodes and in a dissymmetrical position, if the nerves are brought entirely within the area between the two metal plates as shown in Fig. 146. In this way currents are obtained which

pass transversely through the nerves.

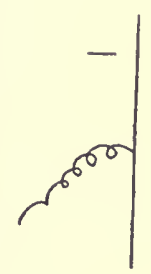

FIG. 146

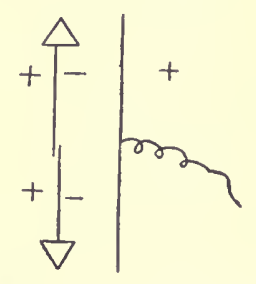

The "interference experiments" of Danilewsky are not only misinterpreted as far as the purely physiological facts are concerned, but their physical analysis leads also to impossibilities. In Danilewsky's experiment a spark does not 
pass between the electrodes, as it does in my experiments, but we have to do with a silent discharge. In this way, however, the oscillatory character of the discharge practically disappears. As is well known, a tuning-fork emits a sound only when the prongs, after they have been moved from their state of rest, spring back quickly. When they return to a state of rest very slowly, they do not give rise to sound. It is the same in the case of a discharge. In the case of a spark discharge we deal with an abrupt release of the tension which must occur in an oscillatory way. In the case of a silent discharge we do not deal with oscillations at all. If Danilewsky speaks of an oscillatory discharge under such circumstances, it is to be remembered that in reality the oscillatory character of the discharge disappears so completely in his experiments, that they corroborate beautifully my view that these effects are not determined through oscillations, but through a single electrostatic discharge.

Of course, it might yet be maintained that electric waves are present in this case in so far as the interruptions by the hammer of the Ruhmkorff are periodic. If we estimate these interruptions in the Ruhmkorff coil as 60 per second (which is certainly high), then, when the velocity of light is in round figures $300,000 \mathrm{~km}$., the wave-length is over 5,000 km.! Does Danilewsky expect us to believe that these waves can interfere between his electrodes which are separated from 50 to $100 \mathrm{~cm}$.? It is also entirely wrong to apply to such waves the term "rays." We expect rays to move in a straight line, and for this reason we do not speak of soundl'ays, since these can go around a corner. The "rays" of Danilewsky would not only go around a corner, but around the Alps, or around the moon. In a similar way there is no sense in saying, as Danilewsky does, that in these experiments a "neutralisation des polarités électriques" occurs. 
We are dealing simply and solely with the lesser irritability of nerves to transverse currents.

The second experiment of Danilewsky is intended to show that we are not dealing with electrostatic effects. $\mathrm{He}$ obtained electrical effects' when the secondary coil of the Ruhmkorff coil was closed by means of the secondary coil of another induction apparatus. I have repeated this experiment, and have found that it is in reality nothing else than the experiment discussed before, and that we can therefore speak as little of the effects of an oscillatory discharge, or of electric waves, in this case as in the previous experiment. To convince oneself of this fact one needs only to close the circuit of the secondary coil of the Ruhmkorff through a rheostat instead of with the spiral of an induction apparatus. If a great resistance is introduced into the rheostat, about 20,000 ohms, all the experiments which I have described under $a$ ) and $b$ ) can be repeated between the terminals of the Ruhmkorff coil. When a resistance of only one ohm is introduced, no effects are obtained! In this case, therefore, we also deal with the production of a high potential at each side of the resistance through the introduction of a high resistance. These charges bring about an electrostatic separation of both kinds of electricities in the muscle preparations. As soon as the discharge takes place, a current passes through the nerve which brings about maximal effects when it passes longitudinally through the nerve; minimal effects when it passes in a transverse direction. The experiments succeed most beautifully when the secondary spiral of the Ruhmkorff is closed through a glass tube filled with distilled water into each end of which dips a copper wire. In this case the glass tube behaves physiologically exactly as the path of the spark in my first-described experiments, and one can here repeat all the experiments which I have discussed in my first publication. But this is possible only 
as long as the distance between the copper wires in the glass tube is great; that is to say, as long as the resistance is great. If the ends of the copper wire are brought close together, so that the resistance between them becomes small, the effects cease. In this case we also deal with the production of a difference in potential which brings about a separation of the ions in the muscle preparations, which leads to the passage of a current through the nerve when the difference in potential dissappears. But the oscillatory nature of the disappearance of the difference in potential has nothing to do with the physiological effect, since the discharge of the Ruhmkorff coil is not oscillatory when it is closed through the tube of water.

The third series of experiments of Danilewsky deal with unipolar stimulation. One pole of the Ruhmkorff coil is connected with the earth, the other with a metallic plate. This experiment differs from the two other methods given above only in this, that the one pole has a potential of zero, while the other has a potential twice as high as that in the other experiments. In regard to the absence of actual oscillations this experiment is similar to the other two. But I would especially emphasize that my previous experiments are in themselves sufficient to show that the oscillatory nature of the discharge of a Ruhmkorff coil (where this property is actually present) does not bring about the physiological effect upon the nerve; but that this effect is determined only through the (single) disappearance of a charge. These things have, therefore, nothing to do with electrical waves.

It is perhaps necessary to touch upon the possible practical application of these experiments in medicine. Danilewsky makes suspicious suggestions in this direction. I scarcely believe that we can expect much of a practical application of these experiments. For one can easily con- 
vince oneself of the fact that a moist glass plate will serve as a complete screen against all electrostatic effects of a charged body upon the preparation. The entire surface of our bodies is covered with such a screen in the form of the superficial layers of the epidermis. In case we are not dealing with enormous discharges, every thought of utilizing these effects in medicine is sliut out. Since in all these cases we are in reality dealing only with the effects of currents (even when we are using an unusually powerful machine), I consider it more rational to use the galvanic current upon the skin of the patient directly instead of utilizing the cumbersome roundabout method of discharging a highly charged body near a patient.

Finally I must call attention to a fundamental error of Danilewsky in his idea of the nature of electrical effects upon protoplasm. Danilewsky believes with Chauveau and d'Arsonval that electricity acts only as a "mechanical stimulus."

Nous possédons, sur ce point, des indications dans les trèsintéressantes recherches de M. d'Arsonval. Dans sa communication à la Société de Biologie de Paris, du 4 juillet 1891, M. d'Arsonval relate que ses propres recherches sur l'irritation électrique et mécanique des nerfs confirment entièrement les vues de M. Chaureau qui, dès 1859, déclarait que l'électricité agit uniquement comme excitant mécanique, surtout à son point de sortie et en raison de la densité à ce point.

In contradiction of this idea I should like to point out that Faraday's idea of electrolysis has become one of the pillars of modern physies and chemistry. In living matter it is only the electrolytes which conduct the current.

1 In a book which Danilewsky has since published he has accepted my view as far as the ionic conception of electrical stimulation is concerned. [1903] 


\section{XXI}

\section{THE PHYSIOLOGICAL PROBLEMS OF TODAY ${ }^{1}$}

IF it be true that the fundamental problem of physics is the constitution of matter, it is equally true that the fundamental problem of physiology is the constitution of living matter. I think the time has come for physiology to return to its fundamental problem.

"Living matter" is a collective term for the qualities common to all living organisms. Comparative physiology alone enables us to discriminate between the general properties of living matter and the functions of specific organs, such as the blood, the nerves, the sense organs, chlorophyll, etc. Nothing has retarded the progress of physiology and pathology more than the neglect of comparative physiology. Comparative physiology shows that secretion is a general function of all living organisms and occurs even where there is no circulation. Hence it was a priori false and a waste of time to attempt to explain secretion from experiments on bloodpressure. Oxidations occur regardless of circulation, and it was a priori a waste of time to consider the blood as the seat of oxidation. Comparative physiology has shown that the reactions of animals to light are identical with the heliotropic phenomena in plants. Hence it is a mistake to ascribe such reactions as the flying of the moth into the flame to specific functions of the brain and the eyes. Sleep is a phenomenon which occurs in insects and plants, and it would be a waste of time to attempt an explanation of sleep on the basis of phenomena of circulation. The best interests of physiology

1 Address delivered at the meeting of the American Society of Naturalists, Ithaca, 1897. This paper was one of seven upon "The Biological Problems of Today," each speaker being limited to ten minutes. 
and pathology demand that the systematic development of comparative physiology be one of the physiological problems of today.

I may be pardoned for calling attention to one special field of comparative physiology which I believe to be especially fertile. I refer to the field of physiological morphology. I applied this name to the investigation of the connection between the chemical changes and the process of organization in living matter. Two series of facts allow us to connect these two groups of phenomena: (1) the fact that phenomena of fermentation lead to an increase in the number of molecules, and thus bring about an increase of osmotic pressure in the cells, this increase of osmotic pressure being the source of energy for the work of growth; (2) the facts of heteromorphosis, $i$. e., the possibility of transforming in certain animals one organ into another or substituting oue organ for another through external influences, such as gravitation, contact, light, etc.

The exact and definite determination of life-phenomena which are common to plants and animals is only one side of the physiological problem of today. The other side is the construction of a mental picture of the constitution of living matter from these general qualities. In this portion of our work we need the aid of physical chemistry and especially of three of its theories: stereochemistry, Van 't Hoff's theory of osmotic pressure, and the theory of the dissociation of electrolytes. We know that the peculiar phenomena of oxidation in living matter are determined by fermentative processes, and we venture to say that fermentations form the basis of all life-phenomena. It has been demonstrated that fermentability is a function of the geometrical configuration of the molecule. Saccharomyces cerevisice is a ferment for such sugars only as have three or a multiple of three atoms of carbon in the molecule. Among the hexaldoses only 
$d$-glucose, $d$-mannose, and $d$-galactose are fermentable, while their stereoisomeres are not fermentable. But the influence of the geometrical configuration goes farther. Voit has suggested and Cremer has demonstrated that there is a farreaching parallelism between the fermentability and assimilation of carbohydrates. Higher animals as well as yeast cells are able to form glycogen from such carbohydrates as are fermentable by yeast. The further development of these stereochemical relations and their extension to proteids and nucleins is another of the problems of physiology which will contribute to the main problem, the analysis of the constitution of living matter. I believe that the influence of stereochemistry will be more or less directly felt in many branches of physiology, in questions of heredity, as well as in the theory of space-sensations, as E. Mach has already intimated.

In living organisms chemical energy is frequently transformed into osmotic energy. Van 't Hoff's theory of osmotic pressure permits an application of the law of conservation of energy to a class of phenomena to which this law was hitherto inapplicable, namely, the phenomena of growth, functional adaptation, secretion, absorption, and even pathological processes such as œdema. The physiologists who thought that the blood-pressure determined secretion could not understand why secretion took place under a higher pressure than the blood-pressure. Comparative physiology shows that secretion does not depend upon circulation, and the theory of osmotic pressure indicates that the osmotic pressure in the cells is more than twenty times as high as the blood-pressure. The work of secretion is done by osmotic pressure and not by blood-pressure. A prominent physiological chemist has become a vitalist because he could not explain why the secretions differ from the blood from which he thinks they are formed. He overlooks among others the fact that the protoplasm possesses the quality of semi-permeability, which 
means that it allows certain substances to pass through and others not. In my opinion, the working out of a theory of semi-permeability is one of the main physiological problems of the day.

The theory of the dissociation of electrolytes is of fundamental importance in the analysis of the constitution of living matter. Pharmacology will feel its influence most directly. Everything seems to indicate that the specific physiological effects of inorganic acids are due to the number of positively charged hydrogen ions in the unit of solution, and the specific physiological effects of alkalies to the negatively charged hydroxyl ions. But the universal bearing of the theory of dissociation upon physiology will perhaps be best seen in the field of animal electricity. An active element of living matter is negatively electric to its surrounding resting parts. We may assume that an acid is formed in the active part, and that the passive parts are neutral. The positive hydrogen ions of the acid have a much greater velocity of migration than the anions. Hence the former will diffuse more rapidly into the passive tissue than the anions, and the active tissue will remain negatively charged. ${ }^{1}$

At no time since the period immediately following the discovery of the law of conservation of energy has the outlook for the progress of physiology appeared brighter than at present. But in order to reap the full benefit of our opportunities, we must bear in mind that the fundamental problem of physiology is the determination of the constitution of living matter, and that in order to accomplish our task we must make adequate use of comparative physiology as well as physical chemistry. Pathology, in particular, will be benefited by such a departure.

1 As far as I am aware, this was the first attempt at applying the principle of batteries of concentration to the explanation of the current of action. [1903] 


\section{XXII}

THE PHYSIOLOGICAL EFFECTS OF IONS. II ${ }^{1}$

The experiments described in this paper are a continuation of the experiments in my first paper on this subject in three directions. ${ }^{2}$ It will be shown by a longer series of experiments that the organic acids behave differently from the inorganic. While the physiological effects of the latter are determined by the concentration of hydrogen ions, this is apparently not the case with the fatty acids, inasmuch as the degree of dissociation and the physiological effects of the fatty acids do not run parallel. We shall not attempt to explain this apparent exception until we have further experimental data at our disposal. We may, however, think of the possibility that the fatty acids undergo a partial oxidation in the muscle.

I have shown in my first paper that a muscle does not change much in weight in a 0.7 per cent. $\mathrm{NaCl}$ solution during the first hour, but that it increases greatly in weight when only a trace of an acid is added. This increase in weight can be explained by assuming that the hydrogen ions of the acid act in the muscle hydrolytically like enzymes and in this way increase the osmotic pressure in the muscle. While the effect of inorganic acids in sufficiently dilute solutions was quantitatively exactly a function of the number of hydrogen ions contained in the unit of volume of the solution, no such relation seemed to exist for the organic acids. I pointed out that this exceptional behavior from the theory of dissociation could be explained through secondary chemical processes. I have since made a series of experiments with

1 Pflugers Archiv, Vol. LXXI (1898), p. 45i.

2 "On the Physiological Effects of Ions, I," Part II, p. 450. 
a larger number of organic acids, especially of the fatty series, which I wish to report here. It is clear that these apparent exceptions to the theory of electrolytic dissociation in the case of the organic acids must yield material for understanding the chemical changes which go on in living matter.

The experiments were made as the previous ones. Five or 10 c.c. of a one-tenth normal solution of the acids were added to 100 c.c. of a $\mathrm{NaCl}$ solution. The gastrocnemius of a frog was introduced into such a solution and its increase in weight determined at certain intervals.

The solutions which contained 10 c.c. of a one-tenth normal acid in 100 c.c. of a 0.7 per cent. $\mathrm{NaCl}$ solution-in which therefore the concentration $V$ equaled 110 - gave more constant results than those solutions in which $V$ equaled 210. The following table gives the results of several series of experiments with a series of acids when $V$ equaled 110. The Arabic figures give the increase in weight which each muscle showed, expressed in per cent. of its original weight after remaining for one hour in the solution.

$(V=110)$

\begin{tabular}{|c|c|c|c|c|c|c|c|}
\hline & I & II & III & IV & $\mathrm{V}$ & VI & Av'ge \\
\hline 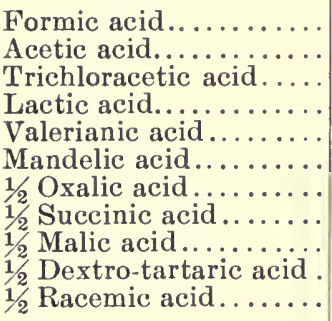 & $\begin{array}{l}5.6 \% \\
4.7 \\
7.3 \\
6.7 \\
4.4 \\
6.5 \\
6.4 \\
6.1 \\
4.0 \\
5.8 \\
6.3\end{array}$ & $\begin{array}{l}4.6 \% \\
3.4 \\
6.8 \\
6.8 \\
5.7 \\
7.5 \\
6.3 \\
4.7 \\
4.4 \\
6.4 \\
5.4\end{array}$ & $\begin{array}{l}5.6 \% \\
3.3 \\
8.0 \\
4.9 \\
7.8 \\
6.0 \\
6.0 \\
5.4 \\
6.6 \\
6.8\end{array}$ & $\begin{array}{l}5.0 \% \\
4.7 \\
\ddot{8} .0 \\
\cdots \\
\ddot{8} . \dot{8} \\
\ddot{6} . \dot{8} \\
7.1 \\
\cdots\end{array}$ & $\begin{array}{l}4.2 \% \\
\cdots \\
\cdots \\
6.9 \\
\cdots \\
\cdots \\
\cdots \\
\ldots \\
\ldots \\
\ldots\end{array}$ & $\begin{array}{l}5.0 \% \\
\cdots \\
7.1 \\
\cdots \\
\cdots \\
\cdots \\
\cdots \\
\cdots \\
\cdots\end{array}$ & $\begin{array}{l}5.0 \% \\
3.9 \\
7.1 \\
7.2 \\
5.0 \\
7.2 \\
6.9 \\
5.6 \\
5.1 \\
6.3 \\
6.2\end{array}$ \\
\hline
\end{tabular}

We will now compare with this series the degree of dissociation of these acids when $V=110 .^{1}$

1 Calculated according to OsTwALD, "Ueber die Affinitătsgrơssen organischer Sauren," Abhandlungen der Sächsischen Gesellschaft der Wissenschaften, Vol. XV, p. 89 . 
Formic acid

- 0.14 Oxalic acid

0.87

Acetic acid

0.04 Succinic acid

0.08

Tricloracetic acid - $\quad-0.94$

Malic acid

0.18

Lactic acid

0.11

Dextrotartaric acid

0.27

Valerianic acid

Racenic acid

0.27

Mandelic acid

0.19

If we compare the effect of the acids on the absorption of water by the muscle with the degree of dissociation, we notice that the effects of the acids vary from each other much less than their degrees of dissociation. Lactic acid, for example, with only 11 per cent. of its molecules in the ionic state brings about just as great an absorption of water by the muscle (7.2 per cent.) as trichloracetic acid, or oxalic acid in which nearly all the molecules are dissociated. Mandelic acid acts just as strongly, even though only 19 per cent. of its molecules are dissociated at the concentration which we employed. The fact that the differences in the effects of the various acids are so much less than the differences in their degrees of dissociation might point to the fact that those acids which are only little dissociated are changed in the muscle into substances which undergo a greater degree of dissociation. I will, however, leave the discussion of this possibility until I have made further experiments, especially on the aromatic acids. At that time I will also give the figures for a greater number of experiments which I have already made with acids for different lengths of time and different concentrations. That in these experiments the acids are really absorbed by the muscle was determined by titration by Mr. Slimmer.

In $\mathrm{HNO}_{3}$, when $V=110$, the increase in the weight of a gastrocnemius weighing $1,731 \mathrm{~g}$. amounted in one hour to $154 \mathrm{mg}$., that is, to 8.9 per cent. of the original weight of the muscle. This agrees exactly with our previous values for this acid, which had given on the average an increase in

$1 \mathrm{Mr}$. Slimmer also prepared the solutions mentioned in this paper. 
weight of 9 per cent. at this concentration. In this experiment the solution contained originally $63.3 \mathrm{mg}$. of $\mathrm{HNO}_{3}$. After the muscle was removed, the solution had lost $5.1 \mathrm{mg}$. of the acid. For trichloracetic acid we found a loss of 14 mg. in two hours. These experiments will be continued. Besides the fact that the hydrogen ions enter the muscle, these experiments also show that the increase in weight which the muscle suffers in the acid solution is much greater than the weight of the acid absorbed. There can scarcely be any doubt that the increase in the weight of the muscle in the acid solution is dependent almost solely, if not entirely, upon an absorption of water. But how the hydrogen ions can lead to an absorption of water by the muscle can at present not be decided definitely. 


\section{XXIII}

\section{WHY IS REGENERATION OF PROTOPLASMIC FRAG- MENTS WITHOUT A NUCLEUS DIFFICULT OR IMPOSSIBLE? ${ }^{1}$}

IT has been shown with certainty by a series of experiments that oxygen is necessary for the development of eggs as well as for the processes of regeneration. The reason for this might be sought, among other things, in the fact that, as I have suggested in two previous papers, synthetical changes are necessary for these processes, and that the syntheses depend upon the supply of oxygen. ${ }^{2}$ It is well known that when a cell is cut into several pieces only the pieces containing a nucleus are capable of regeneration, while the pieces without a nucleus soon disintegrate. This has been interpreted by assuming that the nucleus contains specific formative substances, which it gives off to the protoplasm. This conclusion is, however, not binding. It might well be possible that the nucleus is necessary only for the accomplishment of processes of oxidation. The removal of the nucleus would in this case be associated with an inhibition or a decrease in the processes of oxidation. This would suffice to prevent the regeneration of enucleated pieces of the cell. I wish now to test in how far the facts at hand agree with such a hypothesis.

To bring about oxidations in living tissues the presence of catalytic substances is necessary which either "activate" the atmospheric oxygen, or which render the compounds in the cell capable of taking up atmospheric oxygen more

1 Archiv für Entwickelungsmechanik der Organismen, Vol. VIII (1899), p. 689

2 "Assimilation and Heredity," Monist, 1898. 
energetically. The majority of investigators believe that oxygen is activated in the tissues, and that in this process certain substances act catalytically which, after Traube, we will call "oxygen carriers." It has been possible to extract these oxygen carriers from the cells and to show that in this condition the oxygen carriers are still able to bring about those oxidations which are characteristic of living matter.

The most valuable discovery in this direction was undoubtedly made by Spitzer. ${ }^{1}$ Spitzer has shown that those substances in extracts of tissues, which favor the transfer of oxygen (oxidation ferments) belong to the group of nucleoproteids. The nucleoproteids are typical substances of the nucleus. All these nucleoproteids contain iron. Now, we know that iron salts are especially adapted to accelerate oxidation. There is no reason to doubt that what is true for the aqueous extracts of the cells holds also for the nucleoproteids of living cells. Macallum has proved the existence of iron in the chromatin substance of the cell nuclei. The work of Spitzer, therefore, renders it probable that the nuclens is the organ of oxidation in living matter.

We will now see whether the behavior of cell fragments without the nucleus corresponds to this assumption. Verworn describes the changes which occur in the pseudopodia in these cases as follows: In the pseudopodia of an enucleated piece of Orbitolites droplets are formed which, in part, flow together into larger drops. The connection between the individual drops disappears. "Finally, after about five to seven hours the central portion forms a round lump without pseudopodia, around which are scattered a number of larger and smaller globules, drops, and spindles of protoplasm." Verworn in adopting and misunderstanding the view of Berthold has developed a theory of amœboid movements

1 Pflügers Archic, Vol. LXVII (1897), p. 615.

2 Verworx, Pflügers Archiv, Vol. LI (1892). 
according to which the throwing out and the drawing in of the pseudopodia are attributed to changes in surface tension. This theory is based on the assumption that the pseudopodia are liquid. ${ }^{1}$ This assumption is a physical impossibility.

The pseudopodia of Orbitolites are, according to the drawings of Verworn, cylindrical; their length perhaps a hundred times greater than their circumference. Such a liquid cylinder cannot exist. There is a good reason why rain falls in drops and not in jets. If $r$ is the radius, $h$ the height of a liquid cylinder, it can exist only as long as $h \leqq 2 r \pi$. For this reason alone the entire contraction theory of Verworn is wrong. I will not, however, discuss this theory more closely here. ${ }^{2}$ From these facts in surface tension it follows that the pseudopodia of the Rhizopods cannot be liquid, but must possess a solid framework or a solid membrane. As soon as this solid framework or the solid membrane becomes liquefied the pseudopods must obey the laws of surface tension and break up into drops. The latter is, according to my observations, the process which occurs in fragments of Orbitolites which contain no nucleus.

Is this liquefaction of solid substances a process which is indicative of lack of oxygen? This is undoubtedly the case. Four years ago I showed that the cell-walls of the cleavage cells of Ctenolabrus become liquid when deprived of oxygen. When oxygen is readmitted, the formation of cell-walls begins anew. ${ }^{3}$ Budgett showed in my laboratory that the removal of oxygen leads to the solution of the cell-walls in Infusoria also, and that certain poisons had the same effect. ${ }^{4}$ Kühne has observed the same effect of lack of oxygen. ${ }^{5}$ The

1 Die Bedeutung der lebendigen Substanz (Jena, 1892), p. 38.

2 I do not here mention the chemotropic ideas of Verworn because they rest upon no actual foundation whatsoever.

3"Investigations on the Physiological Effects of Lack of Oxygen," Part I, p. 370 .

4 American Journal of Physiology, Vol. I (1898).

${ }^{5}$ Zeitschrift für Biologie, Vol. XXXVI (1898), p. 472. 
liquefaction of the pseudopodia upon the removal of the nucleus, and the inability of Infusorian fragments without a nucleus to form a new cuticle, correspond entirely with the assumption that the cell fragments without a nucleus are in a condition of decreased oxidative activity.

I have expressed this view for several years in my lectures, and I have had it in mind to perform experiments on pieces of Infusoria without the nucleus under increased oxygen pressure. If my theory be correct, it should be possible to prolong the life of fragments of protoplasm freed from the nucleus by furnishing them a better supply of oxygen. But it seems to me that this experiment has already been made. For while Nussbaum, Gruber, and Verworn found that pieces of Infusoria without the nucleus go to pieces after two days, and only exceptionally live several days, all botanists who have made the same experiment on chlorophyll-bearing-cells (for example, Algæ) have found that cell fragments without the nucleus remain alive five to six weeks. ${ }^{1}$ Assimilation took place in such pieces. It seems to me that the comparatively long duration of life of fragments of Algæ without a nucleus is of great importance in judging of the function of the cell nucleus. As is well known, oxygen is liberated in the assimilation of carbon dioxide. Pieces of Algæ without a nucleus are therefore, in the light, under better conditions of oxygen supply than fragments of Infusoria without a nucleus, for the Infusorian contains no chlorophyll.

It seems to me, therefore, that all the facts which are known thus far very naturally support the idea that the nuclens is the organ of oxidation of living matter; and that fragments of cells without a nucleus are not able to regenerate because their oxidative activity has fallen to too low a point. Such pieces die slowly from asphyxia.

${ }^{1}$ KLeBs, Biologisches Centralblatt, Vol. VII (1888). 
The question as to the significance of the nucleus for development and heredity enters into a new light if these ideas are correct. Nor ean it longer be held that the living organism is merely a combination of individual cells. "By cellular structure we understand the fact that there must be a definite maximal distance, variable, however, for different forms and tissues, between the elements of the protoplasm and the nearest nucleus." "We can now understand the reason for this. If the distance becomes too great, the particular protoplasmic element goes to pieces from asphyxia. That besides this an interchange of other substances occurs between the protoplasm and the nucleus I will, of course, not deny; it is possible or probable that the significance of the cell nucleus is not exhausted by its oxidative activity. It is also scarcely necessary to point out particularly that I do not believe that without the nucleus all processes of oxidation cease in the protoplasm; it rather seems from all the facts at hand that it is only markedly decreased.

1 LOEB, Pfügers Archiv, Vol. LXIX (1897). 


\section{XXIV}

\section{ON THE SIMILARITY BETWEEN THE ABSORPTION OF WATER BY MUSCLES AND BY SOAPS ${ }^{1}$}

THE difficulty which confronts us in the phenomena of the absorption of liquids by tissues consists in this, that we have thus far not been able to find any analogies for these phenomena in the realm of physics and chemistry. I believe to have come upon a series of facts which show that a similarity exists between the absorption of water by muscles and by soaps. This analogy is, among other things, of importance because it may help us decide which forces come into play in the absorption of liquids.

Potassium soaps absorb so much water from the air that they finally become liquid. The sodium soaps also absorb water, but much less than the potassium soaps. The calcium soaps are useless for washing purposes because of their insolubility, or only slight solubility, in water.

If the sodium of a sodium soap is replaced by calcium, water is usually given off; on the other hand, if the sodium is replaced by potassium, water is taken up.

Muscle behaves in exactly the same way. I. have shown in my earlier publications that a muscle neither takes up nor gives off water during the first hour in solutions of neutral salts, which are isosmotic with a 0.7 per cent. $\mathrm{NaCl}$ solution. I found slight variations from this rule in a few salts, especially potassium and calcium salts. These variations were, though, very slight, and yet too great to attribute them to errors in experiment. If, however, the muscles remained in the solutions for more than one hour, these differences

1 Pfiügers Archiv, Vol. LXXV (1899), p. 303. 
became very marked; after eighteen hours, for example, it was found that the muscle kept in an isotonic $\mathrm{KCl}$ solution had gained from 40 to 50 per cent. in weight; that a muscle in a $\mathrm{CaCl}_{2}$ solution lost about 20 per cent. in weight; that the weight of a muscle in $\mathrm{LiCl}$ remained practically unchanged; while that in $\mathrm{NaCl}$ solution had increased a few per cent. in weight. The following gives a summary of these results:

\section{TABLE I}

Changes in weight in the gastrocnemii of frogs kept in solutions equimolecular with a 0.7 per cent. $\mathrm{NaCl}$ solution. Length of the experiment, 18 hours. An increase in weight (expressed in per cent. of the original weight of the muscle) is designated by a +; a loss in weight by a -.

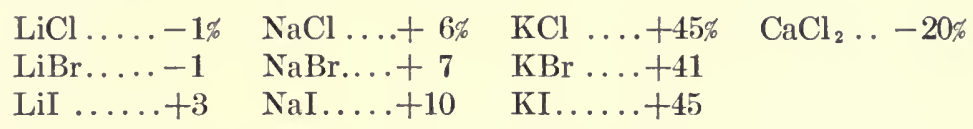

The figures given in this table were corroborated by a large number of experiments. Variations due to individual differences in the muscles and variations in the temperature are unavoidable, but the order of magnitude of the results obtained was always about the same as those given above.

Since the difference in the degree of dissociation of the potassium and sodium salts is very slight, it is of course excluded that differences in osmotic pressure, due to differences in the degree of dissociation, should be responsible for the results obtained.

The potassium and sodium salts of other acids, such as the sulphates and oxalates, also show these differences, though not so markedly.

Wallace and Cushny believe that only the anions and not the cations of salts play a rôle in the absorption of water from the intestines. ${ }^{1}$ If this is true, the absorption of liquids by the intestine must be governed by entirely different laws from those which govern the absorption of

1 Wallace and Coshyx, American Journal of Physiology, Vol. I, p. 411. 
water by muscle. I must, however, call attention to the fact that Wallace and Cushny did not continue their experiments long enough to allow them to draw such a conclusion. In the course of one hour a muscle increases about 2 per cent. in weight in a $\mathrm{KCl}$ solution; in a $\mathrm{CaCl}_{2}$ solution it decreases about $3-5$ per cent.; in a $\mathrm{LiCl}$ or a $\mathrm{NaCl}$ solution its weight remains unchanged. The experiments of Wallace and Cushny lasted less than one hour, and to discover such slight variations as those given in my experiments is impossible in those of Wallace and Cushny.

In what way, now, can we imagine that potassium salts bring about a positive, calcium salts a negative, absorption of water in muscle? When we place a muscle into any of the solutions mentioned above, $\mathrm{Li}, \mathrm{Na}, \mathrm{K}$, and $\mathrm{Ca}$ ions soon begin to diffuse into the muscle. Just as in case of soaps this would lead to the formation of $\mathrm{Na}, \mathrm{K}$, and $\mathrm{Ca}$ soaps, it might lead in muscle to the formation of $\mathrm{Na}, \mathrm{K}$, and $\mathrm{Ca}$ compounds, which behave like the corresponding soaps in at least one particular - in their power of dissolving water.

It is of importance, for what has been said, that $\mathrm{SrCl}_{2}$, $\mathrm{BaCl}_{2}, \mathrm{CoCl}_{2}$, and $\mathrm{MnCl}_{2}$ behave like $\mathrm{CaCl}_{2} . \mathrm{MgCl}_{2}$, however, is much weaker in its action than these. Table II shows the weight lost by muscles when immersed in equimolecular solutions of these five salts.

TABLE II

The loss in weight of muscle (in per cent. of its original weight) in solutions equimolecular with a 0.7 per cent. $\mathrm{NaCl}$ solution. Length of the experiment, eighteen hours.

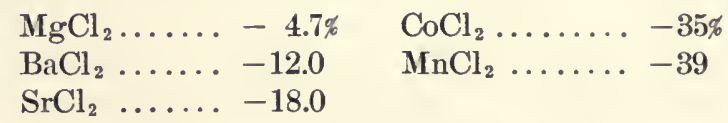

Perhaps the solutions of all the heavy metals will fall into this group; that is to say, they will all bring about a loss of water in muscle.

1 Or of absorbing water. 
The analogy between the behavior of soaps and of muscles is of importance for the mechanics of the absorption of liquids. The majority of authors - for example, Hofmeister -assume that in the absorption of liquids by tissue we deal with imbibition; that is to say, with capillary phenomena. In the absorption of water by soaps, however, we deal with phenomena of solution. ${ }^{1}$ The forces concerned in the latter are osmotic pressures, and not surface tensions, as in capillary phenomena.

The antagonism which has been shown by these experiments to exist between potassium and calcium compounds is of interest in another direction. Ringer has called attention to the fact that an antagonism exists between calcium and potassium salts in their effect on the heart. The latter are supposed to favor the diastole, the former the systole, of the heart. Howell has adopted the views of Ringer. Possibly the above-described characteristics of the two substances may help to explain the phenomena of contractility. I cannot assent to the view that calcium is the "stimulus" for the cardiac activity. Years ago this might have been erroneously said about oxygen. The cause of cardiac activity (as that of every automatic activity) is neither calcium nor oxygen, but heat, or, more correctly, its intensity factor, temperature. Calcium and potassium might be of importance for the changes in the amount of water in various elements, or for their state of matter, and so be of importance for the contraction of the heart.

\section{II}

I had shown in my earlier publications that when a trace of acid is added to a 0.7 per cent. $\mathrm{NaCl}$ solution, a muscle immersed in it absorbs a large amount of water. ${ }^{2}$ I was

1 This statement will probably have to be modified. Sinee water can be removed from soaps by pressure, it is at least partly held there by imbibition. [1903]

2 "On the Physiological Effects of Ions," Part II, pp. 450 and 501. 
interested in testing how isotonic calcium and potassium solutions act upon muscle when acids are added to these solutions. I usually added 10 c.c. of a one-tenth normal acid to 100 c.c. of the salt solution, so that the acid was $\frac{1}{110}$ normal. $\mathrm{HNO}_{3}$ or $\mathrm{HCl}$ were the acids generally employed. I showed in the article cited above that at this concentration we are dealing only with the effects of ions, and that the effect is quantitatively the same whether 10 c.c. one-tenth normal $\mathrm{HCl}$ or 10 c.c. one-tenth normal $\mathrm{HNO}_{3}$ are added.

The experiments yielded the result that acids markedly increase the amount of water absorbed by muscles in $\mathrm{CaCl}_{2}$ solutions, but that they have the reverse effect in solutions of potassium salts, where they diminish the amount of water absorbed. In one experiment the muscle increased 35 per cent. in weight in an isotonic KI solution, but only 6.2 per cent. in an isotonic KI solution to which had been added the amount of acid indicated above! The addition of 10 c.c. of one-tenth normal $\mathrm{HNO}_{3}$ to 100 c.c. KI solution decreased the amount of water absorbed almost 29 per cent. expressed in terms of the original weight of the muscle! In another experiment the muscle increased 54 per cent. over its original weight in an isotonic $\mathrm{KCl}$ solution, but only 39 per cent. after the addition of the acid, or 15 per cent. less. In an isotonic solution of $\mathrm{K}_{2} \mathrm{SO}_{4}$ the muscle lost 4 per cent. of its original weight in eighteen hours. By the addition of 10 c.c. of a one-tenth normal acid to 100 c.c. of the isotonic $\mathrm{K}_{2} \mathrm{SO}_{4}$ solution the muscle lost 22 per cent. of its original weight in the same time!

Exactly the opposite is observed when acid is added to $\mathrm{CaCl}_{2}$ solutions. While a muscle in an isotonic $\mathrm{CaCl}_{2}$ solution loses about 20 per cent. of its weight in eighteen hours, it increases about 30 per cent. when 10 c.c. of a one-tenth normal $\mathrm{HNO}_{3}$ solution are added to 100 c.c. of the $\mathrm{CaCl}_{2}$ solution. 
In regard to the effect of acids, 0.7 per cent. $\mathrm{NaCl}$ solutions are more like $\mathrm{CaCl}_{2}$ solutions. As $\mathrm{I}$ have shown in $\mathrm{my}$ earlier papers, a muscle absorbs 6 to 8 per cent. of its weight of water when immersed for eighteen hours in a 0.7 per cent. $\mathrm{NaCl}$ solution. If 10 c.c. of one-tenth normal $\mathrm{HNO}_{3}$ solution are added to 100 c.c. of the $\mathrm{NaCl}$ solution, the muscle increases about 40 per cent. in weight in the same time.

\section{III}

When a muscle is immersed in a salt solution of a greater concentration than 0.7 per cent., it loses water in such a solution during the first hour or hours. If, however, it remains in such hypertonic solutions for some time, it steadily increases in weight, and this the more the greater the concentration (within certain limits) of the solution in which it is immersed. Table III illustrates this paradoxical behavior. The row of figures on the left gives the concentration; that on the right, the increase in weight of the muscle expressed in per cent. of the original weight of the muscle. The experiment lasted twenty-four hours.

TABLE III

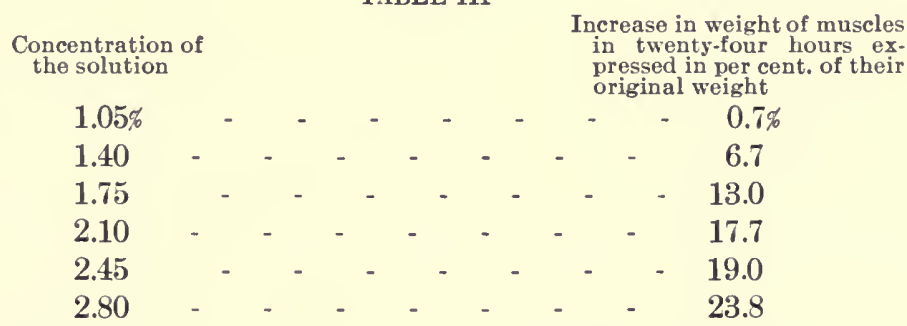

This paradoxical behavior of the muscles is dependent upon secondary changes which take place in the muscles when allowed to remain for a long time in the hypertonic sodiumchloride solutions. I have discussed these changes at length in my study of œedema. ${ }^{1}$ I will only point out in passing

1 Pflugers Archiv, Vol. LXXI (1898). 
that one of the changes which occur in the muscle is the formation of acid. That such a formation of acid, if it occurs, must increase the absorption of water by the muscle has been clearly shown in my previous publications. I do not, of course, believe that the formation of an acid is the only factor which comes into consideration here. The observations on the effect of $\mathrm{K}$ and $\mathrm{Ca}$ on absorption point to the possibility that the $\mathrm{Na}$ ions which enter the muscle alter its substance chemically.

That this assumption is correct is shown by the following facts: If some acid is added to a 0.7 per cent. $\mathrm{NaCl}$ solution, it compels a muscle immersed in it to take up much more water than when the acid is not added. If this same amount of acid is added to a 2.5-5 per cent. $\mathrm{NaCl}$ solution, it has exactly the opposite effect - the muscle finally loses more weight in the hypertonic sodium-chloride solution which contains acid than in the hypertonic solution without acid. I have not yet determined the exact turning-point. It lies below 2.4 per cent. $\mathrm{NaCl}$ and above 1.3 per cent. $\mathrm{NaCl}$. These facts show most strikingly that when a sufficient number of $\mathrm{NaCl}$ molecules or $\mathrm{Na}$ ions - I suspect that we are dealing only with the ions-enter a muscle, the absorptive power of the muscle for water is altered in a similar way as through the introduction of $\mathbf{K}$ ions into the muscle. Table IV shows the difference in the amount of water absorbed by muscles in neutral and in $\frac{1}{110}$ normal acid sodium-chloride solutions in eighteen hours.

TABLE IV

\begin{tabular}{|c|c|c|c|}
\hline \multicolumn{2}{|c|}{ Neutral NaCl Solution } & \multicolumn{2}{|c|}{ 110 Normal Acto NaCl Solution } \\
\hline Concentration & \begin{tabular}{|} 
Increase in \\
Weight in Eight- \\
een Hours
\end{tabular} & Concentration & $\begin{array}{l}\text { Increase in } \\
\text { Weight in Eight- } \\
\text { een Hours }\end{array}$ \\
\hline $\begin{array}{l}4.90 \% \\
1.2 \% \\
0.70\end{array}$ & $\begin{array}{l}+6 \% \\
-2 \\
+7\end{array}$ & $\begin{array}{l}4.90 \% \\
1.22 \\
0.70\end{array}$ & $\begin{array}{l}-36.0 \% \\
+22.2 \\
+40.0\end{array}$ \\
\hline
\end{tabular}


While acids at one time increase, at another time decrease the amount of water absorbed by a muscle, depending upon the nature and the concentration of the salt solution in which the muscles are immersed, alkalies increase absorption under all circumstances. Quantitative differences, however, exist between the different alkalies which I am not yet entirely able to explain, even though I have made more experiments with alkalies than with any other group of substances. These experiments have only served to strengthen my previous assertion that we deal in these cases only with the action of the hydroxyl ions. 
ON IONS WHICH ARE CAPABLE OF CALLING FORTH RHYTHAICAL CONTRACTIONS IN SKELETAL MUSCLE ${ }^{1}$

1. Is 1881 Biedermann published a remarkable observation "On Rhythmical Contractions Brought about in Striated Muscle through Chemical Stimulation." ${ }^{2}$ The observation consists, according to his description, in the following:

The sartorius of a frog, previously poisoned with curare, is carefully removed from the body, if possible at a low temperature $\left(0\right.$ to $10^{\circ} \mathrm{C}$.). If now the muscle preparation fastened rertically into a muscle clamp, and weighted by its femoral stump, is dipped into a 0.6 per cent. sodium-chloride solution . . . containing some ordinary alkaline, crystallized sodium phosphate, besides a small amount of sodium carbonate (in the liter of distilled water were contained $5 \mathrm{~g}$. $\mathrm{NaCl}, 2 \mathrm{~g}$. $\mathrm{Na}_{2} \mathrm{HPO}_{4}$, and 0.4 to $0.5 \mathrm{~g} . \mathrm{Na}_{2} \mathrm{CO}_{3}$ ), which must be kept at a low temperature ( 3 to $10^{\circ} \mathrm{C}$.), one obserres as a rule, after a longer or shorter period of rest, that the immersed muscle begins to beat rhythmically.

The twitchings vary in intensity. At times we have to do with a mere tremor; at times, however, powerful beats and contortions of the muscle occur; sometimes only individual fibers are active; sometimes the whole muscle is involved. Finally, the process may be limited to certain portions of the muscle; at other times the whole muscle may be involved. At low temperatures these phenomena may continue for days.

Biedermann recognizes the importance of this observation for the decision of the question whether the heart muscle is of itself capable of rhythmical activity without the inter. vention of the ganglion cells.

1 Festschrift für Professor Fick (Braunschweig, 1899), p. 101.

'Sitzungsberichte der Wiener Akademie, Vol. LXXXII, Part III (1880). 
In his well-known and thorough work on electro-physiology the same author adds the following:

Strong solutions of $\mathrm{Na}_{2} \mathrm{SO}_{4}$, as also rery dilute solutions of $\mathrm{NaOH}$ (in 5 per cent. $\mathrm{NaCl}$ solution), act in the same way as $\mathrm{Na}_{2} \mathrm{CO}_{3}$, but not so strongly. In view of the similarity in the effects of those substances upon the heart muscle one is justified in speaking of a specific action of sodium salts, mentioned above, in consequence of which the contractile substance of striated muscle is so altered through the presence of even small amounts of these substances that it is stimulated to contraction more easily and by weaker stimuli than is ordinarily the case. ${ }^{1}$

We also know that Ringer has called attention to the importance of calcium and potassium salts for the activity of the heart, so that one might be inclined to believe that certain salts bring about the activity of the heart directly. In this connection Howell considers particularly the calcium salts. ${ }^{2}$

2. It therefore seemed of interest to me to determine whether the power to bring about rhythmical contractions in skeletal muscle was not the property of certain ions. My experiments consisted in observing the behavior of the gastrocnemius muscles of frogs in a series of solutions. The muscle was entirely unweighted and unstretched and freed from all bone. This fact is to be observed in repeating the experiments. Carefully prepared equimolecular or isosmotic solutions were used. The chemicals used were chemically pure, and the water was twice distilled in glass. As we often deal with only very weak contractions, or, more correctly, only with a tremor of individual muscle fibers, the contractions could not be registered graphically, but could only be observed.

Biedermann has already pointed out that the rhythmical contractions of muscles in the solution used by him are not entirely similar to the activity of the heart.

1 W. Biedermann, Electrophysiologie (Jena, 1895), p. 92.

2 W. HI. Howeli, American Journal of Physiology, Vol. II (1898). 
The contractions of a heart preparation fed by an alkaline salt solution are much more regular and even than the contractions of a sartorius preparation; it is to be particularly emphasized that in the first case all the muscle fiber's contract evenly and simultaneously, while, as has been pointed out above, in a sartorius immersed in a salt solution it is the rule that the primitive fibers never contract simultaneously and equally strongly; much oftener the contractions observed are local, and the rhythm of the various local contractions may vary most decidedly.

This difference between the periodic contractions of the muscle and those of the heart holds also in the experiments which I give below. I do not believe, however, that we can conclude from these differences that there are differences in the manner in which the rhythmical activities in the two cases originate. We cannot, for example, conclude from this that the difference is determined through the influence of the ganglion cells in the heart. I believe that we deal, partly at least, with a difference in conductivity. In the heart muscle the stimulus can pass from element to element. If, therefore, only one element is stimulated and caused to contract, the whole heart must become active. In skeletal muscle the sarcolemma prevents such a passage of the stimulus from element to element, and we obtain in consequence irregular isolated contractions of the individual fibers. The case is similar to that observed in Medusæ, in which we find a synchronous activity of all the elements when the continuity of the elements is complete, and a loss in synchrony when the conductivity between the elements is diminished."

3. We will now return to our main problem, and endeavor to answer the question whether only certain ions are able to bring about rhythmical contractions in muscle.

I tested first of all Biedermann's assertion that these

1 Biedermani, loc. cit.

2 Engelmann and Romanes have pointed out this fact. A discussion of this subject is found in my Comparative Physiology of the Brain (New York: Putnam's Sons, 1900 ). 
contractions are due to a specific effect of sodium salts. Without entering into many details, I will only emphasize the fact that lithium, cæsium, and rubidium also bring about such periodic contractions. So far as the anions are concerned, rhythmical contractions occur not only in the chlorides of the metals mentioned above, but also in the $\mathrm{Br}, \mathrm{I}$, and $\mathrm{F}$ salts. In the last-named varieties of salts contractions begin even earlier than in the corresponding chlorides. In a 0.7 per cent. $\mathrm{NaCl}$ solution it usually takes more than an hour before the regular rhythmical contractions begin. These show themselves at first in a slight tremor at the femoral end of the gastrocnemius, become stronger, and finally affect the whole muscle so that the tendon of Achilles executes pendulum-like movements. These periodic movements can still be observed on the following day even at room temperature. In a $\mathrm{NaF}$ solution, equimolecular with a 0.7 per cent. $\mathrm{NaCl}$ solution, the most vigorous contractions set in immediately, but last only about half an hour and then stop. In $\mathrm{LiBr}$ or $\mathrm{NaBr}$ the contractions are stronger, and occur earlier than in $\mathrm{NaCl}$. But whether this can be attributed to the fact that $\mathrm{Br}$ ions are more effective than $\mathrm{Cl}$ ions is questionable. As the muscle is always surrounded by a $\mathrm{NaCl}$ solution and contains $\mathrm{Cl}$ ions, it is clear that $\mathrm{F}$ or $\mathrm{Br}$ or $\mathrm{I}$ ions must at first pass in greater number from the solution into the muscle than the $\mathrm{Cl}$ ions. I cannot say definitely that I ions are more effective than $\mathrm{Br}$ ions. The $\mathrm{Rb}$ and $\mathrm{Cs}$ ions have a poisonous effect like the $\mathrm{F}$ ions; that is to say, the rhythmical contractions which are produced at first soon cease. In $\mathrm{NaBr}, \mathrm{LiBr}, \mathrm{NaI}$, LiI, and $\mathrm{LiCl}$ solutions isosmotic with a 0.7 per cent. $\mathrm{NaCl}$ solution the contractions may continue at room temperature for one or two days, in which, of course, periods of rest are often noticed.

4. If the number of ions entering the muscle determines 
the contractions, one would expect that an increase in the osmotic pressure of the active ious should also be able to cause rhythmical contractions to set in more quickly. We, indeed, find that a solution having a greater concentration than that of a 0.7 per cent. $\mathrm{NaCl}$ solution brings about contractions sooner. In a $1 . \pm$ per cent. $\mathrm{NaCl}$ solution contractions begin immediately and continue uninterruptedly; in a 1.05 per cent. $\mathrm{NaCl}$ solution contractions often do not begin until several minutes after the immersion of the muscle in it; in a 0.7 per cent. $\mathrm{NaCl}$ solution rhythmical contractions only begin after one or one and a half hours. In the highly concentrated solutions the contractions begin immediately, but they also cease very soon. What has been said here for $\mathrm{NaCl}$ solutions holds good also for the solutions of other ions capable of calling forth contractions; for example, $\mathrm{NaBr}$ or $\mathrm{LiBr}$ solutions. I had solutions of these two salts which were isosmotic with the following $\mathrm{NaCl}$ solutions: 3.5, 2.8, 2.1, 1.4, 1.05 , and 0.7 per cent. In the latter concentration it often took some time before rhythmical contractions began, while in the solutions of a greater concentration contractions developed immediately. In solutions isosmotic with a 1.4 per cent. $\mathrm{NaCl}$ solution maximum contractions set in at once; while in the next weaker solution, 1.05 per cent. maximum contractions occurred only after some time. In these strongly concentrated solutions the rhythmical contractions did not, however, continue for so long a time as in the 0.7 per cent. $\mathrm{NaCl}$ solution, or in solutions of $\mathrm{NaBr}$ or $\mathrm{LiBr}$ isosmotic with this.

5. The fact that in salt solutions of high concentration the contractions soon cease points without doubt to an injury of the muscular substance through the salt solution used. I expected that as soon as the contractions ceased in a salt solution the periodic irritability of the muscle had also fallen below a certain point. But this was, however, by no 
means always the case. In a $\mathrm{NaF}$ solution equimolecular with a 0.7 per cent. $\mathrm{NaCl}$ solution contractions ceased after twenty-five minutes. After forty-five minutes $I$ found that the muscle could still be stimulated at a distance of the secondary coil of $370 \mathrm{~mm}$. - a degree of irritability which was not far below the normal. At the same time, however, I found that a muscle which had been in a 0.7 per cent. $\mathrm{NaCl}$ solution for twenty-four hours still contracted, even though its threshold of stimulation, as determined by the same induction coil, had fallen to $300 \mathrm{~mm}$. We have, therefore, a different threshold of stimulation for different ions. One might think that the periodic contractions in the different solutions are brought about in that the ions which penetrate the muscle substance enter into definite combinations with it. That such must exist $I$ have proved in another paper by showing that $\mathrm{Na}, \mathrm{K}$, and $\mathrm{Ca}$ ions entering the muscle produce specific alterations in its osmotic behavior. ${ }^{1}$ Under this assumption it might be thought that when a certain number of $\mathrm{F}$ ions have entered the muscle, the further entrance of $\mathrm{Na}$ and $\mathrm{F}$ ions no longer brings about contractions, while at the same time an induction current is still able to bring about marked contractions. I need scarcely emphasize the fact that a muscle loses its electrical irritability more rapidly in a $\mathrm{NaF}$ solution than in a $\mathrm{NaCl}$ solution isosmotic with it.

6. If in these experiments the rhythmical contractions are brought about through ions, it was to be expected that no periodic contractions should occur in non-electrolytes. I never saw rhythmical contractions begin in chemically pure distilled water.

I also prepared solutions of glycerin, dextrose, cane sugar, and milk sugar.isosmotic with a 0.7 per cent. $\mathrm{NaCl}$

1 "On the Similarity between the Absorption of Water by Muscles and by Soaps," Part II, pp. 510. 
solution; that is, of an osmotic pressure of 4.91 atmospheres. In none of these solutions did rhythmical contractions occur. I cannot as yet, however, say that this is true for all non-electrolytes. The circumstance that contractions occur immediately in a $\mathrm{NaCl}$ solution of a high concentration suggests the possibility that loss of water by the muscle favors the contractions. I therefore introduced the muscle into glycerin and sugar solutions having two, three, four, and five times as high an osmotic pressure as a 0.7 per cent. $\mathrm{NaCl}$ solution. In none of them did rhythmical contractions occur, even though the muscle lost water markedly. What has been said applies, however, only to rhythmical contractions. Single twitches - that is, single separate contractions - were occasionally observed during the first minutes in glycerin solutions having an osmotic pressure of 4.91 atmospheres or more. Such contractions can also be observed, however, at times when fresh muscles are laid upon a glass plate. The glycerin solution is therefore probably only of a secondary importance.

7. I have above quoted the remark of Biedermann according to which the stimulating effect of $\mathrm{NaOH}$, as well as that of $\mathrm{Na}_{2} \mathrm{CO}_{3}$, is attributed to the "sodium salts." I have, however, shown that in the specific effects of very dilute alkalies we are really dealing with the effects of hydroxyl ions. ${ }^{1}$ I have since then corroborated this statement in that I have convinced myself of the fact that $\mathrm{NH}_{4} \mathrm{HO}$, which is much less dissociated than $\mathrm{NaOH}$, also acts physiologically as a much weaker alkali solution. Hydroxyl ions are also present in a $\mathrm{Na}_{2} \mathrm{CO}$ solution which bring about the specific alkali effects of this solution. The idea, therefore, suggested itself that the hydroxyl ions are capable of calling forth rhythmical contractions in a similar way to $\mathrm{Na}$ and other ions. This seems to be true for the $\mathrm{HO}$ ions in even a

1 Part II, p. 450. 
higher degree than in the case of $\mathrm{Na}$ ions, since, according to Gaule, only a trace of $\mathrm{NaOH}$ or $\mathrm{Na}_{2} \mathrm{CO}_{3}$ favors the rhythmical activity of the heart. The same favorable effect of the HO ions shows itself also in the rhythmical contractions of skeletal muscle.

When a muscle is introduced into a 0.7 per cent. $\mathrm{NaCl}$ solution, the rhythmical contractions of individual fibers or the entire muscle begin after about sixty to ninety minutes. If a trace of alkali is added, however, contractions begin much sooner. I will give an example. In one series of experiments the muscle began to beat rhythmically after twenty-seven minutes in 100 c.c. of a 0.7 per cent. $\mathrm{NaCl}$ solution to which had been added 2 c.c. of a one-tenth normal $\mathrm{LiOH}$ solution. In 100 c.c. of a $\mathrm{NaCl}$ solution of the same concentration to which had been added 3 c.c. of a one-tenth normal LiOH solution weak rhythmical contractions began immediately. In 100 c.c. of a 0.7 per cent. $\mathrm{NaCl}$ solution to which had been added 4 c.c. of the same $\mathrm{LiOH}$ solution strong rhythmical contractions began immediately. In the 0.7 per cent. $\mathrm{NaCl}$ solution (to which no $\mathrm{LiOH}$ had been added) it required seventy-two minutes before rhythmical contractions began. Other series of experiments yielded similar results. This shows without a doubt that $\mathrm{LiOH}$ accelerates the appearance of rhythmical contractions. That we are, indeed, dealing only with the action of the hydroxyl ions is shown by the fact that it does not matter what alkali is added (for example, $\mathrm{LiOH}, \mathrm{KOH}$, $\mathrm{NaOH}$, etc.), as long as the degree of dissociation is the same.

It might be concluded from this that the hydroxyl ions indeed belong to that class which of themselves are able to bring about rhythmical contractions, for the rhythmical contractions which occur immediately can be caused only by the hydroxyl ions. 
I now made a series of experiments with a glycerin solution the osmotic pressure of which was 4.91 atmospheres; which was, therefore, isosmotic with a 0.7 per cent. $\mathrm{NaCl}$ solution. I added to 100 c.c. of this solution one-tenth normal $\mathrm{LiOH}$ in different quantities from 1 to 4 c.c. In 110 case did I obtain rhythmical contractions. Similar experiments with sugar solutions having an osmotic pressure of 4.91 atmospheres yielded the same results. These experiments with sugar solutions are, of course, less conclusive, since a portion of the hydroxyl ions are in this case rendered inactive. The addition of 5 c.c. of a one-tenth normal $\mathrm{LiOH}$ to 100 c.c. dextrose or cane sugar caused no contractions. Upon the addition of 10 c.c., however, of a one-tenth normal LiOH solution a few weak contractions appeared during the first minute. Beside the experiments with the glycerin solutions the experiments with distilled water adduce proof. In no case did hydroxyl ions in distilled water bring about rhythmical contractions. One might think perhaps that distilled water reduces the irritability so rapidly that contractions are no longer possible.' That is, however, not the case. In one case in distilled water the muscle was still irritable after an hour to an induction current from the induction coil used in all these experiments when the distance of the coils was $310 \mathrm{~mm}$., while the normal irritability lay at about $390 \mathrm{~mm}$. Rhythmical contractions occur in solutions of sodium salts at a still lower irritability. The addition of 10 c.c. one-tenth normal $\mathrm{LiOH}$ to 100 c.c. of distilled water gave no rhythmical contractions. Even in a one-fortieth normal or one-tenth normal $\mathrm{LiOH}$ solution no rhythmical contractions occur. Very weak, onethousandth to one-hundredth normal $\mathrm{LiOH}$ or $\mathrm{NaOH}$ solu-

1 It was found in these experiments that a dextrose solution isosmotic with a 0.7 per cent. $\mathrm{NaCl}$ solution reduced the i.rritability of the muscle more rapidly than the $\mathrm{NaCl}$ solution; sugar, therefore, is no indifferent substance. That $\mathrm{NaCl}$ is not has been proved by Locke. 
tions were also ineffective. Hydroxyl ions, therefore, do not belong to those ions which are capable of liberating rhythmical contractions. They only accelerate the production of rhythmical contractions when added to electrolytes in which such rhythmical contractions occur without the addition of the hydroxyl ions.

8. What has been said in the foregoing on the effects of hydroxyl ions holds also for hydrogen ions. The addition of hydrogen ions accelerates the appearance of the contractions in a 0.7 per cent. sodium-chloride solution. If 1,2 , or 3 c.c. of a $\frac{1}{10}$ normal $\mathrm{HNO}_{3}$ solution are added to 100 c.c. of a 0.7 per cent. $\mathrm{NaCl}$ solution, rhythmical contractions begin immediately, or at least earlier than in the pure salt solution. It can, however, again be shown that in nonelectrolytes, such as glycerin and sugar solutions, having an osmotic pressure of 4.91 atmospheres acids do not produce this effect, nor do they do it in distilled water, no matter what the concentration of the acid. That we are indeed dealing in this case with the action of hydrogen ions is shown by the fact that inorganic acids produce the same effects if the same number of hydrogen ions are contained in the unit volume. Hydrogen ions, therefore, do not belong to the ions which produce rhythmical contractions.

9. The question now arises how it happens that $H$ and $\mathrm{OH}$ ions accelerate the rhythmical contractions in electrolytes. It might be thought that these ions have an etching effect, and so bring about continually differences in potential between different portions of the muscle fibers. In this way the muscle would be stimulated continually through its own currents and would be kept in a state of rhythmical activity. It would be in harmony with this view that these contractions do not occur in distilled water and in non-electrolytes. Against it, howerver, stands the fact that not every electrolyte brings about rhythmical contractions upon the addition 
of an alkali. If 2 or 3 c.c. of a $\frac{1}{10}$ normal $\mathrm{LiOH}$ solution is added to 100 c.c. of a $\mathrm{KCl}$ solution isosmotic with a 0.7 per cent. $\mathrm{NaCl}$ solution, no rhythmical contractions occur.

One might think that acids and alkalies increase the irritability, and that for this reason their addition would accelerate the contractions. We find, however, that in certain solutions periodical contractions occur when the irritability has been decreased, while in other solutions these contractions do not occur at all even when the irritability is normal or above normal. In 100 c.c. $\mathrm{KCl}$ solution to which had been added 2 c.c. of a $\frac{1}{10}$ normal $\mathrm{LiOH}$ solution the muscle was still irritable after half an hour when the secondary coil was $420 \mathrm{~mm}$. away from the primary, without a single contraction occurring, while another muscle the irritability of which had dropped to $300 \mathrm{~mm}$. in a $\mathrm{LiCl}$ solution still gave strong rhythmical beats at the same time. It can further be easily shown that the addition of an acid which accelerates the beginning of contractions soon decreases markedly the irritability of the muscle.

I am much more inclined to go back to the first explanation given, that certain ions-for example, $\mathrm{Na}$ ions-bring about rhythmical contractions in that they enter the muscle and here form definite compounds. $\mathrm{H}$ and $\mathrm{OH}$ ions have a catalytic action; that is, they accelerate the formation of these compounds. It might also be that they owe their activity to their power of splitting off the material necessary for the formation of the compounds with the $\mathrm{Na}$ ions. ${ }^{1}$

10. We have thus far become acquainted, first, with a group of ions which are able to bring about rhythmical contractions in skeletal muscle ( $\mathrm{Li}, \mathrm{Na}, \mathrm{Rb}, \mathrm{Cs}, \mathrm{F}, \mathrm{Cl}, \mathrm{Br}, \mathrm{I})$; secondly, we have seen that $H$ and $O H$ ions accelerate the appearance of the effect of the ions just named. There is a third class of ions which iuhibit rhythmical contractions.

1 It is also possible that through their effect on the lipoids they increase the permeability of the muscle for Na and other ions or salts. [1903] 
To these belong first of all the $\mathrm{K}$ ions. I prepared a series of potassium compounds, all of which were isosmotic, with a 0.7 per cent. $\mathrm{NaCl}$ solution, namely, $\mathrm{KCl}, \mathrm{KBr}, \mathrm{KI}, \mathrm{K}_{2} \mathrm{SO}_{4}$, and potassium oxalate. Rhythmical contractions did not occur in any of these solutions. We know, however, that $\mathrm{Br}$ ions have the power of causing rhythmical contractions, or at least are able to accelerate the appearance of these contractions, for in $\mathrm{NaBr}$ the contractions occur much sooner than in an isosmotic $\mathrm{NaCl}$ solution. Potassium must, therefore, prevent the contractions.

The sodium compounds corresponding to the potassium compounds just given are all able to bring about rhythmical contractions.

Ca also inhibits the contractions; and not only this, but the entire group, $\mathrm{Be}, \mathrm{Mg}, \mathrm{Ba},{ }^{1} \mathrm{Sr}$, and also $\mathrm{Mn}$ and Co. No contractions occur in these solutions.

The behavior of $\mathrm{Ca}$ is so characteristic and its rôle in the phenomena of contractions of such significance that I shall have to discuss this point in greater detail.

In one series of experiments I used the following solutions:

a) 100 c.c. $\mathrm{NaBr}$ isosmotic with a 0.7 per cent. $\mathrm{NaCl}$ solution.

b) The same plus 2 c.c. of an equimolecular $\mathrm{CaCl}_{2}$ solution (about 1.33 per cent.).

c) The same with 3 c.c. of the $\mathrm{CaCl}_{2}$ solution.

d),e),f) The same with 4,5 , and 6 c.c. respectively of the $\mathrm{CaCl}_{2}$ solution.

The percentage of $\mathrm{CaCl}$ contained in the various solutions was, therefore, in order as follows: $0.0265,0.0387,0.0511$, $0.0633,0.0744$ per cent. A fresh gastrocnemius muscle was introduced into each of these solutions. The concentration of the $\mathrm{CaCl}_{2}$ in the second solution was equal to

1 It was found later on that Ba salts cause contractions in a low concentration. This had been noticed before. Why this was at first overlooked by me I cannot tell. [1903] 
that found in the serum of the turtle (according to Greene). One can scarcely conceive of a more convincing experiment than the foregoing. In the pure $\mathrm{NaBr}$ solution rhythmical contractions occurred after a minute, and lasted uninterruptedly for twelve hours, when the experiment was brought to a close. In the second solution, which contained the least amount of $\mathrm{Ca}$, occasional very weak contractions occurred which were noticeable during the first thirty minutes, but for the remainder of the day the muscle remained absolutely quiet. In the other solutions containing greater amounts of $\mathrm{CaCl}_{2}$ no contractions whatever occurred.

So slight an amount of calcium as 0.026 per cent.- - that is to say, the amount of calcium contained in blood serumis sufficient to render almost entirely impossible the periodical contractions brought about through $\mathrm{Na}$ and $\mathrm{Br}$ ions, and a little more, namely, 0.038 per cent. of $\mathrm{CaCl}_{2}$, suffices to do away with the contractions entirely. ${ }^{1}$

It might be doubted that in these experiments the $\mathrm{Ca}$ acted as the specific inhibiting substance for the muscular contractions. It might be considered possible that the $\mathrm{CaCl}_{2}$ had decreased the irritability of the muscle to such an extent that the liberation of contraction through $\mathrm{Na}$ and $\mathrm{Br}$ ions had been rendered impossible; but that is not the case. I tested after three hours the faradic irritability of all the muscles. That contained in the $\mathrm{NaBr}$ gave the first contractions when the distance of the secondary coil was 310 mm. ; that in the $\mathrm{NaBr}$ plus $0.026 \mathrm{CaCl}_{2}$ solution had the same threshold of stimulation; that in the other solutions was only slightly lower. On the following morning the muscles contained in the $\mathrm{CaCl}_{2}$ solution were more irritable than that in the pure $\mathrm{NaBr}$ solution, which had contracted continually. We can, therefore, only be dealing with the fact that the entrance of $\mathrm{Ca}$ ions into the muscle inhibits the

\footnotetext{
$1 \mathrm{We}$ are therefore indebted to the calcium contained in our blood for the fact that our muscles do not twitch continually.
} 
liberation of rhythmical contractions through $\mathrm{Na}$ and $\mathrm{Br}$ ions. Because of the importance of this fact, I will briefly report another experiment. I repeated the same experiment given above, with this difference, that a 0.7 per cent. $\mathrm{NaCl}$ solution was used instead of $\mathrm{NaBr}$. In this case the periodic contractions began in the pure $\mathrm{NaCl}$ solution in eighty minutes; in the remaining solutions, which contained a trace of $\mathrm{CaCl}_{2}$, contractions did not occur at all, not even in the solution which contained 0.026 per cent. $\mathrm{CaCl}_{2}$.

It could be shown in these experiments also that the faradic threshold of stimulation of the muscle contained in the solution containing $\mathrm{Ca}$ was no lower than that of the muscle which beat rhythmically in the $\mathrm{NaCl}$ solution free from Ca.

In a more concentrated $\mathrm{CaCl}_{2}$ solution-for example, in a solution isosmotic with a 0.7 per cent. $\mathrm{NaCl}$ solution-not only do no contractions occur, but the faradic irritability is also rapidly destroyed. If, however, only a small amount of Ca is present in the $\mathrm{NaCl}$ solution-for example, as much as there is contained in an equal volume of serum-only the specific inhibiting effect of the $\mathrm{Ca}$ ions upon the liberation of the rhythmical contractions through $\mathrm{Na}$ and other ions appears, while the irritability does not suffer.

We therefore come to this necessary conclusion, that there are ions the entrance of which into the muscle has a specific inhibiting effect upon the liberation of rhythmic contractions. For practical purposes the most important of these ions are $\mathrm{Ca}$ and $\mathrm{K}$.

11. An apparent contradiction to what has been said is found when the following experiments are made. Two solutions are prepared, one a 0.7 per cent. $\mathrm{NaCl}$ solution, and a second similar solution to which 2 c.c. of an equimolecular $\mathrm{CaCl}_{2}$ solution have been added to 100 c.c. of $\mathrm{NaCl}$. The latter solution then contains the amount of $\mathrm{CaCl}_{2}$ found 
in the serum. In the former solution the muscle begins to twitch after about eighty minutes, and continues to contract rhythmically from twelve to forty hours. In the second solution either no contractions whatsoever occur, or the contractions begin later and cease earlier, that is, are decreased in number. This is only a repetition of what has been said. If now, after the contractions have ceased in the pure $\mathrm{NaCl}$ solution, the muscle which has been in the $\mathrm{NaCl}$ solution containing $\mathrm{Ca}$, but which has not contracted, is put into the pure $\mathrm{NaCl}$ solution, it begins to contract in this solution, while the other muscle will contract in neither of the two solutions.

The two facts can perhaps be explained upon the following basis: From my observations on the absorption of fluids by muscle, it follows that $\mathrm{Na}, \mathrm{Ca}$, and $\mathrm{K}$ ions must be present in the muscle in combinations in which these three ions can be exchanged one for the other. If the muscle is contained in a solution of one or more of these ions, the relative combination of three kinds of ions is governed by the laws of chemical equilibrium. If only $\mathrm{Na}$ ions are present, but no $\mathrm{K}$ or $\mathrm{Ca}$ ions, a number of $\mathrm{Na}$ ions will take the place of $\mathrm{Ca}$ ions and $\mathbf{K}$ ions until the laws of equilibrium have been fulfilled. In this process the muscle becomes poorer in $\mathrm{Ca}$ compounds, or at least in such $\mathrm{Ca}$ compounds in which $\mathrm{Ca}$ exists in the ionic state and in which it can be replaced by Na ions. (Ca may yet exist in still another form in the muscle substance, and be able to enter from this form into the ionic form through metabolic changes.) If, on the other hand, Ca ions are in the solution then at a low (very low) concentration of the $\mathrm{Ca}$ ions, a substitution of $\mathrm{Na}$ ions for the $\mathrm{Ca}$ ions is at once compensated by an equal substitution of $\mathrm{Ca}$ ions for $\mathrm{Na}$ ions. If the concentration of the $\mathrm{Ca}$ ions is greater, the $\mathrm{Ca}$ ions must crowd out a part of the $\mathrm{Na}$ ions from these combinations. Thus far this is no hypothesis, as 
it is only the application of simple laws to the muscle. We now find, when we keep in mind what has been said above, that the entrance of sodium ions (but also $\mathrm{Cl}, \mathrm{Br}$, and other ions which have been mentioned above or are at present still unknown) into certain muscle compounds is accompanied by contractions. We observe, secondly, that the entrance of $\mathrm{Ca}$ ions into the normal muscle inhibits these contractions. Indeed, one might think that the process of substituting any ions for $\mathrm{Ca}$ ions is adapted in a peculiar way to giving rise to a contraction, while the reverse process, the substitution of $\mathrm{Ca}$ ions for any ions, alters the muscle substance in an opposite sense. In this way it might be explained why a muscle does not contract in the $\mathrm{NaCl}$ solutions containing $\mathrm{Ca}$, while it begins to contract immediately when introduced into a $\mathrm{NaCl}$ solution free from Ca. It also becomes intelligible that the muscle which has been in a pure $\mathrm{NaCl}$ solution for some time no longer contracts. It has no more $\mathrm{Ca}$ ions to exchange. What has been said harmonizes also with the previous observations of Ringer, that a muscle in a $\mathrm{NaCl}$ solution remains irritable for a longer time when the solution contains a trace of $\mathrm{Ca}$ and $\mathrm{K}$ salts. And it also harmonizes with what has been said, that, according to Howell, a muscle from which the $\mathrm{Ca}$ salts have been removed by washing with oxalates loses its irritability. Our views and observations do not, however, agree with Howell's claim that $\mathrm{NaCl}$ "is of importance only in so far as it maintains the osmotic pressure between the tissues and the surrounding fluid." This view of Howell contradicts also the observations of Locke, who showed that $\mathrm{NaCl}$ is not so indifferent a substance. I am gradually coming to believe that, strictly speaking, there is no solution which is merely of osmotic importance for living tissues. Even an isotonic sugar solution (about 4.91 atmospheres pressure) affects the irritability, and probably also other properties, of the muscle to a high degree. We must 
in this not allow the statements of the botanists to lead us astray. We have in the contractile and rhythmically acting animal tissues much more sensitive living reagents than the botanist has in most plants. True has also recently found that $\mathrm{NaCl}$ is not an indifferent substance. He attributes, however, a purely osmotic effect to the pure sugar solutions. ${ }^{1}$ This is, however, incorrect for animal tissues at least.

12. Naturally ions which decrease the irritability must always counteract the effects of an ion capable of calling forth contractions when both are present in the solution. That can be best understood when a large number of $\mathrm{Na}$ salts are prepared which are equimolecular with a 0.7 per cent. $\mathrm{NaCl}$ solution. In nearly all of these solutions rhythmical contractions occur at first. It is dependent only upon the anion how long these contractions continue. While the contractions in a $\mathrm{NaCl}$ or $\mathrm{NaBr}$ solution may last from twenty-four to forty-eight hours, they cease in an isotonic solution of sodium acetate, butyrate, oxalate, tartrate, or citrate in one-half to one and a half hours. In a $\mathrm{Na}_{2} \mathrm{SO}_{4}$ solution the contractions cease in less than two hours. The anions of the given salts diminish very markedly the irritability. In $\mathrm{Na}_{3} \mathrm{PO}_{4}$ no contractions whatsoever occur, and here the irritability is reduced very rapidly. The same holds also for $\mathrm{Na}_{2} \mathrm{CO}_{3}$ equimolecular with a 0.7 per cent. $\mathrm{NaCl}$ solution. Hydrogen and hydroxyl ions also decrease the irritability, even in very dilute solutions. The same is true of $\mathrm{NH}_{4}$ ions.

13. I believe that these and similar facts will help us to understand the phenomena of contraction, and possibly also the phenomena of irritability in general. I will only show in this paper that the conclusions which we have drawn hold also for heart muscle. Aubert has found that the ventricle will beat in a physiological $\mathrm{NaCl}$ solution, but that it is not

1 R. H. TreE, Botanical Gazette, Vol. XXVI (1898). 
able to beat rhythmically in the serum of blood containing Ca. Greene has recently shown that when $\mathrm{CaCl}_{2}$ is added to a physiological $\mathrm{NaCl}$ solution in a concentration equal to that in which it exists in the serum, the pulsations of the ventricle cease, while rhythmical irritability continues. That is the same behavior, therefore, as is the case with the rhythmical contractions of the gastrocnemius, and we may therefore assume that for the heart-beat the same circumstances come into consideration as for the rhythmical contractions of skeletal muscle; with the exception, of course, of the conditions for the conduction of the stimulus which we have discussed under paragraph 2. The rôle of the hydroxyl ions for the heart activity might also be the same as that we have found to be the case for the rhythmical contractions of skeletal muscle. ${ }^{1}$ The further we carry the analysis of the two processes, the more complete, I believe, we shall find their identity, with the exception, of course, of the conditions of conductivity of the stimulus. I find only two contradictory facts. One is originated by Howell-that $\mathrm{NaCl}$ is only of osmotic significance in the activity of the heart. So far as the ventricle is concerned, this statement of Howell's is contradicted by the observations of Aubert. The second assertion comes from Howell's pupil, Greene. ${ }^{2}$ Greene has observed very correctly that $\mathrm{CaCl}_{2}$ in the same concentration as it exists in the serum prevents the rhythmical contractions of the ventricle. Then, however, he adds the following assertion, that "when the amount of $\mathrm{CaCl}_{2}$ in the serum is slightly increased, regular contraction begins."

1 I have recently tried to determine how many free hydroxyl ions the blood contains in the unit volume. I find that it cannot possibly be more, and is probably less, than those present in the same volume of a one-thousandth normal $\mathrm{NaOH}$ solution. Until now we have always made the alkalinity determination of the blood by titration. For the specific alkalinity of the blood, however, only the active alkalin. ity - that is, the concentration of the free hydroxyl ions in the blood-comes into consideration. It has since been found by Friedenthal, Fraenckel, Farkas, and Hoeber that blood has a neutral reaction. [1904]

2 Greene, American Journal of Physiology, Vol. II (1898). 
The concentration with which we have to deal in this case is, according to him, 0.04 per cent. instead of 0.026 per cent. of the serum. So far as the rhythmical contractions of the muscle are concerned, the claim of Greene is incorrect. When a muscle does not contract rhythmically in a $\mathrm{NaCl}$ solution containing $\mathrm{Ca}$, when the concentration of the $\mathrm{CaCl}$ solution is 0.026 per cent, then no contractions occur at all at a concentration of 0.04 per cent., or higher. For the apex of the heart the relations are no different, and the claim of Greene to the contrary rests, so far as I can see from his paper, upon a misunderstanding.

In observing the "stimulating" effect of the 0.04 per cent. $\mathrm{CaCl}_{2}$ solution the strip of heart muscle did not lie in such solution, but hung in a moist chamber, and was moistened with two or three drops of the $\mathrm{CaCl}_{2}$ solution named. It then began to beat rhythmically. If we assume that calcium did indeed have something to do with this, we are still not dealing in this case with the same condition of affairs that we have when heart muscle is immersed in a large quantity, about 100 to 200 c.c., of such solution. In the latter case a larger number of $\mathrm{Ca}$ ions would enter the muscle in the unit of time. By moistening the muscle with two or three drops of a 0.7 per cent. $\mathrm{NaCl}$ solution containing 0.04 per cent. $\mathrm{CaCl}_{2}$ the larger amount of the fluid runs off', and the few $\mathrm{Ca}$ ions which enter the muscle are perhaps in actual number equal to those which enter from a $\mathrm{NaCl}$ solution containing a very small amount, say 0.001 per cent. $\mathrm{CaCl}_{2}$. Greene and Howell have orerlooked the fact that the concentration of the solution is not the determining factor in the latter case, but the number of molecules which are driven into the muscle (through osmotic pressure). When it is found that 100 c.c. of morphine of a certain concentration kill a dog, and when it is further observed that $\frac{1}{10}$ c.c. $n^{\circ} n$ momine solution two or three times as 
strong does not injure the dog, the conclusion cannot be drawn from this that a morphine solution is more harmless the greater its concentration, I do not doubt but that, when a ventricle which does not beat in a 0.7 per cent. $\mathrm{NaCl}$ solution containing 0.026 per cent. $\mathrm{CaCl}_{2}$ is introduced into a 0.7 per cent. solution containing 0.04 per cent. $\mathrm{CaCl}_{2}$, and the quantity of the solution is the same in both cases, the ventricle will not beat in the latter case either. Whether a very dilute $\mathrm{CaCl}_{2}$ solution, the concentration of which lies far below that of the serum (that is, far below 0.026 per cent.), is able to augment the stimulating effect of a $\mathrm{NaCl}$ solution is yet to be tested, and might easily be made to harmonize with what has been said above.

14. Conclusions.

a) There are certain ions-for example, $\mathrm{Na}, \mathrm{Cl}, \mathrm{Li}, \mathrm{F}$, $\mathrm{Br}, \mathrm{I}$, and others - which (in solutions having an osmotic pressure of 4.91 atmospheres) are capable of calling forth rhythmical contractions in muscles. These contractions are not brought about in that the given ions increase the irritability, since, first, these contractions may continue even when the irritability has been diminished; and, secondly, since in solutions of non-electrolytes (for example, glycerin and sugar) of the same osmotic pressure these contractions do not occur even when the tissues have their normal irritability. It is to be believed rather that the entrance of the ions mentioned above into definite compounds in the muscle is the cause of these contractions.

b) There are ions which inhibit the liberation of rhythmical contractions of the normal muscle; for example, Ca, K, $\mathrm{Mg}, \mathrm{Be}, \mathrm{Sr}, \mathrm{Co}$, and $\mathrm{Mn}$. The inhibiting effect of $\mathrm{Ca}, \mathrm{K}$, and possibly also the other ions, does not rest upon the fact that they reduce the irritability of the muscle; for through the addition of only a small amount of $\mathrm{CaCl}_{2}$ to a physiological salt solution the contractions are prevented, while 
the irritability of the muscle suffers less and is maintained for a longer time than in the pure physiological salt solution in which these rhythmical contractions take place. It is rather to be believed that the entrance of $\mathrm{Ca}$ (and $\mathrm{K}$ ) into definite compounds in the muscle renders difficult or impossible the rhythmical contractions.

c) Hydroxyl and hydrogen ions accelerate the beginning of rhythmical contractions when added in a sufficient dilution to the solutions of the ions mentioned under $a$ ). If, however, they are added to solutions of non-electrolytes or ions which inhibit contractions, they do not have these effects. They have, therefore, a catalytic effect in the starting of rhythmical contractions by other substances without, however, being able to call forth these rhythmical contractions directly.

d) According to our present state of knowledge, which is still limited, we dare say, that only ions, and not non-electrolytes, are able to call forth rhythmical contractions in skeletal muscle.

e) The laws governing the periodic contractions of the ventricle of the heart seem to be the same as those which have shown themselves to govern voluntary muscle. 


\section{XXVI}

ON THE NATURE OF THE PROCESS OF FERTILIZATION AND THE ARTIFICIAL PRODUCTION OF NORMAL LARV $\mathbb{E}$ (PLUTEI) FROM THE UNFERTILIZED EGGS OF THE SEA-URCHIN '

1. Former researches had led me to suspect that changes in the state of matter (liquefactions and solidifications) might play an important rôle in the mechanics of life-phenomena. While studying the absorption of liquids by muscle $I$ found that, to all appearances, a $\frac{n}{8}$ solution ${ }^{2}$ of $\mathrm{CaCl}_{2}$ favors the formation of solid compounds in the muscle, while an equimolecular solution of $\mathrm{KCl}$ favors the formation of more liquid compounds. Na ions rank between the $\mathrm{K}$ and $\mathrm{Ca}$ ions. In these phenomena, however, much depends upon the concentration of the salts. We know that the enzymes of coagulation and liquefaction are greatly influenced in their action by the $\mathrm{Ca}, \mathrm{Na}, \mathrm{K}$, and $\mathrm{Mg}$ ions. Ca favors coagulation, and $\mathrm{Mg}$ does the reverse. Between these come the two other ions. In this case also much depends upon the concentration.

I have made a series of studies on the mechanics of lifephenomena, which will be published shortly in this Journal. I wish now to deal only with one part of these studies, namely, that referring to the nature of the process of fertilization.

I found that in $\frac{5}{8} n$ solutions ${ }^{3}$ of $\mathrm{CaCl}_{2}, \mathrm{NaCl}, \mathrm{KCl}$, and $\mathrm{MgCl}_{2}$ the segmentation of fertilized eggs of sea-urchins

1 American Journal of Physiology, Vol. III (October 1, 1899), p. 135.

$2 \mathrm{I}$ propose to substitute in the future the $\frac{n}{8}$ solution of $\mathrm{NaCl}$ for the 0.7 per cent. solution. It is time that we were rid of percentage solutions in physiology.

3 Approximately the concentration of sea-water. 
(Arbacia) proceeded best in $\mathrm{MgCl}_{2}$, next best in $\mathrm{KCl}$, while $\mathrm{CaCl}_{2}$ proved to be the most injurious in the series.

Seven years ago I, and later Norman, found that if the concentration of sea-water be raised sufficiently by the addition of certain salts, a segmentation of the nucleus takes place without any segmentation of the protoplasm. Such eggs, however, when brought back into normal sea-water, divide into as many cells as there are preformed nuclei. This year I tried the effects of equimolecular solutions of $\mathrm{MgCl}_{2}, \mathrm{KCl}, \mathrm{NaCl}$, and $\mathrm{CaCl}_{2}$ upon this process of nuclear division (in which the nuclear membrane is apparently liquefied), and found that the influence of the four salts (or rather kations) followed the order mentioned above.

We know that enzymes as a rule require a slight degree of acidity or alkalinity for their action. I showed last year that the addition of a small amount of $\mathrm{H}$ ions to sea-water retards or prevents segmentation, while a small amount of $\mathrm{HO}$ ions favors and accelerates thedevelopment of the Arbacia egg.

2. It has been known for some time that the unfertilized eggs of echinoderms, worms, and arthropods begin to segment when left for a comparatively long time in sea-water. This has generally been considered a pathological phenomenon. Mead succeded in causing a segmentation of the unfertilized egg of a marine worm, Chætopterus, by the addition of a very small amount of $\mathrm{KCl}$ to sea-water. Morgan tried the effect of more concentrated sea-water on the unfertilized egg of sea-urchins, with results similar to those obtained by me previously with the same methods in fertilized eggs. If the unfertilized eggs are brought back from the more concentrated sea-water into normal sea-water, they break up into as many cells as there are nuclear masses preformed in the more concentrated solution. But in none of these cases did the cell-divisions of the unfertilized eggs lead 
to the formation of a blastula. A heap of cells, at the best about sixty, were formed, and then everything stopped. We cannot utilize these observations for the theory of fertilization, for the simple reason that the essential element of the process of fertilization, namely, the formation of an embryo, was lacking. In the case of tumors or galls we have cell-division and even growth, and yet these cell-divisions do not result in the formation of an embryo.

3. Some recent observations suggested to me that something in the constitution of the sea-water prevented the unfertilized eggs of marine animals from developing parthenogenetically. Last year I found that the striped muscles of a frog beat rhythmically (like the heart) if put into a $\frac{n}{8}$ $\mathrm{NaCl}$ or $\mathrm{NaBr}$ solution. It is only the presence of $\mathrm{K}$ and $\mathrm{Ca}$ ions in the blood that prevents striated muscles from contracting rhythmically in the body. Romanes had observed that if the margin (with the nerve ring) in Hydromedusæ be cut off, the center no longer contracts rhythmically. I found this summer that this is due solely to the presence of $\mathrm{K}$ and $\mathrm{Ca}$ ions in the sea-water. In a $\frac{5}{8} n$ solution of $\mathrm{NaCl}$, or still better of $\mathrm{NaBr}$, the center continues to beat spontaneously. In applying this and my more recent observations on the relative influence of the various ions upon segmentation to the problem of artificial parthenogenesis it seemed to me that by making two changes in the constitution of sea-water the eggs of the sea-urchin might be able to produce perfect embryos without being fertilized. These changes were either a reduction of the $\mathrm{Na}$ and $\mathrm{Ca}$ ions or an increase in the $\mathrm{Mg}$ (or $\mathrm{K}$ ) ions or both. I think that a great number of variations in this sense might bring about the desired effect, but the end of the season allowed me to try only a limited number of variations. Without going into details (which may be reserved for the full report) I will state briefly that the mixture of about 50 per cent. $\frac{20}{8} n$ 
$\mathrm{MgCl}_{2}$ with about 50 per cent. of sea-water was able to bring about the same effect as the entrance of a spermatozoon. ${ }^{1} \quad$ The unfertilized eggs were left in such a solution for about two hours. When brought back into normal sea-water they began to segment and form blastulæ, gastrulæ, and plutei, which were normal in every respect. The only difference was that fewer eggs developed, and that their development was slower than in the case of the normal development of fertilized eggs. With each experiment a series of control experimentș was made to guard against the possible presence of spermatozoa in the sea-water. Unfertilized eggs of the same female were brought into normal sea-water, and in solutions with too little $\mathrm{MgCl}_{2}$. Neither in the normal sea-water nor in any of these solutions with too little $\mathrm{MgCl}_{2}$ did one single egg develop into a blastula or show anything more than the beginning of a segmentation after a long time.

4. From these experiments it follows that the unfertilized egg of the sea-urchin contains all the essential elements for the production of a perfect pluteus. The only reason that prevents the sea-urchin from developing parthenogenetically under normal conditions is the constitution of the sea-water. The latter either lacks the presence of a sufficient amount of the ions that are necessary for the mechanics of cell-division ( $\mathrm{Mg}, \mathrm{K}, \mathrm{HO}$, or others), or it contains too large a quantity of ions that are unfavorable to this process ( $\mathrm{Ca}, \mathrm{Na}$, or others), or both. All the spermatozoon needs to carry into the egg for the process of fertilization are ions to supplement the lack of the one or counteract the effects of the other class of ions in the sea-water, or both. The spermatozoon may, however, carry in addition a number of

1 The subsequent experiments proved that the increase in the concentration of the sea-water caused the development of the eggs. I was aware of this possibility and was looking for it, but was misled through an error in the preparation of the solutions (which I had intrusted to others). This error was afterwa=d discovered and corrected. [1903] 
enzymes or other material. The ions and not the nucleins in the spermatozoon are essential to the process of fertilization (which may interest those who believe with me that physiologists ought to pay a little more attention to inorganic chemistry). I have no doubt that the same principles hold good for the process of fertilization of other, if not ail, the marine animals, although the ions involved will probably differ in various species.

Finally we may ask the question, whether we may expect to produce artificial parthenogenesis in mammalians. Janósik has found segmentation in the unfertilized eggs of mammalians. This is similar to the fact mentioned above, that the unfertilized eggs of sea-urchins may show a segmentation if they stay long enough in the sea-water. I consider it possible that only the ions of the blood prevent the parthenogenetic origin of embryos in mammalians, and I think it further not impossible that a transitory change in the ions of the blood may also allow complete parthenogenesis in mammalians. 


\section{XXVII}

ON ION-PROTEID COMPOUNDS AND THEIR RÔLE IN THE MECHANICS OF LIFE-PHENOMENA. - THE POISONOUS CHARACTER OF A PURE NaCl SOLUTION ${ }^{1}$

\section{INTRODUCTORY REMARKS ON ION-PROTEID COMPOUNDS}

In this series of articles I intend to publish some new facts and ideas concerning the constitution of living matter, and to apply these facts to a number of life-phenomena. The new facts concerning the constitution of living matter are chiefly as follows: The salts or electrolytes in general do not exist in living tissues as such exclusively, but are partly in combination with proteids. The salt or electrolyte molecules do not enter into this combination as a whole, but through their ions. The great importance of these ion-proteid compounds lies in the fact that by the substitution of one ion for another the physical properties of the proteid compounds change (for instance, their power to absorb water and their state of matter). We thus possess in these ionproteid compounds essential constituents of living matter which can be modified at desire, and hence enable us to vary and control the life-phenomena themselves.

By making experiments on the effects of ions upon the absorption of water by muscle I found that a muscle does not take up the same amount of water in equimolecular solutions of various chlorides. ${ }^{2}$ The differences were very striking. While in a 0.7 per cent. $\mathrm{NaCl}$ solution the muscle absorbed about 7 per cent. of its own weight of water within eighteen hours, it absorbed about $40-50$ per cent. of its

1 American Journal of Physiology, Vol. III (1900), p. 327.

2 Part II, p. 510. 
weight of water in an equimolecular $\mathrm{KCl}$ solution. In an equimolecular $\mathrm{CaCl}_{2}$ solution it lost about 20 per cent. of water. In a $\mathrm{LiCl}$ solution it neither lost nor absorbed any water. The same was true for the bromides and iodides of the same metals. Even organic compounds of these metals showed somewhat the same difference, although the effects of the anion in these cases modified the results quantitatively. This difference between the effects of the various metal ions upon the absorption of water by the muscle shows a remarkable parallelism with the influence of the same ions upon the absorption of water in soaps. There are $\mathrm{Na}, \mathrm{K}, \mathrm{Ca}$ and other soaps. While $\mathrm{K}$ soaps absorb enormous quantities of water the $\mathrm{Na}$ soaps absorb much less and the Ca soaps still less than the $\mathrm{Na}$ soaps. If in the $\mathrm{Na}$ soap we substitute $\mathrm{K}$ ions for the $\mathrm{Na}$ ions, the soap takes up quantities of water. If we substitute $\mathrm{Ca}$ ions for $\mathrm{Na}$ ions, the soap loses water. From this I concluded that in the muscle the various metal ions exist in combinations in which they can as easily be substituted for each other as in the soap compounds. These compounds are similar to the soap compounds in one physical quality, namely, the absorption of water. I expressed the opinion that the ions in muscle must be in combination with proteids. If a muscle be put into a $\mathrm{KCl}$ solution, the $\mathrm{K}$ ions of the solution enter the muscle and gradually take the place of the $\mathrm{Na}$ and $\mathrm{Ca}$ ions in these metal proteids. The $\mathbf{K}$ proteids are able to bind more water than the $\mathrm{Na}$ or $\mathrm{Ca}$ proteids. If the muscle be put into a solution of $\mathrm{CaCl}_{2}, \mathrm{Ca}$ ions will take the place of the $\mathrm{Na}$ and $\mathrm{K}$ ions in the proteid compounds of the muscle, and the muscle must lose water. I have carried these experiments farther and may publish some of the more recent results in this series of articles.

I next applied this conception of ion-proteid compounds to a phenomenon which had hitherto been observed only 
occasionally, namely, rhythmical contractions of the muscles of the skeleton." I found that such rhythmical contractions occur only in solutions of electrolytes, $i$. e., in compounds which are capable of ionization. In solutions of nonconductors (urea, various sugars, and glycerin) these rhythmical contractions are impossible. This is an indication that they are a function of the ion-proteids. But only in certain ion solutions are such rhythmical contractions possible. All the solutions of $\mathrm{Na}$ salts are able to produce them, but in a 0.7 per cent. $\mathrm{NaCl}$ solution contractions begin later and are less powerful than in an equimolecular $\mathrm{NaBr}$ solution. This indicates that not only the metal ion influences the physical qualities of the ion-proteids, but that the anion does so as well. This might be understood from the assumption that anions as well as kations may combine with proteids. This forces us to raise the question whether both ions may not combine with the same proteid molecule, only with the difference that the two different ions be added at different places in the molecule. My colleague, Professor Stieglitz, with whom I discussed this question, called my attention to the behavior of amido-acetic acid, which indeed acts in a similar way. From all we know concerning the constitution of proteids it seems justifiable to assume that some of them may very well share certain peculiarities of the amido acids. ${ }^{2}$

The experiments on the rhythmical contractions of the muscles of the skeleton, however, led to some other data concerning the ion proteids. Solutions of $\mathrm{Na}$ ions produce rhythmical contractions only if the muscle cells contain $\mathrm{Ca}$ ions in sufficient numbers. As soon as there is a lack of $\mathrm{Ca}$ ions in the tissues the $\mathrm{Na}$ ions are no longer able to cause rhythmical contractions. On the other hand, if we add $\mathrm{Ca}$

1 Part II, p. 518.

2 SPIRo, Zeitschrifı für physiologische Chemie, Vol. XXVIII (1899), p. 174. 
or $\mathrm{K}$ solutions to the $\mathrm{NaCl}$ solution, it will no longer cause rhythmical contractions in a fresh muscle. It therefore looks as if the substitution of certain quantities of $\mathrm{Na}$ ions for $\mathrm{Ca}$ ions caused contractions; but if this substitution goes too far, the muscle loses its irritability. On the other hand, the presence of $\mathrm{Ca}$ ions in the $\mathrm{NaCl}$ solution prevents the substitution of a sufficient number of $\mathrm{Na}$ ions for $\mathrm{Ca}$ ions, and in the muscle thus prevents rhythmical contractions. It is due to the presence of $\mathrm{Ca}$ (and $\mathrm{K}$ ) ions in our blood that our muscles do not contract rhythmically.

These facts received further support when I tried to determine the active alkalinity of the blood. I had found that a slight decrease in the active alkalinity of sea-water retarded the development and growth of young sea-urchins, while a slight increase in the number of hydroxyl ions accelerated both processes. It seemed to me that the main physiological interest in the alkalinity lay in the osmotic pressure of the free $\mathrm{HO}$ ions in the blood or serum, as only the free $\mathrm{HO}$ ions can have any physiological effects. In the course of my experiments I found that the quantity of free $\mathrm{HO}$ ions in the blood is neither increased by a considerable addition of $\mathrm{NaHO}$ nor decreased by a considerable addition of $\mathrm{HCl}^{1}$ Experiments proved that this is not due to the salts of the blood or serum, but to the proteids. It is evident that the latter have the power of combining with $\mathrm{H}$ and $\mathrm{HO}$ ions. Spiro came to a similar result by starting from a different point of view. ${ }^{2}$ Here again we have to deal with ion proteids.

If we look at this phenomena from a biotechnical viewp. 233.

1 Sproo AND Pemsel, Zeitschrift für physiologische Chemie, Vol. XXVI (1898),

2 The experiments consisted in this, that I added various quantitiez of acid or alkali to ox blood and examined how long the muscle of a frog remained alive in such a solution. While the addition of a small amount of acid or alkali to a physiological saltsolution renders the latter toxic for the muscle, a very much larger quantity of acid or alkali is required to make the blood toxic for the muscle. [1903] 
point, they gain in significance. They teach us that we can impart to a tissue new properties by changing the quality and the relative proportions of the ions in combination with the proteids. The characteristic qualities of every tissue are partly due to the fact that its ion proteids contain certain ions in definite proportions. Any change in this proportion is accompanied by a change in the properties of the tissue.

Ten years ago I started upon experiments in which I substituted at desire one organ for another or transformed one organ into another (heteromorphosis). The agents I used for this purpose were various forms of contact, gravitation, and light. 'But the number of animals in which the phenomena of heteromorphosis could be controlled was rather limited. I concluded at that time that it would be necessary for the development of this technical or constructive side of biology to fina a more elementary point of attack. The ion proteids, on account of the ease with which their properties can be changed by a change of their ions, seemed to offer the desired opportunity. I therefore decided to devote last summer at Woods Hole entirely to experiments in this direction. Marine animals which live in a medium having a high concentration of ions seemed to offer better opportunities than fresh-water or land animals.

A brief report of one part of the summer's work was published in this periodical. ${ }^{2}$ Since then Dr. W. Pauli, of Vienna, has published an address in which he reaches similar conclusions on ion proteids independently. ${ }^{2}$ His conceptions are based on experiments upon the physical qualities of proteids. His address appeared too late to influence me in my work or my ideas, but the clearness of his results and statements was a very welcome support. He speaks in his

1 American Journal of Physiology, Vol. III, p. 135 .

2 W. PAULI, Ueber physikalisch-chemische Methoden und Probleme in der Medizin (Wien, 1900); and "Ueber die physikalischen Zustandänderungen der Eiweisskorper," Wiener akademischer Anzeiger, October 12, 1899. 
address of ion-proteid compounds, and I only need to quote the following sentence in order to show how far his conceptions and mine agree. "We cannot doubt the general existence of ion-proteid compounds in the living organism. We have eren urgent reasons for assuming that all the proteids of the protoplasm exist there only in combination with ions." I shall have a chance to discuss his views further when the full account he promises of his experiments appears.

These introductory remarks may suffice for the present. I will now report on a series of experiments which were undertaken on the assumption of the existence of ion proteids, and the possibility of changing the qualities of tissues by changing the relative proportions of ions in the tissues.

\section{EXPERIMENTS ON FISH}

If it be true that life-phenomena depend upon the presence of a number of various metal proteids $(\mathrm{Na}, \mathrm{Ca}, \mathrm{K}$, and $\mathrm{Mg}$ ) in definite proportions, it follows that solutions which contain only one class of metal ions must act as a poison. The reason for this is that the one class of metal ions will gradually take the place of the other metal ions in the ion proteids of the tissues. Even a pure $\mathrm{NaCl}$ solution must thus be poisonous, although this salt permeates all our tissues and is the main constituent of the inorganic matter of the ocean. I have looked through the literature in vain to find facts which corroborate this view. I found only the following data: Ringer and Locke $^{1}$ mention the fact that in $\mathrm{NaCl}$ solutions the contraction curve of a muscle may show slight variations, and Locke adds that the same is true for certain electric phenomena in the nerve. True has added another observation in this direction. It has been known for many years that if we put plant cells, for instance Spyrogyra, into a very concentrated solution of salts or sugars, the cells lose water and cease to grow. True found that the osmotic

${ }^{1}$ Locke, Archiv fü die gesammte Physiologie, Vol. LIV (1893), p. z01. 
pressure of a $\mathrm{NaNO}_{3}$ and $\mathrm{KNO}_{3}$ solution which is just able to prevent growth in Spyrogyra is lower than that of a sugar solution which renders growth impossible. Hence he concludes that $\mathrm{NaNO}_{3}$ is not harmless for Spyrogyra. ${ }^{1}$ In this case, of course, the concentration of $\mathrm{Na}$ ions was much greater than in the blood or in sea-water. It is, however, easy to give striking illustrations of the fact that a pure $\mathrm{NaCl}$ solution is a strong poison. In a former paper I have shown that Fundulus, a marine fish, can endure an astonishing increase in the concentration of sea-water. An addition of 5 per cent. $\mathrm{NaCl}$ to sea-water does not injure the animal. ${ }^{2}$ I selected it for testing my conceptions concerning the metal proteids. I found that it dies in a short time in a pure $\mathrm{NaCl}$ solution of the same concentration as that in which this salt exists in the sea-water. ${ }^{3}$ In $\frac{5}{8} n$ solutions of $\mathrm{NaCl}$ which were diluted with various quantities of distilled water, the animals lived the longer the greater the dilution was, and in distilled water the young fish lived indefinitely. The following table shows the duration of life of these fish in pure $\mathrm{NaCl}$ solutions of various concentrations:

TABLE I

Average Deration of Life of Young Fundelus in Pure NaCl Solutions of Different Concentration

\begin{tabular}{|c|c|c|c|c|c|}
\hline \multicolumn{5}{|c|}{ Nature of the Solution } & Duration of Life \\
\hline \multicolumn{5}{|c|}{100 c.c. ${ }_{8}^{5} n \mathrm{NaCl}}$. & Less than 12 hours \\
\hline 90 & "6 & 6 & $+10 c$ & d water & About 24 hours \\
\hline 80 & " & 6 & +20 & $"$ & " 30 " \\
\hline 50 & “ & $"$ & +50 & "6 & "6 $40 \quad 6$ \\
\hline 20 & “ & 6 & +80 & 6 & "60 "6 \\
\hline 10 & " & 6 & +90 & $"$ & " $72 \quad$ " \\
\hline 0 & " & $"$ & +100 & $" 6$ & Still alive after 10 days \\
\hline
\end{tabular}

1 True, Botanical Gazette, 1898, p. 407.

${ }^{2}$ LoEB, Archiv für die gesammte Physiologie, Vol. LV (1894), p. 530.

3 For these experiments the young fish which had just hatched were used. As they were less than a centimeter long, their mass was small compared with the volume of the solution. 
This result agrees with our theory. But in order to make the proof complete we must be able to show that an addition of certain other ions annihilates the poisonous effects of a pure $\mathrm{NaCl}$ solution. I tried the following solutions upon Fundulus:

$$
\begin{aligned}
& \text { (1) } 96 \text { c.c. } \frac{5}{8} n \mathrm{NaCl}+4 \text { c.c. }{ }_{8}^{10} n \mathrm{MgCl}_{2} \\
& \text { (2) " " " } \quad+4 \text { c.c. } \frac{5}{8} n \mathrm{KCl} \\
& \text { (3) " " " }+4 \text { c.c. }{ }_{8}^{10} n \mathrm{CaCl}_{2}
\end{aligned}
$$

In each of these solutions the fish died in less than or in about twenty-four hours. After this experiment two salts were tried in combination with $\mathrm{NaCl}$, and the following solutions were prepared:

(1) 96 c.c. $\frac{5}{8} n \mathrm{NaCl}+2$ c.c. ${ }_{8}^{10} n \mathrm{MgCl}_{2}+2$ c.c. ${ }_{8}^{10} n \mathrm{CaCl}_{2}$

(2) " " " $"$ " " $"$ "

(3) " " " $\quad$ " $\frac{10}{8} n \mathrm{CaCl}_{2}+$ " $\frac{5}{8} n \mathrm{KCl}$

This time the result was very striking. In the first of these three solutions the animals lived less than thirty hours, in the second a few hours longer; in the third they were still alive ten days later when I discontinued the experiment. Thus we see that the poisonous effects of the $\mathrm{NaCl}$ solution really disappear if we add a small amount of $\mathrm{K}$ and $\mathrm{Ca}$ ions, which makes the proof of our theory complete.

In the pure $\mathrm{NaCl}$ solutions we have to deal with two ions, $\mathrm{Na}$ and $\mathrm{Cl}$ ions. Are both equally responsible for the poisonous effect? The fact that $\mathrm{KCl}$ and $\mathrm{CaCl}_{2}$ prevent the poisonous effects of the $\mathrm{NaCl}$ solution proves that the metal ions are of greater importance than the $\mathrm{Cl}$ ions.

I stated above that Fundulus stands the addition of rather large quantities of $\mathrm{NaCl}$ to sea-water. I tried to determine whether $\mathrm{K}$ and $\mathrm{Ca}$ ions were able to counteract even larger doses of $\mathrm{NaCl}$ than are contained in a $\frac{5}{8} n \mathrm{NaCl}$ solution. A number of young Funduli were put into the following solutions: 
(1) 100 c.c. ${ }_{8}^{10} n \mathrm{NaCl}$

(2) 96 " " +4 c.c. $5 n \mathrm{KCl}$

(3) 96 " " $"+4 \cdots{ }_{8}{ }^{\circ} n \mathrm{CaCl}_{2}$

(4) 96 " " $+2 \cdots \frac{10}{8} n \mathrm{CaCl}_{2}+2$ c.c. ${ }_{8}^{5} n \mathrm{KCl}$

(5) 93 " " $+5 "{ }_{8}^{0} n \mathrm{CaCl}_{2}+2$ c.c. $\frac{5}{8} n \mathrm{KCl}$

In solutions 1 and 2 the animals died in less than two hours. In solution 3 the animals were found dead the next morning. In solution 4 the animals died within three days; and in solution 5 one animal was still alive at the end of the third day when the experiment was discontinued. The presence of small amounts of $\mathrm{K}$ and $\mathrm{Ca}$ ions prevents or weakens the poisonous effects of even large quantities of $\mathrm{NaCl}$.

I will now consider some possible objections to our theory. One might think that with the $\mathrm{CaCl}_{2}$ a small amount of $\mathrm{HO}$ ions might possibly be introduced in cases in which the $\mathrm{CaCl}_{2}$ was heated before it was dissolved. One might think that these $\mathrm{HO}$ ions were the essential constituent that prolonged the life of these fish. The $\mathrm{K}$ ions were only needed to overcome certain effects of the Ca ions. There is indeed an antagonism between $\mathrm{K}$ and $\mathrm{Ca}$ ions, as shown by Ringer's experiments. But the fact that Fundulus lives indefinitely in distilled water proves that $\mathrm{HO}$ ions are not necessary to maintain its life. The second objection might be that $\mathrm{NaCl}$ used contained impurities. But this objection may be discarded at once. The $\mathrm{NaCl}$ was obtained from several leading factories and was chemically pure. The only impurity possible could have been a trace of $K$. But as a further addition of $\mathrm{K}$ made the $\mathrm{NaCl}$ more harmless, it is out of the question that the trace of $\mathrm{KCl}$ which the $\mathrm{NaCl}$ might have contained could have had anything to do with the poisonous effects. A third possible objection might be that these experiments only prove the necessity of $\mathrm{K}$ and $\mathrm{Ca}$ ions for Fundulus. But this idea is refuted by the fact that Fundulus can live indefinitely in distilled water, it is, perhaps, worthy of mention that the positive proof for the 
poisonous character of a pure $\mathrm{NaCl}$ solution would not have been possible except in a marine animal like Fundulus for which distilled water is not poisonous. Another possibility might have been the presence of a trace of acid. $\mathrm{My}$ colleague, Professor Stieglitz, was kind enough to test the $\mathrm{NaCl}$ used, for acids, but it was found to be absolutely free from acids. Hence I do not see any other possible explanation of the results than the theory from which we started.

What is true for pure $\mathrm{NaCl}$ solutions is, of course, still more true for equimolecular pure solutions of $\mathrm{KCl}$ and $\mathrm{CaCl}_{2}$. They act like poisons. I have not yet been able to convince myself that their poisonous effect can be prevented by the addition of small amounts of other metal ions.

The fact that Fundulus can be thrown from sea-water into distilled water without any considerable swelling, or without any visible injurious effects, may find its explanation through the influence that various ions have upon the absorption of liquids. The above-mentioned experiments on the absorption of liquids by the muscle have shown that the simple osmotic theory of absorption which has been accepted by botanists cannot possibly be correct. I shall deal with this problem in another paper.

\section{EXPERIMENTS ON JELLYFISH (GONIONEMUS)}

The locomotion of Medusæ is due to rhythmical contractions of their swimming-bell. I experimented on a form which is very abundant at Woods Hole, Gonionemus. If we put a Gonionemus into a $\frac{5}{8} n$ solution of $\mathrm{NaCl}$, it soon stops contracting rhythmically. Too many $\mathrm{Na}$ ions take the . place of $\mathrm{Ca}$ and $\mathrm{K}$ ions, and this alters the physical properties of the tissues to such an extent that no more contractions are possible. If such a Medusa is brought back into normal sea-water, it begins to beat again after a short time. In this case $\mathrm{Ca}$ and $\mathrm{K}$ ions take the place of some of the $\mathrm{Na}$ ions 
in the ion proteids, and this restores the irritability (or contractility) of the Medusa. We thus see again that the Na ions in a pure $\mathrm{NaCl}$ solution are poisonous. If this idea were correct, we should expect that in a more diluted $\mathrm{NaCl}$ solution the Medusa would be able to contract much longer. This is indeed the case. I tried the following solutions:

90 cc. $\frac{5}{8} n \mathrm{NaCl}+10$ c.c. distilled water

$$
\begin{array}{llll}
80 & \text { " } & +20 & \text { " } \\
70 & +30 &
\end{array}
$$

The result of the experiments was that the Gonionemus contracts longest in a mixture of equal parts of a $\frac{5}{8} n \mathrm{NaCl}$ solution and distilled water. The case is parallel to that of Fundulus, with the exception that the Gonionemus is not able to stand distilled water. Otherwise the $\mathrm{NaCl}$ is the less poisonous for Gonionemus the more dilute it is. We are forced to conclude that if we add certain other metal ions to the $\mathrm{NaCl}$ solution, its poisonous effects must disappear.

We tried the following solutions:

(1) 96 c.c. $\frac{5}{8} n \mathrm{NaCl}+4$ c.c. $\frac{10}{8} n \mathrm{MgCl}_{2}$

(2) 96 " " +4 c.c. $\frac{5}{8} n \mathrm{KCl}$

(3) 96 " " +4 c.c. ${ }^{10} n \mathrm{CaCl}_{2}$

In the first two solutions the Medusæ make a few contractions during the first minute, and then stop. In the third solution the rhythmical contractions may go on for an hour. If we take 2 c.c. of the $\mathrm{CaCl}_{2}, \mathrm{KCl}$, and $\mathrm{MgCl}_{2}$ solution (instead of 4 c.c.), the results are practically the same. After this the following solutions were tried:

(1) $96 \frac{5}{8} n \mathrm{NaCl}+2$ c.c. $\frac{10}{8} n \mathrm{MgCl}_{2}+2$ c.c. $\frac{5}{8} n \mathrm{KCl}$

(2) " " + " " +2 c.c. $\frac{10}{8} n \mathrm{CaCl}_{2}$

(3) " " $"$ " $\frac{5}{8} n \mathrm{KCl}+2$ c.c. $\frac{10}{8} n \mathrm{CaCl}_{2}$

In solution 1 no contractions occurred, while in solutions 2 and 3 regular contractions set in, whose period was almost normal. They lasted an hour or more. Mg ions act in this case more like $\mathrm{K}$ ions. We thus see again that for the 
Medusa the same is true as for Fundulus. Na ions are poisonous in a pure $\mathrm{NaCl}$ solution, while the same solution is harmless if a certain amount of $\mathrm{K}$ and $\mathrm{Ca}$ ions are present. Our theory that the irritability of tissues depends upon the presence in definite proportions of $\mathrm{Na}, \mathrm{K}$, and $\mathrm{Ca}$ ions is once more verified. It goes without saying that a pure $\frac{5}{8} n$ $\mathrm{KCl}$ and a pure $\frac{10}{8} n \mathrm{CaCl}_{2}$ solution was still more poisonous than a $\frac{5}{8} n \mathrm{NaCl}$ solution.

\section{EXPERIMENTS ON CILIARY MOTION}

The conditions for ciliary movements were studied in the young larvæ (blastula, gastrula, and pluteus) of the seaurchin. The movements of these larvæ are due to cilia which are incessantly active. I found that these larvæ do not die rapidly in a $\frac{5}{8} n \mathrm{NaCl}$ solution. They may live twenty-four hours. But if we add a small amount of $\frac{5}{8} n$ $\mathrm{KCl}$ and $\frac{10}{8} n \mathrm{CaCl}_{2}$, they may be kept alive and in motion for ten days or more. In the latter solution their development can continue, while in the pure $\mathrm{NaCl}$ solution this is not possible.

I was, however, surprised to find that this ciliary motion continued in solutions in which no muscular contractions of Fundulus or Gonionemus were possible. Larvæ which were twenty hours old were able to swim for about forty-eight hours in the following solutions:

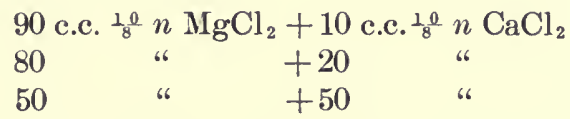

The reader will notice that these solutions contain no $\mathrm{NaCl}$. I tried the effects of these solutions on Gonionemus. As was to be expected, not one contraction was possible in these solutions. The following observation is equally astonishing. Combinations of $\mathrm{NaCl}$ and $\mathrm{KCl}$ were tried:

(1) 80 c.c. $\frac{5}{8} n \mathrm{NaCl}+20$ cc. $\frac{5}{8} n \mathrm{KCl}$

(2) 20 c.c. " +80 " 
In both solutions the ciliary motion continued for more than six, but less than eighteen, hours. The first solution seemed to be a little more harmless than the second. Anybody who has had experience with the effects of $\mathrm{K}$ ions on muscular contraction will realize that it is out of the question to expect a muscle to keep its contractility for over six hours in any of these solutions. Neither was Gonionemus able to contract in these solutions. These experiments certainly warn us against taking it for granted that the mechanics of protoplasmic motions is the same everywhere, although there may be some identity up to a certain point. In the case of the blastula we have to deal with very young embryonic tissue, and we shall see in one of the subsequent publications that embryonic tissue, or rather the egg-cells, differ radically from the muscles and the ganglia, as far as the effects of ions are concerned.

\section{ARE THE NA IONS OF OUR BLOOD AN INDIFFERENT SUBSTANCE?}

A pure solution of $\mathrm{NaCl}$ (of about 0.7 per cent.) has been called the physiological salt solution, inasmuch as the tissues of a frog may live in such a solution for forty-eight hours. 'The $\mathrm{NaCl}$ in our blood is considered to play chiefly the rôle of preventing the tissues from losing or taking up any water. ${ }^{1}$ According to our opinion, the $\mathrm{Na}$ ions of the blood as well as of the sea-water are essential for the maintenance of lifephenomena. $^{2} \quad$ A reduction of the $\mathrm{Na}$ ions in the blood would lead to a loss of $\mathrm{Na}$ ions and a substitution of other ions in their place in the ion proteids of the tissues. But does the fact that a frog's muscle can live for about forty-eight hours in a $\frac{1}{8} n \mathrm{NaCl}$ solution without being poisoned indicate that a pure $\mathrm{NaCl}$ solution is harmless for the muscle? A

1 Howell, American Journal of Physiology, Vol. II (1898), p. 4 i.

2 Very recently Overton has published a similar idea, but without realizing that the same idea had already been expressed and verified by me in a number of papers. [1903] 
$\frac{1}{8} n \mathrm{NaCl}$ solution is certainly not so poisonous as a $\frac{5}{8} n$ solution of the same salt. A Fundulus that would be killed by a ${ }_{8}^{5} n \mathrm{NaCl}$ solution in twelve hours is able to live in a $\frac{1}{8} n$ $\mathrm{NaCl}$ solution two or three days, which is as long as or a little longer than, the frog's muscle lives at the same (summer) temperature in a solution of the same concentration. That the effects of a pure $\mathrm{NaCl}$ solution upon a frog's muscle are in no way different from those on Fundulus is proved, moreover, by the fact that the muscle lives longer in a $\mathrm{NaCl}$ solution if small amounts of $\mathrm{KCl}$ and $\mathrm{CaCl}_{2}$ are added. This explains the superiority of Ringer's solution over a physiological salt solution. Ringer's solution prevents the $\mathrm{Na}$ ions of the physiological salt solution from taking the place of the $\mathrm{Ca}$ and $\mathrm{K}$ ions in the tissues. Contractility is possible only if the $\mathrm{Na}, \mathrm{Ca}$, and $\mathrm{K}$ ions exist in definite proportions in the ion proteids. Hence there is no reason for supposing that what we have proved for marine animals does not hold good for other animals.

\section{SUMMARY}

The main results of this paper are as follows:

1. A pure solution of $\mathrm{NaCl}$ of the same concentration as sea-water is a strong poison for many (if not all) marine animals. The poisonous effects of this solution are due to the $\mathrm{Na}$ ions. The same is true for pure equimolecular solutions of $\mathrm{CaCl}_{2}$ and $\mathrm{KCl}$.

2. The poisonous effects of the $\mathrm{Na}$ ions are antagonized by the addition of a small amount of $\mathrm{Ca}$ and $\mathrm{K}$ ions. Through the presence of these two ions the $\mathrm{Na}$ ions in the ocean lose their poisonous effect.

3. The $\mathrm{Na}$ ions of the blood would not allow the tissues to live. The presence of $\mathrm{Ca}, \mathrm{K}$, and possibly other ions counteracts the poisonous effects of $\mathrm{Na}$ ions in the blood. This is the reason why tissues live longer in Ringer's solution than in a physiological salt solution. 
4. The reason for all these peculiar effects of the $\mathrm{Na}$, $\mathrm{Ca}$, and $\mathrm{K}$ ions is that these (and other) ions form combinations with the proteids of the protoplasm. The various metal-proteids show various physical qualities. Muscles are only contractile as long as they contain all three classes of ions in a certain proportion, which, however, may vary within certain limits. In a pure solution of $\mathrm{NaCl} \mathrm{Na}$ ions will gradually take the place of the $\mathrm{Ca}$ and $\mathrm{K}$ ions in the ion proteids of the tissues, and this leads to a loss of contractility or irritability. This is the reason why a pure $\mathrm{NaCl}$ solution is poisonous. For the same reason pure equimolecular solutions of other chlorides are also poisonous.

5. The conditions for the ciliary motion of the larvæ of the sea-urchin are in various respects different from those mentioned above. The ciliary motion of these organisms can continue for several days in a solution of $\mathrm{MgCl}_{2}$ and $\mathrm{CaCl}_{2}$ which is free from $\mathrm{Na}$ ions. 


\section{XXVIII}

ON THE DIFFERENT EFFECTS OF IONS UPON MYOGENIC AND NEUROGENIC RHYTHMICAL CONTRACTIONS AND UPON EMBRYONIC AND MUSCULAR TISSUE ${ }^{1}$

I. ON THE DIFFERENT EFFECT OF IONS UPON THE MARGIN AND the CENTER of a hYDROMEdUsa (Gonionemus)

Is a preceding paper ${ }^{2}$ I gave a number of facts which force us to assume that not the salts themselves, but their ions, are in combination with the proteids, and that the physical qualities of the various ion proteids are different. This being true, a pure solution of an electrolyte ought to be poisonous, and I have been able to prove that a pure $\mathrm{NaCl}$ solution of the strength in which marine animals live kills them in a comparatively short time. The addition of a small amount of certain other metal ions ( $\mathrm{K}$ and $\mathrm{Ca}$ ) renders the solution harmless. This supports the assumption that irritability depends upon the various ions, especially the metal ions $(N a, C a, K$, and $M g)$ existing in definite proportions in the tissues. But as each tissue has its own specific irritability, it would follow that various tissues must possess the various ions in different proportions. This paper contains the result of a series of investigations on this subject.

Gonionemus propels itself by rhythmical contractions of its swimming-bell. The swimming-bell, however, does not contract continuously, like the heart, but in groups of rhythmical contractions, followed by longer pauses. The swimming-bell of the Medusa may be divided into two regions, a marginal region containing the double nerve ring

1 American Journal of Physiology, Vol. III (1900), p. 383.

2 Part II, p. 544. 
and its ganglia, and the central region which has no ganglia, but is said to possess scattered ganglion cells. The case is similar to that of the heart, which has ganglia in the auricles and sinus vinosus, whose ventricle, however, is free from ganglia, but contains scattered ganglion cells.

Romanes first stated that if we cut a Hydromedusa in two, the marginal part with the ganglia will continue to beat rhythmically very much like the whole Medusa, while the center ceases to beat. These results have been confirmed by several authors, but I have found that the statement of Romanes is only correct for sea-water. If the center of a Hydro-medusa be put into a pure $\frac{5}{8} n \mathrm{NaCl}$ or $\frac{5}{8} n \mathrm{NaBr}$ solution, it begins to beat rhythmically for an hour immediately after the operation. Hence the center as well as the margin is capable of spontaneous contractions. But why does the center not beat rhythmically in sea-water? If it be put into a solution of 98 c.c. $\frac{5}{8} n \mathrm{NaCl}+2$ c.c. $\frac{10}{8} n \mathrm{CaCl}_{2}$, it no longer beats rhythmically. The same is true for a solution of 98 c.c. $\frac{5}{8} n \mathrm{NaCl}+2$ c.c. $\frac{5}{8} n \mathrm{KCl}$, or a solution of 96 $\mathrm{NaCl}+2 \mathrm{CaCl}_{2}+2 \mathrm{KCl}$. Hence the $\mathrm{Ca}$ and $\mathrm{K}$ ions of the sea-water prevent the center from beating rhythmically.

This harmonizes with my previous experiments on the muscles of the skeleton. ${ }^{1}$ The latter are able to beat rhythmically in a pure $\mathrm{NaCl}$ or a $\mathrm{NaBr}$ solution or any solution with $\mathrm{Na}$ ions. But a small addition of $\mathrm{Ca}$ ions or $\mathrm{K}$ ions, or both, prevents rhythmical contractions. We owe it to the presence of these ions in our blood that our muscles do not contract rhythmically like the heart.

Thus we see that there is a typical difference between the effects of ions on rhythmical contractions originating in the muscles directly and those originating in parts which contain ganglia or which originate in the latter themselves. Incesmuch as the whole Gonionemus beats in the rhythm of

1 Part II, p. 518. 
the margin, and inasmuch as the whole Gonionemus is just as immune against the $C a$ and $K$ ions of the sect-water as the margin, it follows that the normal contractions of the Gonionemus originate in the part which contains the ganglia. It is probable, moreover, that the maryin and the center must contain the three metal ions $(\mathrm{Na}, \mathrm{Ca}$, and $\mathrm{K})$ in different proportions. That this is only a difference in degree, however, is proved by the fact that an increase in the amount of $\mathrm{K}$ and $\mathrm{Ca}$ ions above that of the sea-water will finally stop the rhythmical contractions of the margin. On the other hand, it is probable that a very small amount of $\mathrm{K}$ and $\mathrm{Ca}$ ions, smaller than that in the sea-water, allows the center to beat rhythmically.

This difference between the margin and the center is not the same in all Medusæ. If we cut off the margin in an Acalepha (for instance, Aurelia aurita), the center begins to beat in sea-water a short time after the operation. It is possible that a comparative study of the heart-beat would reveal similar facts.

We have thus far shown that the center of a Gonionemus is able to beat for about an hour in a pure $\mathrm{NaCl}$ solution, while the whole Gonionemus or the margin is able to beat in a $\mathrm{NaCl}$ solution containing in addition a small amount of $\mathrm{K}$ and $\mathrm{Ca}$ ions. How does a whole Gonionemus behave in a pure $\mathrm{NaCl}$ solution? As stated above, the contractions of Gonionemus occur in sea-water in groups followed by long pauses. If a Gonionemus be put into a $\frac{5}{8} n \mathrm{NaCl}$ solution, the swimming-bell contracts without interruption and the rate of contraction increases considerably. It may within two minutes reach a rate of 200 contractions per minute, but soon ceases to beat. If the $\frac{5}{8} n \mathrm{NaCl}$ solution be diluted with distilled water, the increase in the rate of contractions occurs more slowly and the contractions continue longer. If we use a solution of 98 c.c. $\frac{5}{8} n \mathrm{NaCl}+2$ c.c, $\frac{10}{8} n \mathrm{CaCl}_{2}$, it 
contracts much more slowly, but the contractions last longer. In a solution of 98 c.c. $\frac{5}{8} n \mathrm{NaCl}+2$ c.c. $\frac{5}{8} n \mathrm{KCl}$ it does not beat at all, with the exception of a few contractions at the beginning. In a solution of 96 c.c. $\frac{5}{8} n \mathrm{NaCl}+2$ c.c. $\frac{5}{8} n \mathrm{KCl}+2$ c.c. $\frac{10}{8} n \mathrm{CaCl}_{2}$ it beats very slowly, but much longer than in any other of the solutions mentioned. In pure $\frac{5}{8} n \mathrm{KCl}$ or $\frac{10}{8} n \mathrm{CaCl}_{2}$ solutions no contractions occur.

The explanation of all these facts seems to me to be as follows: If a Gonionemus be put into a pure $\mathrm{NaCl}$ solution, $\mathrm{Na}$ ions begin to enter the tissues. As soon as they contain a certain number of $\mathrm{Na}$ ions, any further increase of the $\mathrm{Na}$ ions raises the rate of contractions. On the other hand, the substitution of $\mathrm{Ca}$ and $\mathrm{K}$ ions for $\mathrm{Na}$ ions has the opposite effect (as long as not too many $\mathrm{Na}$ proteids are formed). If too many $\mathrm{Na}$ ions have entered into combination with the proteids, the irritability ceases. We shall see later that in this case the substitution of $\mathrm{Ca}$ or $\mathrm{K}$ ions for $\mathrm{Na}$ ions restores the irritability.

Thus the Na ions play an important rôle in the rhythmical contractions. It is just as necessary that a certain number. of $\mathrm{Na}$ proteids exist in the tissues of the Gonionemus as that a certain number of $\mathrm{Ca}$ and $K$ proteids be present. The proportion of these three proteids is, however, apparently different in the margin and in the center. In both kinds of tissue the relative number of $\mathrm{Na}$ proteids is greater than that of the other proteids.

The view differs from the one generally held in connection with the heart-beat, that the $\mathrm{NaCl}$ in the blood serves mainly the purpose of preventing the tissues from losing or taking up water, ${ }^{1}$ while the $\mathrm{Ca}$ salts are considered as the cause of the systole and the $\mathrm{KCl}$ is said to favor the diastole of the heart. The fact that a Medusa not only contracts

1 Howell, American Journal of Physiology, Vol. II (1898), p. 47. 
rhythmically in a pure $\mathrm{NaCl}$ solution, but beats muclı more rapidly in such a solution than in sea-water, shows that neither the $\mathrm{Ca}$ nor $\mathrm{K}$ ions of the surrounding medium are directly necessary for the systole or diastole. If they have any effect, they only diminish the rate of contraction (besides maintaining the contractility much longer). But the abovementioned erroneous conception concerning the rôle of the three ions can be disproved in another way. I had solutions of cane sugar and glycerin prepared which were isosmotic with a $\frac{5}{8} n \mathrm{NaCl}$ solution. The following solutions were tried:

(1) 96 c.c. distilled water +2 c.c. $\frac{5}{8} n \mathrm{KCl}+2$ c.c. ${ }_{8}^{10} n \mathrm{CaCl}_{2}$

(2) " cane sugar + " " $"$ " "

(3) " glycerin $\quad$ " $"$ " $"$ " $"$ "

(4) " ${ }_{5}^{5} n \mathrm{LiCl}+$ " $"$ "

(5) " $\quad \frac{5}{8} n \mathrm{NaCl}+40 "$ " $"$ "

(6) " $\frac{5}{8} n \mathrm{NaBr}+$ " " + " "

In the first four solutions no rhythmical contractions occurred after the first minute. In the fifth and sixth solutions the rhythmical contractions continued for several hours. If it were true that the $\mathrm{NaCl}$ serves only to maintain the osmotic pressure, while the $\mathrm{Ca}$ produces the contractions, we ought to expect that the Gonionemus would contract just as well in the glycerin or sugar or $\mathrm{LiCl}$ solution as in the $\mathrm{NaCl}$ solution. I have made, in addition to these, a number of other experiments, all of which prove that only in solutions of electrolytes (especially $\mathrm{Na}$ salts) is the Gonionemus able to contract rhythmically. The belief that calcium is the stimulus that produces the heart-beat is based upon another observation which I think was first made by Howell and his pupils.' When a heart stops beating in Ringer's solution it begins to beat again (for a little while) in a solution which contains more $\mathrm{Ca}$. It is easy to confirm this observation for

1 Ibid. 
Gonionemus. If a Gonionemus is thrown into a solution of 98 c.c. $\frac{5}{8} n \mathrm{NaCl}+2$ c.e. $\frac{10}{8} n \mathrm{CaCl}_{2}$ solution or a pure $\frac{5}{8} n$ $\mathrm{NaCl}$ solution, it stops contracting after a certain time, but beats again for a little if thrown into a solution with more $\mathrm{CaCl}_{2}$ (for instance, 95 c.c. $\frac{5}{8} n \mathrm{NaCl}+5$ c.c. $\frac{10}{8} n \mathrm{CaCl}_{2}$ ). This seems to favor the assumption that the $\mathrm{Ca}$ ions are the stimulus for the contraction of the swimming-bell of a Medusa. But a simple control experiment shows that this assumption is erroneous. If we throw a Gonionemus first into the stronger solution (for instance of 95 c.c. $\frac{5}{8} n \mathrm{NaCl}+5$ c.c. $\frac{5}{8} n \mathrm{CaCl}_{2}$ ), and wait until it stops contracting, it will begin to contract again if we put it back either into the solution with less $\mathrm{CaCl}_{2}$ (for instance, 98 c.c. $\frac{5}{8} n \mathrm{NaCl}+2$ c.c. $\frac{10}{8} n \mathrm{CaCl}_{2}$ ) or into a pure $\mathrm{NaCl}$ solution. The true explanation of this phenomenon is, I believe, as follows: In the pure $\mathrm{NaCl}$ solution or the solution with little $\mathrm{CaCl}_{2}$, too many $\mathrm{Na}$ ions combine with the proteids, and this leads to a loss of irritability. If the Gonionemus be brought into a solution with more $\mathrm{Ca}$ and less $\mathrm{Na}$ ions, some $\mathrm{Ca}$ ions will take the place of $\mathrm{Na}$ ions in the tissues, and this restores the irritability. But finally too many $\mathrm{Ca}$ ions enter, and the physical qualities are changed again, thus making the Gonionemus inirritable. If the same Gonionemus then be put into a pure $\mathrm{NaCl}$ solution or into a $\mathrm{NaCl}$ solution with fewer $\mathrm{Ca}$ ions, the $\mathrm{Na}$ ions will take the place of some of the $\mathrm{Ca}$ ions, and this will restore the irritability.

We thus arrive at the conclusion that the rhythmical contractions of Gonionemus depend upon the presence of $\mathrm{Na}, \mathrm{Ca}$, and $\mathrm{K}$ ions in definite proportions in the ion proteids of the tissues. These proportions evidently differ in various kinds of tissues. Myogenic contractions are prevented by a smaller amount of $K$ and $C a$ ions in the surrounding $\mathrm{NaCl}$ solutions than neurogenic contractions or contractions originating in parts containing ganglia. 
II. ON THE DIFFERENT EFFECTS OF IONS UPON UNDIFFERENTIATED EMBRYONIC TISSUE AND UPON MUSCLE

While the method established in the preceding section may be successfully applied to all kinds of tissues, I was most interested to know whether there is a marked difference between undifferentiated embryonic and differentiated older tissue. By embryonic protoplasm or tissue I mean the early egg-cells, the growing regions in plants and animals, rapidly growing tumors, regenerating parts or organs, in short, cells which are characterized by rapid multiplication. If we are ever to build up a technical or constructive, in the place of a merely analytical, biology, we shall be able to do it on the basis of a more thorough knowledge of the character of embryonic matter. I tried to find out whether the various metal ions have the same effect upon the undifferentiated egg-cells as upon muscle. These experiments throw some light upon another problem. The karyokinetic cell-division has been identified with phenomena of muscular contraction. We shall see incidentally how far such an idea is justifiable.

In my former experiments on development I was guided by the idea that the various morphological stages were preceded by chemical changes. In order to see how much justification there is for this idea I tried to discover whether lack of oxygen or an increase in the concentration of seawater affects the embryo differently in different stages of its development. ${ }^{1} \quad$ I used for these experiments the eggs of a marine fish (Fundulus). The eggs of this fish complete their development in about two weeks (at the proper temperature). We may discriminate three stages in the development of this fish. The first consists solely of processes of cell-division and the expansion of the blastoderm. This stage lasts about twenty-four hours. It is followed by the formation and beginning differentiation of the embryo during the second

1 Part I, p. 309. 
twenty-four hours. The third stage of development begins with the establishment of muscular activity, especially the heart-beat, about seventy-two hours after fertilization.

If newly fertilized eggs be exposed to a partial oxygen vacuum, the development may go on for some time (about twenty-four hours). The eggs, however, may remain alive in the oxygen vacuum for four days. If after that time they are put back into normal sea-water, they develop into normal fish, which hatch in due time. If we put an embryo which is three days old into the same oxygen vacuum, it loses its power of development within twenty-four hours. The older the embryo, the more deleterious is the lack of oxygen. This is comprehensible only on the assumption that the morphological differentiation is accompanied or preceded by changes in the chemical constitution of the embryo.

The same result was obtained in experiments in which the concentration of sea-water was raised by the addition of $\mathrm{NaCl}$, but curiously enough in this case the younger embryo was more sensitive to an addition of $\mathrm{NaCl}$ to sea-water than the older embryo. An addition of $5 \mathrm{~g}$. of $\mathrm{NaCl}$ to 100 c.c. of sea-water did not prevent the development of the Fundulus egg, but an addition of $10 \mathrm{~g}$. of $\mathrm{NaCl}$ to 100 c.c. of seawater prevented the formation of an embryo. Newly fertilized eggs began to segment in such a solution, but stopped very soon and lost their power of development permanently within from six to ten hours. A germ that was allowed to develop during the first twenty-four hours in normal seawater withstood much better a solution of sea-water to which 10 per cent. of $\mathrm{NaCl}$ had been added. In such a solution it could go on with its development for several days; in some cases as long as ten to fourteen days. An embryo which had been allowed to develop in normal sea-water until its circulation was established (third or fourth day) was even 
able to live for several days in sea-water to which $2 t$ per cent. $\mathrm{NaCl}$ had been added. When I made these experiments I still accepted the common view that $\mathrm{NaCl}$ was an indifferent substance, and that in these experiments it acted only osmotically. The results of my recent work and of experiments to be mentioned in this paper, however, prove that we have to deal with the effects of $\mathrm{Na}$ and $\mathrm{Cl}$ ions in these experiments. It therefore follows that the $\mathrm{Na}$ and $\mathrm{Cl}$ ions (especially the former) are more injurious during the earliest stages of cell-division than during the later stages. I made my new experiments on the effects of various ions upon development on the eggs of the same form.

If the eggs of Fundulus be put into a $\frac{5}{8} n \mathrm{NaCl}$ solution immediately after fertilization, the development stops in most cases at an early stage ( $6+$ to 128 cells) and only a few eggs form an embryo. If the development does not stop during the first twenty-four hours, it continues as a rule normally for one or more weeks. Hence a pure $\mathrm{NaCl}$ solution seems to be more poisonous during the first twenty-four hours of development than during the later stages. Control experiments verify this assumption. Eggs that were allowed to develop the first eighteen or twenty-four hours in sea-water, and are then put into a $\frac{5}{8} n \mathrm{NaCl}$ solution, continue to develop in almost every case. No embryo is able to hatch in these solutions.

In our previous paper we showed that a young fish died in a few hours in such a solution. The fact that the egg lives longer in it may be due either to the fact that the tough egg membrane does not allow the ions to penetrate so fast into the embryo, or to the presence of the yolk which to a certain extent may regulate the proportion of ions in the embryo.

If we dilute a $\frac{5}{8} n \mathrm{NaCl}$ solution with distilled water, we find that in a $\frac{1}{2} n \mathrm{NaCl}$ solution all the newly fertilized eggs may form an embryo. Some of the embryos even hatch in 
such a solution. Their duration of life after hatching is, however, very short. The fact that the eggs of Fundulus are able to develop in sea-water to which as much as 5 per cent. $\mathrm{NaCl}$ has been added shows that other constituents of the sea-water are able to counteract the poisonous effects of a pure $\mathrm{NaCl}$ solution. In a solution of 98 c.c. $\frac{5}{8} n \mathrm{NaCl}$ +2 c.c. $\frac{5}{8} n \mathrm{KCl}$ only a small number of embryos are formed. They cannot be kept alive for more than a week. In a solution of 98 c.c. $\frac{5}{8} n \mathrm{NaCl}+2$ c.c. $\frac{5}{8} n \mathrm{CaCl}_{2}$ every egg develops, but only in exceptional cases does the fish hatch. Those that hatch die immediately afterward. The addition of even as little as $\frac{1}{2}$ c.c. $\frac{10}{8} n \mathrm{CaCl}_{2}$ to 100 c.c. $\frac{5}{8} n \mathrm{NaCl}$ causes all the eggs to develop. A small amount of Ca ions counteracts the poisonous effect of a large quantity of $\mathrm{Na}$ ions sufficiently to allow the development to go on, but not enough to allow the embryos to hatch. In a solution of 96 c.c. $\frac{5}{8} n$ $\mathrm{NaCl}+2$ c.c. $\frac{10}{8} n \mathrm{CaCl}_{2}+2$ c.c. ${ }_{8} n \mathrm{KCl}$ not only all the eggs develop, but the young fish hatch and live indefinitely.

In distilled water all the eggs are able to develop, and the young fish hatch in due time and live indefinitely. Hence the $\mathrm{Ca}$ and $\mathrm{K}$ ions of the above-mentioned solution are not directly necessary for the development of the fish. They are only indirectly necessary to counteract the poisonous effects of the $\mathrm{Na}$ ions in a solution of a $\mathrm{Na}$ salt. In a glycerin solution of the same osmotic pressure as a $\frac{5}{8} n \mathrm{NaCl}$ solution, no embryo was formed. In mixtures of glycerin and sea-water embryos formed, but the glycerin acted as a poison; the more glycerin the solution contained, the quicker it killed them.

Thus far our results agree entirely with our previous results on the poisonous character of a pure $\mathrm{NaCl}$ solution. Such a solution has a poisonous effect on the germ of Fundulus, and the $\mathrm{Na}$ ions are exclusively or mainly responsible for the poisonous effect. But this poisonous 
effect is much more marked during the first twenty-four hours of development than during the later stages.

Everyone who has had experience with the effects of $\mathrm{KCl}$ upon the contraction of muscles knows how poisonous a pure $\mathrm{KCl}$ solution is. I was much surprised to find that a $\frac{5}{8} n$ $\mathrm{KCl}$ solution is even less harmful to the newly fertilized egg of Fundulus than a $\frac{5}{8} n \mathrm{NaCl}$ solution. More eggrs develop in the former than in the latter solution. The following table gives a clear illustration of this condition: Mixtures of $\frac{5}{8} n \mathrm{NaCl}$ and $\frac{5}{8} n \mathrm{KCl}$ solutions were used. Each solution had about seventy to eighty eggs. The percentage of eggs that formed embryos is indicated for each solution.

TABLE I

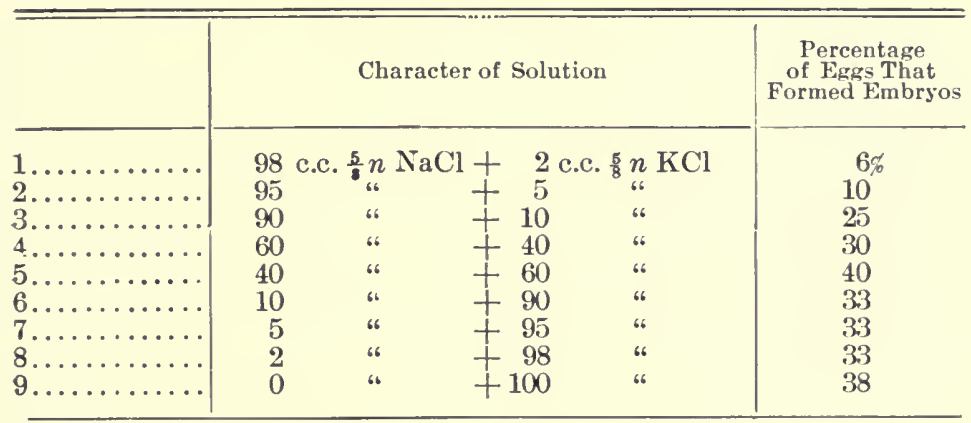

It is evident that if the number of $\mathrm{K}$ ions is greater than the number of $\mathrm{Na}$ ions, the percentage of eggs which are able to develop is larger. It is remarkable that in a solution of $98 \mathrm{NaCl}+2 \mathrm{KCl}$ fewer eggs from an embryo than in $95 \mathrm{NaCl}+5 \mathrm{KCl}$ or in $90 \mathrm{NaCl}+10 \mathrm{KCl}$, although in these last two solutions the amount of $\mathrm{KCl}$ is far in excess of that in sea-water. Hence we are forced to conclude that $\mathrm{K}$ ions are less poisonous for the earlier stages of Fundulus than $\mathrm{Na}$ ions. It is better for the egg that $\mathrm{K}$ ions enter into combination with the proteids of the protoplasm than $\mathrm{Na}$ ions. 
As soon, however, as the heart begins to beat and circulation becomes necessary for the embryo, the $\mathrm{K}$ ions become more poisonous than the Na ions. Only in the first three solutions is the heart of the embryo able to beat for a few days. But even in these solutions no embryo lives longer than about a week. In the other solutions the embryos die much earlier. This should certainly serve us as a caution in taking it for granted that the cell-division is due to contractile phenomena of the same order as those occurring in the muscle.

$\mathrm{Ca}$ ions are in small quantities more beneficial, in larger quantities more injurious, than $\mathrm{Na}$ ions. The addition of a little $\frac{10}{8} n \mathrm{CaCl}_{2}$ to a pure $\mathrm{NaCl}$ or a pure $\mathrm{KCl}$ solution causes all the eggs to develop, but very soon a limit in the addition of $\mathrm{CaCl}_{2}$ is reached where no more embryos are able to form. The following table shows this in a very marked way:

TABLE II

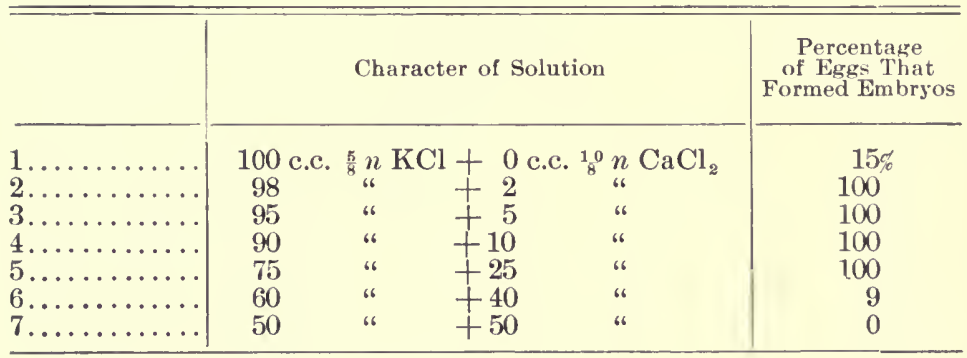

In none of these solutions was an embryo able to hatch or to live through the whole period necessary for development. The $\mathrm{K}$ ions in these solutions caused a cessation of the heart-beat. The more $\mathrm{K}$ ions the solution contained, the sooner this happened. In mixtures of $\mathrm{Na}$ and $\mathrm{Ca}$ ions the limit where $\mathrm{Ca}$ ions prevent the formation of an embryo is still lower. As a rule in a mixture of 75 c.c. $\frac{5}{8} n \mathrm{NaCl}+$ 25 c.c. $\frac{10}{8} n \mathrm{CaCl}_{2}$ no embryo is formed. 
It has long been maintained that there is an antagonism between $\mathrm{Ca}$ and $\mathrm{K}$ ions. The following experiment demonstrates this relation in a very striking way: If we mix 75 c.c. of sea-water with 25 c.c. $\frac{10}{8} n \mathrm{CaCl}_{2}$, as a rule only a very small percentage of the eggs are able to form an embryo. But if we add a large quantity of $\mathrm{KCl}$, almost every egg forms an embryo. In two experiments not a single embryo was formed in a mixture of 75 c.c. of sea-water +25 c.c. $\frac{10}{8} n$ $\mathrm{CaCl}_{2}$, while in 50 c.c. of sea-water +25 c.c. $\frac{10}{8} n \mathrm{CaCl}_{8}$ +25 c.c. $\frac{5}{8} n \mathrm{KCl}$ every egg formed an embryo. I have repeated this experiment very often, and in each case obtained similar results. But while the $K$ ions antagonized the poisonous effects of the Ca ions upon the formation of the embryo, the poisonous effects of the $K$ ions upon the heartbeat were not counteracted by the Ca ions. In none of the embryos formed in this solution was the heart able to beat sufficiently long to enable the embryo to complete its development. As a rule, on the sixth day every egg was dead.

In a pure $\frac{10}{8} n \mathrm{CaCl}_{2}$ solution the germ died in the early stages of segmentation (four- to eight-cell stages). It appeared to be coagulated. Not even in a mixture of equal parts of such a solution with distilled water was a single embryo formed. In a solution of 25 c.c. $\frac{10}{8} n \mathrm{CaCl}_{2}$ with 75 c.c. of distilled water embryos could be formed. In one case as many as 30 per cent. of the eggs contained embryos. This is the more remarkable as in a mixture of $7 \tilde{5}$ c.c. of sea-water $+2 \tilde{5}$ c.c. $\frac{10}{8} n \mathrm{CaCl}_{2}$ a much smaller percentage of eggs formed embryos. In a $\frac{1}{8} n \mathrm{CaCl}_{2}$ solution all the eggs formed embryos whose development was normal.

We should expect that if we put eggs immediately after fertilization into a pure solution of a Na salt whose anion precipitates calcium, the fatal effects of the $\mathrm{Na}$ ions upon the development would be still more obvious than in a pure $\mathrm{NaCl}$ solution. The precipitation of $\mathrm{Ca}$ ions in the protoplasm 
would accelerate the disproportion between the $\mathrm{Na}$ and $\mathrm{Ca}$ ions of the protoplasm. I tried $\frac{10}{8} n \mathrm{Na}_{2} \mathrm{SO}_{4}$ solution. In no experiment was a single embryo formed, and in each case the development of the germ stopped in an earlier stage than in the pure $\mathrm{NaCl}$ solution. This corroborates our view that the poisonous character of the pure $\mathrm{NaCl}$ solution is due to the fact that for the development of the egg the $\mathrm{Na}$, $\mathrm{Ca}$, and $\mathrm{K}$ ions must exist in definite proportions in the protoplasm.

In a pure $\frac{10}{8} n \mathrm{MgCl}_{2}$ solution no egg can develop. Even in equal parts of ${ }_{8}^{10} n \mathrm{MgCl}_{2}$ and distilled water only a small proportion of eggs ( 20 per cent.) were able to form embryos, none of which hatched. $\mathbf{M g}$ ions behave toward the egg of Fundulus very much like $\mathrm{Ca}$ and unlike $\mathrm{K}$ ions. In a solution of 98 c.c. $\frac{5}{8} n \mathrm{NaCl}+2$ c.c. ${ }_{8}^{10} n \mathrm{MgCl}_{2}$ all the eggs form embryos, although no fish hatch. But in larger quantities the $\mathrm{Mg}$ ions are not so poisonous as the Ca ions. Even in a mixture of equal parts of $\frac{5}{8} n \mathrm{NaCl}+\frac{10}{8} n \mathrm{MgCl}_{2}$ as many as 75 per cent. of the eggs form embryos (although none of the latter hatch). This behavior of the $\mathrm{Mg}$ ions is similar to the one described in my paper on the absorption of liquids. The above-mentioned experiments on the effects of $\mathrm{K}$ ions show very clearly that the effect of these ions upon celldivision is altogether different from their effect upon the rhythmical contractions. This is not only true for the cells of Fundulus, but also for the egg-cells of the sea-urchin. I intend to discuss the effect of ions upon the cell-division in the eggs of sea-urchins in the next paper.

\section{SOME GENERAL CONCLUSIONS}

1. The results of this paper bear upon several other problems which we have thus far had no chance to discuss sufficiently. There has been a controversy as to whether the contractions of the heart are myogenic or neurogenic. 
The problem is the same as for Gonionemus. In the latter it s certain that under ordinary circumstances $(i . e$., in the presence of the $\mathrm{K}$ and $\mathrm{Ca}$ ions of the sea-water), the impulses for the rhythmical contractions originate in the nerrous system, or at least in the margin. It is, howerer, not the histological or morphological structure of the ganglia which allows them to be so important, but their chemical constitution. The center of Gonionemus is able to beat rhythmically in a pure $\mathrm{NaCl}$ or $\mathrm{NaBr}$ solution. It is true that the center of Gonionemus (and the apex of the heart) contain single scattered ganglion cells. One might think that these latter are responsible for the rlyythmical contractions of the center which occur in pure $\mathrm{NaCl}$ or $\mathrm{NaBr}$ solutions. But the muscles of the skeleton (even if curarized) show rhythmical contractions in the same pure $\mathrm{NaCl}$ or $\mathrm{NaBr}$ solutions, provided the latter do not contain any $\mathrm{K}$ or $\mathrm{Ca}$ ions.

2. It would be unwarranted to say that $\mathrm{Ca}$ or any other ions are the cause of, or the stimulus for, the rhythmical contractions in Gonionemus, or the heart, or any other organ. It would be much nearer the truth to assume that for the possibility of rhythmical contractions the $\mathrm{Na}$, $\mathrm{Ca}$, and $\mathrm{K}$ ions must exist in definite proportions in the tissue which is expected to show rhythmical activity. Only so long as these proportions are preserved does the tissue possess such physical properties and such labile equilibrium as to be capable of rhythmical processes or contractions. If the tissue has permanently or temporarily more $\mathrm{Ca}$ and fewer $\mathrm{Na}$ ions than are required for the above-mentioned physical properties and condition of equilibrium, an increase of $\mathrm{Na}$ ions in the tissue will cause rhythmical contraction. In such a case the tissue will begin to contract rhythmically or beat at an increased rate in a pure $\mathrm{NaCl}$ solution. If the tissue, however, contains too many $\mathrm{Na}$ and too few $\mathrm{Ca}$ ions, a further increase of the latter in the tissue will cause the beginning 
of rhythmical contractions. In this case the addition of $\mathrm{Ca}$ ions to a pure $\mathrm{NaCl}$ solution will produce rhythmical activity. In a former paper I have shown that skeletal muscle can be caused to beat rhythmically if we increase the number of its $\mathrm{Na}$ ions without increasing the number of its $\mathrm{Ca}$ ions. In one of the next papers it will be proved that the same result can be obtained more rapidly if we decrease the number of Ca ions in the muscle by precipitating them.

3. The phenomena of muscular contractility and the phenomena of cell-division are considered by many authors as being of the same order. The rays of the astrosphere are said to be contractile fibrils which pull the chromosomes apart and accomplish the division of the mother-cell into two daughter-cells. I do not see how we can harmonize this hypothesis with the fact that enormous quantities of $K$ ions in no way interfere with the process of karyokinesis, while even a much smaller amount of $\mathrm{K}$ ions annihilates muscular activity in a very short time. In the preceding paper I mentioned the fact that the ciliary motion of the blastulæ of the sea-urchins continues in the presence of enormous quantities of $\mathrm{K}$ ions. The riddle of contractility is still unsolved. It yet remains to be proved that the ciliary motion and cell-division are due to contractile processes identical with those in the muscle. Our experiments on the effects of $\mathrm{K}$ ions should warn us against taking such an identity for granted.

4. While a solution of $\mathrm{NaCl}$ with a small amount of $\mathrm{K}$ and Ca ions allows all the various vital processes to go on (except such special phenomena as the formation of the skeleton, with which we shall deal in the next paper), we find other combinations of ions which enhance some of the vital processes, while they prevent others. The most important combination in this direction is the mixture of $\frac{5}{8} n \mathrm{KCl}$ with a small amount of $\frac{10}{8} n \mathrm{CaCl}_{2}$. In such a solution the first 
stages of the development of the Fundulus egg occur in a normal way. The fact that such a solution does not contain any $\mathrm{Na}$ ions raises the question whether the main importance of ions in these phenomena does not lie in the influence they have upon the physical qualities of the protoplasm (absorption of liquids, state of matter, etc.) If this were the case, we might easily understand that various mixtures of ions might bring about the same effect upon tissues, provided that they affect the physical qualities of the protoplasm in the same manner. In the next paper we shall show that the eggs of the sea-urchin can reach the blastula stage in a mixture of $\frac{10}{8} n \mathrm{MgCl}_{2}$ and $\frac{10}{8} n \mathrm{CaCl}_{2}$. But each of these vicarious mixtures serves only for a certain class of vital processes, while a mixture of $\mathrm{NaCl}$ with a small amount of $\mathrm{Ca}$ and $\mathrm{K}$ ions allows the whole cycle of life phenomena (with certain exceptions) to be completed.

5. Herbst ${ }^{1}$ has tried to prove that practically every substance contained in the sea-water is necessary for the development of the egg of the sea-urchin. His proof consisted chiefly in removing one of the constituents of the sea-water, and showing that in such modified sea-water the eggs were not able to develop. This method does not warrant the conclusions Herbst has drawn from them. In a solution of 96 c.c. $\frac{5}{8} n \mathrm{NaCl}+2$ c.c. $\frac{10}{8} \mathrm{CaCl}_{2}+2$ c.c. $\frac{5}{8} n \mathrm{KCl}$ all the $\mathrm{Fun}-$ dulus eggs develop and hatch. If we remove the $\mathrm{Ca}$ ions, the majority of Fundulus eggs cannot develop, and of the few that develop none hatch. According to Herbst it would follow that the surrounding medium must contain $\mathrm{Ca}$ ions for the development and hatching of the Fundulus eggs. Yet we have seen that the Fundulus egg develops and hatches in distilled water. Ca ions become a necessity only if the surrounding solution contains $\mathrm{Na}$ ions in excessive quantities.

1 Herbst, Archiv für Entwickelungsmechanik, Vol. V (189i), p. 649. 


\section{XXIX}

ON THE ARTIFICIAL PRODUCTION OF NORMAL LARV A FROM THE UNFERTILIZED EGGS OF THE SEAURCHIN (ARBACIA) ${ }^{1}$

\section{INTRODUCTORY REMARKS}

Eight years ago I published the results of some experiments on the effects of an increase in the concentration of sea-water upon the segmentation of the egg. I had found that the addition of a small quantity of $\mathrm{NaCl}$ to sea-water retarded segmentation in the egg of the sea-urchin. By increasing the concentration a point was soon reached where no further segmentation occurred. If one carefully selects the minimum increase in the concentration which is able to prevent the segmentation of the egg, and the eggs be kept in this solution for one or more hours, a peculiar phenomenon occurs. When put back into normal sea-water the eggs do not segment into two, four, eight cells, and so on, successively, but begin to divide into more than two cells very soon after being brought back into the sea-water. The longer the egg is kept in concentrated sea-water, the greater is the number of cells into which it breaks up at once. I repeatedly saw an undivided egg go into a morula stage within fifteen minutes after it was put back into the normal sea-water. I did not make a thorough histological examination of these eggs. Dr. Conklin was kind enough to stain a lot of eggs that had been in concentrated sea-water and which showed no trace of segmentation. "Some of these eggs showed very distinctly from four to about thirty nuclei; in other eggs the segmentation of the nucleus was not so perfect. The nucleus, extremely large, seemed to consist of

1 American Journal of Physiology, Vol. III (April 1, 1900), p. 434. 
Artificial Production of Normal Larye 577

several parts, which, howerer, were still connected." These histological examinations were not thorough enough, and it was my intention to have them continued. The explanation I gave for this phenomenon was as follows: "The segmentation of the protoplasm is the effect of a stimulus which the nucleus applies to the protoplasm and which makes the protoplasm close around the nucleus." On the other hand, if we put an egg into sea-water whose concentration has been raised by the addition of certain salts, the protoplasm loses water, and this loss of water brings about a loss of irritability. There is a certain concentration at which the nucleus is still able to divide, while the protoplasm loses its ability to respond to the stimuli enanating from the nuclei. This, it seemed to me, was what happened in the more concentrated sea-water. The nucleus divided, but the protoplasm had lost its irritability on account of the loss of water. Hence there existed a segmentation of the nucleus without a segmentation of the protoplasm. But as soon as such an egg was put back into normal sea-water the protoplasm began to take up more water and respond to the stimuli of the nucleus (these stimuli I considered to be chemical). Hence the protoplasm divided at once into as. many cells as there were nuclei preformed. ${ }^{1}$

The following year Morgan stated that he had repeated my experiments and confirmed them, but was unable to agree with me as regards the nuclear division. ${ }^{2}$ He found only one nucleus in the egg and concluded that no segmentation of the nucleus occurs in the concentrated sea-water, but that a rapid division of the nucleus occurs when the eggs are put back into normal sea-water. As he had made only four experiments in ail, I asked the late Professor Norman, who worked in my laboratory, to make a larger number of

1 Loes, Journal of Morphology, Vol, VII (1892), p. 253.

2 T. H. Morgax, Anatomischer Anzeiger, Vol. IX (1894), p. 141. 
experiments in order to find out whether there was a division of the nuclens without a segmentation of the protoplasm, and whether this division was mitotic. Norman found that by carefully selecting the concentration of the sea-water a division of the nucleus without a segmentation of the protoplasm occurred, and, moreover, that the division was mitotic. ${ }^{1}$ The number of cells into which the egg divides at once when brought back into normal sea-water is often larger than the number of the nuclei preformed in the concentrated seawater. It therefore seems as if a further division of the nuclear matter occurs immediately after the eggs are put back into normal sea-water. The addition of sodium chloride seemed to injure the eggs, and I asked $\mathrm{Mr}$. Norman to try the effects of other chlorides. He found that an increase in the concentration of sea-water by the addition of $\mathrm{MgCl}_{2}$ is less harmful than that of any other chloride.

It seems to me that it is necessary to discriminate in these experiments between two different effects produced by the addition of salts (or the increase of the concentration of seawater). The one effect is that produced on the nucleus and consists of a destruction (liquefaction?) of the nuclear membrane, and possibly a dissolution of the substance which binds the chromosomes together. This effect seems within certain limits to increase with the concentration of the seawater. The other effect consists in the gradual suppression of the motility of the protoplasm. This may possibly be due to a decrease in the fluidity of the protoplasm (water rigor). This effect also becomes stronger with the increase in the concentration of the sea-water. At a certain point in the increase of the concentration the nuclear membrane will be dissolved and the chromosomes scattered (through protoplasmic motions), while the protoplasm is no longer able to undergo segmentation. This was observed by Norman. If

1 W. W. Normax, Archiv für Entwickelungsmechanik, Vol. III (1836), p. 106. 
Artificial Production of Norial Larve 579

the concentration is a little higher, the dissolution of the nuclear membrane occurs, but the protoplasm on account of its rigor is unable to scatter the chromosomes and to segment. If such eggs be put back into normal sea-water, the protoplasm gradually loses its condition of rigor. The motions that lead to the scattering of chromosomes return sooner than the ability to segment. In such cases the process probably occurs in the form in which Morgan observed it. There may be intermediate stages and variations.

I mention these experiments mainly for the reason that they led Morgan to a very important step, namely, to try the effect of an increase in the concentration of sea-water upon unfertilized eggs. He found that eggs that were put into sea-water whose concentration had been raised by the addition of $1 \frac{1}{2}$ per cent. $\mathrm{NaCl}$ or $3 \frac{1}{2}$ per cent. $\mathrm{MgCl}_{2}$ began to segment into two or more cells when put back into normal seawater. This segmentation went in some cases about as far as the sixty-four-cell stage, but then the development stopped. ${ }^{1}$

Meade made the observation that the unfertilized eggs of Chrtopterus could be caused to throw out the polar bodies by the addition of a small amount of $\mathrm{KCl}$ to sea-water. The addition of $\mathrm{NaCl}$ had no such effect. ${ }^{2}$ Last year Dr. Mathews made an experiment with rennet ferment which he did not publish. In a previous paper on the origin of fibrinogen he had expressed the idea that the origin of the astrospheres in a cell was due to a process of coagulation. He tried the effect of rennet ferment upon unfertilized eggs of the sea-urchin to see whether he could in this way cause the egg to develop. The eggs were put into a solution of rennet tablet and when taken out began to segment, but the development did not go beyond the division into a comparatively small number of cells. The phenomenon

I T. H. Morgax, Archiv für Entwickelungsmechanik, Vol. VIII (1899), p. 448.

$2 \mathrm{MEAD}$, Lectures delivered at Woods Hole, 1595 (Boston: Ginn \& Co.). 
resembled the one described by Morgan to such an extent that Mathews came to the conclusion that it was not the rennet which acted in his experiments, but the salts in the rennet tablets. In other words, it was practically the increase in the concentration of the sea-water which brought about the segmentation of the unfertilized egg, just as in Morgan's experiment.

There are some earlier observations concerning the fact that unfertilized eggs may show the beginnings of segmentation. Hertwig mentions, ${ }^{1}$ that the eggs of Arthropods, Echinoderms, and Annelids show a beginning of segmentation when left in sea-water for a long time (about twenty hours). Tichomirof is quoted as having produced artificially a beginning of development in the eggs of Bombyx. But these eggs are naturally parthenogenetic. Nussbaum ${ }^{2}$ has repeated these experiments, and, as far as I can see, the unfertilized eggs of Bombyx seem to develop naturally just as well as with the treatment given them by Tichomirof. There is a statement by Dewitz ${ }^{3}$ that treatment with corrosive sublimate causes the eggs of a frog to show a beginning of segmentation, but, if, I am not mistaken, Dewitz made no sections through these eggs, and he himself expressed his doubts to me as to whether there was a real segmentation, or whether the surface of the egg simply resembled that of segmented eggs.

Kulagin recently made the following statement: "I exposed unfertilized eggs of fish and amphibians to diphtheria antitoxin, and noticed in many the process of segmentation." 4 As this one sentence is all he has published about his experiments, it is impossible to express an opinion concerning them. If there was a real segmentation, it still remains an

1 O. Hertwig, Die Zelle und die Gewebe, Vol. I, p. 239.

2 M. Nussbaum, Archiv für mikroshopische Anatomie, Vol. LIII (1899), p. 44.

3. J. Dewitz, Biologisches Ccntralblatt, Vol. VII (1887), p. 93.

4 KulaGix, Zoologischer Anzeiger, Vol. XXI (1898), p. 653. 
open question whether it was not caused by the salts of the serum. This constitutes about all the data existing at the time I started my experiments. ${ }^{1}$

I had in the meantime made my experiments on the effects of ions upon the rhythmical contractions of muscle, and reached the conclusion that by changing the ions contained in a tissue we can impart to it qualities which it does not ordinarily possess. ${ }^{2}$ I concluded that it might be possible to produce blastulæ, or even plutei, from an unfertilized egg by merely changing the ions in the egg. Such changes were possible in three ways: first, by altering the qualitative constitution of the sea-water without altering its total osmotic pressure; second, by altering its osmotic pressure by the addition of certain salts; and, third, by combining both methods. The last way led to positive results.

I began my experiments with a study of the effects of various ions on the development of the fertilized egg.

\section{THE EFFECTS OF VARIOUS IONS UPON THE FERTILIZED EGGS OF ARBACIA}

The eggs were fertilized in normal sea-water, and after five minutes were put into the various solutions. The greatest care was used with the eggs, and as little sea-water as possible was added to the artificial solution to be tested. The eggs were collected in vessels in such a way as to form a thick layer. One or two drops from a pipette gave all the eggs needed for an experiment. These two drops consisted chiefly of eggs with the minimum amount of sea-water. The volume of each of the artificial solutions was 100 c.c.

One chloride in solution.-In a $\frac{5}{8} n \mathrm{NaCl}$ solution 10 , 20 , and in one case 50 per cent. of the eggs began to segment. They very rarely reached the sixteen-cell stage. The majority

1 I should have mentioned also the observations made by R. Hertwig, that by adding strychnin to sea-water the eggs of the sea-urchin can be caused to show the first segmentation. [1903]

2 Part II, p. 518. 
of the eggs stopped developing at the two-cell stage. The size of the cells was as a rule unequal from the beginning.

In a mixture of 90 c.c. of this solution with 10 c.c. of distilled water about 80 per cent. of the eggs developed, some of which even reached the thirty-two-cell stage. In making more dilute solutions fewer eggs segmented, and in solutions that were more dilute than a mixture of 70 c.c. $\frac{5}{8} n \mathrm{NaCl}+40$ c.c. distilled water as a rule no eggs segmented. This was not due to the reduction in the osmotic pressure, for in a solution of 70 c.c. $\frac{5}{8} n \mathrm{NaCl}+30$ c.c. of cane sugar of the same osmotic pressure but very few eggs began to segment. They did not develop beyond the four-cell stage. In equal parts of the $\mathrm{NaCl}$ and the sugar solution not an egg segmented.

In a $\frac{5}{8} n \mathrm{KCl}$ solution about $70-80$ per cent. of the eggs segmented, and many reached the eight-cell stage. A slight dilution of the $\mathrm{KCl}$ allowed the eggs to reach the thirty-twocell stage. Even in a mixture of 60 c.c. $\mathrm{KCl}$ and 40 c.c. distilled water about 5 per cent. of the eggs began to segment, but reached only the two- or four-cell stage. In more dilute solutions no segmentation occurred. The cleavage cells were more equal in size than in the $\mathrm{NaCl}$ solutions. It is obvious that a pure $\mathrm{KCl}$ solution is more favorable for segmentation than the pure equimolecular $\mathrm{NaCl}$ solutions. In a former paper I published a similar observation on the Fundulus egg.

In a $\frac{10}{8} n \mathrm{MgCl}_{2}$ solution the eggs reached the thirtytwo-cell stage, and in more diluted solutions, for instance 50 c.c. $\mathrm{MgCl}_{2}+50$ c.c. of distilled water, the development went even farther (sixty-four cells or more). But the various experiments with a pure $\mathrm{MgCl}_{2}$ solution varied somewhat in their results. On the whole, the $\mathrm{MgCl}_{2}$ was more favorable than the $\mathrm{KCl}$ or $\mathrm{NaCl}$.

In a $\frac{10}{8} n \mathrm{CaCl}_{2}$ solution there was at the best only the beginning of a segmentation. In a mixture of 90 c.c. 
$\frac{10}{8} n \mathrm{CaCl}_{2}$ with 10 c.c. of distilled water I occasionally saw an egg in the two-cell stage. In more dilute $\mathrm{CaCl}_{2}$ solutions no trace of a segmentation occurred. Hence $\mathrm{Mg}$ and $\mathrm{K}$ were more farorable than $\mathrm{Na}$ and $\mathrm{Ca}$ ions for the concentration used in the experiments. It is very evident from these experiments that the optimum concentration for each of these four chlorides is different.

In a $\frac{5}{8} n \mathrm{LiCl}$ solution the majority of eggs remained unsegmented, and only very few reached the two-cell stage. Mixtures of $\mathrm{LiCl}$ with sugar were no more advantageous. In pure glycerin and sugar solutions of the same osmotic pressure as that of a $\frac{5}{8} n \mathrm{NaCl}$ solution no egg segmented. It is evident that the quality of the ions is of more importance in these experiments than the osmotic pressure, and that $\mathrm{NaCl}$ is not an indifferent substance.

Two chlorides in solution.- - In a solution of one chloride the eggs of Arbacia cannot reach the blastula stage. Are mixtures of two chlorides more favorable for segmentation? Among the possible mixtures of the two chloride solutions of the same osmotic pressure as the sea-water I found those between $\frac{10}{8} n \mathrm{MgCl}_{2}$ and $\frac{10}{8} n \mathrm{CaCl}_{2}$ the most favorable. The following twelve mixtures were prepared: ${ }^{1}$

(1) 100 c.c. ${ }_{8}^{10} n \mathrm{MgCl}_{2}+0$ c.c. ${ }_{8}^{10} n \mathrm{CaCl}_{2}$

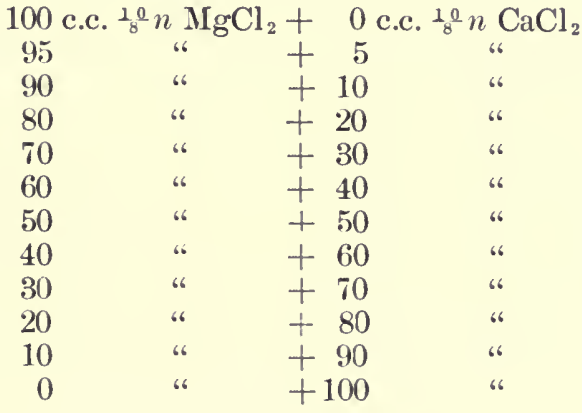

${ }^{1}$ It will save repeating these figures if I may state here that the same twelve proportions were used in all the following experiments with two chlorides in solution. 
In the first solution the eggs reached the thirty-two-cell stage. In the second, third, and fourth solutions they formed blastulæ, which, however, did not move. I first thought that for the motility of the cilia the presence of other ions might be required, but I found that blastulæ that had developed in normal sea-water continued their motion for two days in a solution of 80 c.c. of $\frac{10}{8} n \mathrm{MgCl}_{2}+20$ c.c. of seawater. It is possible, however, that in such a solution cilia cannot be formed. I placed a lot of these eggs that had reached the blastula stage in a mixture of $\mathrm{MgCl}_{2}$ and $\mathrm{CaCl}_{2}$ in normal sea-water. The next morning they moved about in the most lively manner. It is certainly contrary to the current ideas concerning adaptation that the egg of Arbacia should reach the blastula stage in a solution which is practically free from $\mathrm{Na}$ ions.

In the fifth solution only very few eggs segmented and reached the eight-cell stage, while the other solutions were still worse. The segmentation was more regular the more $\mathrm{Mg}$ the solution contained, and became more irregular the more the $\mathrm{Ca}$ ions predominated. One of the chief features of this irregularity was the unequal size of the cleavage cells. As in certain eggs the unequal size of the cleavage cells is a characteristic feature which plays a great rôle in the theories of development, it is of interest that such differences can be brought about through the presence of a certain quantity of definite ions, especially of $\mathrm{Ca}$ and $\mathrm{Na}$ ions.

In the mixtures of $\frac{5}{8} n \mathrm{NaCl}$ with $\frac{10}{8} n \mathrm{MgCl}_{2}$ the results were not so good. No swimming blastulæ were formed. In solutions of 90 to 30 c.c. of $\mathrm{MgCl}_{2}$ with 10 to 70 c.c. of $\mathrm{NaCl}$ a morula stage was reached.

Mixtures of $\frac{10}{8} n \mathrm{MgCl}_{2}$ with $\frac{5}{8} n \mathrm{KCl}$ were still less favorable. The solutions with more $\mathrm{MgCl}_{2}$ than $\mathrm{KCl}$ reached the thirty-two-cell stage, or even went a little farther in their development. 
Mixtures of $\frac{5}{8} n \mathrm{KCl}$ with ${ }_{8}^{10} \mathrm{CaCl}_{2}$ allowed only the beginning of the segmentation, and this only as long as $\mathrm{CaCl}_{2}$ was used in very small quantities. In 96 c.c. $\mathrm{KCl}+4$ c.c. $\mathrm{CaCl}_{2}$ one egg in a thousand went into the two-cell stage, or formed two large cells with two micromeres; but in 90 c.c. $\mathrm{KCl}+10$ c.c. $\mathrm{CaCl}_{2}$ not one egg segmented, and the solutions with more $\mathrm{Ca}$ were not more favorable.

A combination of $\frac{5}{8} n \mathrm{NaCl}$ with $\frac{10}{8} n \mathrm{CaCl}_{2}$ was equally poisonous. Even in 98 c.c. $\mathrm{NaCl}+2$ c.c. $\mathrm{CaCl}_{2}$ the eggs did not go beyond the beginning of the segmentation, and in 96 c.c. $\mathrm{NaCl}+4$ c.c. $\mathrm{CaCl}_{2}$ the eggs died in the four-cell stage. It is worthy of mention that in these solutions the cleavage cells were very unequal in size.

Mixtures of $\frac{5}{8} n \mathrm{KCl}$ and $\frac{5}{8} n \mathrm{NaCl}$ were, on the other hand, almost as farorable as the $\mathrm{MgCl}_{2}$ solutions. In 98 c.c. $\mathrm{NaCl}+2$ c.c. $\mathrm{KCl}$ the eggs reached the sixty-four-cell stage or went even beyond this. It was the same in 96 c.c. $\mathrm{NaCl}+4$ c.c. $\mathrm{KCl}$ for almost every egg divided. With more $\mathrm{KCl}$ and less $\mathrm{NaCl}$ the results were less favorable. In a former paper we pointed out that the comparative harmlessness of $\mathrm{K}$ ions for the phenomena of cell-division is in striking contrast with the harmfulness of the same ions for the phenomena of muscular contraction. We thus see that the following two combinations of two chlorides in solution are the most favorable for development: (1) 90 c.c. $\frac{10}{8} n \mathrm{MgCl}+10$ c.c. $\frac{10}{8} n \mathrm{CaCl}_{2}$; and (2) 98 c.c. $\frac{5}{8} n \mathrm{NaCl}+2$ c.c. $\frac{5}{8} n \mathrm{KCl}$.

Three chlorides in solution.--Neither with one nor with two chlorides in solution was it possible to obtain swimming blastulæ. From the experience with Fundulus ${ }^{1}$ I expected that a combination of three metal ions (especially $\mathrm{NaCl}$. with small amounts of $\mathrm{KCl}$ and $\mathrm{CaCl}_{2}$ ) would allow the eggs of the sea-urchin to complete their development.

1 Part II, p. 5.4. 
This was indeed the case. In a mixture of 96 c.c. $\frac{5}{8} n \mathrm{NaCl}$ +2 c.c. $\frac{5}{8} n \mathrm{CaCl}_{2}+2$ c.c. $\frac{5}{8} n \mathrm{KCl}$ the eggrs not only reached the blastula stage and swam around in the most lively way, but they reached the gastrula and even pluteus stage, with the exception, however, that practically no skeleton was formed. Such larvæ lived for about ten days in this solution!

We might think that the $\mathrm{NaCl}$ is an indifferent substance, and that the $\mathrm{Ca}$ and $\mathrm{K}$ ions are responsible for the effect. From what has been shown in the foregoing papers of this series it follows that this assumption is erroneous. The same can be proved again directly for this case. I had canesugar and glycerin solutions prepared of the some osmotic pressure as a $\frac{5}{8} n \mathrm{NaCl}$ solution. Table I gives the results of a series of experiments.

TABLE I

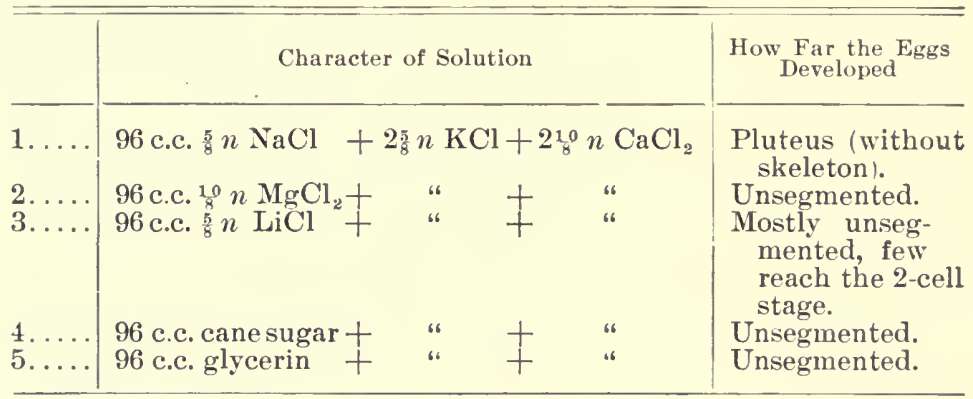

The results could not be more striking. $\mathrm{MgCl}_{2}$ is more favorable for the segmenting egg than $\mathrm{NaCl}$, but still with the addition of $\mathrm{Ca}$ and $\mathrm{K}$ ions not an egg segments! These experiments prove once more that the conception formed in the previous papers is correct, namely, that a pure $\mathrm{NaCl}$ solution is poisonous, and that it requires a small amount of both $\mathrm{Ca}$ and $\mathrm{K}$ ions to antagonize the poisonous effect of a $\mathrm{NaCl}$ solution. It seems that for the egg of a sea-urchin the three metal ions in the above-mentioned proportion give the colloids those physical properties which allow them to go 
through the changes of cell-division and assimilation required for the process of development. I next tried whether it was necessary that the $\mathrm{Ca}$ and $\mathrm{K}$ ions be added in equal proportions to the $\mathrm{NaCl}$. Table II gives the results of such experiments.

It is obvious that the proportion of $\mathrm{K}$ and $\mathrm{Ca}$ ions may vary within certain limits as long as they are present in sufficient quantity. I will add that I have not yet found any other combination of three chlorides that yields swimming blastulæ. In the foregoing papers I mentioned that the anions are not indifferent, and that in a $\mathrm{NaBr}$ solution the rlythmical contractions of a muscle begin even sooner than in an equimolecular $\mathrm{NaCl}$ solution. I made some experiments on the effect of bromides on development. In a solution of 96 c.c. $\frac{5}{8} n \mathrm{NaBr}+2$ c.c. $\frac{5}{8} n \mathrm{KCl}+2$ c.c. $\frac{10}{8} n \mathrm{KCl}$ the eggs developed into normal blastula. In a solution of 96 c.c. $\mathrm{LiBr}+2$ c.c. $\mathrm{CaCl}_{2}+2$ c.c. $\mathrm{KCl}$ the eggs reached the sixteen-cell stage, while in the corresponding $\mathrm{LiCl}$ solution practically no segmentation took place. All these ex-

TABLE II

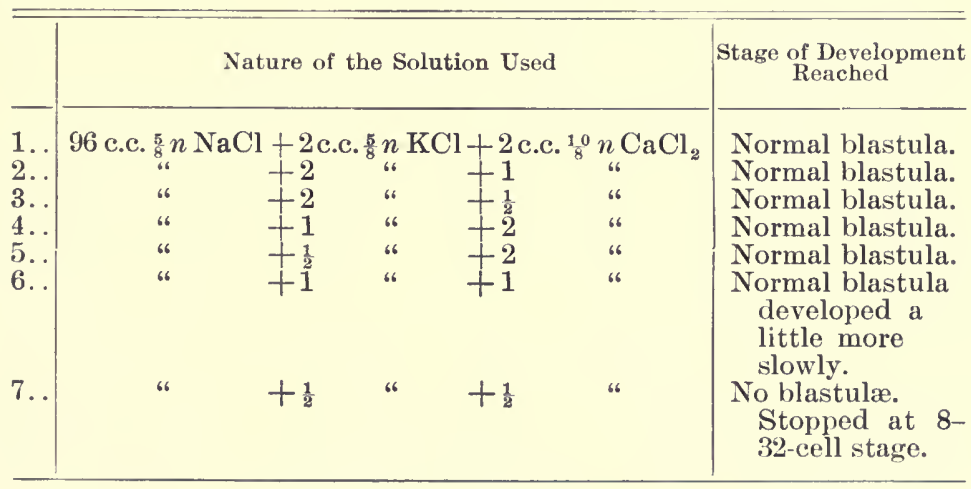

periments together give us the impression that different combinations of ions may exist which all have the same effect. 
It seems as if the physical condition of the colloids was the essential point, and that this might be affected by various ion combinations in the same vay.

Solutions which allow the formation of a skeleton. - The next question was what ions should be added to the abovementioned solutions in order to obtain plutei with a skeleton.

A

B

1.

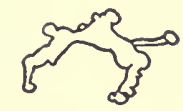

1.
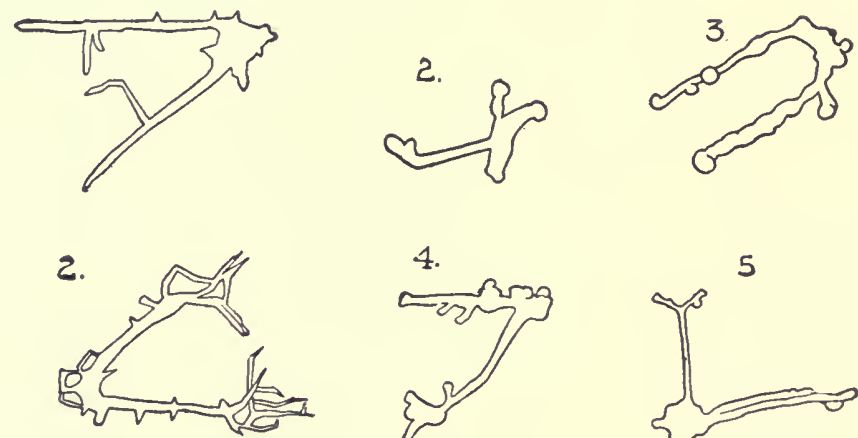

4.
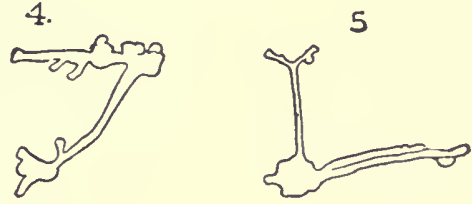

FIG. 147

I found that a trace of $\mathrm{Na}_{2} \mathrm{CO}_{3}$ has that effect. In a solution of 95 c.c. $\frac{5}{8} n \mathrm{NaCl}+2$ c.c. $\frac{10}{8} n \mathrm{CaCl}_{2}+1$ c.c. $\frac{5}{8} n \mathrm{KCl}$ +1 c.c. $\frac{1}{8} n \mathrm{NaCO}_{3}$ a skeleton was formed within three days. This skeleton was not quite normal. It showed a formation of knobs and spheres which I never saw in the skeleton formed in normal sea-water (Fig. $147 \mathrm{~B}$ ). I was anxious to obtain plutei with normal skeletons, and succeeded in doing so by adding a trace of $\mathrm{MgCl}_{2}$ to the above-mentioned solution. The solution which yielded plutei with a normal skeleton consisted of 95 c.c. $\frac{5}{8} n \mathrm{NaCl}+1$ c.c. $\frac{10}{8} n \mathrm{M}_{6} \cdot \mathrm{Cl}_{2}+1$ c.c. $\frac{5}{8} n$ $\mathrm{KCl}+2$ c.c. $\frac{10}{8} n \mathrm{CaCl}_{2}+1$ c.c. $\frac{1}{8} n \mathrm{Na}_{2} \mathrm{CO}_{3}$. The skeleton is sketched in Fig. 147, $A$. It was therefore evident that 
a small amount of $\mathrm{Na}_{2} \mathrm{CO}_{3}$ allowed the formation of a skeleton. The addition of $\mathrm{Na}_{2} \mathrm{CO}_{3}$ causes an addition of $\mathrm{HO}$ ions as well as of $\mathrm{CO}_{3}$ ions. Which of the two are responsible for the formation of a skeleton? The substitution of $\mathrm{KHO}$ for the $\mathrm{Na}_{2} \mathrm{CO}_{3}$ did not allow the formation of a skeleton. We must therefore conclude that it is the $\mathrm{CO}_{3}$ ion which is essential. ${ }^{1}$

Conclusions. -We thus see that a mixture of 96 c.c. $\frac{5}{8} n$ $\mathrm{NaCl}($ or $\mathrm{NaBr})+2$ c.c. $\frac{5}{8} n \mathrm{KCl}+2$ c.c. $\frac{10}{8} n \mathrm{CaCl}$ is sufficient to allow the fertilized egg of Arbacia to develop into the gastrula stage. But does this force us to conclude that the three kations $\mathrm{Na}, \mathrm{K}$, and $\mathrm{Ca}$ are utilized by the egg for the process of development? I think that our previous experiments on Fundulus ${ }^{2}$ may serve as a criterion in answering the question. In a pure $\mathrm{NaCl}$ solution the young fish died rapidly, while in the above-mentioned mixture they remained alive. And yet this same fish could live indefinitely in distilled water. This proves that it does not require any ions from the surrounding medium. It might be possible that only $\mathrm{Na}$ ions were needed for the development of the sea-urchin egg. In this case the $\mathrm{K}$ and $\mathrm{Ca}$ ions would have to be present in order to prevent the poisonous effects which a pure $\mathrm{NaCl}$ solution would produce. On the other hand, we found that in a mixture of $\mathrm{MgCl}_{2}$ and $\mathrm{CaCl}_{2}$ which is practically free from $\mathrm{Na}$ ions the eggs can develop and almost reach the blastula stage. This makes it still more difficult to state positively that the $\mathrm{Na}$ ions of the surrounding medium are needed for the development of the sea-urchin egg. Perhaps it is safest to assume that for the process of cell-division and development a certain physical conditiona certain labile equilibrium - of the protoplasm of the col-

1 For further facts concerning the formation of a skeleton in sea-urchins see Herbst, Archiv für Entwickelungsmechanik, Vol. II (1896), p. 45j; and DrIEsch. ibid., Vol. IX (1899), p. 137.

2 Part II, p. 544. 
loids has to be maintained. This requires certain ions in definite proportions, either $\mathrm{Na}, \mathbf{K}$, and $\mathrm{Ca}$ (or other combinations, for instance $\mathrm{Mg}$ and $\mathrm{Ca}$ ). Distilled water is a poison for the eggs of Arbacia. Hence, if $\mathrm{Na}$ be one of the ions of the surrounding solution, $\mathrm{Ca}$ and $\mathrm{K}$ ions are likewise required.

My results differ somewhat from those obtained by Herbst. ${ }^{1}$ But I pointed out in my last paper that Herbst was misled by his method. ${ }^{2}$ This method consisted in making a solution of the same complication as the seawater, in which, however, one constituent was omitted. In case the eggs did not develop in such a solution, this was considered a proof that the constituent omitted was necessary for the development of the eggs. My experiments show that this conclusion is not correct. It is quite possible that the substance which was omitted or removed was not directly necessary for the egg, but only indirectly, inasmuch as it served to counteract the poisonous effects of another constituent of the solution.

It seems to me that my experiments necessitate the introduction of a new conception, namely, that of physiologically balanced salt solutions. By this I mean salt solutions which contain such ions and in such proportions as completely to annihilate the poisonous effects which each constituent would have if it were alone in solution. Sea-water and blood (and approximately a mixture of 96 c.c. $\frac{5}{8} n \mathrm{NaCl}+2$ c.c. ${ }_{8}^{10} n$ $\mathrm{CaCl}_{2}+2$ c.c. $\frac{5}{8} n \mathrm{KCl}$ ) are physiologically balanced salt solutions.

It will be necessary to investigate how far the conclusions of pharmacologists, botanists, and bacteriologists concerning the effects of various salts require a correction on the basis of these new facts and conceptions. Their consideration might even prove of use in problems of inımunity and adaptation.

${ }^{1}$ Herbst, loc. cit., Vol. V (1897), p. 649.

2 Part II, p. 559. 
Artificial Production of Normal Larve 591

III. IS IT POSSIBLE TO PRODUCE BLASTLLE FROM UNFERTILIZED EGGS WITHOUT RAISING THE CONCENTRATION OF THE SEA-WATER?

The early experiments with which I started had indicated that an increase in the concentration of the sea-water caused the segmentation of the nucleus in the fertilized egg. Morgan's experiments had shown that the same influence may cause the unfertilized egg to show a beginning of segmentation. In Mead's experiments, however, there was practically no increase in the osmotic pressure of the sea-water, while the nature of the ions seemed to determine the result. I wished to find out whether a blastula could be secured from an unfertilized egg without raising the concentration (the total osmotic pressure) of the sea-water. All my experiments thus far have yielded the result that this is impossible, and that by this method only a beginning of a segmentation can be produced in an unfertilized egg. It goes without saying that in these experiments bacteriological precautions are necessary to guard against the possibility of the introduction of spermatozoa by the instruments, or of their presence in the sea-water. One has a pretty reliable criterion for the entrance of a spermatozoon into the egg of Abacia in the formation of the egg membrane. An unfertilized egg has no distinct membrane, but immediately after the fertilization a very distinct and rather thick membrane is formed. As none of the eggs in the following experiment formed a membrane or showed more than the beginning of a segmentation, we may reserve the discussion of 'our methods of protection against fertilization for the next section. Unfertilized eggs of the same female were divided into three lots. One was put into a solution of 96 c.c. $\frac{5}{8} n \mathrm{NaCl}+2$ c.c. $\frac{5}{8} n \mathrm{KCl}+$ 2 c.c. ${ }_{8}^{10} n \mathrm{CaCl}_{2}$. After three and one-half hours a few of the eggs showed a beginning of segmentation. After eight hours a majority of the eggs had divided into from 2 to 4 
cells. Some had even gone a little farther. ${ }^{1}$ But then the segmentation stopped. No egg had a membrane. A second lot was put into normal sea-water. Eight hours later none of these eggs had segmented or had a membrane. This indicates that a mere change in the constitution of the seawater without any change in the osmotic pressure may cause the beginning of a segmentation of the egg. A third lot was put into a solution of 96 c.c. ${ }_{8}^{10} n \mathrm{MgCl}_{2}+2$ c.c. ${ }_{8}^{10} n \mathrm{CaCl}_{2}+$ 2 c.c. $\frac{5}{8} n \mathrm{KCl}$. No egg segmented. One lot of these eggs was put back into normal sea-water five hours later. A few eggs now went into the two-cell stage, but developed no farther.

In a mixture of 75 c.c. $\frac{10}{8} n \mathrm{MgCl}_{2}$ with 25 c.c. distilled water a small number of unfertilized eggs segmented. In equal parts of $\frac{10}{8} n \mathrm{MgCl}_{2}$ and $\frac{5}{8} n \mathrm{NaCl}$ no eggs segmented.

In Mead's experiments it was $\mathrm{KCl}$ that caused the eggs of Chætopterus to throw out their polar bodies. I put unfertilized eggs of Arbacia first into sea-water for five hours. No eggs showed a trace of beginning segmentation. After this the eggs were put for two hours into a mixture of 90 c.c. sea-water and 10 c.c. $\frac{5}{8} n \mathrm{KCl}$. When put back into normal sea-water, in fifteen minutes almost every other egg began to divide, but the segmentation never went beyond the sixteen-cell stage at the best. Neither these nor the abovementioned experiments gave constant results. The greatest differences existed in the proportion of eggs that showed a segmentation. In a former paper I had proved that the addition of a small amount of $\frac{1}{10} n \mathrm{NaHO}$ caused an increase in the rate of development and growth of the unfertilized Arbacia egg, while the equally small addition of an acid $(\mathrm{HCl})$ produced the opposite effect. This summer I tried the effect of $\mathrm{HO}$ and $\mathrm{H}$ ions upon the unfertilized egg. The following solutions were prepared:

I I am now inclined to believe that the normal concentration of the sea-water was slightly less than that of a $5 n \mathrm{NaCl}$ solution, and that this beginning of a i arthenogenetic development was due to the fact that the solution used was slightly hycertonic. [1903] 
Artificial Production of Noralal Larve 593

(1) 99 c.c. sea-water +1 c.c. $\frac{1}{10} n \mathrm{KHO}$

(2) 98 " $\quad+2$ "

(3) $99 \quad$ " $\quad+1$ c.c. $\frac{1}{19} n \mathrm{HCl}$

(4) 98

(5) 97

" +2 "

" +3 "

In solution 1 almost every egg was in segmentation five hours later, but the segmentation was very irregular and often incomplete, and the egg showed very lively amœboid motions. Never more than 10 cells were formed. In solution 2 the effects were similar, but fewer eggs segmented. The segmentation did not go any farther. In solutions 3, 4 , and 5 not an egg showed any trace of segmentation, nor did any egg in the normal sea-water segment.

Some of the eggs that were put into solutions 4 and 5 were left there only ten minutes, and then brought back into normal sea-water. Five hours later many of these eggs had begun to segment. The segmentation did not go beyond the first cell-division. It should be said that the sea-water naturally contains some free $\mathrm{HO}$ ions. After a short treatment with acid the $\mathrm{HO}$ ions in the sea-water were able to produce an effect which they could not have had if the acid treatment had not been applied.

None of these experiments, however, led to the formation of a blastula, nor did they offer any promise of the possibility of producing blastulæ in an artificial way. The experiments were made at various periods of the spawning season. After these and some other unpromising attempts I tried whether an increase in the concentration of sea-water would yield better results than a mere change in the proportion of the ions. Instead of using $\frac{5}{8} n \mathrm{NaCl}$ and $\mathrm{KCl}$ and $\frac{10}{8} n \mathrm{CaCl}_{2}$ and $\mathrm{MgCl}_{2}$ solutions I now tried $\frac{10}{8} n \mathrm{NaCl}$ and $\mathrm{KCl}$ and ${ }_{8}^{20} n \mathrm{MgCl}_{2}$ and $\mathrm{CaCl}_{2}$ solutions. I do not wish to give an account of all the experiments $I$ made in this direction, but prefer to confine myself to an account of one 
experiment which led me in the right direction. In this experiment the following four mixtures were used:

(1) 60 c.c. $\frac{20}{8} n \mathrm{MgCl}_{2}+40$ c.c. of sea-water

(2) 60 c.c. ${ }_{8}^{10} n \mathrm{KCl}+$

(3) 60 c.c. ${ }^{10}{ }^{0} n \mathrm{NaCl}+$

(4) 60 c.c. $\frac{20}{8} n \mathrm{CaCl}_{2}+$

A lot of unfertilized eggs were distributed in these four solutions, and remained in the same for one hour and fifty minutes. They were then brought back into normal seawater. The eggs that had been in the first $\left(\mathrm{MgCl}_{2}\right)$ solution began to show an amœboid change of form (indicative of a segmentation) in about fifteen mimutes after they were brought back into normal sea-water. About one in a thousand eggs were in this amoboid stage. One does not see such changes in the normal egg where the membrane limits the amoboid motions. Fifty minutes later one in a thousand eggs divided into 2 or 3 cells. The cells were of about equal size. About two and one-half hours after the eggs had been put back into normal sea-water about one egg in five hundred had segmented, and the segmentation had proceeded to the eight-cell stage, although not all the eggs had reached this stage. But then the development stopped. The next morning the eggs were still without any membrane. All looked normal and healthy. In this experiment the volume of normal sea-water into which the eggs were put after they had been in the $\mathrm{MgCl}_{2}$ solution was small (only a watchglass full). Hence the few drops of the $\mathrm{MgCl}_{2}$ solution which were transferred with the eggs modified the sea-water, and I think interfered with their development. It seemed to me that by avoiding this source of error, and by using large dishes with several hundred cubic centimeters of sea-water instead of the watchglass, it might perhaps be possible to see the eggs develop further.

The eggs that had been in solution $2(60$ c.c. $\mathrm{KCl}+40$ 
c.c.sea-water) also began to segment. The next morning about 1 per cent. of the eggs were divided into from 2 to 4 cells. They were all without membranes, but they looked less normal than the $\mathrm{MgCl}_{2}$ eggs, and soon began to disintegrate.

The third lot of eggs had been in 60 c.c. $\mathrm{NaCl}+40$ c.c. sea-water. Practically none of these eggs segmented during the next twenty-four hours, and none formed a membrane. The fourth lot of eggs had been in 60 c.c. $\mathrm{CaCl}_{2}+40$ c.c. sea-water. A few of these showed a beginning of segmentation, but every egg had a membrane. I have found since that in pure $\mathrm{CaCl}_{2}$ solutions of even lower concentration unfertilized eggs form a membrane. It is possible that the formation of a membrane consists in a process of coagulation which is favored by $\mathrm{Ca}$ ions. ${ }^{1}$

I made a parallel series of experiments with fertilized eggs of the same female. The eggs were, as usual, fertilized in normal sea-water, and five minutes later were put into the various solutions. The eggs were divided into four lots, and put into solutions of the same character as in the above-mentioned experiment with unfertilized eggs. Like the unfertilized eggs, the fertilized eggs remained in the solution one hour and fifty minutes. When brought back into normal sea-water those that had been in solution 1 ( 60 c.c. $\mathrm{MgCl}_{2}+40$ c.c. sea-water) began to divide in fifteen minutes. The segmentation was very regular. Two hours and forty-five minutes later every egg was segmented into from 8 to 32 cells. Every egg had a membrane. The next morning a large number of eggs swam about in the blastula stage, still having a membrane. This observation is of importance, as it shows that even in eggs that were in a mixture of 60 c.c. $\frac{20}{8} n \mathrm{MgCl}_{2}$ with 40 c.c. sea-water the

1 Hertwig showed that unfertilized eggs form a membrane in water saturated with chloroform. Herbst found that benzol, toluol, and xylol bring about the same effect. All these media have a coagulating effect. Hersst, Biologisches Centralblatt, Vol. XIII (1892), p. 14. 
existence of a membrane may serve to show whether eggs were fertilized or not. The fertilized eggs that were put into the second solution $(\mathrm{KCl})$ did not reach the blastula stage. They stopped at about the thirty-two- to the sixtyfour-cell stage. Those that had been in the third solution $(\mathrm{NaCl})$ were in about the same condition, with the exception perhaps that at first the segmentation was more unequal. In the fourth solution $\left(\mathrm{CaCl}_{2}\right)$ no egg segmented, and only one egg in a thousand showed a beginning of segmentation, consisting of an incision at one side of the egg.

I finally wished to know how fertilized and unfertilized eggs behaved if left for eighteen hours in a mixture of 60 c.c. $\frac{20}{8} n \mathrm{MgCl}_{2}+40$ c.c. sea-water. The unfertilized eggs formed no membrane, but a very large part, more than 50 per cent., of the eggs was divided into from 2 to 8 cells. The fertilized eggs had a membrane. In regard to segmentation there was little difference between the two lots. It was especially this circumstance which made me hope that with a little more care it would be possible to raise living larvæ from unfertilized eggs by treating them with a suitable mixture of $\frac{20}{8} n \mathrm{MgCl}_{2}$ solution and sea-water.

In these and other similar experiments, which I will not describe, it was moreover evident that after the treatment with $\mathrm{Mg}$ ions the character of the segmentation was much more normal than after the treatment with $\mathrm{K}$ and $\mathrm{Na}$ or $\mathrm{Ca}$ ions. The $\mathrm{K}$ ions were nearest the $\mathrm{Mg}$ ions in their effect. The Cajons were the most unfavorable. Theformer experiments of Norman had also yielded the result that the $\mathbf{M g}$ ions were the most harmless for the segmentation of the sea-urchin egg.

iv. THE ARTIFICIAL PRODUCtion OF NORMAL LARV TEI) FROM THE UNFERTILIZED EGG OF THE SEA-URCHIN

The most serious danger in experiments with unfertilized eggs is the possibility that the sea-water or the instruments 
contain spermatozoa. It is imperative to guard against both possibilities. The sea-urchins have practically died out in the immediate neighborhood of the Woods Hole laboratory, and we have to send out the steam launch to collect them. For this reason even at the height of the spawning reason there is little danger of the sea-water containing spermatozoa in such quantities as to interfere with experiments on unfertilized eggs. Moreover the danger that the spermatozoa contained in the sea-water of the laboratory may interfere with experiments on unfertilized eggs is not very great, even at the height of the breeding season. This is shown indirectly by the fact that in the experiments described in the previous chapter not a single egg was fertilized through contamination of the sea-water with spermatozoa. The spermatozoa if scattered in sea-water soon lose the power of impregnating the egg. Gemmill found experimentally that this occurs in less than five hours after the spermatozoa leave the testicle. ${ }^{1} \quad$ My experiments were carried on after the breeding season was practically over, in September, when the majority of sea-urchins contained practically no more eggs. I had already made up my mind that my further experiments would have to be postponed a year, when through the kindness of Professor Bumpus of the Fish Commission I obtained a few dozen sea-urchins that he had collected early in the season and kept in a small pond. It happened that almost every one of these animals was a female and full of eggs. Though there was little possibility that the running water of the marine laboratory could contain any spermatozoa of sea-urchins which were able to fertilize eggs, I had no right to take anything for granted in this direction. I therefore conducted with each experiment a series of control experiments to guard against the possibility of contam-

1 Gemsill, Journal of Anatomy and Physiology, Tol. XXIV (1900), p. 163. The results are much better if sterile sea-water is used, as was the case in Fischer's experiments. [1903] 
ination of the sea-water with spermatozoa. As a rule, I proceeded in the following way. The unfertilized eggs of one female were divided into three or more lots. One lot was put into the artificial solution by which I hoped to cause the development of the unfertilized eggs. The second lot was put into normal sea-water to serve as a test or control for the presence of spermatozoa in the sea-water. The third lot was put into an artificial solution which as a rule differed less from the normal sea-water than the solution which caused the development of the egg. Whenever the eggs of one lot were put back into normal sea-water, the eggs of the other lots were put into the same sea-water. Thus all three lots of eggs were kept in sea-water of exactly the same degree of contamination. In no case did a single egg of the three lots form a membrane. No egg of lot 2, which remained in normal sea-water all the time and served as a test for the presence of spermatozoa, showed any derelopment except a beginning of segmentation (2-3 cells) after abont twenty hours. In no case did any of the eggs of lot 2 or 3 develop into a blastula.

The chief sources of infection in such experiments are the instruments and the hands of the experimenter if he opens male and female animals at the same time. The dishes in my experiments were cleaned with fresh water, in most cases the evening before the experiment was made. The instruments which were used had been cleaned in fresh water and kept dry for twenty-four hours. In case the first animal opened was a male the instruments were laid aside, the hands disinfected, and new instruments used for the next animal. It happened that in almost every one of the following experiments the first animal I opened was a female, and thus the chief danger of contamination by spermatozoa was naturally avoided.

But even if the experiments had not been carried on with 
such precautions, the results obtained were of such a character as to absolutely exclude in themselves any idea of contamination by spermatozoa. In all the successful experiments the cultures of unfertilized eggs that had been treated with the right $\mathrm{MgCl}_{2}$ solution were teeming with blastulæ the next day. Twenty per cent., in some cases even more, almost 50 per cent. of the eggs, had developed. In former experiments with unfertilized eggs where no such precautions were taken, I never noticed that more than perhaps one egg in a thousand developed. I shall describe each series of experiments independently. The $\mathrm{MgCl}_{2}$ used in these experiments was chemically pure, but had been dried by heating it.

First series.-Unfertilized eggs of the same female were divided into four lots and distributed into the following four solutions :
(1) 60 c.c. ${ }_{8}^{2 n} n \mathrm{MgCl}_{2}+40$ c.c. sea-water
(2) 100 c.c. ${ }_{8}^{10} n \mathrm{MgCl}_{2}$
(3) 100 c.c. $\frac{10}{8} n \mathrm{CaCl}_{2}$
(4) 100 c.c. normal sea-water

After the eggs had been in these solutions one and onehalf hours they were carefully examined. Not one had a membrane and not one was segmented. Twenty minutes later one part of the eggs of each of these four solutions was transferred back into normal sea-water. The latter was the same for all four solutions. This time I took special care to see that each lot of eggs was given enough normal sea-water (about 200 c.c.). After they had been back in the normal sea-water for about two hours and fifty minutes, they were examined again. The eggs that had been in solution 1 (60 c.c. ${ }_{8}^{20} n \mathrm{MgCl}_{2}+40$ c.c. sea-water) were all without a membrane. About 20 per cent. of the eggs were segmented into as many as 32 cells. The eggs that had been in solution $2\left(100\right.$ c.c. $\left.\frac{10}{8} n \mathrm{MgCl}_{2}\right)$ were without any membrane and unsegmented. Many of those that had been in solution 
3 (100 c.c. $\frac{10}{8} n \mathrm{CaCl}_{2}$ ) had membranes. A few were segmented very irregularly in to 2 to 3 cells. All the eggs were examined again three hours later. Those that had been in solution 1 were now in a morula stage. As they had no membranes, their outline was very irregular, and I wondered what kind of blastula would result if these eggs ever reached that stage. The eggs that had been in solution 2 (100 c.c. $\frac{10}{8} n \mathrm{MgCl}_{2}$ ) were without membranes and unsegmented. Of the eggs that had been in solution $3\left(100\right.$ c.c. $\left.{ }^{10} n \mathrm{CaCl}_{2}\right)$ about 5 per cent. were segmented into from 2 to 4 cells of very unequal size. The last examination had taken place in the evening. The next morning the eggs of solution 1 were teeming with blastulæ; some with regular, the majority, however, with most fantastic outlines (see Fig. 149). Their size was very unequal. I expected as much from the irregular appearance of the morulæ of the evening before. In the fertilized egg the membrane prevents any irregularity in the form of the blastulæ. The unfertilized eggs, however, have no membrane, and hence the cells are only kept together by an intercellular substance or by adhesion; but it is very probable that the processes of cell-division are accompanied by amœboid motions (Fig. 148), which have the effect of making the arrangement of cells irregular. I have noticed and described this effect of the amoboid motions of the cleavage cells in my experiments on eggs whose membrane I had caused to burst and whose contents partly flowed out of the egg. 'These extraovates behaved very much like the unfertilized eggs. In the latter case it was evident from the size of the blastulæ that only in rare cases had the whole egg developed into one single blastula. As a rule, each egg gave rise to several blastulæ. Through the amœboid motions connected with the process of cell-division groups of cells became disconnected and developed into dwarf blastulæ. I

I I,OEB, Archiv für Entwickelungsmechanik, Vol. I (1895), p. 453. 
Artificial Production of Normal Larve 601

shall discuss this point more fully in connection with the drawings.

I have not yet mentioned one control experiment which I made in this series. I had one part of the eggs of the same female fertilized and put into the same four solutions for the same time as the unfertilized eggs. Every one of the fertilized eggs formed a membrane. The behavior of these eggs and their larvæ differed also in other respects from the larvæ produced from the unfertilized eggs. While the blastula of the fertilized eggs even after the treatment with solution 1 swam at the surface of the sea-water, the parthenogenetic blastula were all at the bottom of the dish and unable to rise. This difference seems to be typical, as I found it in all my experiments. All the parthenogenetic blastulæ in these experiments died during the day. It goes without saying that the blastulæ which developed from the fertilized eggs treated with solution 1 did not show the ragged condition of the parthenogenetic larvæ that had developed without a membrane.

Unfertilized eggs that had been in solution 2 for one hour and fifty minutes were the next day unsegmented and without membrane. The unfertilized eggs that had been in solution 3 were all dead. The unfertilized eggs that had been kept in normal sea-water all the time were without a membrane and unsegmented. Thus it is evident that the unfertilized eggs of Arbacia, if put for one hour and fifty minutes in a solution of 60 c.c. $\frac{20}{8} n \mathrm{MgCl}_{2}+40$ c.c. seawater are able to develop into blastulæ which move about. But it is also evident from the control experiments that this cannot be due to the partial pressure or concentration of the $\mathrm{Mg}$ ions alone, for in solution 2 (100 c.c. $\frac{10}{8} n \mathrm{MgCl}_{2}$ ) the concentration of the $\mathrm{Mg}$ ions was almost the same as in solution 1, and yet no unfertilized egg was caused to segment by this solution. That the latter solution is not very poisonous 
for the Arbacia egg is shown by the fact that the fertilized eggs of Arbacia develop better in this solution than in 60 c.c. ${ }_{8}^{20} n \mathrm{MgCl}_{2}+40$ c.c. sea-water. Hence it is evident that the $\mathrm{Mg}$ ions alone were not able to bring about the development of the unfertilized Arbacia eggs that had been in solution 1. Either the presence of other ions, such as are contained in the 40 c.c. of sea-water or the increased osmotic pressure in the mixture of 60 c.c. $\frac{20}{8} n \mathrm{MgCl}_{2}+40$ c.c. seawater is essential for the development. The osmotic pressure of a $\frac{10}{8} n \mathrm{MgCl}_{2}$ solution is not very different from that of sea-water.

Second series.-It was, of course, my next task to repeat this experiment. I now knew which solution must be used in order to obtain parthenogenetic blastulæ, but I wanted to find out how long the eggs must remain in this solution in order to develop into a blastula. I put a quantity of unfertilized eggs of one female into a solution of 60 c.c. ${ }_{8}^{20} n \mathrm{MgCl}_{2}+40$ c.c. sea-water at ten o'clock. At various intervals a portion of these eggs was taken out of the solution and put back into 200 c.c. of normal sea-water. The first lot was put back into normal sea-water after thirty minutes. No egg had a membrane and none was segmented. The second lot was put back into normal sea-water after sixty-five minutes, the third lot after one hour and forty minutes, the fourth after one hour and fifty minutes, the fifth after two hours and five minutes, the sixth after two hours and fifteen minutes, lot 7 after two hours and thirty minutes, and the eighth lot after three hours and fifteen minutes. The first, second, and eighth lots differed much in regard to the time they were exposed to the artificial solution from lots $3,4,5,6$, and 7 , which were taken out of the solution at much shorter intervals. No egg in any of these solutions had any membrane or showed any trace of segmentation at the time they were put back into normal 
sea-water. At 1:15 all the eggs were examined again. In lots 3 to 7 many eggs were segmented into from 2 to 16 cells. The sixteen-cell stages were only found in lot 4 . The rest had not gone beyond the eight-cell stage. In lot 2 very few eggs had segmented; in lot 1 all the eggs were segmented. No egg had a membrane. Another examination of the eggs was made at 3:05. In lot 1 about 1 per cent. of the eggs was segmented in 2 cells; in lot 2 about 5 per cent. of the eggs were divided, most of them into 2 , some of them, howerer, into 8 or even 16 cells. In lot 3 about 20 per cent. segmented. Some had reached the thirty-two-cell stage. In lot 4 more than 20 per cent. were segmented, some as far as into 32 cells. In lot 5 almost every second egg was segmented. Some had reached about the thirtytwo-cell stage. The same was true of lots 6 and 7 . In lot 8 many eggs had segmented, but they were far behind in their development. No egg had a membrane. The single cells did not stick as closely together as they did in the fertilized egg with the membrane. I was afraid from the appearance of the eggs, that they would not give rise to blastulæ, inasmuch as it seemed as though the cleavage cells would all fall apart.

The eggs were not examined until the next morning. In lots 1 and 8 there were practically no blastulæ in motion, or if there were any they escaped my observation. In lot 7 I found a small number of blastulæ. In lots $3,4,5$, and 6 the water at the bottom of the dish was teeming with blastulæ, which with their irregular outlines and the variation in size betrayed clearly that they had developed from eggs without a membrane.

In the afternoon I found living larva only in lots 3, 4, 5 , and 6 . Some larvæ seemed to be in a gastrula stage, and some even in the transitional stage to the pluteus form. Many had died, and this accounted perhaps for the fact that 
no blastule were left in lots 2 and 7 , where they had at most been very scarce. The next morning only a few larvæ were left in lots 3 to 6 , and these died during the day.

I stated at the beginning of my experiments that only a part of the eggs of one female were put into the $\mathrm{MgCl}_{2}$ solution. The others were left in normal sea-water to serve as control material. None of these eggs which were in the same sea-water as that used for the eggs treated with the $\mathrm{MgCl}_{2}$ solution formed any membrane. After twenty-four hours a few eggs were found divided into 2 cells. No egg developed beyond this stage.

This experiment shows that the time during which unfertilized eggs must remain in contact with a mixture of 60 c.c. $\frac{20}{8} n \mathrm{MgCl}_{2}+40$ c.c. sea-water in order to give rise to blastulæ is limited in two directions. If the eggs remain only thirty minutes in such a solution, a few of them may begin to develop, but none will reach the blastula stage. But if the unfertilized eggs remain in this solution from one and one-half to two hours, more than 20 per cent., and as many as 50 per cent., may develop, and the solution then teems with moving blastulæ, which however remain at the bottom of the dish. On the other hand the time limit will be exceeded if the eggs are left in the solution more than two and one-half or three hours.

I tried another experiment in this series to see how soon the unfertilized eggs would lose their power of being affected by the $\mathrm{MgCl}_{2}$ solution. The eggs were left in normal seawater for eighty minutes, then put in a solution of 60 c.c. ${ }_{8}^{20} n \mathrm{MgCl}_{2}+40$ c.c. sea-water for two hours. Two hours later they were put back into normal sea-water. A large number of eggs began to segment, but I did not find any blastulæ the next day.

Third series.-Thus far I had found the right solution for producing blastulæ from unfertilized eggs, and had found 
about how long the eggs must remain in this solution. I now desired to verify these results and in addition find out accurately how far the proportions between sea-water and the $\frac{20}{8} n \mathrm{MgCl}_{2}$ solution might vary without interfering with the results. The unfertilized eggs of one female were distributed in the following solutions:

(1) 60 c.c. $\frac{20}{8} n \mathrm{MgCl}_{2}+40$ c.c. sea-water

(2) $30 \quad$ " $\quad+70$

(3) Normal sea-water

At five different periods (one hour, one hour and forty minutes, one hour and fifty-five minutes, two hours and twenty minutes, two hours and forty-five minutes) portions of the eggs in solutions 1 and 2 were brought back into normal sea-water. After all that has been said, it seems superfluous to give all the details as explicitly as in the preceding experiments, and I shall therefore confine myself to a description of the main results as they appeared next morning. The eggr in solution 3 (normal sea-water) had no membranes nor had any egg segmented. It is obvious that unfertilized eggs do not always undergo a beginning of segmentation in normal sea-water after twenty or twenty-four hours. Of the eggs that had been in solution 1 for one hour and fifty-five minutes, about 25 per cent. had developed into a blastula which swam about. About the same result was obtained in the lot that had been for two hours and twenty minutes in solution 1 . The appearance of these blastulæ was the same as in the previous experiments. Most of them were only fractions of one egg, and it was not uncommon to see four smaller blastulæe swim together, each apparently having developed from one of the blastomeres of the four-cell stage. In the other lots which were taken from solution 1 a few blastulæ were formed. The eggs that had been in this solution for one hour were practically all undivided, except that one in a thousand had segmented into 
2 to 3 cells. It was not much better in the lot of eggs that had been in this same solution for one hour and forty minutes. The lot that had been in the solution two hours and forty-five minutes had living blastulæ, but not so many as the two lots mentioned above. It is therefore obvious that the eggs of different females show slight variations in the time required for the eggs to remain in the mixture of 60 c.c. $\frac{20}{8} n \mathrm{MgCl}_{2}$ +40 c.c. sea-water in order to reach the blastula stage.

I have thus far only spoken of eggs that had been in solution 1. Of the eggs that had been in solution 2 not one developed into a blastula. Those that had been in this solution for two hours had not even segmented. Only the eggs that had remained in that solution for two hours and forty-five minutes showed a beginning of segmentation (2 cells), but only one in a thousand had segmented. It is evident that either the amount of $\mathbf{M g}$ ions or the total osmotic pressure of the solution was too small to cause the unfertilized eggs to develop. These experiments with negative results are however very valuable as control experiments against the possible contamination of the sea-water with spermatozoa. If in such cases contamination had happened, the eggs that had been in solution 2 ought to have developed equally as well as, or better than, those that had been in solution 1. The same remark might apply to the preceding and following experiments. None of the eggs in any of these solutions formed a membrane.

Fourth series.-In all the experiments in which blastulæ were produced from the unfertilized eggs three conditions were united: (1) the total osmotic pressure of the artificial solution was higher than that of sea-water; (2) the amount of the Mg ions was increased; (3) the absolute amount of the other ions normally present in sea-water was reduced. In this series I desired to find out whether the third condition was essential, and whether the mere increase in the 
Artificial Production of Normal Larve 607

osmotic pressure was not sufficient. Moreover I wished once more to repeat the former experiments. The unfertilized eggs of one female were distributed in the following solutions;

(1) 60 c.c. ${ }_{8}^{20} n \mathrm{MgCl}_{2}+40$ c.c. sea-water

(2) 100 c.c. sea-water $+3 \frac{1}{2}$ gr. (wet) $\mathrm{MgCl}_{2}$

(3) 100 c.c. sea-water +8 gr. (wet) $\mathbf{M g C l}_{2}$

(4) Normal sea-water

At various intervals a lot of the eggs were taken out of each of the four solutions and put into normal sea-water. The eggs that had been in solution 1 from one and one-half to two hours had developed into blastulæ the next norning. The number of blastulæ was comparatively larger than in any of my previous experiments. The eggs that had been in solutions 2 and 3 contained no blastulæ. Solution 2 is, by the way, the one Norman and Morgan had used in their experiments. In solution 4 no egg was even segmented the next day. In none of the four solutions had any egg formed a membrane. These experiments show that the substitution of a number of $\mathrm{Mg}$ ions for one-half of the ions naturally contained in the sea-water is either necessary or more favorable than the mere addition of $\mathbf{M g}$ ions. This experiment explains why Morgan did not succeed in getting live larvæ, having treated the eggs with solution 2. But I intend to determine in my future experiments whether the addition of a little more than $3 \frac{1}{2} \mathrm{gr}$. of $\mathrm{MgCl}_{2}$ and a little less than $8 \mathrm{gr}$. of the solution to 100 c.c. of sea-water may not give more favorable results.

Fifth series.-I next wished to try whether it would not be possible to carry the artificial development of the unfertilized egg one step farther. The blastulæ thus far obtained were by no means healthy, and although some of them looked normal, they died before they had time to reach the pluteus stage. This latter result I was inclined to ascribe to the 
poisonous effect of the $\mathrm{Mg}$ ions, and it seemed possible to me that a decrease in the amount of $\mathrm{MgCl}_{2}$ and a slight increase in the amount of sea-water might allow the eggs to reach the pluteus stage. The eggs of two females were distributed in the following solution:
(1) 60 c.c. ${ }_{8}^{20} n \mathrm{MgCl}_{2}+40$ c.c. sea-water
(2) 50 c.c.
$+50$
(3) Normal sea-water

The eggs were brought back into normal sea-water after one hour and five minutes, one hour and thirty minutes, and
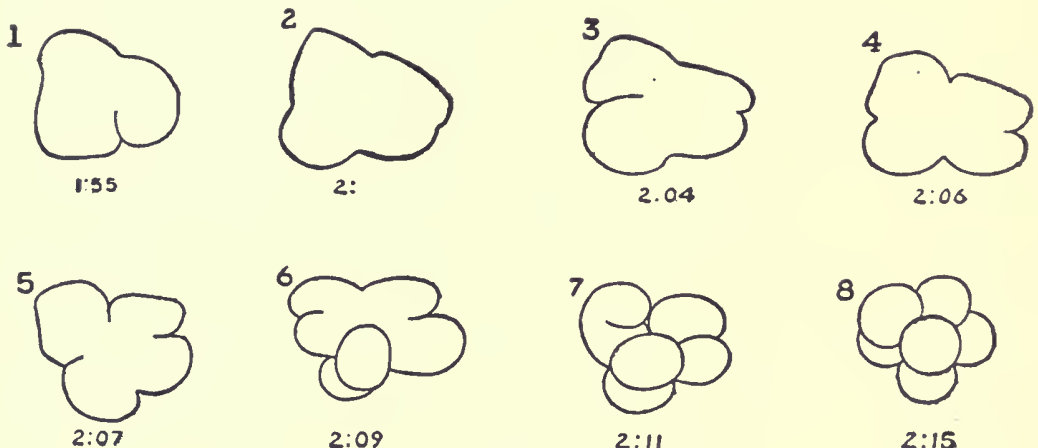

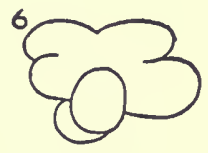

2:09

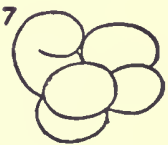

2:11

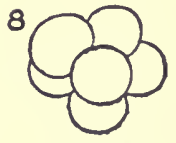

2:15

FIG. 148

one hour and forty minutes. Only the eggs of the last lot that had been in the solution one hour and forty minutes showed the beginning of a development. I believe that I took out the eggs too soon. In some cases such eggs are able to develop, but in others they are not, and I think it probable that if the eggs had been left a little longer in solution 1 or 2 they would have developed further. I made some camera drawings of the way in which the eggs were segmented (Fig. 148). The successive stages of the segmentation of one and the same egg up to the six-cell stage were drawn. The reader will see from the drawings that the egg went within twenty minutes from practically an undivided 
egg into a six-cell stage. It is obvious that these cell-divisions are accompanied by most striking amœboid motions, which are characteristic of all the eggs without a membrane. I believe that these amœboid motions exist in the fertilized eggs just as well, but the membrane prevents them from becoming so conspicuous as in the unfertilized eggs where there is no membrane. In the normal eggs these amœboid motions are more symmetrical, and this is another reason why they escape our observation. When I made my first experiments on the effect of more concentrated sea-water upon the segmentation of fertilized eggs, the idea struck me that the segmentation by budding (Knospenfurchung) was the outcome of amøboid motions, and I soon afterward expressed the idea that the same is true for the process of celldivision in general. ${ }^{1}$ The two nuclei of the mother cell are the centers around which the protoplasm streams and flows. These amøboid motions are only one episode in the process of cell-division, for whose full explanation other phenomena of an entirely different character must be taken into consideration.

Sixth series.-The preceding experiment was repeated, but this time with due consideration of the fact that the eggs must remain long enough (two hours) in the artificial solution. The eggs of two females were distributed in three solutions:

(1) 60 c.c. $\frac{20}{8} n \mathrm{MgCl}_{2}+40$ c.c. sea-water

(2) 50 c.c. " $\quad 50$ c.c. "

(3) Normal sea-water

None of the eggs formed a membrane. Some of those that had remained in normal sea-water segmented after twenty hours. They divided into from 2 to 3 cells and not further. I have already mentioned the fact that the unfertilized eggs of various females differ somewhat in their

1 LOEB, Archiv für Entwickclungsmechanik, Vol. I (1895), p. 453. 
tendency to segment in normal sea-water. It may be possible that these variations enhance or diminish the effects of artificial solutions upon the development of unfertilized eggs. The eggs that had been for two hours in solution 1 had the

1.

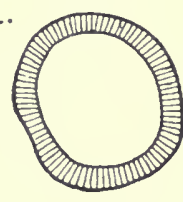

c.
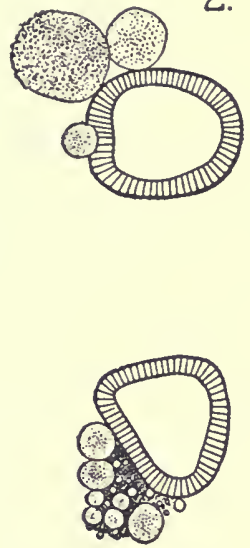

5.
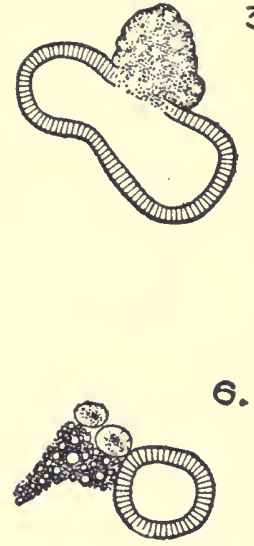

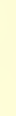

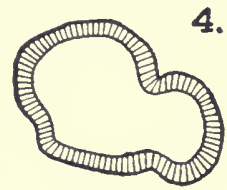

3.
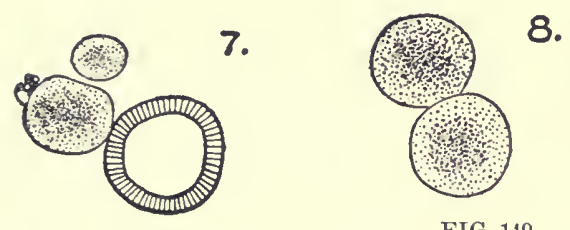

9.

FIG. 149

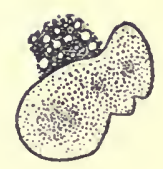

next day developed into the characteristic blastulæ some of which are represented in Fig. 149. Some of these blastulæ originated possibly from the whole mass of one egg, for instance 1, 3, and 4. But even here the irregular outline betrays clearly that the blastulæ originated from eggs without a membrane. As I said in an earlier experiment, the outlines of the eggs became irregular through the amœboid motions of the blastomeres, and in the blastulæ the outline 
of the irregular morula stage is preserved. This is intelligible if we remember that the blastula originates through the cleavage cells moving or sticking to the periphery of the egg. The other blastulæ represented only smaller pieces of a single egg. In some cases one part of the egg disintegrated and formed débris attached to the other part which reached the blastula stage $(5,6$, and 7$)$. Each one of these blastulæ was moving and had to be immobilized to make the cameradrawing. It is impossible to give a fair idea of the variety of forms of blastulæ one sees in such experiments. No egg of this lot (solution 1 ) reached the pluteus stage. All died the second day. The eggs that had been in solution 2 (equal parts of

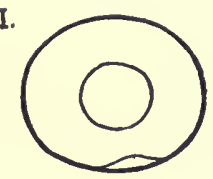

II.

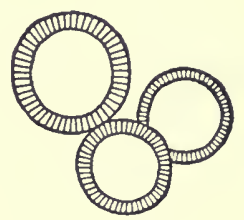

III.

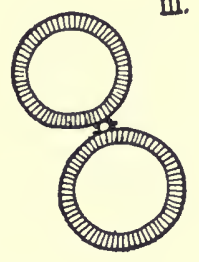
${ }_{8}^{20} n \mathrm{MgCl}_{2}$ and sea-water) looked very different from the preceding lot (Fig. 150). After twenty-four hours many of them had developed into blastulæ. These blastulæ left no doubt that they came from eggs without a membrane, inasmuch as in the majority of cases several blastulæ originated from one egg. Quadruplets were especially frequent (Fig 150 , Iv and v), but twins and triplets were also quite common. I watched their development, and am thus quite certain that these multiple embryos sticking together came from one egg. The feature that distinguished these embryos 
from those that had been treated with the stronger $\mathrm{MgCl}_{2}$ solution, however, was the fact that the former all had regular and sharp outlines and were free from débris. The outlines of the blastulæ were much more spherical. These blastulæ had greater vitality than the others and kept alive during the
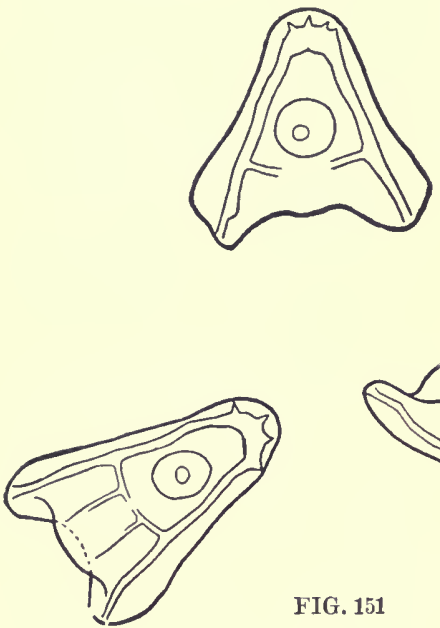

FIG. 151 next thirty-six hours. The next morning a number of them had reached the pluteus stage with a perfectly normal skeleton and intestine, but they died the following day (Fig. 151). They had lived more than two days. Their development was slower than in the case of fertilized eggs.

All these blastulæ and plutei swam about on the bottom of the dish, not rising to the surface like the larvæ from fertilized eggs.

The control eggs that had been left in the normal seawater remained unsegmented, with the exception of a few which on the second day were found divided into 2 or 3 cells. The latter, of course, segmented no further. None of these eggs had a membrane.

Seventh series.-The preceding series had shown that a mixture of equal parts of $\frac{20}{8} n \mathrm{MgCl}_{2}$ and sea-water is more favorable for the development of the eggs than a mixture with more $\mathrm{MgCl}_{2}$ and less sea-water, for instance 60 c.c. $\mathbf{M g C l}_{2}$ and 40 c.c. sea-water. In the latter mixture the eggs seemed to suffer more. It must, however, be stated that as far as the comparative number of eggs is concerned that 
undergo development, the solution with 60 c.c. $\mathrm{MgCl}_{2}$ and 40 c.c. sea-water is equally good or even better than the mixture of equal parts of both. I now tried whether a mixture with less $\mathrm{MgCl}_{2}$ would still be favorable. A mixture of 40 c.c. ${ }_{8}^{20} \mathrm{n} \mathrm{HgCl}_{2}+60$ c.c. sea-water was found ineffective. The eggs remained two hours in this solution, and a few of them segmented afterwards, but as the number was comparatively small I did not follow up this experiment. It is possible that a mixture of 40 c.c. $\frac{20}{8} n \mathrm{MgCl}_{2}+60$ c.c. sea-water is too weak to bring about artificial parthenogenesis of the egg of Arbacia. In one of the preceding experiments we found that by treating the eggs with a mixture of 30 c.c. $\frac{20}{8} n \mathrm{MgCl}_{2}+60$ c.c. sea-water we were not able to bring about parthenogenesis.

Eighth series.-It was evident that in order to produce plutei from the unfertilized egg of Arbacia we must confine ourselves to solutions which contain less than 60 and more than 40 per cent. of $\frac{20}{8} n \mathrm{MgCl}_{2}$. In the next experiments the following four solutions were tried:

(1) 55 c.c. $\frac{20}{8} n \mathrm{MgCl}+45$ c.c. sea-water

(2) 50

$+50$

(3) 45

$+55$

(4) Normal sea-water

At three different intervals (two hours, two hours and ten minutes, two hours and twenty minutes) portions of the eggs were taken out of these four solutions and put back into normal sea-water. Two hours later in each of the lots that had been in the first three solutions about 50 per cent. of the eggs were segmented into from 2 to 16 cells. None of them had a membrane. No egg in solution 4 (normal sea-water) was segmented or had a membrane. The next morning the eggs that had been in solution 1 were teeming with blastulæ. Many of them resembled the blastulie of Fig. 149, but the majority were clean and free from débris. 
The eggs that had been in solution 2 had a large number of blastulæe and gastrulæ. They were free from débris and looked very much like those drawn in Fig. 150. The eggs taken from solution 3 had very few blastulæ. The latter, however, were perfect, except that the single egg as a rule produced more than one embryo. The majority of the eggs were still in the morula stage. The next morning, fortyeight hours after the treatment with the $\mathrm{MgCl}_{2}$ solution, each one of the three dishes contained perfect plutei. Many eggs of solution 3 which the previous day were still in the morula stage had in the mean time developed into blastulie or plutei. This time the plutei were still alive on the following day (seventy-two hours after the treatment with the artificial solution). Their vitality was not much less than that of the normal plutei which often died just as early. I mentioned that I had put back the eggs from the $\mathrm{MgCl}_{2}$ solutions into normal sea-water at three different intervals. Those taken out last gave the best results. It is very obvious that the unfertilized eggs develop much more slowly than the fertilized eggs. The latter reach the pluteus stage at the proper temperature within twenty-four hours or little more, while the unfertilized eggs reach the pluteus stage after forty-eight hours at the same temperature. I had the same experience in all my experiments with unfertilized eggs. The eggs that liad been left in normal seawater remained undeveloped and not one egg had a membrane. One egg in a hundred was segmented after twentyfour hours in 2 or 3 cells, but none developed further.

Ninth series. - This time I intended once more to repeat my experiments and at the same time make control experiments of an altogether different character. I will first speak of the repetition of the old experiments. The unfertilized eggs of one female were put into the following two solutions: 
(1) 50 c.c. $\frac{20}{8} n \mathrm{MgCl}_{2}+50$ c.c. sea-water

(2) Normal sea-water

Two hours later the eggs from solution 1 were put back into normal sea-water. Three and a half hours later about 50 per cent. of the eggs that had been in solution 1 were divided into from 2 to 16 cells, but not an egg had a membrane. The control eggs that had been in normal sea-water all the time were all without membrane and absolutely unsegmented. Millions of eggs were examined under the microscope. The next morning the eggs that had been in solution 1 had reached the blastula stage and were swimming about. A small number were in a gastrula stage and even beginning to assume a pyramidal form. In the control eggs not one had developed. Perhaps one in a hundred had amœboid forms such as precede segmentation in unfertilized eggs, but not an egg was segmented, and not one had a membrane. The next day some of the blastulæ of the other lot had reached the pluteus stage. The control experiments will be discussed in the next paragraph.

Possible sources of error and objections.-From all these experiments I draw the conclusion that by putting the unfertilized eggs of Arbacia for two hours into a solution of 60 c.c. ${ }_{8}^{20} \mathrm{n} \mathrm{MgCl}_{2}+40$ c.c. sea-water the eggs develop into blastulæ if brought back into normal sea-water. If we put the unfertilized eggs for about two hours into a solution of equal parts of $\frac{20}{8} n \mathrm{MgCl}_{2}$ and sea-water, the eggs may reach the pluteus stage. The possible objection might be that the eggs were fertilized. Such fertilization could only have been caused by the instruments or hands of the experimenter having been in contact with spermatozoa, or by the sea-water containing spermatozoa. The first possibility was absolutely excluded through the above mentioned precautions. The second possibility was rendered practically impossible, as, first, the spawning season was practically over, and, second, 
the spermatozoa lose their power of fertilizing eggs in a very short time (in about five hours). But that it was absolutely excluded is proven by the following facts:

1. None of the unfertilized eggs kept in normal sea-water developed or formed a membrane. I examined millions of eggs in each experiment. Not one was found that was fertilized. The sea-water used in this case was the same as that used for the unfertilized eggs that did develop. If the sea-water had contained spermatozoa, the unfertilized eggs kept in normal sea-water all the time should have been fertilized.

2. None of the eggs which developed after treatment with $\mathrm{MgCl}_{2}$ solution ever had a membrane. Fertilized eggs which were put immediately after fertilization into a mixture of equal parts of $\frac{20}{8} n \mathrm{MgCl}_{2}$ and sea-water and kept there for two hours did not lose their membrane. In the ninth series I made the following control experiments: Unfertilized eggs that had been in the above-mentioned $\frac{20}{8} n \mathrm{MgCl}_{2}$ solution for two hours were put into normal sea-water to which fresh sperm was added. In this case a number of eggs formed membranes.

3. No blastula originated from an egg that had been kept for some time in one of the following solutions:

(1) 100 c.c. ${ }_{8}^{10} n \mathrm{MgCl}_{2}$

(2) 30 c.c. ${ }_{8}^{20} n$ " +70 c.c. sea-water

(3) 40 " " 460 "

(4) 100 c.c. sea-water $+3 \frac{1}{2}$ gr. (wet) $\mathrm{MgCl}_{2}$

and the solutions mentioned in chap. iii. Yet eggs of the same female that had been kept for some time in a mixture of 50 or 60 c.c. $\frac{20}{8} n \mathrm{MgCl}_{2}$ and 50 or 40 c.c. of sea-water developed into blastulæ or plutei. This happened in spite of the fact that the vitality of the latter eggs had suffered more than that of those in the above-mentioned solutions with more sea-water and less $\mathrm{MgCl}_{2}$. Moreover the water 
was always changed in both classes of eggs simultaneously, and the chances for fertilization of the eggs from spermatozoa contained in the sea-water were equal for both. If the sea-water had contained any spermatozoa capable of impregnating the eggs, those eggs that had been in solutions with less $\mathrm{MgCl}_{2}$ should have been fertilized first.

4. In almost all the experiments eggs were taken out of the mixture of 60 to 50 c.c. $\frac{20}{8} n \mathrm{MgCl}_{2}+40$ to 50 c.c. sea-water at different periods. In no case did a single egg develop into a blastula that had been in this solution for less than one half-hour, and generally only those eggs yielded blastulæ that had been in this solution for about two hours. If the sea-water had contained spermatozoa, the latter should have fertilized those eggs first which had been a shorter time in the artificial solution. On the other hand, the eggs that had been left in the artificial solution more than two and one-half hours as a rule yielded fewer or no blastulæ.

5. I stated above that even at the height of the spawning season eggs are rarely fertilized by spermatozoa contained in the running sea-water. I do not think one would be likely to see more than one egg in a thousand undergo development under such conditions, provided that no contamination through the instruments occurred. In our experiments which were made at the end of the spawning season about 20 to 50 per cent. of the eggs that had been kept in the right solution developed. It is out of the question to attribute such a result to spermatozoa contained in the sea-water.

6. As far as I can see, there is only one possible source of error left. It might be that the sea-water contained spermatozoa, but that these spermatozoa were not able to fertilize normal eggs, while a treatment of the egg with the mixture of 60 c.c. ${ }_{8}^{20} n \mathrm{MgCl}_{2}+40$ c.c. sea-water increased its susceptibility to impregnation, or a treatment of the spermatozoon with the same solution increased the 
fertilizing power of the spermatozoon. Both possibilities must, however, be discarded. As far as the liability of the egg to impregnation is concerned, I made the following experiments in the last series. Unfertilized eggs were put into a solution of 50 c.c. ${ }_{8}^{20} n \mathrm{MgCl}_{2}+50$ c.c. sea-water and left in this solution for two hours. They were then taken out and fertilized with fresh spermatozoa. At the same time another lot of the eggs of the same female which had been kept for two hours in normal sea-water were fertilized with sperm of the same male. Practically erery egg of the latter lot developed into a blastula, while only about 50 per cent. of those eggs that had been in the $\mathrm{MgCl}_{2}$ solution reached the blastula stage. Hence the treatment with $\mathrm{MgCl}_{2}$ diminishes the power of development of eggs, but does not. increase it. As far as the spermatozoa are concerned, former experiments by Norman, Morgan, and myself showed that a slight increase in the concentration of the sea-water destroys the fertilizing power of spermatozoa very rapidly. In my experiments $\mathrm{I}$ added $2 \mathrm{gr}$. of $\mathrm{NaCl}$ to 100 c.c. of sea-water.

The spermatozoa which had been in this solution for only a few hours, when brought back into normal sea-water, fertilized only a thousandth part or less of the normal eggs, while the spermatozoa of the same animal which had remained in normal sea-water fertilized at the same time almost all the eggs. ${ }^{1}$

Morgan repeated my experiments, obtaining the same result. ${ }^{2}$ Norman tried the effects of a slight increase of $\mathrm{MgCl}_{2}$ upon spermatozoa. ${ }^{3}$ I repeat his statement:

I put sperm at 8:30 into $\mathrm{MgCl}_{2}$ solution $2 \frac{1}{2}$ gr. to 100 c.c. of sea-water. At 8:30 some of the sperm was mixed with normal unfertilized eggs, and within three minutes the eggs were fertilized. At 8:42 eggs and sperm were again mixed. In two minutes egg membranes began to become risible, showing normal fertilization,

1 LoeB, Journal of Morphology, Vol. VII (1892), p. 253.

2 Morgax, Anutomischer Anzeiger, Vol. IX (1894), p.141.

3 Normax, Archiv für Entwickelungsmechanik, Vol. III (1896), p. 106. 
and within another minute all the eggs were fertilized. At 8:52 another test was made, but at this time the egg membrane did not appear, showing that fertilization did not take place. At 9 o'clock about one egg in every 100 was fertilized.

Norman repeated these experiments several times with the same result. They prove that even a small addition of $\mathrm{MgCl}_{2}$ to sea-water, much smaller than in any of our experiments, suffices to annihilate the power of impregnation in the spermatozoa in a very short time. In my own experiments the increase in the osmotic pressure of the sea-water was much greater than in Norman's experiments. I made another control experiment in the ninth series which bears on the same question. Unfertilized eggs were left in a solution of equal parts of $\frac{20}{8} n \mathrm{MgCl}_{2}$ and sea-water for two hours. At the end of that time they were put back into normal sea-water to which sperm was added which had also been in a solution of equal parts of $\frac{20}{8} n \mathrm{MgCl}_{2}$ and seawater for two hours. Only very few of the eggs formed a membrane.

There is, as we saw, a typical difference between the blastulæ and plutei which develop from fertilized and unfertilized eggs. The former rise to the surface, the latter swim at the bottom of the dish. If eggs be kept for two hours in the $\mathrm{MgCl}_{2}$ solution and then fertilized with normal sperm, the blastulæ rise to the surface. If they be fertilized with sperm that had been in $\mathrm{MgCl}_{2}$ solution for two hours, they remain at the bottom of the dish like the unfertilized eggs. It is thus clear, I think, that even this last possible objection that the treatment with the $\mathrm{MgCl}_{2}$ solution increases the impregnating power of the spermatozoa, or the impregnability of the egg must be discarded. Hence I draw the conclusion that the unfertilized eggs that had been treated with equal parts of ${ }_{8}^{20} n \mathrm{MgCl}_{2}$ and sea-water developed parthenogenetically. 
v. SOME REMARKS CONCERNING THE NATURE OF THE PROCESS OF FERTILIZATION

The facts of the preceding section force us to transfer the problem of fertilization from the realm of morphology into that of physical chemistry. There is certainly no reason left for defining the process of fertilization as a morphological process. The morphology of the spermatozoon itself becomes of secondary importance as far as the process of fertilization is concerned.

The spermatozoon not only starts the development of nonparthenogenetic eggs, but it is also the bearer of the hereditary qualities of the male. From our experiments it becomes evident that these two functions of the spermatozoon are not necessarily bound together, for nobody would assume for an instant that the hereditary qualities that are carried by the spermatozoon could be imparted to the egg by a change in the inorganic constituents of the sea-water. We have learned to attribute the different activities of a cell to different enzymes. We must in future consider the possible or probable separation of the fertilizing qualities of the spermatozoon from the transmission of hereditary qualities through the same. ${ }^{1}$

The plutei produced from the unfertilized egg resemble closely in every regard those produced from the fertilized egg. The latter in many cases live longer than the former, but even this was not so in every case, and it is not impossible that in further experiments parthenogenetic plutei with a greater duration of life will be produced. The only difference between parthenogenetic and normal blastulie is that the latter rise to the surface of the water, while the former do not. One might think that this was due to the influence of the $\mathrm{MgCl}_{2}$ solution on the egg. This is, however, not the case. Eggs that had been in such a solution

${ }^{1}$ Loeb, Biological Lectures, Woods Hole, 1899, Ginn \& Co., Boston. 
Artificial Prodection of Norifal Larie 621

and were fertilized afterward rose to the surface. Even this difference might be caused to disappear by further experimentation.

An agency which causes the egg to go through only the first stages of segmentation, which lead, for instance, to a division of the egg into 2,4 , or 8 cells, need not necessarily have much in common with those agencies in the spermatozoon that cause the development of the fertilized egg. But if the egg can be caused through an artificial influence to reach the blastula stage and swim about, the artificial cause must have more in common with the effective element in the spermatozoon. If however the artificial influences cause the egg to reach the pluteus stage, or in other words cause the egg to develop as far as the fertilized egg can be developed at present in our laboratory, I think the two processes of artificial and natural development must be pretty closely allied.

It is in harmony with our statement that a very large number of conditions cause an unfertilized egg to reach a two- or four-cell stage. It suffices to leave the eggs for some time in sea-water (about twenty-four hours). A slight increase in the alkalinity of the sea-water causes the beginning of a segmentation much sooner. A short treatment with sea-water that is faintly acid has the same effect. An increase in the concentration of the sea-water which probably causes a loss of water in the egg has the same effect (Morgan). Morgan found more recently that treatment with a solution of strychnia salts may lead to a beginning of segmentation. Possibly in this case the alkalinity of the sea-water was modified. But none of these or the other methods mentioned above has yielded blastulæ, gastrulæ, or plutei.

There is at present only one way known by which the

1 Morg.s, Science, Vol. XI (1900), N. S., p. 176. R. Hertwig had found this many years ago. 
unfertilized egg of Arbacia can be caused to develop into a pluteus. ${ }^{1} \quad$ This consists in treating the unfertilized egg for two hours with a mixture of about equal parts of a $\frac{20}{8} n$ $\mathrm{MgCl}_{2}$ solution and sea-water. It is of theoretical interest to find how this treatment may possibly affect the egg substance. The bulk of our protoplasm consists of proteids, which according to their physical behavior belong to the colloidal substances. The proteids are characterized by two qualities which are of the utmost importance in the analysis of life phenomena. The proteids change their state very easily, and readily take up or lose water. It is more than probable that one or both of these qualities may account for muscular contractility and protoplasmic motion. The agencies which affect these two variable qualities of the protoplasm most powerfully are, first of all, certain enzymes (for instance, plasmase, trypsine, etc.). Almost equally powerful are ions in certain concentrations. As I have dwelt upon this point in my three preceding publications, ${ }^{2}$ it need not be repeated here. But I wish to call attention to a most interesting paper by Dr. E. Pauli, which has recently appeared and which throws more light on this subject. $^{3} \quad$ The third agency is temperature.

In our experiments it was evidently the second factor which affected the condition of the colloids. The transitory treatment of the unfertilized eggs with a mixture of equal parts of a $\frac{20}{8} n \mathrm{MgCl}_{2}$ solution and sea-water brings about a change in the physical conditions of certain colloids which is not reversed by putting them back into normal sea-water, and which allows them to develop into normal plutei.

As far as the spermatozoon is concerned, it may bring about the same change in the condition of the colloids in

\footnotetext{
1 I have not been able to raise the fertilized eggs of Arbacia beyond the pluteus stage in the laboratory.

2 Part II, pp. 539, 54t, and 559.

3 Paul, Archiv für die gesammte Physiologie, Vol. LXXVIII (1899), p. 315.
} 
the egg, either by its carrying specific ions into the egg or by carrying enzymes, or in some other way which is as yet unknown to us. It is certainly remarkable that the spermatozoa contain a large amount of ash $(5$ per cent., according to Hammarsten). In the parthenogenetic egg the colloids are from the beginning in such a condition as to allow the development to proceed. In other animals it is perhaps solely the ion constitution of the sea-water or of the blood which prevents the eggs from developing parthenogenetically. I shall discuss this point more fully in connection with further experiments on this subject. 


\section{XXX}

\section{ON ARTIFICIAL PARTHENOGENESIS IN SEA-CRCHINS ${ }^{1}$}

In the last October number of the American Journal of Physiology I published a preliminary note on the artificial production of larve from the unfertilized eggs of the seaurchin. I mentioned that unfertilized eggs were able to develop into normal plutei after having been in a solution of equal parts of a $\frac{20}{8} n \mathrm{MgCl}_{2}$ solution and sea-water for about two hours. The control experiments by which the possibility of the fertilization of these eggs through spermatozoa had been excluded were briefly mentioned. In the April number of the same journal a full description of my experiments was published which I believe puts an end to any doubt concerning the possibility of an error. Nevertheless, I decided to repeat these same experiments with the additional precaution of using steritized sea-water. Through the kindness of the board of trustees of the Elizabeth Thompson Fund I was enabled to make further experiments on artificial parthenogenesis at the Pacific coast. These experiments have led to a number of new results, which will be published in the American Journal of Physiology. Here I will confine myself to a description of the precautions which were taken in these experiments to exclude the possibility of a fertilization of the eggs through spermatozoa.

The sea-water used for these experiments was heated the day before, very slowly, to a temperature of from 50 to $70^{\circ}$ C., and was kept at that temperature for about ten minutes and allowed to cool very slowly. The control experiments proved that, as was to be expected, the spermatozoa are killed by this treatment. During the time the water was heated no sea-urchin was opened in the laboratory or was even 
kept there. The sterilized sea-water was kept in special flasks and covered jars which were utilized for this purpose only. Before we started an experiment we disinfected our hands thoroughly with soap and brush in the same way as is customary in a surgical operation. Every sea-urchin before it was opened was exposed for from two to five minutes to a powerful stream of fresh water, and care was taken to wash the whole surface of the animal as thoroughly as possible with fresh water. The mouth of the sea-urchin was then cut out with scissors that had been sterilized the day before in the flame and had been kept dry since. Through the excision of the mouth the sexual glands were exposed, and their color allowed to decide whether the animal was a male or a female. If the first animal that was opened was a female, the intestine was removed with a sterilized forceps, and care was taken not to bring the forceps in contact with the ovaries or with the outside surface of the animal. After the intestine had been removed and nothing left except the ovaries, the inside of the animal was repeatedly filled with fresh water and washed out. Then each of the five ovaries were taken out in toto with a sterilized section lifter, and special pains were taken that the ovaries did not come in contact with the surface of the sea-urchin or with the hands of the experimenter. The ovaries were first put into a dish of fresh water, were washed off carefully, and then put into sterilized sea-water.

One portion of the eggs was put into sterilized sea-water to serve as control material. A second portion was put into a mixture of equal parts of sterilized sea-water and a $\frac{20}{8} n$ $\mathrm{MgCl}_{2}$ solution. An hour or two later these eggs were taken out of this mixture and put into sterilized sea-water. While of the latter eggs as many as 25 per cent. developed into blastulæ and swam around the next day, not an egg of the control material even segmented. We spent hours 
searching the control material for segmented eggs, but were never able to find a single one.

In addition to these control experiments we made several others. It was necessary to apply the mixture of equal parts of the $\frac{20}{8} n \mathrm{MgCl}_{2}$ solution and sea-water for from one to two hours to bring about the development of the unfertilized eggs. We made it a rule to take out one portion of eggs from this solution much earlier - in some cases after ten minutes. In no case did one of these eggs segment or develop.

A third series of control experiments was applied. Solutions with less $\mathrm{MgCl}_{2}$ and more sea-water were tried. In solutions of 30 c.c. $\frac{20}{8} n \mathrm{MgCl}_{2}$, and 70 c.c. sea-water not an egg was able to develop.

If the first animal opened in these experiments happened to be a male, the instruments were at once laid aside for disinfection, and the next animal was opened by another experimenter with the same precautions.

In some experiments we used sea-water that had been filtered through a new Pasteur filter. Although no spermatozoa are able to pass through such a filter, the eggs treated with a mixture of equal parts of a $\frac{20}{8} n \mathrm{MgCl}_{2}$ solution and filtered sea-water developed, while none of the control eggs were able to develop.

In one of the former papers I mentioned the fact that the mixture used for artificial fertilization killed the spermatozoa in a comparatively short time and injured many of the eggs. Contrary to the common prejudice, it is a fact that spermatozoa are much more sensitive and are killed much sooner than the egg.

My experiments at Pacific Grove were carried on with Strongylocentrotus franciscanus and S. purpuratus. In both animals artificial parthenogenesis can easily be accomplished.

In the experiments at Pacific Grove I enjoyed the valuable assistance of Mr. W. E. Garrey. 


\section{XXXI \\ ON THE TRANSFORMATION AND REGENERATION OF ORGANS $^{1}$}

I

Several of the older scientists, for instance, Bonnet, Spallanzani, and Dalyell had occasionally observed that in the place of a head a tail may be regenerated in lower animals. ${ }^{2} \quad$ These casual observations had been considered as curiosities or pathological cases, and scientists took no further notice of them. It occurred to me that it might be possible to produce the substitution of one organ for another at desire, and that in this way we might gain an insight into the physiology of morphological processes. Having tried in vain to accomplish this result during the year 1888 in Kiel, I succeeded the following year at Naples. I found that if the foot of a Tubularian be cut off and the foot end of the stem surrounded on all sides by sea-water a head will be produced instead of a foot, while the same end produces a foot if it is in contact with some solid body, like the bottom of the aquarium. This arbitrary substitution of one organ by another I called heteromorphosis in contradistinction to the case of regeneration in which the same organ is reproduced. I succeeded in showing that phenomena of heteromorphosis can easily be produced in all kinds of Hydroids and in Tunicates. ${ }^{3}$

Since then a great number of heteromorphoses in various classes of animals have been obtained. The most brilliant accomplishment in this field of science is undoutedly Herbst's discovery that if in Crustaceans the eye together

1 American Journal of Physiology, Vol. IV (1900), p. 60.

2 Part I, p.115.

3 Loc, cit.

627 
with the optic ganglion be removed, an antenna will be produced in the place of the eye, while if the eye alone is cut off an eye is regenerated. The presence or absence of the optic ganglion decides whether a regeneration or a heteromorphosis will follow.'

I found, very early in my experiments, that in certain Hydroids a heteromorphosis can be produced without any organ being cut off or any wound being inflicted upon the animal. In Antennularia - a Hydroid common at Naplesthe arrangement and orientation of the organ as well as the direction of growth is dominated by gravitation. The animal consists of a straight vertical stem, which forms stolons at its lower end and which carries small branches with limited growth at regular intervals. On the upper surface of these branches the polyps are found. If such a stem be suspended horizontally in the water the lateral branches which are directed downward and which had finished growing now begin to grow downward very rapidly. At the same time the polyps on these branches disappear. The downward-growing parts no longer resemble the old side-branches but look like roots. A closer examination reveals the fact that they not only possess the morphological appearance of roots but also the physiological reactions of the latter, inasmuch as they are positively geotropic and stereotropic, while the branches do not show these forms of irritability. In this case the tissue of the polyps which disappeared seems to have been transformed into the tissue of roots. ${ }^{2}$

I made a similar observation shortly afterwards at Woods Hole in another Hydroid, Margelis. When the uninjured points of a stem of Margelis are brought in contact with a solid body the point of the stem assumes the form and

1 Herbst, Archiv für Entwickelungsmechanik, Vol. IX (1899), p. 215.

2 Part I, p. 191. 
Transforming axd Regenerating Organs 629

reaction of a root. It looks as if the contact with a solid body brought about a transformation of the stem into root material which is morphologically and physiologically different from the stem. ${ }^{1}$ But as neither Antenuularia nor Margelis is sufficiently transparent, it was not possible to ascertain that a transformation of polyps and stems into stolons occurs in this case.

Miss Bickford made an observation in my laboratory which helped in making the assumption of a transformation of organs more probable. Small pieces were cut from a stem of a Tubularian. These pieces were smaller in size than a normal polyp. Miss Bickford found that within sixteen hours such a piece assumed the form of a polyp. ${ }^{2}$ Driesch confirmed her observation. ${ }^{3}$

Last summer I had an opportunity to observe directly the transformation of organs under the influence of contact. My observations were made at Woods Hole on a transparent Hydroid, Campanularia. This Hydroid attaches itself with stolons to solid bodies. The stem with the polyps grows at right angles with the solid body to which its stolons are attached. If these Campanulariæ be cultivated on a vertical wall all the stems assume an exactly horizontal position in the water. The stem of a Campanularia is the most perfect specimen for negative stereotropism I have ever observed. If a stem be cut off and put on the bottom of a watchglass filled with sea-water, all the polyps that touch the glass are transformed into the material of the stem. This material creeps out of the stem, forming stolons wherever it comes in contact with the glass, giving rise to polyps on its upper surface which is in contact with sea-water. The polyps continue growing at right angles toward the

\footnotetext{
1 LOEB, Woods Hole Biological Lectures, 1893.

2 Bickford, Journal of Morphology, Vol. IX (1894), p. 417.

3 DRIEscH, Vierteljahrschrift der Naturforscher-Gesellschaft, Zürich, 1896.
} 
bottom of the dish. All these processes may occur in less than a day, and can be observed directly with a lens. I will try to give a description of these phenomena with the aid of camera drawings I made while observing them. Fig. 152 shows the condition of a Campanularia stem that had been put on the bottom of a watchglass the
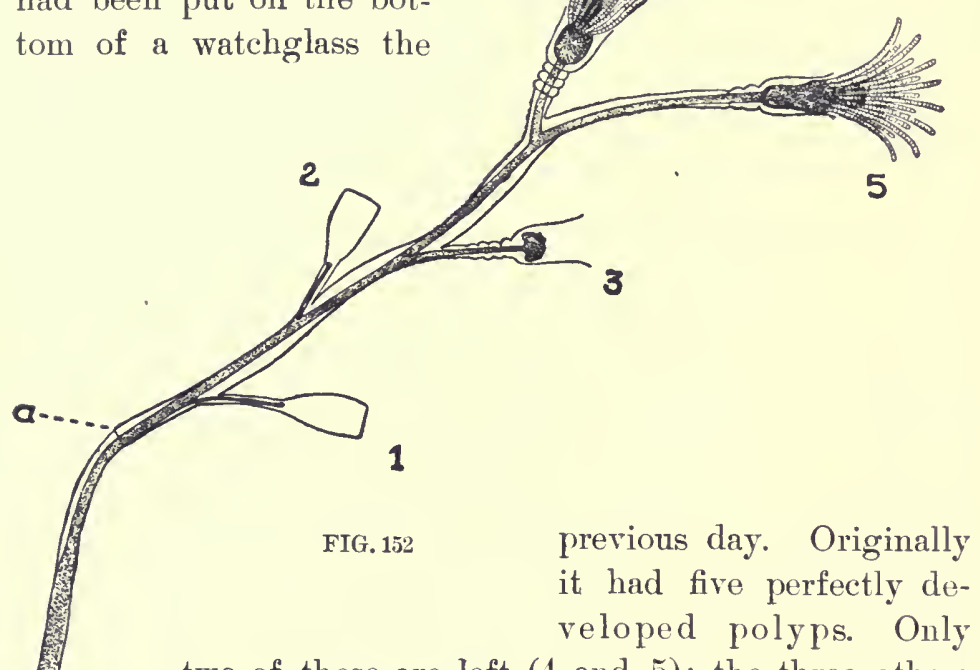
two of these are left (4 and 5); the three others $(1,2$, and 3$)$ have disappeared. At the lower end, $a$, of the original stem a new stolon, $a b$, has grown out. What had become of the three polyps that had disappeared? I watched them very closely and found that they were transformed into a shapeless mass and withdrawn into the stem. I will describe this process of transformation of polyps into the material of the stem more minutely with the help of Figs. 153, 154, 155. These are not taken from the same stem, but as the process occurs almost always in the same form, this makes no material difference.

The transformation of a polyp into the less differentiated 
material of the stem begins with a shortening and folding together of the tentacles (polyp 1 in Fig. 153). This process is at the beginning the same as that which occurs upon any stimulation of the polyp and especially in the act of taking up food. But while in the latter case the tentacles unfold again, in the case of the transformation of the polyp they remain together. Very soon all the tentacles begin to fuse into a homogeneous mass. This process of fusing begins usually at

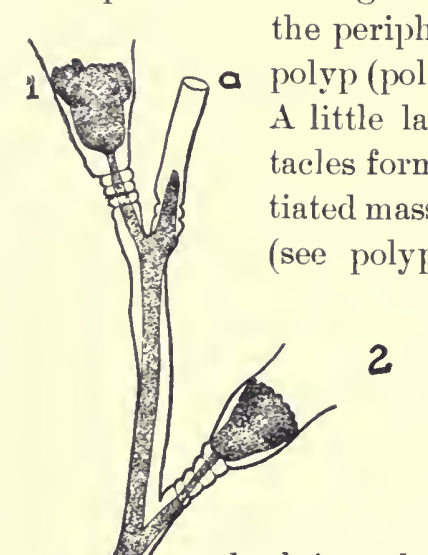
the peripheral end of the poly (polyp 2, Fig. 153). A little later all the tentacles form an undifferentiated mass of protoplasm (see polyp 1, Fig. 15̈).

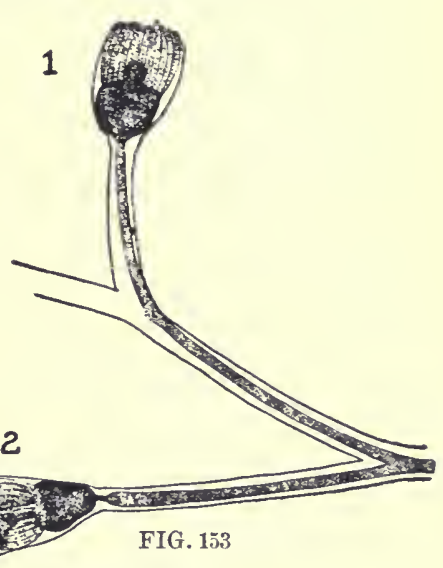
In the next stage (2, Fig. 154) the 2 original differentiation of the crown of the polyp into tentacles can no longer be recognized.

At this stage the transformed shapeless mass of the polyp begins to flow back into the stem (1, Fig. 155). A little later only a fraction of the original protoplasm of the polyp is left in the periderm, the rest having crept back into the stem (2, Fig. 155). In polyps 3, 2, and 1 (Fig. 152) FIG. 154 we see the further stages of this process of the polyp material flowing back into the stem.

The transformation of polyps and their creeping into the stem occurs probably in a similar way in an Antennularia which is put into the water horizontally. The main difference between an Antennularia and a Campanularia is that in the latter this transformation is produced by the polyp coming 
in contact with a solid body, while, in an Antennularia a change in the position of the polyp toward the vertical suffices to bring about this result. ${ }^{1}$

While these processes are going on, the material of the stem begins to creep or grow out of the original periderm. It

\section{1}

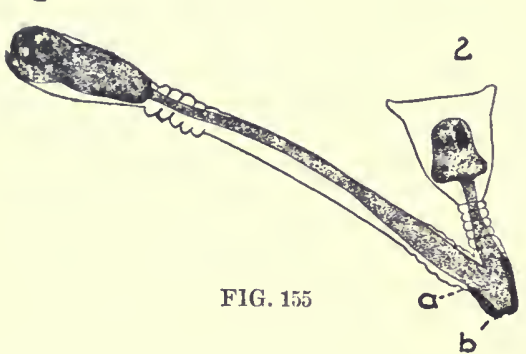
seems to me worth while to call the attention of the reader to the fact that in this case the process of grouth is identical with the process of progressive motion of a motoplasmic mass. In plants growth occurs mostly near the apex of an organ. If we look at the increase in size of the stolon from the point of view of grow th we notice that its growing point is near the arex, just as in plants. But if we look at it from the point of view of progressive amoboid motion we notice that only the foremost point creeps and that the rest of the protoplasm is pulled out more passively. That the protoplasm of the stem is under a strain will be seen by a glance at Figs. 152, 153, 15t, and 156. The cœenosarc or protoplasm lies in the periderm in the same way as a stretched rubber thread would lie. Wherever the periderm is bent the protoplasm touches it on the concave side. It follows as nearly as possible the shortest line in the periderm. It is possible that the strain under which the cœnosare is kept causes the protoplasm to flow in the direction of the strain toward the tip of the stolon. Botanists are inclined toward an exclusively osmotic conception of the process of growth. I have come more and more to the conclusion that the osmotic theory of growth is not in harmony with the phenomena

1 In former papers I have described the fact that in Eudendrium the polyps are thrown off when the stems are put into small dishes. Such phenomena may occur also in Campanularia, but this was not the case here. [1903] 
of absorption. I do not consider it impossible that the phenomena of protoplasmic motion which we can actually observe in the growth of a stolon in Campanularia exist also in the phenomena of growth of other organisms, plants as well as animals. I have already called attention to this possibility in a former paper.

Before we leave this subject I wish to describe how the nature of the contact localizes the development of polyps from stolons and stems. The piece, $b c$, Fig. 156, was cut out from a fresh Campanularia stem and had been put into a watchglass filled with sea-water. This piece had a normal polyp at $i$, which was transformed into a mass of undifferentiated protoplasm and began to flow back into the stem. Simultaneously a new stolon began to grow out at $c$, and very soon reached the considerable size, $c d$. Then a new polyp, $h$, began to rise on the upper surface of the stem. It grew at right angles toward the watchglass, a point which cannot be rendered accurately in the drawing. A new stolon, $a b$, began to grow or creep out simultaneously at 1. Curiously enough, as soon as this happened the protoplasm began to flow back from the old stolon, $c d$. At the time the drawing was made

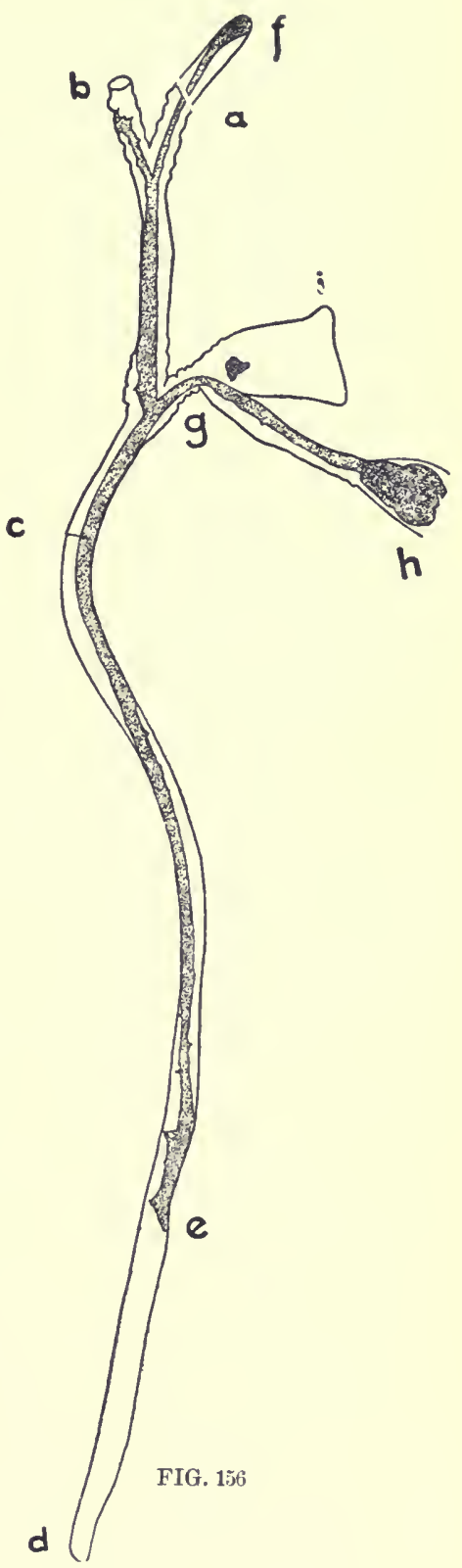


it had flowed back to the point $e$. This was on the third day of the experiment. I have however noticed that the stem can send out stolons in different directions simultaneously.

The hereditary arrangement of organs in Hydroids is unequivocally determined by external circumstances, especially contact. A germ or larva of a Hydroid will form roots on one side only, namely the side where it touches solid bodies: on the opposite side where it touches seawater it will produce polyps or stems. The negative stereotropism of the latter or their positive heliotropism as in the case of Eudendrium will cause them to continue growing away from the solid body into the sea-water. Weismann is therefore wrong in assuming that the hereditary arrangement of the organs in Hydroids is due to a definite arrangement of the elements in the germ.

\section{II}

What is the character of the physical or physiological processes which underlie the transformation of organs? Such complicated formations as the polyp in Campanularia are only possible if certain of the constituents are solid. The transformation of such a polyp into the more shapeless flowing or creeping material of the stem can only be due to a liquefaction of these solid constituents. It is moreover certain that contact with sea-water favors the formation of polyps with its more solid elements, while the contact with solid bodies favors the formation of the more fluid material of the stem or stolon. Hence it seems as if the nature of contact in this case determined the state of matter of certain colloids in the Campanularia. ${ }^{1} \quad$ Although I had observed the influence of the nature of contact upon these phenomena fur many years I had not been able to form any definite idea of

1 I do not need to mention especially that the periderm does not participate in these liquefactions. 
Trangforming and Regenerating Organs 630

how the nature of the contact could possibly influence these processes, and I do not think that anyone else has thus far offered an explanation. While studying the literature on the coagulation of the blood I came across Duclaux's account of this process in his Traité de microbiologie, ${ }^{1}$ and it seemed to me that if his notions are correct they might also be applied to our problem of contact-heteromorphosis. According to Duclaux it is the character of the contact applied to the leucocytes which decides whether the enzyme of coagulation, the plasmase, becomes effective or not. As long as the leucocyte touches the endothelium of the bloodvessels the blood remains liquid because the contact of the leucocytes with the endothelial cells does not allow the fibrin enzyme to act. If, however, the leucocyte touches a piece of glass the plasmase becomes active and causes coagulation. If the glass is covered with a layer of oil coagulation does not occur. Duclaux assumes that surface tension phenomena decide the setting free of plasmase on the part of the leucocyte. Whether this latter assumption be correct or not matters little for our purpose. We only need to carry the analogy between the influence of contact upon the state of matter of fibrinogen and the state of matter of certain colloids in the Hydroids far enough to assume that both depend upon definite enzymes becoming active through certain forms of contact acting upon the cells in which they are formed. In the case of the blood a solidifying enzyme, in the case of the polyps a liquefying enzyme is made active if the leucocyte or the polyp come in contact with glass or some other solid body.

These considerations possibly allow of a wider application than to the mere case of contact-heteromorphosis. When a piece of our skin is cut off, the cells of the margin of the wound begin to multiply and spread out over the gap. We

1 Declacx, Traité de microbiologie, Vol. II, Paris, 1899. 
might say the change in the character of the contact causes an increase in the cell-divisions. This is still more obvious where whole organs are produced or regenerated. In one of my former papers I pointed out a very definite chemical difference between embryonic tissue and muscle tissue. ${ }^{1}$ The former is more immune against $\mathrm{K}$ ions and more sensitive toward $\mathrm{Ca}$ ions. It has long been noticed, especially by botanists, that young tissue contains comparatively more $\mathrm{K}$ than old tissue. I am inclined to assume that this accounts for the fact that young tissue contains more water or has a greater degree of turgidity than old tissue. An increase in $\mathrm{K}$ allows the protoplasm to take up more water, an increase in Ca has the opposite effect. ${ }^{2}$ Ion effects and the effects of certain enzymes of liquefaction or solidification are often similar, or may at least support each other. It is not impossible that the increase in cell-divisions among the cells of the margin of the wound may be due to the different character of the contact to which these cells are exposed during or after the lesion, inasmuch as this different contact sets free or throws into activity certain enzymes which do not act as long as these cells are in their natural surroundings, $\rho . g$., as long as they are in contact with other cells.

In returning after this digression to our main subject we must mention that the nature of the contact is not the only means by which solid elements in living tissues may be liquefied. Five years ago I proved that lack of oxygen liquefies the cell walls in the blastomeres of a teleost egg (Ctenolabrus), ${ }^{3}$ and Budgett showed in my laboratory that lack of oxygen produces the same phenomenon in Infusoria. This case may find its explanation through the well-known experiment of Pasteur on the effect of oxygen on yeast cells. With plenty of oxygen the yeast cells multiply abundantly,

\footnotetext{
1 Part II, p. 559.

2 Part II, p. 510.

3 Part I, p. 370 .

4 Budgett, American Journal of Physiology, Vol. I (1898), p. 210.
} 
but produce comparatively little fermentation; with little oxygen they multiply less but cause a more abundant development of alcohol and $\mathrm{CO}_{2}$. In the liquefaction of the cellwalls of the blastomeres of Ctenolabrus or of Infusoria we may have the analogue of the increased fermentation in Pasteur's experiment. In the latter we have to deal with a special enzyme, the zymase.

Miescher pointed out that in the salmon a liquefaction of muscular tissue occurs, and that the liquid products are utilized for the formation of sexual cells. Miescher was inclined to ascribe the liquefaction of the muscle to lack of oxygen. He noticed that the liquefaction of the muscle was preceded by a reduction in the blood supply of the muscles. ${ }^{1}$ My own and Budgett's observations agree with Miescher's views. ${ }^{2}$

It is possible that the processes of histolysis in the metamorphosis of insects are of a similar character, and some authors have claimed that the histolysis in this case is brought about by a process of asphyxiation. Metschnikoff assumes that a phagocytosis plays an important rôle in these phenomena of histolysis. It is certain that in my experiments on Ctenolabrus and in Budgett's experiments on Infusoria no phagocytes were present, and it is practically impossible that they played a rôle in the above-mentioned phenomena in Campanularia. I do not think that the liquefaction of colloids requires the presence of phagocytes any more than the liquefaction of crystals.

1 Die histochemischen und physiologischen Arbeiten von F. Mriescher, Leipzig, Vol. I (1897), pp. 94-100.

2 It is possible that in the case of Campanularia the histolytic phenomena do not stop with the liquefaction of certain constituents, but that this process is followed by hydrolysis. [1903] 


\section{XYXII}

\section{FURTHER EXPERIMENTS ON ARTIFICIAL PARTHENO- GENESIS AND THE NATURE OF THE PROCESS OF FERTILIZATION ${ }^{1}$}

1. In my previous communications on the subject of artificial parthenogenesis ${ }^{2}$ I had confined myself to the proof of the fact that the unfertilized eggs of Arbacia and Strongylocentrotus franciscanus and purpuratus, are capable of a development into the pluteus form if kept for from one to two hours in a mixture of equal parts of a $\frac{20}{8} n \mathrm{MgCl}_{2}$ solution and sea-water. The above-mentioned solution, which brings about the artificial development of the egg, differs in three directions from the constitution of the normal seawater. First, the osmotic pressure of the solution is higher than that of the normal sea-water; second, one-half of the salts contained in normal sea-water are removed. It might be possible that the sea-water contains ions which are injurious to the development, and that the removal of these ions makes the development of the unfertilized eggs possible. Third, a considerable amount of $\mathrm{MgCl}_{2}$ is brought into solution, and it might be that the Mg ions have a specific "stimulating" effect upon the development. For the determination of the nature of the process of fertilization it was necessary to find out which of the three conditions is essential for the production of artificial parthenogenesis.

2. I had already mentioned in a previous paper that the mere change in the constitution of the sea-water, if not accompanied by an increase in its osmotic pressure, can only

1 American Journal of Physiology. Wol. IV (August 1, 1900), p. 178. These experiments were carried out with the aid of the Elizabeth Thompson Science Fund.

2 Part II, pp. 539, 576, and 624. 
cause the egg to go through a few segmentations, but cannot cause the parthenogenetic production of a blastula or a later stage of development. The increase in the osmotic pressure of the solution is therefore an essential condition for artificial parthenogenesis. As the season was at an end, it was not possible for me to decide last autumn whether the other two above-mentioned conditions are equally essential. Through the aid of the Elizabeth Thompson Fund I was enabled to carry on experiments in co-operation with Dr. W. E. Garrey at Pacific Grove during the spring, ${ }^{1}$ and I have since had a chance to continue this work at Woods Hole. My new results enable me to give a more definite answer to the question of the nature of the process of fertilization. I first tried to ascertain whether the $\mathrm{MgCl}_{2}$ plays a specific rôle in artificial parthenogenesis, or whether its place may be taken by some other salt. I found that the latter is the case. $^{2} \quad$ A mixture of equal parts of a $\frac{10}{8} n \mathrm{NaCl}$ solution and sea-water, or of equal parts of a $\frac{10}{8} n \mathrm{KCl}$ solution and seawater, is just as effective as, if not more so than, a $\frac{20}{8} n$ $\mathrm{MgCl}_{2}$ solution. Unfertilized eggs of Strongylocentrotus, if left for seventy minutes in any of these solutions, developed, and some of them reached the pluteus stage. Such eggs remained alive as long as ten days. Even a mixture of equal parts of a ${ }_{8}^{20} n \mathrm{CaCl}_{2}$ solution and sea-water brought about the development of the eggs, but it was necessary to take the eggs out in about forty to fifty minutes, as otherwise the solution killed them. None of the eggs treated with the $\mathrm{CaCl}_{2}$ solution developed beyond the blastula stage, or lived longer than one day.

I noticed that in these experiments with a $\frac{10}{8} n \mathrm{NaCl}$ or

1 I wish to express my thanks to Professor Jenkins, of Stanford University, for kindly allowing me the use of the Hopkins Laboratory.

2 I had been misled in my original experiments of 1899 through the fact that the solutions which I considered as isosmotic differed in their concentration, owing to an error in their preparation. When I resumed the experiments in $1900 \mathrm{I}$ discovered the error and corrected it. [1903] 
$\mathrm{KCl}$ solution only a comparatively small number of eggs reached the blastula stage, certainly many less than in my previous experiments with $\mathbf{M g C l}_{2}$ on Arbacia. A further examination revealed the fact that the $\mathrm{MgCl}_{2}$ solution which I had used was, through an error or a misunderstanding of the assistant who made it, weaker than a $\frac{20}{8} n$ solution. As soon as I found this out, I started experiments with more diluted $\mathrm{NaCl}$ and $\mathrm{KCl}$ solution. Instead of using equal parts of a $\frac{10}{8} n \mathrm{NaCl}$ or $\mathrm{KCl}$ solution and sea-water, I used the following mixtures:

$20 \frac{20}{8} n \mathrm{NaCl}+30$ distilled water +50 sea-water,

or- $\quad 17 \frac{1}{2} \frac{20}{8} n \mathrm{NaCl}+32 \frac{1}{2}$ distilled water +50 sea-water.

In both cases more eggs reached the blastula and pluteus stage than with the original stronger mixture. In one case unfertilized eggs developed beautifully after having been for two hours in a solution of equal parts of $152 \frac{1}{2} n \mathrm{NaCl}$ +35 distilled water +50 sea-water. But this was nearly the lowest limit for artificial parthenogenesis in Arbacia. As a rule, 25 per cent. or more of the unfertilized Arbacia eggs reached the blastula stage.

3. It was thus proved that $\mathrm{MgCl}_{2}$ does not play a specific rôle in the production of artificial parthenogenesis. It remained to decide whether it is essential to remove one part of the normal constituents of the sea-water, or whether the mere increase of the osmotic pressure suffices. I found that the increase in the osmotic pressure of the sea-water is all that is needed. In the experiments in which the maximal number of unfertilized eggs reached the bastula stage about 1 gram $\mathrm{NaCl}$ had been added to the sea-water. We can produce the same increase in the osmotic pressure of the sea-water by adding 10 c.c. of the $2 \frac{1}{2} n \mathrm{NaCl}$ or $2 \frac{1}{2} n \mathrm{KCl}$ solution ${ }^{1}$ to 90 c.c. of sea-water. In this case the mixture

$1 \mathrm{My} 2 \frac{1}{2} n \mathrm{NaCl}$ solution contained $146.25 \mathrm{~g}$. in a liter. The $2 \frac{1}{2} n \mathrm{KCl}$ solution contained $186.25 \mathrm{~g}$. in a liter. 
contained practically all the constituents of normal sea-water. Yet if unfertilized eggs of Arbacia are left in such a solution for from one and one-half to two hours, as many as 50 per cent. of the eggs may reach the blastula stage when put back iato normal sea-water. Many of these eggs die in the blastula stage and only a small number reach the gastrula or pluteus stage. The blastulæ are like those which I described in one of my former papers. ${ }^{1}$ In the majority of cases more than one blastula develops from one egg. I have seen as many as six moving blastulæ arise from one egg. The tendency to give rise to more than one embryo is greater in the egr of Arbacia than in the egg of Strongylocentrotus. This difference is probably due to the fact that even the unfertilized egg of Strongylocentrotus often forms a fine membrane which is much thimner than the one produced through the entrance of a spermatozoon, but which is sufficient to keep the blastomeres together. The addition of $\mathrm{NaCl}$ or $\mathrm{KCl}$ to sea-water favors the formation of this membrane.

4. In all the experiments mentioned thus far the increase in the osmotic pressure had been brought about by the addition of electrolytes. This might be considered as an indication that the electrically charged ions in the sea-water played an important rôle in the production of parthenogenesis. I myself was originally inclined to such an assumption. I have convinced myself, however, that an increase in the osmotic pressure of the sea-water through the addition of cane-sugar or urea can produce parthenogenesis. My stock solution of cane-sugar (rock candy) was $2 n$ and contained $684.3 \mathrm{~g}$. in a liter, while the stock solution of urea was $2 \frac{1}{2} n$ and contained $150.31 \mathrm{~g}$. in a liter. I found that the unfertilized eggs of Arbacia were able to develop after they had been for from one and one-half to two hours in one of the following solutions:

${ }^{1}$ Part II, p. 5 \%6. 
(1.) 100 sea-water $+252 n$ cane-sugar

(2.) $82 \frac{1}{2}$ sea-water $+17 \frac{1}{2} 2 \frac{1}{2} n$ urea

Both the sugar solution as well as the urea solution injured the eggs, the urea solution much more than the sugar solution. I made an attempt to produce parthenogenesis by submitting unfertilized eggs to a pure cane-sugar solution whose osmotic pressure was about equal to that of the seawater, to 90 c.c. of which 10 c.c. of a $2 \frac{1}{2} n \mathrm{NaCl}$ solution had been added. When the unfertilized eggs of Arbacia were put for about two hours into a mixture of $602 n$ cane-sugar +40 distilled water or $552 n$ cane-sugar +45 distilled water, many of them segmented and a few developed into swimming blastulæ, but they died within the first twentyfour hours. This proves conclusively that the development of the unfertilized egg is produced through an increase in the concentration of the surrounding solution. As it is immaterial whether the increase in the osmotic pressure is brought abont by electrolytes or non-conductors, there can be no doubt that the essential feature in this increase in the osmotic pressure of the surrounding solution is a loss of water on the part of the egg.

5. Having reached the conclusion that the loss of water, or rather the loss of a certain amount of water, causes the parthenogenetic development of the egg, it seemed possible to take another step in advance. In all the previous experiments the unfertilized eggs had been submitted to a solution of higher osmotic pressure for from one to two hours, and were then put back into normal sea-water to develop. If the initial loss of water on the part of the egg were all that is required for the production of artificial parthenogenesis, it would be possible to find a solution which would not only take away water from the egg, but which would also allow development to go on. I remembered from my earlier experiments on the effects of an increase in the concentration 
of sea-water upon development ${ }^{1}$ that so slight an increase in the concentration of sea-water as is sufficient to induce parthenogenesis allowed the development of the eggs to go on for at least twenty-four hours. I found that if we put unfertilized eggs into a mixture of 93 sea-water and $72 \frac{1}{2} n$ $\mathrm{NaCl}$ solution, many eggs develop in the solution, and some of them even reach the blastula stage and swim about. If we use a mixture of 90 sea-water and $102 \frac{1}{2} n \mathrm{NaCl}$ solution, the development stops earlier, for the simple reason that such a solution is more injurious. Those facts show clearly that the function of the artificial solution in the production of parthenogenesis is that it has to deprive the egg of a certain amount of water. In the majority of cases the solutions that produce such an effect are at the same time too injurious to allow the egg to develop or live long enough to reach the blastula stage. This is the reason why we have to take the eggs out of this solution and bring them back into normal sea-water, if we wish them to develop into normal larvæ.

6. A consequence of the loss of water on the part of the egg is an increase in its osmotic pressure. The osmotic pressure inside the egg is furnished chiefly or almost exclusively by electrolytes. It is thus not impossible that the ions in the egg, if their concentration is raised, bring about that change which causes the egg to develop. If we assume that the spermatozoon starts the development of the egg in the same way as in the case of artificial parthenogenesis it follows that the spermatozoon must possess more salts or a higher osmotic pressure than the eggs. As I pointed out in a former paper, this seems to be the case. But there is no reason why the spermatozoon should not bring about the same effects that we produce by reducing the amount of water in the egg in some different way. At present, how-

1 Journal of Morphology, Vol. VII (1892), p. 253. 
ever, the only light that can be thrown upon the nature of the process of fertilization must be expected from an analysis of the effects of a loss of water upon the egg.

It seems as if the liquefaction of the nuclear membrane and other constituents of the nucleus were a prerequisite for cell-division. Norman showed that a certain increase in the concentration of the sea-water brings about a distribution of the chromosomes in the egg. Morgan's observations agree with this. But as all these observations were made with solutions whose osmotic pressure was considerably higher than that of the solutions used in my experiments, new observations will be required to decide this question. HoppeSeyler, in one of his papers, points out that a loss of water on the part of the protoplasm brings about a diminution in the processes of oxidation. We know that lack of oxygen can bring about the liquefaction of solid constituents. I add these remarks for those who enjoy the speculative side of biology. But at the best a theory cannot give us anything more than the facts it includes, and it is therefore clearly our task to supply the lacking experimental data in this field of biology before we begin to theorize.

7. I think we should try to discover first of all whether the process of development can be started by depriving the egg of water in a few forms only, or whether this is a general condition. I have thus far tried among the sea-urchins Arbacia and Strongylocentrotus franciscanus and purpuratus. Each of these forms is capable of osmotic parthenogenesis. I am confident that the same is true for all species of seaurchins, although the optimal increase in the osmotic pressure of the surrounding solution may vary for different forms. But I consider it of more importance that with the same methods I have been able to produce artificial parthenogenesis in a starfish (Asterias Forbesii). By putting the 
unfertilized eggs of this starfish for about two hours into a mixture of 88 c.c. of sea-water and 12 c.c. of a $2 \frac{1}{2} n \mathrm{NaCl}$ solution the eggs can be forced to develop and reach the blastula stage, if put back afterward into normal sea-water. I have not yet found the optimal condition for the parthenogenetic development of Asterias, but the facts thus far obtained suffice to state that a certain increase in the osmotic pressure of the surrounding solution (and a loss of a certain amount of water on the part of the egg) causes the egg of this form to develop parthenogenetically.

I have mentioned in another place ${ }^{1}$ the precautions and control experiments used to guard against the presence of spermatozoa. I do not consider it necessary to repeat these statements in this paper, but will mention one additional precaution, for which I am indebted to the collector of the Marine Biological Laboratory, Mr. Gray. Mr. Gray selects the females of Arbacia for my experiments, so that in all these later experiments I have not had one male in the laboratory. Not one egg developed in the control material. All the sea-water used in these experiments was heated to the temperature of $70^{\circ} \mathrm{C}$.

\section{CONCLUSIONS}

The results of my experiments are as follows:

1. Through a certain increase in the osmotic pressure of the surrounding solution the unfertilized eggs of some (probably all) Echinoderms (Arbacia, Strongylocentrotus, Asterias) can be caused to develop into normal blastulæ or even plutei.

2. This increase in osmotic pressure can be produced by electrolytes as well as by non-conductors. It is therefore probable that the parthenogenetic development is caused by the egg losing a certain amount of water.

1 Part II, p. 576. 


\section{XXXIII}

EXPERIMENTS ON ARTIEICIAL PARTHENOGENESIS IN ANNELIDS (CHETOPTERUS) AND THE NATURE OF THE PROCESS OF FERTILIZATION'

\section{INTRODUCTION AND METHODS}

Mr preceding papers on artificial parthenogenesis ${ }^{2}$ had proved that by an increase in the osmotic pressure of the sea-water the eggs of many, if not all, Echinoderms can be caused to develop parthenogenetically. Two new problems presented themselves for immediate consideration. The one was to raise the parthenogenetic larvæ until they were sexually differentiated, in order to decide whether or not they are of uniform sex. The second problem was to try whether artificial parthenogenesis is confined to the group of Echinoderms or whether it is a more general phenomenon. As the means for the raising of sea-urchins were not available at Woods Hole this year, the former problem had to be postponed. The solution of the second problem, however, was possible, and yielded the result that the unfertilized eggs of Chætopterus, a marine Annelid, can be caused to develop into swimming ciliated larvæ (trochophores). A short preliminary report of this result has been published in Science. ${ }^{3}$

In experiments on parthenogenesis the greatest precautions are necessary to exclude the possibility of a contamination of the eggs by spermatozoa. I purposely selected Chætopterus for my further experiments on account of the possibility of discriminating between and separating the females and males. If the experimenter handles females and males in the same experiment or with the same instru-

1 American Journal of Physiology, Vol. IV (1901), p. 423.

2 Part II, pp. 539, 576, 624, and 638.

${ }^{3}$ Science, Vol. XII (1900), p. 170. 
ments, it is extremely hard to aroid an infection of the eggs by sperm. I proceeded as follows in the experiments with Chætopterus. As soon as the animals were brought into the laboratory by the collector, the tubes in which they live were opened and the worms removed. As soon as the first female was found it was put into a special dish and thoroughly washed off with sea-water, the water being renewed from six to twelve times in succession. The sea-water in the laboratory was found to be absolutely free from spermatozoa of Chætopterus. (The animals are found on the beach of an island at some distance from the laboratory.) After the female had undergone the process of washing, it was exposed to a current of sea-water over night to remove as far as possible any spermatozoa that might have been left on the surface. The next day the animal was ready to be used for an experiment. On that day and before the experiment began, the experimenter did not bring his hands in contact with any other Chætopterus or with the aquarium that contained such animals. His hands and instruments were sterilized with fresh water. The posterior part of the animal which contains the eggs was cut off and thoroughly washed for two minutes in distilled or fresh water. Had any spermatozoon been left on the surface of the animal, the distilled water would have killed it. After this the part containing the eggs was put into a vessel with sterilized sea-water, washed off once more and then put into another dish containing sterilized sea-water. In this dish the single parapodia were opened successively, the eggs sucked out from each with a pipette, and then collected in another dish with sterilized sea-water. After all the eggs had been collected they were divided into two lots. The one lot remained in normal (sterilized) sea-water, to serve as control material. The other lot was distributed into the various solutions whose effect I intended to test. In no case did I see a single egg of the 
control material develop into a larra. I noticed only that after from seven to ten hours some of these eggs may show a beginning of a segmentation which, however, soon ceases. This phenomenon seems to be quite common among many marine animals. I mentioned in a former paper that $O$. Hertwig had already noticed that it is a common occurrence among Arthropods, Worms, and Echinoderms. ${ }^{1}$ If, however, no such aseptic measures against spermatozoa were taken, a number of eggs in the control material usually reached the trochophore stage. The sea-water used in these experiments was sterilized by heating it slowly to a temperature of from $60^{\circ}$ to $80^{\circ} \mathrm{C}$. In a smaller number of experiments I used sea-water which had gone through a Pasteur (Chamberland) filter which, of course, is absolutely impermeable to spermatozoa: ${ }^{2}$ If the eggs of more than one female were used for an experiment, all the eggs were first gathered in one dish, thoroughly mixed, and then divided into two lots, one to serve as control material and one to be distributed into the various solutions. Thus the control material and the material experimented upon consisted always of the eggs of the same females. It goes without saying that the same was the case in all my previous experiments on Echinoderms.

\section{ARTIFICIAL PARTHENOGENESIS CAUSED BY AN INCREASE IN THE OSMOTIC PRESSURE OF THE SEA-WATER}

It was natural to try first whether or not the same means that cause the parthenogenetic development in Echinoderms are also sufficient to bring about the parthenogenetic development of the eggs of Chætopterus.

First series. - When I received the first material, I at

1 O. Hertwig, Die Zelle und die Gewebe, Vol. I (1893), p. 239.

2 In almost all the experiments the sea-water used was sterilized. In a few exceptions this precaution was purposely omitted in order to find out whether or not the sea-water in the laboratory contained spermatozoa of Chætopterus. This, however, was not the case. 
once started an experiment, although I knew that it was practically impossible to exclude contamination by spermatozoa if I attempted to isolate the eggs immediately after having handled a male. The female was washed off in sterilized sea-water, but of course I was aware that this would not suffice to get rid of any spermatozoa that might be sticking to the surface of the animal. The eggs, however, were taken and distributed into the following five solutions:

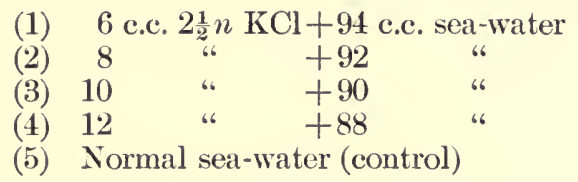

One part of the eggs remained one hour and twenty-five minutes, the rest one hour and forty minutes in the solutions. The experiment was started in the afternoon. The next morning ${ }^{1}$ I found numerous swimming larvæ (trochophores) in the material that had been in the first four solutions for one hour and twenty-five minutes. In the second lot they were less numerous. But even in the control material I found two swimming trochophores. It followed that the Chrtopterus were either naturally parthenogenetic or the precautions against the entrance of spermatozoa had not been sufficient.

Second series.-From now on I applied the rigid antiseptic measures against spermatozoa described above in the introduction. The following solutions were used:
(1) 8 c.c. $2 \frac{1}{2} n \mathrm{KCl}+92$ c.c. sea-water
(2) 10 c.c. $2 \frac{1}{2} n \mathrm{KCl}+90$ "
(3) 12 c.c. $2 \frac{1}{2} n \mathrm{KCl}+88$ "
(4) 12 c.c. $2 \frac{1}{2} n \mathrm{NaCl}+88$ "
(5) 20 c.c. $2 \frac{1}{2} n \mathrm{MgCl}_{2}+80$
(6) Normal sea-water (control)

1I shall in the following descriptiou of the experiments consider only whither or not swimming trochophores were formed. The morphological details will be given in section $\mathrm{v}$. It goes without saying that all tho experiments deal with unfertil ized eggs, unless the contrary is distinctly stated. 
All the sea-water had been sterilized the previous day by heating it to a temperature of $80^{\circ}$; one part $(a)$ of the eggs remained one hour, a second part $(b)$ one hour and twenty minutes in these solutions.

The first four solutions yielded numerous swimming trochophores; their number was greatest in the first two solutions. Lot $a$ of the $\mathrm{MgCl}_{2}$ solution yielded no swimming blastulæ, but lot $b$ had a few. The control eggs were completely undeveloped, with the exception that after about ten hours a few showed the beginning of a segmentation, which in no case led to the formation of more than from 4 to 6 cells. During the next forty-eight hours no further development occurred, and the eggs died and disintegrated. According to this experiment the unfertilized eggs of Chrtopterus are not able to develop in normal sea-water. They can, however, be caused to develop into trochophores if exposed for about an hour to sea-water whose concentration has been raised through the addition of the right quantity of $\mathrm{KCl}$ or $\mathrm{NaCl}$.

Third series.-The next task was to ascertain how much the osmotic pressure of the sea-water must be raised in order to bring about the parthenogenetic development, and whether the increase in osmotic pressure necessary for this purpose was the same in each case. The solutions used were as follows:

(1) 10 c.c. $2 \frac{1}{2} n \mathrm{KCl}$

(2) $12 \frac{1}{2}$ c.c. $2 \frac{1}{2} n \mathrm{KCl}$ +90 c.c. sea-water

(3) 30 c.c. $2 n$ cane-sugar +70

(4) $12 \frac{1}{2}$ c.c. $2 \frac{1}{2} n \mathrm{NaCl}+87 \frac{1}{2}$

(5) Normal sea-water (control)

The osmotic pressure in solutions 2, 3, and 4 was about the same. The eggs remained sixty-five minutes in these solutions, and were then put back into normal sea-water. While a great number of the eggs that had been in solutions 
1 and 2 developed into trochophores, very few of the eggs of solution 4 and none of solution 3 reached the trochophore stage. The control eggs remained undeveloped.

Fourth series. - The results were obviously puzzling if the increase of the osmotic pressure was the only factor that brought about the development of the unfertilized eggs of Chætopterus. But they would be intelligible if there were, in addition to the effect of an increase in the osmotic pressure, a specific effect of the $\mathrm{KCl}$ or the $\mathrm{K}$ ions. In order to decide this, the unfertilized eggs of a female were distributed into the following solutions:

$\begin{array}{lrrrr}\text { (1) } & 5 \text { c.c. } 2 \frac{1}{3} n & \mathrm{KCl}+95 & \text { c.c. sea-water } \\ (2) & 10 & \text { " } & \text { " }+90 & \text { " } \\ (3) & 15 & \text { " } & \text { " }+85 & \text { " } \\ (4) & 5 & \text { " } & \mathrm{NaCl}+95 & \text { " } \\ (5) & 10 & \text { " } & \text { " }+90 & \text { " } \\ \text { (6) } & 15 & \text { " } & \text { " }+85 & \text { " } \\ \text { (7) } & \text { Normal sea-water (control) }\end{array}$

The eggs remained one hour in these solutions.

The next day the control eggs (7) were undeveloped. The eggs that had been in the first three solutions were teeming with trochophores. In lots 4 and 5 not a single swimming trochophore was found, although many eggs had begun to develop. The development stopped, however, in an early stage. Of the eggs that had been in solution 6 a large number had reached the trochophore stage and were swimming. These results were as clear as could be desired. In order to bring about artificial parthenogenesis through the addition of $\mathrm{NaCl}, 15$ c.c. of the $2 \frac{1}{2} n$ solution had to be added, while 5 c.c. of a $2 \frac{1}{2} n \mathrm{KCl}$ solution were sufficient.

Fifth series.-There was a possibility that the effect produced by $\mathrm{NaCl}$ was a specific $\mathrm{Na}$ effect, and not an effect of the increase in osmotic pressure. An experiment with canesugar could decide this question. My stock solution of 
cane-sugar was a $2 n$ solution, while my $\mathrm{NaCl}$ solution was $2 \frac{1}{2} n$. On account of the electrolytic dissociation, more than 30 c.c. of the cane-sugar solution were required to produce the same increase of osmotic pressure as by 15 c.c. of the $2 \frac{1}{2} n \mathrm{NaCl}$ solution. The following solutions were tried:

(1) 40 c.c. $2 n$ cane-sugar +60 c.c. sea-water

(2) 20 " " "

(3) 10 " " "

(4) $10 \quad 212 n \mathrm{KCl}+90$

(5) Normal sea-water (control)

The eggs remained fifty-five minutes in these solutions. Eight hours later swimming ciliated trochophores were found in the eggs that had been in solutions 1 and 4 . In 2 and 3 there were no swimming larvæ. In the control material all the eggs were still spherical and unsegmented. The next morning about 25 per cent. of the eggs that had been in solution 1 swam about in the most lively manner. A few trochophores were found among the eggs that had been in solution 2. But the control eggs and the eggs that had been in solution 3 had in the best case only reached the earliest stages of segmentation. This leaves no doubt that an increase in the osmotic pressure of the sea-water is sufficient to bring about artificial parthenogenesis in the eggs of Chætopterus.

Sixth series.- In order to make this conclusion stronger, it was necessary to try the effect of an increase in the osmotic pressure of the sea-water by the addition of still other substances. The following were tried:

(1) 5 c.c. $5 n \mathrm{CaCl}_{2}+95$ c.c. sea-water

(2) 10 " "

(3) $10 \quad 2 \frac{1}{2} n \mathrm{MgCl}_{2}+90 \quad$ "

(4) 20 " " $"+80$ "

(5) 30 " " $\quad+70$

(6) Normal sea-water (control) 
The eggs remained in these solutions one hour, and were then put back into normal sea-water. I neglected to look at them the same evening. The next morning I found a small number of swimming larve among the eggs that had been in solution 5 ( 30 c.c. $2 \frac{1}{2} n \mathrm{MgCl}_{2}+70$ c.c. sea-water). The control eggs were undeveloped; the $\mathrm{Ca}_{2}$ eggrs had gone to pieces. The experiment demonstrated only that the increase of the osmotic pressure through $\mathrm{MgCl}_{2}$ can bring about the development of the unfertilized eggs of Chætopterus.

Seventh series. - I suspected that my failure to get swimming trochophores from a mixture of sea-water and a $5 n$ $\mathrm{CaCl}_{2}$ solution might have been due to the poisonous effect of the calcium, having noticed in my previous experiments on the artificial parthenogenesis in sea-urchins that the parthenogenetic larvæ produced by the addition of $\mathrm{CaCl}_{2}$ to seawater soon died. I therefore started a new experiment early in the morning and watched the eggs during the day. I found indeed that an increase in the osmotic pressure of the sea-water by the addition of $\mathrm{CaCl}_{2}$ leads to the formation of swimming trochophores from the unfertilized eggs of Chætopterus. The solutions used were as follows:

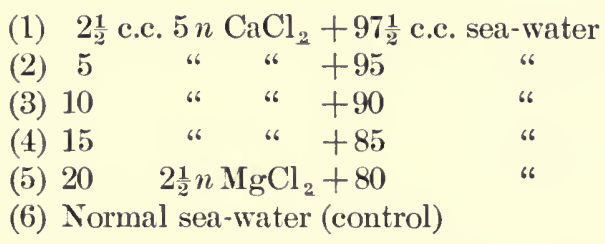

The eggs were exposed to these solutions for fifty minutes. After nine hours the eggs that had been in solution 3 contained living trochophores which died during the night. None of the other solutions gave rise to swimming trochophores.

Eighth series. - As there was no more doubt left that the increase in the osmotic pressure of the sea-water or the loss 
of a certain amount of water on the part of the egg caused the parthenogenetic development of the eggs of Chrtopterus in these experiments, it now remained to ascertain how long the eggs must remain in these solutions in order to develop. I put the unfertilized eggs of a female into a mixture of 85 c.c. sea-water +20 c.c. $2 \frac{1}{2} n \mathrm{NaCl}$. The tirst lot were taken out of this mixture after ten minutes, the second after thirty, the third after sixty, the fourth after ninety, and the fifth after one hundred and twenty minutes. The same evening (nine hours later) I found swimming trochophores among the eggs that had been taken out of the third and fourth lots. The eggs of the first lot did not show any trace of development at that time. Of those of the second lot about one in a hundred had begun to develop. In the fifth lot the eggs had apparently undergone development, but I found no swimming larvæ. The eggs had possibly been injured by their long stay in the more concentrated sea-water.

The next morning about 20 to 40 per cent. of the eggs of the third and fourth lots were swimming about in the trochophore stage. The rest did not contain any living larvæ, although some of the eggs were in the early segmentation stages.

It is therefore necessary to leave the unfertilized eggs of Chætopterus more than thirty and less than one hundred and twenty minutes in a mixture of 85 c.c. sea-water +20 c.c. $2 \frac{1}{2} n$ $\mathrm{NaCl}$ in order to cause them to reach the trochophore stage.

Conclusions. - From these experiments we are allowed to draw the following conclusions:

1. The unfertilized eggs of Chætopterus do not reacin the trochophore stage if left in normal sea-water, provided the proper precautions are taken against contamination by spermatozoa. Such eggs show no change during the first seven to nine hours, but may begin to segment after that time. In such cases the segmentation as a rule does not proceed beyond 
the two- to four-cell stages, but may in exceptional cases go as far as the twelve- to sixteen-cell stages. We may say that Chætopterus possesses a higher degree of parthenogenetic tendency than the Arbacia egg, which begins to segment later, after about twenty hours, and does not proceed beyond the two- to four-cell stage.

2. The unfertilized eggs of Chætopterus are able to develop into swimming trochophores if they are put for about one hour into one of the following solutions and then put back into normal sea-water:

\begin{tabular}{|c|c|c|c|}
\hline \multirow{2}{*}{\multicolumn{2}{|c|}{ (1) $15-20$ c.c. $2 \frac{1}{2} n \mathrm{NaCl}$}} & \multicolumn{2}{|c|}{ +85 c.c. sea-water } \\
\hline & $2 n$ cane-sugar & +60 & \\
\hline (3) & $2 \frac{1}{2} n \mathrm{MgCl}_{2}$ & +70 & “ \\
\hline (4) 10 & $5 n \mathrm{CaCl}_{2}$ & +90 & " \\
\hline
\end{tabular}

All these solutions have one element in common, namely, the about equal increase of the osmotic pressure. It seems therefore justifiable to assume that the increase in the osmotic pressure or the loss of water on the part of the egg is the cause of the parthenogenetic development of these eggs.

3. $\mathrm{KCl}$ or perhaps the $\mathrm{K}$ ions seem to possess a specific effect upon the eggs of Chætopterus. We shall discuss this fact more fully in the next section.

Objections considered. - The possible objection that the eggs of Chætopterus are naturally parthenogenetic in normal sea-water or that spermatozoa had contaminated the seawater is rendered impossible through the behavior of the control eggs and the antiseptic precautions taken. As far as I can see, there is only one objection left, which, however, although far-fetched and highly improbable, shall be considered. It might be argued that Chætopterus is hermaphroditic, but that the eggs and spermatozoa do not mature simultaneously. This prevents fertilization of eggs in normal sea-water. But the increase in the osmotic pressure of 
sea-water might increase the motility or fertilizing power of the spermatozoa. The contrary is, however, true. The eggs of the same female were divided into two lots. The one was put into normal sea-water, the other was exposed for fifty minutes to a mixture of 70 c.c. sea-water +30 c.c. $2 \frac{1}{2} n$ $\mathrm{MgCl}_{2}$. At about the same time the sperm of one male was distributed into two solutions of exactly the same character.

After fifty minutes the eggs that had been in normal seawater were divided into three portions. To the first portion was added sperm from the normal sea-water; to the second was added sperm that had been for fifty minutes in a mixture of 30 c.c. $2 \frac{1}{2} n \mathrm{MgCl}_{2}+70$ c.c. sea-water. To the third portion no sperm was added; it was intended to serve as control material. The result was as striking as could be desired. While the eggs to which the sperm from the normal sea-water had been added developed without exception into trochophores, not one egg developed in lot 2, to which the $\mathrm{IgCl}_{2}$ sperm had been added. The control eggs remained likewise undeveloped.

A number of the unfertilized eggs that had been in the $\mathrm{MgCl}_{2}$ for fifty minutes reached the trochophore stage.

This experiment proves conclusively that the $\mathrm{MgCl}_{2}$ solution annihilates or certainly diminishes the fertilizing power of spermatozoa. In a previous series of experiments I had been able to show that the same is true for the eggs of sea-urchins.

In addition I convinced myself through microscopic examinations that the females used were not hermaphroditic.

III. THE SPECIFIC EFFECT OF K IONS ON THE DEVELOPMENT OF THE UNFERTILIZED EGGS OF CHETOPTERCS

The preceding experiments seemed to indicate that $\mathrm{KCl}$ has a specific effect upon the development of the unfertilized eggs of Chætopterus. Mead had already found ${ }^{1}$ that if $\frac{1}{2}$ per

1 MEAD, Biological Lectures, Woods Hole, 1898 (Boston: Ginn \& Co.). 
Artificial Parthenogenesis in Annelids 657

cent. $\mathrm{KCl}$ is added to sea-water the unfertilized eggs of Chætopterus throw out their polar bodies, while the addition of $\frac{1}{2}$ per cent. $\mathrm{NaCl}$ to sea-water produces no such effect. It seemed of interest to find out whether the $\mathrm{K}$ ions were possibly able to cause the parthenogenetic development of Chætopterus larvæ without the osmotic pressure of the seawater being raised.

Ninth series.--The following mixtures were prepared:

(1) 10 c.c. $2 \frac{1}{2} n \mathrm{KCl}+90$ c.c. sea-water

(2) 5 " " +95 "

(3) $2 \frac{1}{2}$ " " +98

(4) Normal sea-water (control)

The eggs remained in the solutions one hour. The seawater used had been sterilized by heating it to a temperature of $80^{\circ} \mathrm{C}$., as in all the previous experiments.

The next morning each of the first three lots contained a large number of free swimming larvæ, while the control material contained none.

Tenth series.-I intended to find out the minimum amount of $\mathrm{KCl}$ necessary to bring about artificial parthenogenesis. Moreover, I wished to know whether the addition of $\mathrm{KCl}$ to sea-water did not act more quickly upon the eggs than an increase in the osmotic pressure by some other substance. Seven solutions were used:

(1) $\frac{1}{2}$ c.c. $2 \frac{1}{2} n \mathrm{KCl}+99 \frac{1}{2}$ c.c. sea-water

(2) 1 " "

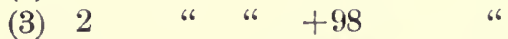

(4) 10 " " "

(5) 1 " $\mathrm{NaCl}+99$ "

(6) 2 " " 4 "98 "

(7) Normal sea-water (control)

One lot of eggs remained in these solutions from five to ten minutes, the others from sixty to seventy minutes.

The results were as follows: None of the two lots that had 
been in solution 1 reached the trochophore stage. None of the eggs that had been only five minutes in the second solution reached the trochophore stage. But the lot of eggs that had remained one hour in the second solution yielded a small number of swimming trochophores. The eggs that had been in solutions 3 and 4 differed widely from the preceding lots. They were teeming with swimming trochophores, those that had been in these solutions five minutes as well as those that had been in the solutions one hour.

The control eggs and the eggs of lots 5 and 6 did not derelop, although a number went through the first stages of segmentation.

I had observed in my former experiments that the eggs of sea-urchins can develop parthenogenetically if left permanently in sea-water whose concentration is raised but little. If the eggs of sea-urchins are put for two hours into a mixture of 92 c.c. sea-water +8 c.c. $2 \frac{1}{2} n \mathrm{NaCl}$, they will not, develop into blastulæ when put back into normal sea-water; but if left for some time or permanently in such a solution, a small number of blastulæ may be formed. A number of the unfertilized Chætopterus eggs were left permanently in solutions 1-6. The next morning the eggs that had been left in solution $2(1 \mathrm{KCl}+99$ c.c. sea-water $)$ had swimming trochophores. The eggs in solution 1 did not reach the trochophore stage. In the othersolutions everything was dead.

Eleventh series.-This series was practically a repetition of the preceding one, with the exception that the eggs remained from twenty to thirty minutes in the solutions, which were as follows.
(1) 1 c.c. $2 \frac{1}{2} n \mathrm{KCl}+99$ c.c. sea-water
(2) $1 \frac{1}{2}$ " " " $+98 \frac{1}{2}$ "
(3) 2 " " $6+98$ "
(4) 10 " " $\quad$ " 90
(5) Normal sea-water (control) 
The eggs that had been in solution 1 had very few swimming trochophores, those that had been in solutions 2 and 3 had many, and those that had been in solution 4 still more. The control eggs were mostly undeveloped; a small number were segmented into from 2 to 16 cells.

Tuelfth series.-In the experiments thus far mentioned a $2 \frac{1}{2} n \mathrm{KCl}$ solution had been added to normal sea-water. As the osmotic pressure of the sea-water is about equal to that of a $\frac{5}{8} n \mathrm{KCl}$ solution, in all these experiments with $\mathrm{KCl}$ there was a rise in the osmotic pressure of the sea-water. I now wished to try whether this increase in osmotic pressure is essential for the $\mathrm{KCl}$ effect, or whether a mere increase in the number of $\mathrm{K}$ ions without an increase in the osmotic pressure of the sea-water is able to bring about the parthenogenetic development of the eggs of Chætopterus. The solutions used were as follows:

(1) 2 c.c. $2 \frac{1}{2} n \mathrm{KCl}+91$ c.c. sea-water +7 c.c. distilled water

(2) 3 " " $"$ "

(3) 2 " " "

(4) 3 " " "

(5) 5 " $\mathrm{MgCl}_{2}+95$

(6) Normal sea-water (control)

The eggs remained in the solution fifty-five minutes. Nine hours later (the same evening) swimming trochophores were found in those that had been in the first four solutions. The eggs that had been in the other two solutions were entirely undeveloped. Some had been left permanently in these solutions. Some of those left in solutions 1 and 2 had reached the trochophore stage and were swimming about.

The next morning these results were confirmed. Fully one-third of all the eggs that had been fifty-five minutes in solutions 1-4 swam about as trochophores. Those that had been in solutions 5 and 6 had not reached the trochophore stage; only a few eggs had begun to segment. 
Thirteenth series.--It was evident that the $\mathrm{KCl}$ brought about artificial parthenogenesis, even if the osmotic pressure of the sea-water was not raised. I now tried whether a pure $\mathrm{KCl}$ solution was able to cause artificial parthenogenesis, and whether this was possible when the osmotic pressure of such a solution was lower than that of sea-water. The solutions used were as follows:

(1) 10 c.c. $2 \frac{1}{2} n \mathrm{KCl}+90$ c.c. distilled water

(2) 20 " " +80

(3) 25 " " " +75

(4) 2 " " +98 sea-water

(5) Normal sea-water (control)

The osmotic pressure of solutions 1 and 2 was smaller than that of normal sea-water. One portion was left thirteen, the other fifty minutes in these solutions.

The next morning a large number of swimming trochophores was found in every one of the dishes that contained eggs taken from the first four solutions. The control solutions were absolutely free from trochophores.

Fourteenth series. - The experiment was so surprising that I wished to repeat it. The following solutions were prepared:

(1) 10 c.c. $2 \frac{1}{2} n \mathrm{KCl}+90$ c.c. distilled water

(2) 2 c.c. " " +98 c.c. sea-water

(3) Normal sea-water (control)

The eggs were left in the solutions fifty minutes. The water was sterilized. The next morning the eggs that had been in solutions 1 and 2 contained living larve, while the eggs in the normal sea-water were undeveloped.

Fifteenth series. - I wished next to know whether the KCl solution might be still more diluted without annihilating its effect upon the unfertilized Chrtopterus eggs. Four solutions were used: 
(1) 5 c.c. $2 \frac{1}{2} n \mathrm{KCl}+95$ c.c. distilled water

(2) 10 " " $\quad$ "

(3) 15 " 645

(4) Normal sea-water (control)

The eggs were left in these solutions seven minutes and were then put back into sterilized sea-water. The next morning about 1 per cent. of the eggs that had been in solution 1 were swimming about. The eggs that had been in solution 2 had practically all reached the larva stage, although not all of them were swimming. The eggs that had been in the third solution contained swimming larvæ, but fewer than the other two lots. The control eggs had remained absolutely unsegmented during the first nine to ten hours. They showed, however, a beginning of segmentation (2-3 cells) the next morning.

Sixteenth series. - There was no longer any doubt concerning the fact that $\mathrm{KCl}$ is able to bring about the development of the unfertilized eggs of Chætopterus. It was, moreover, apparent from experiment 10 that if only $\frac{1}{2}$ c.c. $2 \frac{1}{2} n \mathrm{KCl}$ is added to $99 \frac{1}{2}$ c.c. of sea-water, no trochophores are formed. It was natural to conclude from this that a certain minimal amount of $\mathrm{K}$ ions must enter the egg in order to make it reach the trochophore stage. In order to decide this the following experiment was tried. The eggs of one female were put into a solution of 2 c.c. $2 \frac{1}{2} n \mathrm{KCl}+$ 98 c.c sea-water, and put back into normal sea-water at various intervals, viz., after one minute, three minutes, seven minutes, nine minutes, thirteen minutes, twenty minutes, forty minutes. The results of this experiment were as definite as could be desired.

After from nine to ten hours the eggs of the first lot (that had been in the $\mathrm{KCl}$ sea-water for one minute only) were absolutely unsegmented. In the second lot (three minutes) a few eggs were segmented, but no trochophore was formed. 
Lot 5 (thirteen minutes) had trochophores which did not yet move, and in lot 6 (twenty minutes) and lot 7 (forty minutes) trochophores were found that were just beginning to move. The control eggs were absolutely unsegmented.

The next morning I found no trochophores in the first lot (one minute), but many eggs in a two- to eight-cell stage. In lot 2 (three minutes) about 1 per cent. of the eggs were swimming about as trochophores. In lot 4 about 10 per cent. of all the eggs were swimming about as trochophores; in lot 5 (13 minutes) it was about the same. In lot 6 , whose eggs had been for twenty minutes in the KCl sea-water, about 50 per cent. swam about in the trochophore stage. Lot 7 seemed to contain not quite so many trochophores.

It is therefore necessary that the unfertilized eggs remain more than one minute in a mixture of 2 c.c. $2 \frac{1}{2} n \mathrm{KCl}$ +98 c.c. sea-water in order to develop; three minutes (or possibly a little less) is sufficient. This indicates clearly that a certain quantity of $\mathrm{K}$ or $\mathrm{KCl}$ must enter the egg in order to bring about the development. This quantity is very small. It seems to vary, however, for the individual eggs, inasmuch as the number of eggs that developed was greater the longer the eggs remained in the $\mathrm{KCl}$ solution. If they remain too long in such a solution, the $\mathrm{KCl}$ acts like a poison. From twenty to sixty minutes seems to be the optimal time.

Seventeenth series. - I wished to determine once more what was the smallest amount of $\mathrm{KCl}$ that must be added to sea-water in order to bring about artificial parthenogenesis of the Chrtopterus eggs. The following solutions were used:

(1) $\frac{1}{2}$ c.c. $2 \frac{1}{2} n \mathrm{KCl}+99 \frac{1}{2}$ c.c. sea-water

(2) 1 " "

(3) $1 \frac{1}{2} "$ " " +98

(4) Normal sea-water (control)

The eggs were left in these solutions over night. The 
Artificial Parthenogenesis in Annelids 663

next morning, after they had been in these solutions for twenty-four hours, the first solution contained many eggs in the beginning stages of segmentation but not one swimming larva could be discovered. The second and third solutions contained a large amount of swimming larvæ; in the second they were more numerous than in the third. In the control material only a few eggs began to segment; no swimming larvæ were to be found. This confirms our former observation that an addition of $\frac{1}{2}$ c.c. $2 \frac{1}{2} n \mathrm{KCl}$ to $99 \frac{1}{2}$ c.c. sea-water is insufficient to produce parthenogenesis, while the addition of $1 \mathrm{KCl}$ is sufficient.

Eighteenth series. - There is something paradoxical in the fact that the addition of 2 c.c. $2 \frac{1}{2} n \mathrm{KCl}$ to 98 c.c. seawater can produce parthenogenesis in three minutes, while the addition of $\frac{1}{2}$ c.c. $2 \frac{1}{2} n \mathrm{KCl}$ to $99 \frac{1}{2}$ c.c. sea-water cannot accomplish the same result in twenty-four hours. Before I accepted this as a fact I wished to see it confirmed once more. The same solutions were applied as before:

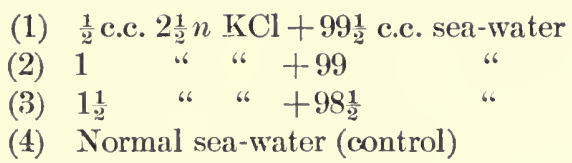

Part of the eggs were put back into normal (sterilized) sea-water after thirty minutes, while the others remained in the solution during the next twenty-four hours. As far as the latter are concerned the results were exactly like those described in the preceding experiment. The eggs that had remained in solution 1 over night had not developed beyond the early cleavage stages. No egg had reached the trochophore stage. In the second solution a large number of swimming larvæ were found, and in the third solution they were numerous. About 75 per cent. of all the eggs were in the trochophore stage, and many of these were swimming about.

The eggs that had remained in these solutions only thirty 
minutes showed the following condition the next morning: Those that had been for thirty minutes in the first solution had no trochophores; only a few had begun to segment. The eggs that had been taken out of solution 2 after thirty minutes had formed many larvæ, but fewer than the eggs that had remained in the solution. Those that had been taken out of solution 3 after thirty minutes had formed many swimming larvæ. The control eggs were undeveloped, save a few that had begun to segment.

While a stay of thirty minutes in a mixture of 1 c.c. $2 \frac{1}{2}$ $\mathrm{KCl}+99$ c.c. sea-water suffices to cause the eggs to develop parthenogenetically, a stay of thirty hours in a solution of $\frac{1}{2}$ c.c. $2 \frac{1}{2} n \mathrm{KCl}+99 \frac{1}{2}$ c.c. sea-water remains without any effect. This may mean that a minimal quantity of $\mathrm{K}$ or $\mathrm{KCl}$ must enter the eggs in a certain minimal time or rather suddenly. It may, however, find a different explanation.

Nineteenth series.-Is the fertilizing power of the $\mathrm{KCl}$ due to the $\mathrm{K}$ ions or to the $\mathrm{KCl}$ molecules? The unfertilized eggs of one female were distributed into the following solutions:

(1) 1 c.c. $2 \frac{1}{2} n \mathrm{KBr} \quad+97$ c.c. sea-water

(2) 2 " " 498 "

(3) 1 " " $\mathrm{KNO}_{3}+99$

(4) 2 " " $\quad+98$

(5) $3 \quad 1.2 n \mathrm{~K}_{2} \mathrm{SO}_{4}+97$

(6) Normal sea-water (control)

The eggs remained in these solutions thirty minutes, and were then put back into normal sea-water. The eggs that had been put in solutions 2,4 , and 5 formed a large number of swimming larvæ, the others remained undeveloped. This experiment proves that the $\mathrm{K}$ ions and not the $\mathrm{KCl}$ molecules produce the parthenogenetic development of the eggs of Chætopterus.

Conclusions.--These experiments confirm the conclusion 
drawn above, that the unfertilized eggs of Chætopterus cannot develop into a trochophore if left in normal sea-water. A small number of $\mathrm{K}$ ions, however, is able to cause them to develop parthenogenetically. If the eggs are put for three minutes into a mixture of 2 c.c. $2 \frac{1}{2} n \mathrm{KCl}+98$ c.c. seawater, they are able to develop parthenogenetically. If the sea-water contains fewer $\mathrm{K}$ ions, $e . g$., if we add 1 c.c. $2 \frac{1}{2} n$ $\mathrm{KCl}$ to 99 c.c. sea-water, the eggs must remain longer in the solution. Finaliy, if we add only $\frac{1}{2}$ c.c. $2 \frac{1}{2} n \mathrm{KCl}$ to $99 \frac{1}{2}$ c.c. sea-water, the eggs are not able to develop parthenogenetically, no matter how long they are left in such a solution. They can be caused to reach the trochophore stage by a pure $\mathrm{KCl}$ solution of considerably lower osmotic pressure than that of sea-water. If the sea-water contained only a slightly greater proportion of $\mathrm{K}$, we should find that Chrtopterus was "normally" parthenogenetic.

IV. ARTIFICIAL PARTHENogenesis PRODUCED BY A SLIGHT ADDITION OF HCL TO SEA-WATER

In my experiments on Echinoderms, I had found that the addition of a small quantity of acid or alkali causes the unfertilized eggs of sea-urchins to segment much more quickly than is the case in normal sea-water. I intended to try the effects of the same agencies on the eggs of Chrtopterus. The sea-water is slightly alkaline, $i$. e., has a small quantity of free hydroxl ions in solution.' If we add more alkali, the number of the hydroxyl ions is but slightly increased, inasmuch as a precipitate of $\mathrm{Mg}(\mathrm{HO})_{2}$ is formed. With acids it is different. If we add a certain small amount, the sea-water becomes neutral; and if we add more, it becomes acid according to the amount and degree of dissociation of the acid used. All the sea-water in these experiments was sterilized.

1 This was the common view held at that time. I havesince found that sea-water is neutral. [1903] 
Twenticth series. - The following solutions were used:

(1) 100 c.c. sea-water +2 c.c. $\frac{1}{10} n \mathrm{NaHO}$

(2) 100 " 42 " $\mathrm{KHO}$

(3) $96 \quad \cdots \quad+4 \quad \frac{1}{4} n \mathrm{Na}_{2} \mathrm{CO}_{3}$

(4) $100 \quad$ " $\quad+2$ is $n$ HCl

(5) 100 "

(6) Normal sea-water (control)

The eggs of one female were distributed in these solutions. One portion of the eggs was taken out of these solutions and put back into normal sea-water; the others remained permanently in these solutions. Twenty-four hours later the results appeared to be as follows: Of the eggs that had remained in the solutions for twenty-four hours, those in solutions 2 and $t$ had well-developed trochophores that swam about. In solution 1 several eggs seemed to have developed, but I was unable to find one swimming or with cilia. Those in the other solutions were undeveloped. The eggs that had been in solutions 2 and 4 for only five to ten minutes had a few trochophores; the others were undeveloped.

It is evident that KHO is more effective than $\mathrm{NaHO}$, and it is natural that the effect of the $K$ ions should have been added to the effect of the $\mathrm{HO}$ ions. But the fact is very striking that the addition of a small amount of $\mathrm{HCl}$ to the sea-water caused the parthenogenetic development of the Chætopterus eggs.

Twenty-first serics.-The unfertilized eggs of a Chrtopterus were distributed in the following solutions:

(1) 100 c.c. sea-water +1 c.c. $2_{1}^{1} n \mathrm{nCl}$

(2) 100 " 100 " 2 " "

(3) 100 " 400 "

(4) Normal sea-water (control)

One portion of eggs remained in the solutions five minutes, the others permanently. The eggs that were taken from the solutions after five minutes were undeveloped, with the 
exception of a few that had been in solution 2 and which reached the trochophore stage. The eggs that remained permanently in solutions 1 and 2 formed a large number of swimming larwæ. The eggs in solutions 3 and 4 were undeveloped and dead.

Tuenty-second series. - It was evident that the addition of 2 c.c. $\frac{1}{10} n \mathrm{HCl}$ to 100 c.c. sea-water was able to cause the development of the unfertilized eggs of Chrtopterus, especially if the eggs remained permanently in this solution. I intended to see how long the eggs must remain in such a solution in order to reach the trochophore stage. Eggs were put into such a solution and taken out in intervals of ten, thirty, sixty, ninety, and one hundred and twenty minutes, respectively. One portion remained there permanently. A large number of swimming larvæ developed only in the latter portion; in the former there were none. The control eggs remained absolutely undeveloped.

Although these experiments are not yet finished, they seem to indicate that in a solution of 100 c.c. sea-water + 2 c.c. $\frac{1}{10} n \mathrm{HCl}$ the unfertilized eggs of Chætopterus can reach the trochophore stage.

\section{v. MORPHOLOGICAL OBSERVATIONS ON THE DEVELOPMENT OF THE UNFERTILIZED EGGS OF CHæTOPTERUS}

I have thus far confined myself to the statement that certain solutions are capable of causing the unfertilized eggs of Chætopterus to reach the trochophore stage and swim about. Nothing has been said as yet concerning the mode of development of these parthenogenetic eggs. I have watched their development very carefully and have made a number of camera drawings. This part of the work is essential for experiments on parthenogenesis. If one wishes to be absolutely certain in regard to the parthenogenetic character of the development, a close continuous observation 
and study of the eggs during the first seven to nine hours is necessary. During this time the parthenogenetic eggs throw out their polar bodies, segment, and become trochophores, while the control eggs or the eggs treated with ineffective solutions remain quite spherical and unchanged.

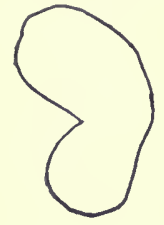

The egg of Chrtopterus is very dark and opaque, and it is for this reason much more difficult to determine the number of cleavage cells in it than in the egg of most Echinoderms. The firtilized egg of Chætopterus develops very quickly. At a favorable temperature the cilia develop five hours after fertilization,
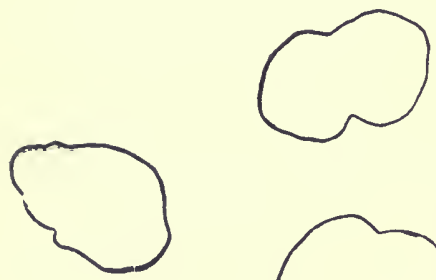
and the larva begin to swim. The development of the unfertilized eggs differs in most cases from that of the fertilized eggs. It is a little slower, and the nature of the segFIG. 157

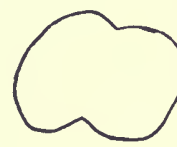
mentation and the distinctness of the single cleavage spheres vary considerably with the nature of the ions that are added to the sea-water, or the agency employed to bring about artificial parthenogenesis. If $\mathrm{K}$ salts are used, one does not, as a rule, notice much more of the beginning development, except that the eggs become irregular in their outline and amœboid. In the experiments with $\mathrm{Ca}$ salts and acids, the cleavage spheres were much more distinct and regular. Fig. 157 gives a good average picture of the amoboid character of the $\mathrm{K}$ eggs. In the experiment in which these eggs were drawn the unfertilized eggs of a Chætopterus were put into a mixture of 98 c.c. sea-water +2 c.c. $2 \frac{1}{2} n \mathrm{KCl}$ at $9: 43$. They remained in this solution forty minutes, and were then put back into normal sea-water. Three hours later, at 1:40, the drawing (Fig. 
157) was made. It is impossible to recognize any distinct cleavage spheres in these eggs. All that can be said is that they have lost their spherical outline and are amœboid. I have never seen anything like this in fertilized eggs, or in the unfertilized control eggs that are left in normal sea-water. If the latter segment at all, they do not begin to do so until after seven to nine hours or later, and they form more distinct cleavage cells.

The appearance of the eggs and the form of segmentation are thus distinctly a function of the constitution of the sea-water. Inasmuch as the $\mathbf{K}$ eggs give rise to trochophores which may look as normal as those developing from a fertilized egg, it is evident that the appearance of the cleavage cells is of very little importance in the formation of the embryo.

The difference between the development of unfertilized $\mathrm{K}$ eggs and fertilized eggs can be seen from Fig. 158. In the experiments in which these drawings were made the eggs of one female were divided into two lots. The one was fertilized at 11:45 by the addition of sperm; the other was put at the same time for fifty-five minutes into a mixture of 98 c.c. sea-water +2 c.c. $2 \frac{1}{2} n \mathrm{KCl}$. In about fifteen to twenty minutes after the eggs were put into this mixture they threw out their polar bodies; sometimes one, sometimes two were visible. This harmonizes with Mead's observations. In the unfertilized control eggs that had remained in normal sea-water nothing of this kind was noted.

Fifty-five minutes after the eggs had been put into the $\mathrm{KCl}$ mixture they were put back into normal (sterilized) seawater. In from ten to thirty minutes they began to lose their spherical shape, and in some eggs little processes or knobs appeared and remained or were withdrawn. The eggs resembled amœbæ in their behavior. In Fig. 158, on the left side, the development of the fertilized lot is represented; 
Fertilized.

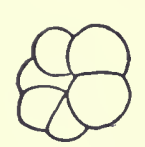

12.45
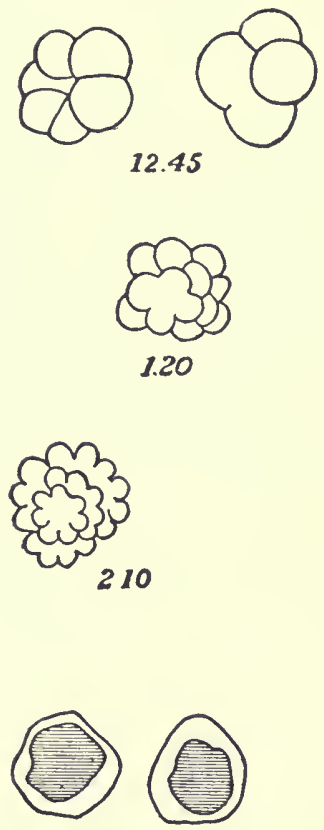

3.40
Unfertilized.

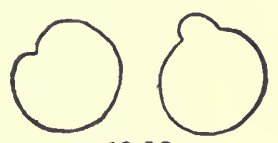

1255

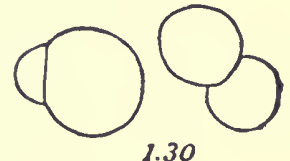

1.30
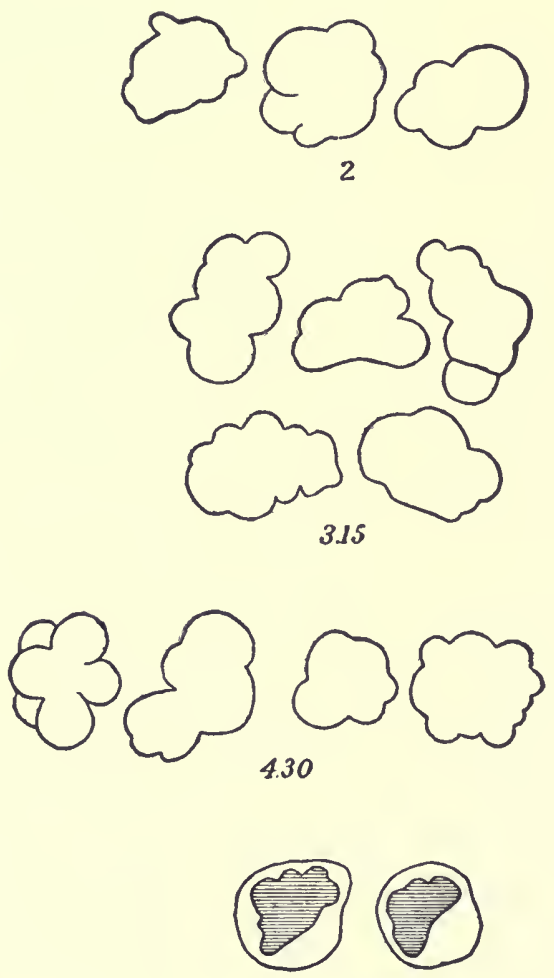

7.40

FIG. 158 
on the right side the development of the unfertilized eggs. At about the same time a drawing of the fertilized and the unfertilized $K$ eggs was made. At 12:45 some of the fertilized eggs were found in the four- to eight-cell stage. The unfertilized eggs were only amoboid at that time. Some of them (see Fig. 158) at 12:55 showed an incision, as if they were about to divide. At 1:20 some of the fertilized eggs had reached the sixteen-cell stage, and at 1:30 only a few eggs were found among the K eggs that seemed to be segmented. At 2:10 the fertilized eggs were in an advanced stage of cell-division, while the $\mathrm{K}$ eggs were not distinctly segmented. At 3:40 the fertilized eggs had reached the trochophore stage, with a clear edge and a dark center. At that time the most differentiated eggs of the parthenogenetic lot were in the condition that is represented at 3:15 in Fig. 158. At 4:30 we find these eggs still in the same condition, and not until 7:40 did the parthenogenetic eggs reach the beginning of the trochophore stage-clear edge and dark center (Fig. 158). The fertilized eggs had formed their cilia, and at about 5 o'clock were swimming around, while the $K$ eggs did not begin to swim until 8 or 9 o'clock. The unfertilized control eggs which had remained in normal seawater during this time were at 8 o'clock still absolutely spherical, and had given no signs of development or change.

Although the drawings in Fig. 158 give an idea of the development of the parthenogenetic eggs, this idea has to be supplemented by the statement that not all the eggs behaved like those drawn. The majority of parthenogenetic eggs never showed any higher degree of differentiation during their development than those drawn in Fig. 157; many eggs even remained spherical. The number of trochophores was always considerably larger than the number of eggs that became amœboid. The majority of parthenogenetic trochophores are perfectly spherical. I have often wondered 
whether it was possible for the unfertilized $\mathrm{K}$ eggs to reach the trochophore stage without any visible external signs of cleavage. ${ }^{1}$ I shall have to postpone a definite answer to this question until next year.

Another point worth mentioning is the fact that phenomena of cleavage seem to be reversible in this form, inasmuch as

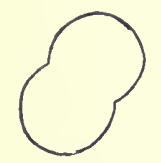

8.04

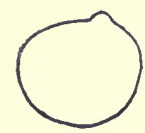

$8.05 \frac{1}{2}$

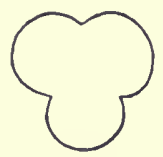

$8.04 \frac{1}{2}$

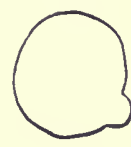

8.06

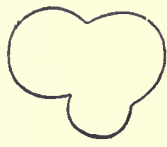

805

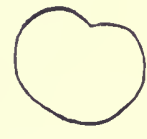

$806 \frac{1}{2}$

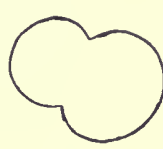

$8.05 !$

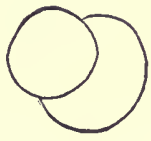

808 an egg divides into two spheres which very soon fuse again. Such changes, which occur very suddenly, may be occasionally observed in unfertilized Chætopterus eggs. Fig. 159 shows the successive stages which were observed in one egg within four minutes. I had watched thes $\mathrm{e}$ lively changes for several minutes before I decided to draw them. The egg had been for an hour in a mixture of 95 c.c. sea-water +5 c.e. $2 \frac{1}{2} n \mathrm{NaCl}$, and had been back in sea-water for eight hours. When I began to draw the egg, it had the appearance of being in the two-cell stage (Fig. 159, 8:04). Ten seconds later it changed suddenly into a three-cell stage, the

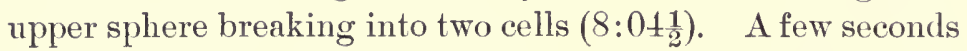
after this the lower sphere began to flow into the right upper sphere (8:05), and at 8:05 $\frac{1}{4}$ it had disappeared completely. The egg was again in the two-cell stage $\left(8: 05 \frac{1}{4}\right)$. Then the

1 Professor F. Lillie in the following year confirmed this suggestion. [1903] 
two spheres fused, and a small sphere or droplet appeared above $\left(8: 05 \frac{1}{2}\right)$. This disappeared almost immediately, and a new little droplet broke loose at the right lower side of the egg $(8: 06)$. It disappeared in a few seconds, and the egg once more divided, but with an altogether different position of the cleavage plane $\left(8: 06 \frac{1}{2}, 8: 07 \frac{1}{2}\right)$. In a few seconds the two spheres fused into one cell, and a number of small droplets appeared below (8:08). Of course it is impossible to tell whether or not these single spheres or droplets contained nuclei. These phenomena are of importance for

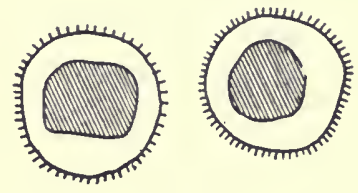

FIG. 160 the mechanics of development, inasmuch as they show that the bulk of the egg is liquid, and that in the case of Chætopterus its viscosity is very small, and less than in the case of the sea-urchin's egg. It is hard to understand what kind of structure could be preformed in a liquid mass of such low degree of viscosity beyond the differentiation into nuclear and protoplasmic material and possibly centrosomes.

The appearance of the trochophores originating from unfertilized eggs is exactly like that of those arising from fertilized eggs, if one compares equal stages of development. Fig. 158 gives no good idea of the trochophore, inasmuch as the latter is at first spherical. Fig. 160 shows two parthenogenetic trochophores, drawn by the camera with the exception of the cilia, which are more or less diagrammatic. The eggs from which these trochophores originated had been treated with $\mathrm{KCl}$. It is hardly necessary to mention that the appearance of the trochophores developing from parthenogenetic eggs depends greatly upon the treatment the egg had received. I mentioned this point in connection with the artificial parthenogenesis of sea-urchins.

A point which must be discussed is the duration of life of the parthenogrenetic trochophores. All the Chæ- 
topterus larvæ, those that developed from fertilized eggs as well as those that developed from unfertilized eggs, died after two days. As the fertilized eggs developed faster than the unfertilized eggs, the trochophores that had developed from the former eggs were in a more advanced stage at the time of death than the parthenogenetic trochophores. But to judge from the energy of their motion, the vitality of the parthenogenetic trochophores equaled that of the trochophores emanating from fertilized eggs. ${ }^{1} \quad$ The cause of death was apparently the development of micro-organisms in the poorly aerated culture dishes. The parthenogenetic larvæ of Arbacia lived, under similarly unfavorable conditions, as long as ten days.

VI. ON THE EFFECT OF VARIOUS IONS ON THE ARTIFICIAL PRODUCTION OF PARTHENOGENETIC GIANT AND DWARF EMBRYOS IN ARBACIA AND CHETOPTERUS

In a former paper on the artificial parthenogenesis of sea-urchins I have mentioned the fact that as a rule more than one embryo originates from one egg. ${ }^{2}$ It was not unusual to see 3 , 4, or even 6 blastulæ arise from one egg. Of course each of these embryos was smaller than the normal embryo of Arbacia in which the whole mass is utilized for one embryo. In my first experiments I had caused the parthenogenetic development of the eggs of Arbacia by raising the osmotic pressure of the sea-water through the addition of $\mathrm{MgCl}_{2}$. I have since found that it depends upon the nature of the substance which is added to the seawater whether the parthenogenetic larvæ are dwarfs or of normal size. If the unfertilized eggs of Arbacia are put

1 In the following year I found that the vitality of these parthenogenetic larve is considerably lower than that of the larve which came from fertilized eggs. [1903]

2 Part II, p. 576. 
Artificial Parthenogenesis in Annelids 675

into sea-water whose osmotic pressure has been raised by the addition of $\mathrm{KCl}\left(e . g ., 88\right.$ c.c. sea-water +12 c.c. $\left.2 \frac{1}{2} n \mathrm{KCl}\right)$, and if after two hours they are put back into normal seawater, they will develop into swimming larvæ. In this case, as a rule, only one embryo develops from an egg, and dwarf larvæ are an exception. If, however, instead of $\mathrm{KCl}$ the corresponding quantity of $\mathrm{NaCl}$ or $\mathrm{MgCl}_{2}$ is added to the sea-water, as a rule more than one embryo originates from one egg, and larvæ of normal size are rare. I have not made many experiments with $\mathrm{CaCl}_{2}$, but it seems to act more like $\mathrm{KCl}$ than like $\mathrm{NaCl}$. In the experiments in which the osmotic pressure of the sea-water was raised by canesugar, dwarf blastulæ were also observed.

I have already mentioned in an earlier paper that the lack of a membrane favors the origin of more than one embryo from the unfertilized egg. The fertilized egg has a membrane which keeps the cleavage cells together. But if the membrane be destroyed, the egg may give rise to more than one embryo. In a small number of unfertilized eggs the treatment with $\mathrm{KCl}$ gives rise to a very thin film, which may act as a membrane and prevent the cleavage cells from becoming separated. But such a fine film is lacking in the majority of eggs treated with $\mathrm{KCl}$ (or $\mathrm{CaCl}_{2}$ ) in the right proportions to produce parthenogenesis. And yet we do not notice the falling apart of cleavage cells which in the case of the $\mathrm{NaCl}$ eggs or $\mathrm{MgCl}_{2}$ eggs leads to the formation of more than one embryo from an unfertilized sea-urchin's eggs. The observation of the process of cleavage shows that the treatment of the eggs with $\mathrm{KCl}$ increases their power of adhesion. The various cleavage cells of a $\mathrm{K}$ egg stick together, while after a treatment with $\mathrm{NaCl}$ the cleavage cells adhere much less to one another and fall apart. The same tendency is produced by the addition of $\mathrm{MgCl}_{2}$ to sea-water. It is quite possible that the relative amount of the various 
ions influences the degree of agglutination in the cleavage cells. Herbst has observed that in sea-water without Ca the cleavage cells of fertilized eggs show a tendency to fall apart. ${ }^{1}$

It was to be expected that if $\mathrm{KCl}$ makes the cells of the same egg stick together, it might also cause several eggs to agglutinate. We know, from the experiments of Driesch ${ }^{2}$ and Morgan ${ }^{3}$ on the eggs of sea-urchins and of Zur Strassen ${ }^{4}$ on the eggs of Ascaris, that if two eggs stick together they may give rise to a single embryo of larger dimensions. I have never observed giant embryos in the parthenogenetic eggs of sea-urchins. But I have seen them in almost every experiment in which the Chætopterus eggs had been treated with potassium. In such cases often two or more eggs would stick together, and the result was either two or more trochophores grown together or a single giant embryo of twice or three times the mass of a normal trochophore. Of course there were all kinds of transitions between the two extremes. The formation of one giant embryo through the fusion of two or more eggs is the more remarkable as the Chætopterus eggs possess a membrane even in the unfertilized condition. This membrane is evidently liquefied at the point of contact of two eggs. This agglutination caused by $\mathrm{K}$ is not only noticeable in unfertilized but also in fertilized eggs of Chætopterus. Fig. 161 shows a number of trochophores which originated from agglutinating fertilized eggs of Chætopterus. All these and many other specimens of this kind were found in a few drops of the culture taken out with a pipette. I have tried to make camera drawings of the various types that occurred. The embryos were eight hours old, and began to move. No. 1 (Fig. 161) is a trochophore

1 Herbst, Archiv für Entwickelungsmechanik, Vol. IX (1900), p. 424.

2 DrIEsch, ibid., Vol. X (1900), p. 411.

3 Morgan, ibid., Vol. II (1895), p. 65.

+ Zer Strassex, ibid., Vol. VII (1898), p. 642. 
developed from one egg; No. 2 shows two trochophores which are grown together but are otherwise independent. In No. 3 we notice the beginning of a common organization, inasmuch as the clear peripheral areas (on the right side) are fused together. In Nos. 4,5 , and 6 the clear areas are almost com-

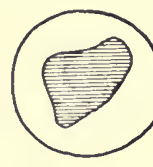

1.

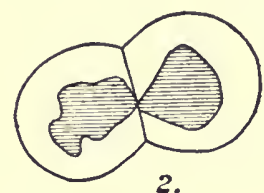

2.
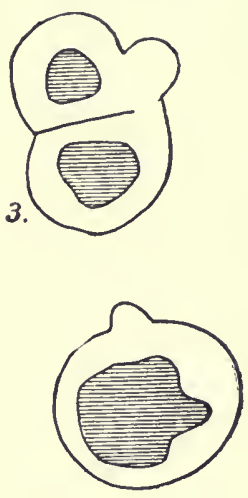

7.

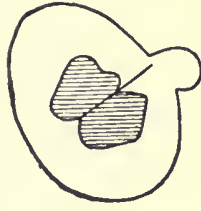

4.

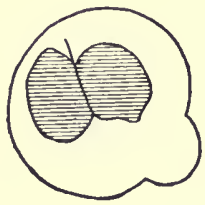

5 .

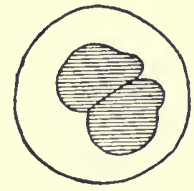

6 .

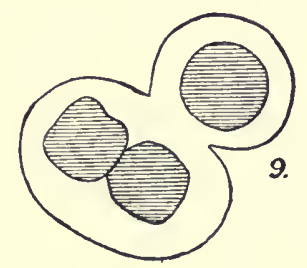

FIG. 161

pletely fused together, and only the dark centers remain separated. In No. 7 both eggs are fused completely and form one giant embryo with one set of organs. Cases like this are very frequent in the material treated with $\mathrm{KCl}$. Nos. 8 and 9 are examples of the fusion of more than two eggs. I have seen four eggs form one giant embryo with one common dark center and one common clear area. Such monsters swam, but usually died sooner than the single embryos. 
The fact that the fusion of two eggs into one giant embryo occurs so much more readily in Chrtopterus than in Arbacia may be due to the difference in the viscosity of the two eggs.

The formation of one giant embryo from two eggs in Chrtopterus is so very interesting for the reason that the Chætopterus egg possesses a characteristic cell-lineage. We must conclude from this that the cell-lineage is either a secondary element in the formation of the embryo or that the earlier processes of differentiation in the Chrtopterus egg are partly or wholly reversible (see section $\mathrm{x}$ ).

I have made very few experiments with $\mathrm{CaCl}_{2}$, but in these giant embryos were formed. Eggs that had been in a solution of 90 c.c. sea-water +10 c.c. $5 n \mathrm{CaCl}_{2}$ for one hour gave rise to a number of giant embryos. A sure way to produce giant embryos in Chætopterus is to put the unfertilized eggs for about one hour into a mixture of 97 c.c. seawater +3 c.c. $2 \frac{1}{2} n \mathrm{KCl}$.

I have occasionally, but very rarely, found that the fertilized eggs of Chrtopterus show agglutination in normal seawater. The same phenomenon seems to occur in the eggs of Ascaris, according to Zur Strassen. ${ }^{1}$

Dwarf embryos are rarely found in Chrtopterus. I have found them in the experiments with $\mathrm{HCl}$. Perhaps the existence of a membrane prevents the unfertilized eggs of Chætopterus from forming dwarf embryos as easily as the unfertilized eggs of the sea-urchins.

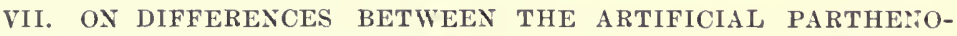
GENESIS OF ECHINODERUS AND CHETOPTERUS AND THE POSSIBILITY OF A HYBRIDIZATION BETWEEN THE TWO

It is impossible to hybridize Arbacia and Chætopterus in normal sea-water. I have tried a number of experiments with negative results, as was to be expected. The negative

1 Zur Strassex, loc. cit. 
result may be due to the impossibility of the spermatozoon of the one species entering the egg of the second species, or to the fact that the spermatozoon of Chrtopterus brings about the development of the Chrtopterus egg by substances which are ineffective in the Arbacia egg, and vice versa, or the spermatozoon of the one species is poisonous for the egg of the other species, or vice versa. ${ }^{1} \quad$ The second possibility is of interest to us on account of the fact that we can bring about the parthenogenetic development of the Chætopterus eggs by means which have no effect upon the Arbacia egg.

When we intend to produce artificial parthenogenesis in the eggs of Echinoderms, it is only necessary to put them for from one and one-half to two hours in sea-water, the osmotic pressure of which has been raised about $37 \frac{1}{2}$ to 75 per cent.; that is, into sea-water to which has been added $12 \frac{1}{2}$ to 25 per cent. of its volume of a $2 \frac{1}{2} n \mathrm{NaCl}$ solution or of a solution isosmotic with the latter. We have not yet determined the osmotic pressure of the sea-water at Woods Hole, and on indirect data assume that it is about isosmotic with a $\frac{5}{8} n$ $\mathrm{NaCl}$ solution. The optimal increase of osmotic pressure varies for different species and even for different females of the same species. It may be that the temperature of the water and the degree of maturity of the eggs play a rôle. In making experiments of this kind, it is necessary to use always a series of solutions of different osmotic pressure and to take the eggs out at various intervals, from one-half to two hours or more, until the optimum concentration and time have been ascertained.

An increase in the osmotic pressure of the sea-water is also able to cause artificial parthenogenesis in Chætopterus. The chief difference between the Chætopterus and Arbacia eggs is that at the same temperature the Chætopterus eggs

1 Certain constituents of the blood (globulins, enzymes?) frequently destroy the blood corpuscles of other species that are not closely related. 
do not need to stay so long in the more concentrated solution as the eggs of Arbacia.

Although in this regard the difference between Chætopterus and Arbacia is slight, a very striking difference exists in regard to the specific effects of $\mathrm{K}$ ions upon the development. While a pure $\mathrm{KCl}$ solution of lower osmotic pressure than sea-water, or sea-water with a slight increase of $\mathrm{K}, e . g$., a mixture of 98 c.c. sea-water +2 c.c. $2 \frac{1}{2} n \mathrm{KCl}$, causes the parthenogenetic development of the eggs of Chætopterus that have been exposed to such a solution only a few minutes, such solutions are without any effect upon the unfertilized eggs of sea-urchins (Arbacia). I left the unfertilized eggs of Arbacia repeatedly in a mixture of 98 c.c. sea-water +2 c.c. $2 \frac{1}{2} n \mathrm{KCl}$ or 97 c.c. sea-water +3 c.c. $2 \frac{1}{2} n \mathrm{KCl}$ for from three minutes to twenty-four hours without any development following, with the exception of a few eggs that reached the two-cell stage after about twenty hours. But this happens just as well in normal sea-water.

As far as the Arbacia eggs are concerned, I can only state that if we increase the osmotic pressure of the sea-water by adding $\mathrm{KCl}$, a slightly smaller increase in the osmotic pressure is required to bring about the parthenogenetic development than if we add $\mathrm{NaCl}$. I found regularly that while 90 c.c. sea-water +10 c.c. $2 \frac{1}{2} n \mathrm{KCl}$ sufficed to cause a great many eggs to reach the blastula stage, a mixture of 90 c.c. sea-water +10 c.c. $2 \frac{1}{2} n \mathrm{NaCl}$ was practically ineffective. I had to take $87 \frac{1}{2}$ c.c. sea-water $+12 \frac{1}{2}$ c.c. $2 \frac{1}{2} n \mathrm{NaCl}$. It is, however, possible, that this difference is only apparent. As the sea-water consists chiefly of $\mathrm{NaCl}$, the addition of $10 \mathrm{c.c}$. of a $2 \frac{1}{2} n \mathrm{NaCl}$ to 90 c.c. sea-water will increase the osmotic pressure of the sea-water less than the addition of 10 c.c. of a $2 \frac{1}{2} n \mathrm{KCl}$ solution, as the degree of dissociation is less if the concentration is higher. Further experiments with pure $\mathrm{NaCl}$ and $\mathrm{KCl}$ solutions will have to decide whether the dif- 
Artificial Parthenogenesis in Arxelidg 691

ference in the degree of dissociation is responsible for the result.. A second typical difference between the Arbacia egrg and the Chætopterus egg consists in the fact that the latter can be caused to develop by a small addition of $\mathrm{HCl}$ to sea-water. Any other inorganic acid would probably act in the same way, as the addition of a small amount of $\mathrm{Cl}$ ions has no such effect. This small addition of acid diminishes or neutralizes the alkalinity of the sea-water, but I have failed to test whether the latter is rendered acid.

The same treatment does not cause the Arbacia eggs to develop beyond the two- or four-cell stage, even if they are left in the solution for twenty-four hours. I have made a number of new experiments this summer, but I have only been able to confirm the experiments mentioned in a former paper. ${ }^{1}$

I have pointed out that the experiments on artificial parthenogenesis force us to assume that the influence of the spermatozoon upon the development and the transmission of the qualities of the male depend upon different constituents of the spermatozoon. On the basis of this assumption the possibility of a successful hybridization between animals as far apart as Worms and Echinoderms might be considered. If we could cause the egg of Chætopterus to develop by treating it with $\mathrm{KCl}$ and at the same time force the spermatozoon of an Arbacia (or a similarly distant animal) to enter into the egg, we might carry Echinoderm qualities into an Annelid egg. ${ }^{2} \quad$ But in all my attempts at thus crossing the female Chætopterus with the male Arbacia perfect trochophores without Echinoderm characteristics resulted. Although the problem may not be capable of solution in these two forms, I think that the experiments on artificial par-

1 Part II, p. siti.

2 Provided the spermatozoon of the Echinoderm contains no poison for the Annelid egg. 
thenogenesis will ultimately make hybridizations possible which otherwise would be impossible. I intend to continue these experiments.

VIII. PRELIMINARY EXPERIMENTS ON PHASCOLOSOMA, FUNDULUS, GONIONEMUS, AND PODARKE

I will report briefly on experiments which I began but was not able to finish, partly from lack of material and partly from lack of time. My experiments on Phascolosoma were carried further than the rest. I began with putting the unfertilized eggs of this form in mixtures of 90 c.c. sea-water +10 c.c. $2 \frac{1}{2} n \mathrm{KCl}$ and leaving them in this solution from thirty to one hundred and fifty minutes. I never saw an egg reach the two-cell stage. Then stronger solutions were tried, and now some of the eggs began to segment. When the eggs were put into a mixture of about 30 c.c. $2 \frac{1}{2} n \mathrm{KCl}$ +70 c.c. sea-water for about thirty minutes, they reached a thirty-to sixty-cell stage. The appearance of the eggs was so good that possibly in a continuation of these experiments parthenogenetic larvæ will be produced. In these experiments I received valuable advice from Dr. Gerould of Dartmouth College, who is thoroughly familiar with the biology and embryology of this form.

In Fundulus, a teleost fish, I succeeded in causing the unfertilized eggs to reach the two-cell stage, but lack of material prevented my carrying the experiments further.

In my experiments on Gonionemus, a Medusa, I was assisted by Dr. Murbach, who was kind enough to select the females for me. Dr. Murbacl had observed that by putting these animals into the dark they can at any time be caused to lay eggs.

My attempts (four experiments) to cause artificial parthenogenesis in these eggs have failed. All I was able to accomplish was to force the eggs to become amœboid and creep about, but no segmentation occurred. 
In Podarke, an Annelid, I succeeded in producing the first segmentation in unfertilized eggs. I interrupted these experiments to go on with experiments on Chætopterus which were much more promising.

\section{NATURAL AND ARTIFICIAL PARTHENOGENESIS}

In a definite although very small number of animals each egg possesses the quality to develop parthenogenetically. Instances of this are to be found in the bees, social wasps, Bombyx, Psyche, Daphnia, plant lice and others. In all these animals the egg can be fertilized also by a spermatozoon. How does it happen that in these forms, although fertilization may occur, the egg is, under certain conditions at least, able to develop parthenogenetically? Our experiments show, that if the constitution of the sea-water were only slightly different, that is, if it contained a little more $\mathrm{K}$, Chætopterus would have to be added to the list of normally parthenogenetic animals. What I stated in my preliminary report, is certainly true for Chætopterus, namely, that it is the constitution of the sea-water which prevents many or certain forms from being "naturally" parthenogenetic. By reversing this statement we may say that in the naturally parthenogenetic animals it may be due to the constitution of the blood (or the sea-water?) that the egg can develop without fertilization.

The bridge between the phenomena of natural and artificial parthenogenesis is formed by those animals in which physical factors decide whether or not their eggs develop parthenogenetically. In plant lice parthenogenesis is the rule only as long as the temperature is high or the plant has plenty of water. If we lower the temperature or let the plant dry out, sexual reproduction occurs. The drying out of the plant causes the tissues of the lice to lose water. The factor, loss of water, makes the artificial parthenogenesis of 
Echinoderms and Chrtopterus possible. In plant lice the effect is of the same kind, only in the opposite direction.

I have read somewhere the statement that Artemia salina is parthenogenetic, while Branchipus is not. Branchipus is a fresh-water Crustacean which, if raised in concentrated salt solutions (salt lakes), becomes smaller and undergoes some other changes. In that case it is called Artemia. If Artemia is parthenogenetic while Branchipus is not, it would mean that the unfertilized eggs of the Branchipus cannot develop in fresh water, while they are abie to develop in solutions of much higher osmotic pressure. This would be identical with our observation on the artificial parthenogenesis of Echinoderms and Chætopterus.

As I have mentioned in a former paper, $O$. Hertwig makes the statement that the unfertilized eggs of a number of marine animals which deposit their eggs in sea-water begin to develop after a number of hours, but do not develop beyond the first cleavage stages. Arbacia eggs reach the two-cell stage in about twenty hours; the egg of Chætopterus may develop as far as twelve or sixteen cells. According to Hertwig, not only the eggs of Annelids and Echinoderms, but also those of certain Crustaceans show this peculiarity. I have mentioned in a former paper the observation made by Janosik that in the ovary of mammals occasionally eggs are found in the process of cell-division. We shall make use of these facts in the next section.

I finally wish to say a few words concerning experiments published by Mr. Viguier of Africa, who maintains that the eggs of Arbacia, Toxopneustes, and other sea-urchins are naturally parthenogenetic.' It would contradict neither my experiments nor my views if his statement were correct, as in all my papers I have assumed that these and many other (if not all) eggs have a tendency to develop parthenogeneti-

I Viguier, Comptes rendus de l'Académie des Sciences, Paris, July 2, 1900. 
cally, and that it is only due to the constitution of the seawater (or blood?) if they do not do so under natural conditions. $\quad$ It might be that the constitution of the sea-water at Algiers differs from that of the rest of the world, and allows the eggs of the sea-urchin to develop parthenogenetically. The experiments of Mr. Viguier are, however, not of such a character as to make this probable. They are few in number, and he seems to have omitted no possibility which could further the contamination of his eggs by spermatozoa. He always handled males and females together, and opened males and females in the same experiment. No mention is made of a sterilization of his hands or instruments. Whenever males and females are in the same dish there is danger that the water may be full of spermatozoa, especially if the material is fresh. The sperm sticks to the surface of the females and it is absolutely impossible to avoid fertilization of the eggs. To be sure, Viguier mentions a precaution he took, but this precaution shows that he is not familiar with the methods of sterilization or disinfection. He washed the females off in filtered sea-water. As everybody knows, the spermatozoa go through filter paper, and, in addition, seawater does not remove the spermatozoa from the surface of the female, for the latter stick to solid bodies, as Dewitz has proved. In order to avoid this source of infection I washed the surface of the female several minutes in distilled water, or under a powerful stream of fresh water which kills the spermatozoa. I have in my former papers given a description of the precautions necessary in experiments on parthenogenesis. These were by no means exaggerated if one wished to guard absolutely against contamination. I did not even succeed in excluding contamination by spermatozoa in my first Chætopterus experiment (see p. 649), although my precautions were vastly superior to those taken by Viguier.

1 Part II, p. 539. 
Another surprising fact in Viguier's paper is that he does not mention whether or not his unfertilized eggs had a membrane. In my researches on Arbacia I have considered the lack or presence of a membrane the most important criterion for deciding whether the development of the eggs is due to the entrance of a spermatozoon or to the osmotic or chemical treatment they have received. The fertilized eggs form a thick membrane, while the unfertilized eggs generally have no membrane (unless treated with certain salts in excessive quantities and for a long time). The cleavage of the parthenogenetic egg that has no membrane differs so radically from that of the fertilized egg within a membrane, that it must arouse the interest or surprise of any morphologist. These differences are most noticeable during the first hours of the development. As soon as the egg approaches the blastula stage the membrane very often begins to disintegrate. I do not think that any experienced observer would have dared to publish the statement that the unfertilized eggs of Arbacia reach the pluteus stage, without having convinced himself that the "unfertilized" eggs had no membranes."

Mr. Viguier makes the statement that he tried to repeat my experiments but was not able to confirm them. This does not surprise me, as he had not read my papers, and as he did not even know how my solutions had been prepared. My experiments have been repeated and confirmed by the following authors: Dr. C. Herbst (Naples), Professor E. B. Wilson (Columbia University), Dr. Hans Winkler (Tübingen), and Dr. S. Prowazek (Prague), and partly by Professor A. Giard (Paris). In addition they were repeated with success by all the members of the class in physiology and embryolgy at Woods Hole last summer. As far as the statement is concerned that the unfertilized eggs of Arbacia or

1 Viguier's paper has been criticised by A. GIARD, Comptes rendus de la Societé de Biologie, Vol. LII (1900), p. 761. 
Strongylocentrotus are able to develop into plutei in normal sea-water, I can say that this is most certainly not the case at Woods Hole, in California (according to my own very numerous observations), in Beaufort, N. C., and at Naples and other places on the Mediterranean, that have been visited by competent experimenters.

X. THE BEARING OF ARTIFICIAL PARTHENOGENESIS ON THE THEORY OF FERTILIZATION AND OF LIFE PHENOMENA IN GENERAL

The general opinion concerning the rôle of the spermatozoon in the process of fertilization is that it acts as a stimulus, and that as such it starts the development of the egg. This statement is certainly wrong for those eggs in which we have been able to produce artificial parthenogenesis. For these eggs, like many others, begin to segment without any spermatozoon, if they are left long enough in normal sea-water. The only difference between these and the fertilized eggs is that the former begin to segment much later and their development stops in the early segmentation stages ( $t$ wo to sixteen cells at the most). The latter may be due to the fact that the egg dies before it has time to develop further.

If we consider the fact that the eggs show at least a beginning of a segmentation under "normal" conditions, the act of fertilization assumes a different aspect. The spermatozoon can no longer be considered the cause or the stimulus for the process of development, but merely an agency which accelerates a process that is able to start without it, only much more slowly. Substances that accelerate chemical or physical processes which would occur without them are called catalyzers (Ostwald). According to this definition we may assume that the spermatozoon carries a catalytic substance into the egg, which accelerates the process that would start anyhow, but much more slowly. 
Through these facts and conceptions the phenomena of artificial parthenogenesis assume a different aspect. It would be wrong to say that the $K$ ions are the stimulus that causes the developmental process. They merely act as catalyzers, accelerating a process that would otherwise proceed too slowly. The loss of water on the part of the egg cell must have a similar effect, but possibly a less direct one. It may be that the loss of water alters the chemical processes in the egg in such a way as to give rise to the formation of a substance which acts catalytically.

Whether or not the catalytic substances introduced by the spermatozoon are identical with those employed in my experiments, I cannot say. I consider it probable that in the case of Chrtopterus the natural fertilization is not brought about by $\mathrm{K}$ ions, inasmuch as the normal development does not show the characteristics of a treatment of the eggs with $\mathrm{K}$.

I have made a series of experiments with various enzymes to bring about the development of the unfertilized eggs of Arbacia, thus far without any results. The only enzyme that caused the egg to segment at all was papain. But I cannot be certain whether this was not due to some accidental constituent of the enzyme preparation used. The other enzymes were absolutely without effect. If we wish to find the active principle in the spermatozoon, we must make experiments in the direction of those begun by Winkler. ${ }^{1}$ This author used extracts of the spermatozoon, and found that such extracts caused the eggs of sea-urchins to reach the two- or four-cell stage. As such a result can be brought about by slight alterations in the osmotic pressure or constitution of the sea-water, and as such alterations occurred in Winkler's experiment, I am not yet certain that these

1 WrNkLER, Nachrichten der königlichen Gesellschaft der Wissenschaften, Göttingen, 1900 . 
results were actually due to the substances extracted from the spermatozoon. But his experiments are certainly in the righ.t direction.

The idea that the spermatozoon and the substances which cause parthenogenesis act only catalytically, has a great bearing upon the theory of life phenomena. It means that if we accelerate the processes of cell-division in the mature egg (by specific catalyzers) the egg can live; but if these processes occur too slowly at the ordinary temperature (as is the case in the unfertilized egg in normal sea-water), the egg dies. The introduction of the catalytic substances which accelerate the processes of development saves the life of the egg. This may be made intelligible on the following assumption. Two kinds of processes are going on in the mature egg after it has left the ovary. The one leads to the formation of substances which kill the egg; the other leads to the formation of substances which allow growth and celldivision, and are not poisonous. We may use as an illustration Pasteur's well-known experiments on the behavior of yeast cells in the presence and absence of atmospheric oxygen. In the presence of oxygen the yeast cells multiply on a sugar solution, while the zymase effect is comparatively small. In the absence of oxygen the multiplication of cells is limited or may stop, while the zymase effect becomes more prominent. The products of alcoholic fermentation are comparatively harmless for the yeast cell, and for this reason an increase in the fermentative activity of the cell does not cause the death of the yeast. I imagine that matters are similar in the mature egg cell after it has left the ovary, with this difference, perhaps, that the substances formed (by fermentation?) in the egg cell are more poisonous for the egg than the alcohol and the other products of fermentation are for the yeast. The process that causes the death of the egg cell and the one that causes cell-division are at least 
partly antagonistic. They are both inhibited by a low temperature, so that in this case death does not occur, although no cell-division is possible. If we succeed in finding a substance which accelerates the process of cell-division at the normal temperature, this will at the same time lead to a suppression or a reduction of the antagonistic process that shortens life. In the case of the egg of Chætopterus a trace of $\mathrm{K}$ ions acts as such a catalytic substance; possibly a trace of $\mathrm{H}$ ions; and perhaps certain substances that are formed when the egg loses a certain amount of water. For the Echinoderm egg we know at present only the last factor. In addition there are the catalytic substances carried or produced by the spermatozoon (ions? enzymes?). But there are certainly other catalytic substances, as is prored by tumors and galls, in which the variety of structures corresponds to an almost equal variety of parasites. ${ }^{1}$

It is very important to realize that the introduction of catalytic substances into the egg does not prolong its life unless the egg has reached a critical point determined by two sets of conditions. The one is the maturity of the egg, the other the change of conditions connected with the egg leaving the ovary. As long as the egg is immature it lives without the introduction of these substances or the spermatozoon, and this may be true for the mature egg as long as it remains in the ovary. The fact that there is an age limit for the derelopmentof carcinoma may be a similar phenomenon. The cataly tic substances which are given off by the cancer parasite may not be able to bring about cell-division in theepithelial cells unless the latter have reached a critical point, which is at least partly determined by the age of the individual.

1 We do not need to assume a specific parasite for each kind of tumor. Tera. tomas may be explained on the basis of the parthenogenetic tendency of the mammalian egg in connection with some chemical change that furnishes the catalytic substance. But it is not impossible that even in benign tumors, such as a teratoma, the catalytic substance may be due to parasitic organisms. 
We generally consider development as a process which can only occur in one direction, or, in other words, is irreversible. But this is certainly not generally the case. I showed in a recent paper that the morphogenetic processes in Hydroids are reversible. If the polyp of a Campanularia is brought in contact with a solid body, it is transformed into undifferentiated material and later into a stolon. If the same organ is brought in contact with sea-water, it gives rise to a polyp again. ${ }^{1}$ The same may be done with Margelis and other Hydroids. In Antennularia a change in the orientation of a branch with polyps will bring about the transformation of this material into a stolon. Between the two phases the material must pass through an undifferentiated stage where it is neither polyp nor stolon. It will be the task to determine how far in the animal kingdom the developmental processes are found to be reversible. It is obvious that in a form with a reversible development death will not necessarily follow a certain stage of development (corresponding to senility in man).

It is not impossible that "natural" death is comparable to the situation which is present in the mature egg after it leaves the ovary. Nature has shown us the way by which at this critical point death can be avoided in the case of the egg.

1 Part II, p. 627. 


\section{XXXIV}

ON AN APPARENTLY NEW FORM OF ABNORMAL IRRITABILITY (CONTACT-IRRITABILITY ?) PRODUCED BY SOLUTIONS OF SALTS (PREFERABLY SODIUM SALTS) WHOSE ANIONS ARE LIABLE TO FORM INSOLUBLE CALCIUM COMPOUNDS ${ }^{1}$

\section{INTRODUCTION}

A series of papers published from my laboratory has furnished the proof that the rhythmical contractions of striped muscles, the swimming bell of jelly-fish, the heart and the lymph hearts depend upon the presence of $\mathrm{Na}$ ions in the surrounding solution. Calcium ions have a tendency to diminish or inhibit the contractions altogether, although a small number of them must exist in the tissues in order to preserve contractility. ${ }^{2}$ This point having been settled, I next tried whether the sodium ions bring about these effects directly or indirectly. I have not finished these researches so far as the rhythmical contractions of the muscle are concerned, but in pursuing this problem I have found a number of facts which show that certain salts can bring about effects indirectly by giving the muscle or nerve properties which they do not possess normally and which to my knowledge have not yet been described. If we put a fresh muscle (gastrocnemius) of a frog for a short time (e.g., one to three minutes) into a solution of a sodium salt whose anion is liable to form insoluble calcium compounds (e.g., $\mathrm{NaFl}, \mathrm{Na}_{2} \mathrm{CO}_{3}$, $\mathrm{Na}_{2} \mathrm{HPO}_{4}$, sodium oxalate, sodium citrate, etc.), the muscle will as a rule not show any reaction except perhaps a slight

1 American Journal of Physiology, Vol. V (1901), p. 362.

2 It is possible that certain other ions may act as a substitute for the $\mathrm{Ca}$ ions for this purpose. 
shortening. But as soon as it is taken out of the solution and comes in contact with air, it goes into tetanus or performs a series of powerful contractions. The tetanus or the contractions cease at once and relaxation of the muscle occurs when the muscle is put back into the solution.

It was found that not only the change of contact from the above-mentioned solutions to air but also to a number of other media produce these contractions. What the nature of the stimulus in this case is I cannot say definitely. Provisionally I will assume that we are dealing with contact-irritability and I will call the above-mentioned reaction of the muscle the contact-reaction. It would seem as though the entrance of the anions of the above-mentioned solutions caused a change in the superficial layer of the muscle or its individual fibers, either by precipitating calcium or by otherwise altering the constitution of the protoplasm. This change is intensified by the increase in $\mathrm{Na}$ ions

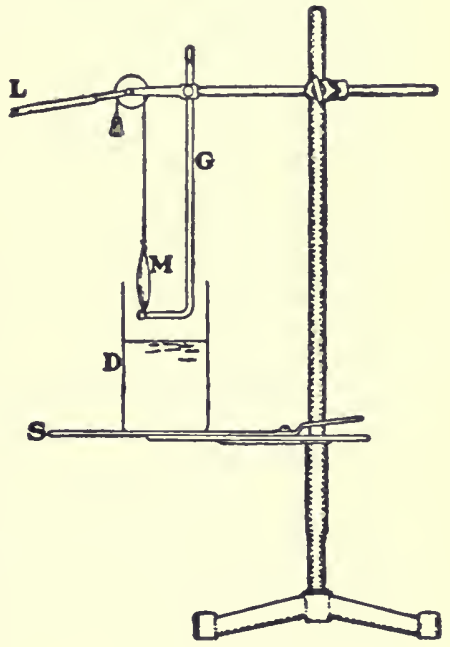

FIG. 162 in the same layer. In this condition the muscle is sensitive to the nature of the substance with which it comes in contact.

In these experiments one end of the gastrocnemius of a frog is tied to a glass rod, G (Fig. 162), and the other end is tied to the lever, L. A dish, D, containing the solution is raised from below when we wish to submerge the muscle, and is lowered when we wish to bring the muscle into contact with air.

In order to demonstrate the contact-irritability I used a solution of 1 gram-molecule of sodium fluoride or sodium citrate, etc., in about 8 or 10 liters. If the fresh gastrocnemius of a frog be put into such a solution for about one 
minute, the muscle will show a slight contraction when taken out of the solution. If the process be repeated, a stronger contraction will follow when the muscle is removed, and after a series of submersions have occurred the muscle will give one or a series of powerful contractions every time it is taken out of the solution and brought into contact with air. After a certain time, which may be an hour or more, and which varies according to the solution, the reaction becomes weaker and finally ceases.

If we use a stronger concentration than 1 gram-molecule in 8 liters, we get more powerful contractions, but the irritability of the muscle disappears sooner.

\section{THE NATURE OF THE SOLUTIONS WHICH PRODUCE CONTACT- IRRITABILITY IN MUSCLE}

Solutions of cane-sugar or urea were unable to produce the contact-reaction in muscle. I have tried these solutions in all concentrations from 0 to normal or even $2 n$. A large number of electrolytes were then tested. None of the salts of $\mathrm{Li}, \mathrm{K}, \mathrm{Ca}, \mathrm{Mg}$, and $\mathrm{NH}_{4}$ gave rise to the contact-reaction. This statement is based upon experiments with $\mathrm{LiCl}, \mathrm{Li}_{2} \mathrm{SO}_{4}$, $\mathrm{Li}_{2} \mathrm{CO}_{3}, \mathrm{KCl}, \mathrm{K}$ citrate, $\mathrm{K}$ oxalate, $\mathrm{MgCl}_{2}, \mathrm{MgSO}_{4}, \mathrm{NH}_{4} \mathrm{Cl}$, $\left(\mathrm{NH}_{4}\right)_{2} \mathrm{CO}_{3}$, and ammonium citrate. The degree of dilution used was as a rule 1 gram-molecule in about 8 or 10 liters. In some instances stronger solutions were tried, but with the same negative result. ${ }^{1}$

In my experiments on rhythmical contractions I have shown that the sodium ions have a specific rôle in the production of these contractions. It seemed also possible that they play such a rôle in the production of the contact-irritability. But I found that $\frac{n}{8}$ or even stronger solutions of $\mathrm{NaCl}, \mathrm{NaBr}, \mathrm{NaI}, \mathrm{NaNO}_{3}$ did not bring about the contact-

1 Zoethout showed later in my laboratory that the addition of a trace of potassium citrate to the sodium-citrate solution facilitates the production of contact. irritability. [1903] 
irritability; neither did sodium acetate nor other salts whose anions form soluble calcium compounds.

But the sodium salts whose anions precipitate calcium promptly produce these reactions. $\mathrm{NaFl}, \mathrm{Na}_{2} \mathrm{CO}_{3}, \mathrm{Na}_{2} \mathrm{HPO}_{4}$ sodium oxalate, sodium citrate, ${ }^{1}$ sodium tartrate give the contact reaction in a dilution of 1 gram-molecule in 8 or 10 liters of water or even less. $\mathrm{NaHCO}_{3}$ gives the reaction but requires a higher concentration, $e . g$., 1 gram-molecule in 4 to 5 liters of water. If we put the muscle into a solution of $\mathrm{Na}_{3} \mathrm{PO}_{4}$, it goes at once into a powerful tetanus. This tetanus may be partly or wholly due to the high concentration of $\mathrm{HO}$ ions in this solution. When a muscle goes into tetanus in a solution, we cannot, as a rule, demonstrate the contact-reaction. Thus I have never succeeded in producing contact-reaction by a $\mathrm{Na}_{3} \mathrm{PO}_{4}$ solution. $\mathrm{NaH}_{2} \mathrm{PO}_{4}$ does not cause contact-irritability, but this is in harmony with our general result.

The $\mathrm{HO}$ and $\mathrm{H}$ ions deserve special attention. In my experiments on rhythmical contractions I found that while they are not able to produce rhythmical contractions directly, they accelerate the beginning of these contractions in the presence of $\mathrm{Na}$ ions. In addition to such a catalytic action common to both the $\mathrm{HO}$ and $\mathrm{H}$ ions, the former have another effect which they do not share with the $\mathrm{H}$ ions. The muscle produces constantly $\mathrm{H}_{2} \mathrm{CO}_{3}$ and possibly other acids. These acids will increase the solubility of $\mathrm{Ca}$ salts and increase the number of $\mathrm{Ca}$ ions in the tissues. An addition of $\mathrm{HO}$ ions will counteract this effect.

It is due to the presence of free $\mathrm{HO}$ ions that solutions of $\mathrm{Na}$ valerianate and $\mathrm{Na}$ formate give rise to a slight degree of contact irritability in muscle, although calcium formate and calcium valerianate are soluble. If we diminish the

1 The citrates require an alkaline reaction for the precipitation of calcium This condition is fulfilled in the fresh normal muscle. 
alkalinity of a sodium formate and sodium valerianate solution by adding a small amount of free formic or valerianic acid (without, however, rendering the solution entirely neutral) they no longer produce the contact-irritability in muscle. A small amount of alkali added to a $\mathrm{NaCl}$ solution may or may not produce a slight degree of contactirritability.

The solubility of $\mathrm{CaSO}_{4}$ is comparatively high, and we therefore cannot expect $\mathrm{Na}_{2} \mathrm{SO}_{4}$ to be very effective for the production of contact-irritability. In solutions of $1 \mathrm{gram}-$ molecule $\mathrm{Na}_{2} \mathrm{SO}_{4}$ in 10 liters or less, I sometimes got and sometimes failed to get the contact-reaction. May it not be possible that the amount of free $\mathrm{Ca}$ ions in the muscle of a frog varies at different periods of the year, and may not this fact account for the seasonal variation in the irritability of these animals? But if a $\mathrm{Na}_{2} \mathrm{SO}_{4}$ solution fail to produce contact-irritability in a muscle an addition of some $\mathrm{HO}$ ions will produced the desired effect. As a rule 4 c.c. $\frac{n}{10} \mathrm{LiHO}$ or any other hydrate to 100 c.c. of the $\mathrm{Na}_{2} \mathrm{SO}_{4}$ solution is the optimum. We can produce the contact-reaction also through the addition of a small amount of acid to the $\mathrm{Na}_{2} \mathrm{SO}_{4}$ solution, e.g., 4 c.c. of $\frac{n}{10} \mathrm{HNO}_{3}$ (or any other inorganic acid) to 100 c.c. of the $\mathrm{Na}_{2} \mathrm{SO}_{4}$ solution. The effects are not so strong as if we add alkali.

The sulphates showed an exceptional behavior in still another direction. With one exception only sodium salts give rise to contact-irritability and this exception is a sulphate, namely $\left(\mathrm{NH}_{4}\right)_{2} \mathrm{SO}_{4}$. It would almost seem that the sulphates have physiological effects aside from their effect upon calcium. This is in harmony with Miss Moore's experiments, in which she found that sulphates are as capable of antagonizing the poisonous effects of a pure $\mathrm{NaCl}$ solution as calcium salts. ${ }^{1}$

1 Moore, American Journal of Physiology, Vol. V (1901), p. 87. 
It should finally be mentioned that sodium butyrate, sodium succinate and sodium asparaginate did not produce the contact-reaction.

Haring thus proved that sodium salts, whose anions precipitate calcium give rise to contact-irritability, it was to be expected that solutions of calcium salts would prevent or antagonize the contact-reaction. I found that by adding a small amount of $\mathrm{CaCl}_{2}$ to a Na-citrate solution the latter solution no longer produced the contact-reaction. The addition of 1 c.c. of a $5 n \mathrm{CaCl}_{2}$ solution to 100 c.c. of an effective sodium-citrate solution was sufficient to cause a muscle to lose its contact-irritability at once. Only after a prolonged stay in pure sodium-citrate solution does the contact-irritability return.

While all the facts thus seem to harmonize with the view that a decrease in the amount of $\mathrm{Ca}$ ions in the tissues (and possibly an increase in the amount of $\mathrm{Na}$ ions) is the essential condition for the production of the contact-reaction, it is yet possible that the sodium salts whose anions form insoluble calcium compounds may have a specific effect upon other constituents of the protoplasm, $e . g$., proteids.

III. ON THE NATURE OF THE APPARENT CONTACT-REACTION

The reaction which we have provisionally called the contact-reaction appears when a muscle, after having been submerged in a sodium-citrate or any of the other abovementioned effective solutions, is brought into contact with air. In this change from solution to air a number of conditions change and it is now our task to determine which is the essential one.

As soon as the muscle is taken out of the solution and brought into air, more $\mathrm{O}_{2}$ may diffuse into and more $\mathrm{CO}_{2}$ may diffuse from the muscle. These two conditions have, however, nothing to do with the reaction. The experiments 
were repeated in an almost pure atmosphere of $\mathrm{CO}_{2}$ instead of air and the contact-reaction was as powerful as in air.

A second change is the sudden evaporation of water from the surface of the muscle upon its leaving the solution. The following experiment might suggest that this evaporation is the cause of the contact-reaction. If we pack a muscle, that gives powerful contact contractions, tightly in moist filter paper the reaction will not occur when the muscle is taken out of the solution, but will occur when the filter paper is removed. Nevertheless, evaporation has nothing to do with the reaction. We get the contact-reaction quite as well in a moist chamber as in dry air. Furthermore we get the reaction if we bring the muscle directly from the sodiumcitrate or fluoride solution into oil, without exposing it to air. We can make this experiment in the following way. The lower half of the dish, D (Fig. 162), is filled with the effective sodium-citrate solution, the upper half with oil (I used sperm and olive oil). The muscle is first brought into the sodium-citrate solution and then, by lowering the support S, into the oil. Powerful contractions occur. Evaporation of water from the surface of the muscle is, therefore, not the cause of the contractions.

After this had been established it was to be expected that changes in temperature were not responsible for the contact reaction. Experiments in which the muscle was rapidly cooled and heated yielded only negative results.

The next possible cause to be considered was electricity. The fact that a change from the salt solution to a non-conductor (air, oil) caused contractions suggested the possibility that these contractions were in reality electrical break contractions, the muscle itself acting as a battery. The only fact which did not seem to accord with this explanation was the lack of a make contraction when the muscle was put into 
the solution. A number of experiments excluded the assumption that the contraction or tetanus of the muscle which occurs when it leaves the sodium-citrate solution is due to a break shock. I connected the two opposite ends of the muscle by means of a thick copper wire. In this case the muscle contracted just as powerfully as before when taken out of the sodium-citrate solution, although no break shock of any strength was possible. Another still more decisive fact was found. After the muscle had been treated for some time with a sodium-citrate solution the break contraction could be produced by dipping the muscle for a short time, e. $g$., thirty seconds, into a $\frac{n}{8}$ or $\frac{n}{4}$ solution of cane-sugar. As soon as the muscle was brought into contact with air, contractions occurred. The same was true for glycerin solutions. Both the sugar and the glycerin solution are nonconductors. The possibility of a mechanical stimulation as the cause of the contact-reaction was next to be considered. As long as the muscle is in the solution each of its elements is under the hydrostatic pressure of the column of liquid above it. If we expose the muscle to the air this pressure ceases. This might suggest the idea that a decrease of the hydrostatic pressure upon the muscle causes its contraction. The dipping of the muscle into the solution causes a relaxation of the concentrated muscle, and the inference should be drawn that an increase of the hydrostatic pressure causes relaxation. The following experiments prove the erroneousness of this view. T'he bottom of the dish was filled with a liquid of much higher specific gravity than the sodiumcitrate solution, $e . g$., with chloroform, $2 n$ cane-sugar solution, or metallic mercury, and the sodium-citrate solution was put carefully above the sugar solution or chloroform. The muscle was then brought from the sodium-citrate solution into the sugar solution by raising the dish D (F:g. 162). In this case I noticed regularly one or more powerful contrac- 
tions, although the hydrostatic pressure on the surface of the muscle was increased.

It thus seems to me that none of the known forms of muscular irritability suffices to explain the phenomena with which we are dealing. We have before us an apparently new form of muscular irritability, probably contactirritability.

Contact-irritability is a very general form of irritability among plants and lower animals. I need only to remind the reader of the phenomena of stereotropism and of the fact that by mere contact-effects a polyp of a campanularia can be transformed into a stolon. But contact-irritability certainly exists among certain cells of vertebrates, for example, the leucocytes. The nature of the body with which leucocytes come into contact determines whether or not they give off fibrin ferment and cause coagulation of the blood or other liquids which contain fibrinogen. How the nature of the contact can influence the leucocytes is still a mystery. One might think of surface tension phenomena or the formation of double electric layers at the surfaces in contact.

If the phenomena described in this paper were really contact-phenomena, a further search should reveal that only a change of contact from certain bodies to other bodies can cause contractions of the muscle.

I have begun experiments in this direction, and have thus far found the following facts:

Contractions occur when the muscle passes:

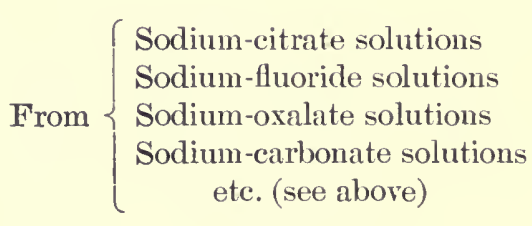

Air

$\mathrm{CO}_{2}$

Oil

To

$2 n$ sugar solution

Glycerin

Chloroform

Toluol 
Relaxation of the contracted muscle will occur when the muscle passes from any medium in the right column above to any medium in the left column.

After the muscle has been treated for some time with any of the efficient solutions ( $\mathrm{Na}$ citrate, etc.) the contractions are also produced when the muscle passes:

\section{From ${ }_{8}^{n}$ or ${ }_{4}^{n}$ sugar solution to air \\ From ${ }_{8}^{n}$ or $\frac{n}{4}$ glycerin to air \\ From any salt solution to air}

A very interesting and theoretically important fact is that the muscle loses this particular form of irritability very soon when it remains in contact with the air, oil, sugar solution, glycerin, or salt solutions different from those that produce this specific irritability. In $\mathrm{LiCl}$ or $\mathrm{NaCl}$ solutions the contact-irritability is lost as fast as, if not faster than, in a sugar or glycerin solution. We can re-establish the irritability, however, if we put the muscle back into the sodiumcitrate solution for some time. This fact, together with those mentioned before, suggests the following as the most probable explanation of the peculiar phenomena of contraction with which we have been dealing: the solutions which produce the contact-irritability possess anions that are liable to form insoluble calcium compounds. They are all with one exception - $\left(\mathrm{NH}_{4}\right)_{2} \mathrm{SO}_{4}-\mathrm{Na}$ salts. Whatever the effects of these anions may be, the fact that in less than a minute the contact effects are noticeable indicates that only the surface layer of the muscle or, what is less probable, the surface layer of each individual fiber, is altered. It is impossible for the anions to migrate deeper into the muscle in so short a time. In the surface layer of the muscle or the individual fibers we have temporarily a diminution of Caions. We have, then, a muscle, whose surface layer differs from that of an ordinary excised muscle. If this layer is once established the muscle contracts at any change from the media of the 
left column of the above list to those of the right column. But it is obvious too that as soon as this change occurs the surface layer gradually undergoes an alteration, for example, in air, sugar solution, $\mathrm{NaCl}$ solution, etc. This change, in which the contact-irritability is lost, occurs most rapidly in a $\mathrm{CaCl}_{2}$ solution. This suggests the following possibility. The loss of contact-irritability of the muscle in air or oil, etc., is due to the migration of $\mathrm{Ca}$ ions from the interior of the fiber or the muscle to the surface, thus re-establishing approximately the original normal surface condition. If we then put the muscle back for a short time into a sodiumcitrate or sodium-fluoride, etc., solution, a diminution of Ca ions will again occur in the surface layers and the contact-irritability will be re-established, As is to be expected the time the muscle remains in the solution is as important as the concentration of the solution. If we dip a muscle for a few seconds only into a sodium-citrate solution (1 grammolecule in 10 liters) the contact-irritability cannot be produced, as there is not time for a large enough number of anions to diffuse into the muscle.

Still another fact harmonizes with our assumption. If we lift only a piece of the muscle out of the sodium-citrate solution, not the whole muscle contracts, but only the individual fibers that come in contact with the air. Similarly a more powerful contraction occurs when we lift the thick femur end of the gastrocnemius out of the solution than if we expose the thin tendon-Achilles end to the air.

Finally it should be mentioned that the latent period is somewhat long in these experiments. I have not measured it yet exactly; but it may be a considerable fraction of a second, especially when the contact-irritability is about to disappear. This somewhat long latent period would harmonize well with the assumption of contact-phenomena.

Although I have spoken chiefly of the diminution of 
Abrormal Irritabiliti Prodeced bi Salts 703

$\mathrm{Ca}$ ions as the effect of the sodium-fluoride and similar solutions, I wish to state that I consider it possible that solution may have other effects which play a rôle in these phenomena.

IV. THE EFFECTS OF SODIUM FLUORIDE AND CORRESPONDING SOLUTIONS UPON THE NERVE

If we try the experiments described above on curarized muscles we get little or no result. This would indicate that the contact-reaction is not due to an effect of these solutions upon the muscle but upon the nerve elements in the muscle. There is a second possibility, namely that curare, although it does not abolish the electrical irritability of muscle, may yet alter its substance enough to prevent the effects of contact stimuli, or prevent the formation of the hypothetical surface layer.

It may be said with certainty that sodium-fluoride, sodiumcitrate, and the corresponding solutions act upon the nerve in a way altogether different from that in which they act npon muscle. If we put the nerve alone (without the muscle) into one of these solutions which contains 1 gram-molecule in about ten liters, as a rule nothing will happen during the first five minutes. The removal of the nerve from the solution will not call forth a contraction of the muscle. After about five minutes the muscle will begin to twitch rhythmically, and very soon the muscle will shorten steadily until it reaches a high degree of tetanic contraction. This twitching continues as long as the nerve is in the solution. As soon as the nerve is taken out of the solution and exposed to the air the muscle relaxes more or less completely, and the twitchings become less numerous. As soon as the nerve is put back into the sodium-citrate solution the contraction increases again and the twitchings become more powerful. This may be repeated very often. It is obvious that the 
nerve behaves in exactly the opposite way from the muscle. The latter contracts when taken out of the solution and exposed to the air, and relaxes when put back into the solution. If the nerve alone (without the muscle) be put into the solution, contractions of the muscles occur while the nerve is in the solution, and partial or complete relaxation is observed when the nerve is taken out.

These experiments on the nerve give one the impression that the sodium-citrate solution and the solutions of the other sodium salts whose anions precipitate calcium stimulate the nerve chemically. Albert Mathews has recently found that weak solutions of sodium salts can cause contractions of the muscle when the nerve alone is put into the solution, while the salts of the other metals can only produce contractions when their osmotic pressure is considerably higher than that of the tissues. I have confined my experiments chiefly to those sodium salts whose anions precipitate calcium. But I think I can show definitely that these salts are not the direct stimulus that calls forth the contractions of the muscle, but play only an indirect rôle, inasmuch as they make the nerve more sensitive for another kind of stimulus, either a mechanical- or a contact-stimulus. When the nerve alone has been put into a sodium-citrate solution (of 1 gram-molecule in about 10 liters) and the muscle has begun to contract powerfully, a gradual relaxation of the muscle is observed when the nerve is taken out of the solution and allowed to hang in the air. But at any time the contractions and the final tetanus of the muscle will begin again when the nerve is brought into contact with any solid or liquid body, no matter whether it is a conductor or a nonconductor. As soon as the contact ceases and the nerve is surrounded by air again on all sides the muscle gradually relaxes. This can be repeated quite often with the same result. Among the substances whose contact causes con- 
traction I may mention hard rubber, glass, filter paper, varnished and unvarnished wood, bone, muscle, all kinds of metals. Among the liquids tried were oil, glycerin, sugar solutions and several salt solutions. It is thus obvious that in a sodium-citrate solution two influences are united, first the effects of the citrate ion which causes a modification or an increase in the irritability of the nerve, and second, the liquid character of the solution. The latter is the direct cause for the contraction.

Another point is of interest in this connection. The sodium-citrate or sodium-fluoride solution increases the electrical irritability of the nerve so that it can easily be stimulated by its own current of demarkation. This increase occurs regularly before the twitchings of the muscle begin.

In my experiments on artificial parthenogenesis in Chætopterus I found that there are two ways by which the unfertilized egg can be caused to develop - first, by certain ions $(\mathrm{K}, \mathrm{H})$, and second, by causing the egg to lose water. It follows from the facts of dissociation that a loss of water on the part of the egg must alter the proportion of ions in the egg. It thus becomes possible that the artificial parthenogenesis produced by the loss of water is in reality an ion effect. In regard to the twitchings caused by putting the nerve into solution Mathews has shown that two cases must be distinguished - first, the effect of specific ions, and second, the effect of loss of water. Any solution whose osmotic pressure is high enough can cause contractions if the nerve be put into it. Is it not possible that the loss of water in the nerve acts in the same way as the citrate or fluoride ions? The limited solubility of $\mathrm{CaSO}_{4}$ would make this possible. I tried whether a nerve after having been put into a $2 n$ sugar solution long enough to cause muscular contractions would show the above-mentioned meclianical or contact-irritability. This was indeed the case. If such a 
nerve is taken out of the sugar solution and brought into contact with' solid bodies, it gives rise to stronger contractions. But, as was to be expected, the nerve loses this irritability again when put into $\frac{n}{8} \mathrm{NaCl}$ or $\mathrm{Na}$ citrate solution. In such a solution water will enter the muscle and restore the original condition, and only later will the entrance of citrate ions show its effect.

It now remains to be seen how far these facts can throw light upon the heart-beat. The fact that a heart which has ceased to beat in a solution often begins to beat again when taken out of the solution reminds us of the contact-reaction of muscle described above.

\section{SUMMARY}

1. Certain salt solutions ( 1 gram-molecule in 8 or 10 liters) bring about an apparently new form of irritability in muscles, which may be called provisionally contact-irritability. A muscle that has been treated in this way will contract powerfully when it passes from the salt solution to air, $\mathrm{CO}_{2}$, oil, sugar solution, etc., or from glycerin solutions, sugar solutions to air.

2. The salts whose solutions produce this form of irritability are (with one exception) sodium salts, whose anions are liable to precipitate calcium, namely:

Sodium fluoride $\mathrm{Na}_{2} \mathrm{HPO}_{4}$

Sodium citrate

Sodium carbonate

Sodium oxalate

Sodium tartrate

3. If the nerve alone (without the muscle) be put into one of these salt solutions ( 1 gram-molecule in 8 or 10 liters), the muscle begins to twitch in about five minutes and finally goes into tetanus. If the nerve be taken out of the solutions, the contractions cease. Although this seems to indicate that the salts or their ions stimulate the nerve directly, it can be shown that they only modify or increase the irritability of the nerve. For when the same nerve is brought 
into contact with any solid or liquid body (conductor or nonconductor) the contractions of the muscle will be resumed, while they will gradually cease or diminish when the nerve is again surrounded by air on all sides.

4. The fact that certain ions are capable of bringing about forms of irritability in nerves and muscles which do not exist normally may perhaps furnish the explanation of a number of certain morbid phenomena (neuroses, hysteria) in which the motor and sensory reactions of the patient are modified. 


\section{XXXV}

\section{THE TOXIC AND THE ANTITOXIC EFFECTS OF IONS}

AS A FUNCTION OF THEIR VALENCY AND POSSIBLY THEIR ELECTRICAL CHARGE ${ }^{1}$

\section{INTRODUCTION}

FIve years ago I published a series of papers on the physiological effects of the electric current which impressed upon me the long-known fact that the galvanic current is the most universal and effective stimulus for life-phenomena. This fact suggested the idea that it should be possible to influence life-phenomena just as universally and effectively by the electrically charged molecules - the ions - as we can influence them by the electric current.

My first aim was to find out whether or not it is possible to alter the physiological properties of tissues by artificially changing the proportion of ions contained in these tissues. In this way originated the investigations on the effect of ions upon the absorption of water by muscles, ${ }^{2}$ the effects of ions upon the rhythmical contractions of muscles, and Medusæ, ${ }^{3}$ the heart of the turtle, ${ }^{4}$ and the lymph hearts ${ }^{5}$ of the frog, the rôle of ions in chemotropic phenomena ${ }^{6}$ and the influence of ions upon embryonic development, ${ }^{7}$ and the development

1 American Journal of Physiology, Vol. VI (1902), p. 411. A preliminary report of these experiments appeared in Pfügers Archiv für die gesammte Pysiologie, Vol. LXXXVIII (1901), p. 68.

2 Part II, pp. 450, 501, and 510.

3 Part II, pp. 518, 559, and 692; Archiv für die gesammte Physiologie, Vol. LXXX (1900), p. 229.

4 D. J. Lingle, American Journal of Physiology, Vol. IV (1900), p. 26.

5 A. Moore, ibid., p. 386.

6 W. E. GarreY, ibid., Vol. III (1900), p. 291.

7 Part II, pp. 5 э9 and 576. 
of unfertilized eggs (artificial parthenogenesis). ${ }^{1} \quad$ Those who have followed my work on artificial parthenogenesis may have noticed that from the start I aimed at bringing about artificial parthenogenesis through ions. It seemed to me that I could not find any better test for my idea that the electrically charged ions influence life-phenomena most effectively than by causing unfertilized eggs to develop by slightly altering the proportion of ions contained in them. I believe that all these experiments proved what I expected they would prove, namely, that by slightly changing the proportion of ions in a tissue we can alter its physiological properties.

The next step taken consisted in proving that it was indeed the electrical character of the ion that determined its specific efficiency. I succeeded in doing this three years ago. It was known that a frog's muscle gives rise to twitchings or rhythmical contractions when immersed in certain solutions. - I showed that such contractions occurred only in solutions of electrolytes, and not in solutions of non-conductors (distilled water, various sugars, glycerin, urea). ${ }^{2}$ Soon after I showed the same to be true also for the rhythmical contractions of the Medusæ. ${ }^{3}$ From observations made in my laboratory, the same fact was shown to hold for the turtle's heart by Mr. Lingle, ${ }^{4}$ and for the lymph hearts of the frog by Miss Moore. ${ }^{5}$ I am confident that this fact will be proved universally.

In the physiology of the heart one frequently encounters the statement that calcium is the stimulus for the contraction of the heart. I had found that a muscle is able to twitch p. 594 .

1 Part II, p. 646. Archiv für die gesammte Physiologie, Vol. LXXXVII (1901),

2 Part II, p. 518.

3 Part II, pp. 553 and 559.

4 Lisgle, American Journal of Physiology, Vol. IV (1900), p. 26.5.

5 Moore, ibid., Vol. V (1900). p. 8 i. 
rhythmically when immersed in the solution of salts with a monovalent kation - I obtained contractions in $\mathrm{Na}, \mathrm{Li}, \mathrm{Rb}$, and Cs salts - but that the addition of a small quantity of a bivalent kation- $\mathrm{Ca}, \mathrm{Mg}, \mathrm{Sr}, \mathrm{Be}, \mathrm{Mn}$. Co-inhibits these rlytlimical contractions. ${ }^{1}$ This seemed to be a direct contradiction to the statement that calcium salts are the "cause" of the heart-beat. The significance of the calcium had to be looked for, then, in another direction. It was soon found that the muscle, the apex of the heart, and a Medusa contract rhythmically in a pure sodium-cliloride solution, but that they soon come to a standstill. If, lowever, a trace of a soluble calcium salt is added to the sodiumchloride solution, the contractions continue much longer. I concluded from this that the pure sodium-chloride solution acts, in the long run, as a poison - that is to say, brings about definite, but at present unknown, physical changes in the protoplasm - but that a trace of a calcium salt annililates this toxic action. The amount of calcium necessary for this antitoxic effect is, of course, much smaller than the amount necessary to inlibit the rhythmical contractions. Soon after I succeeded in demonstrating conclusively the poisonous effect of a pure sodium-chloride solution, and the annihilation of this effect by calcium. ${ }^{2}$ The eggs of a marine fish (Fundulus) develop normally in sea-water, but they can develop just as well, as I had previously found, in distilled water. The addition of ions from the outside is consequently not necessary to the development of this animal. I found, now, that if the freshly fertilized eggs of this fish are put into a pure sodium-chloride solution having a concentration equal to the concentration of the sodium chloride in the sea-water (about $\frac{5}{8} \mathrm{~m}$ ), not a single egg can develop into an embryo. If, however, a trace of a calcium salt is

1 Part II, p. 518.

2 Part II, p. 559; Archiv für die gesanmte Physiologie, Vol. LXXX (1900), p. 229 
added to a sodium-chloride solution, as many eggs develop, and in just as normal a manner, as in ordinary sea-water. The calcium ions in this case undoubtedly serve the purpose of annihilating the poisonous effect of a pure sodiumchloride solution.

In the meantime I had become familiar with the brilliant experiments of Hardy upon the influence of ions and the galvanic current upon colloidal solutions. ${ }^{3}$ They indicated to me that the next step I had to take was to see whether or not the valency and the sign of the electrical charge of an ion determine its physiological effects. I suspected that the antitoxic effect of the calcium ion in the above-mentioned experiment was due to its electrical charge and decided to investigate in a more systematic way whether or not the sign and quantity of the electrical charge influence life-phenomena. My experiments carried on at Woods Hole this summer showed conclusively that this is the case for the antitoxic effects of ions, and probably for the production of rhythmical contractions through ions. It seems at least possible that it is true also for artificial parthenogenesis. ${ }^{2}$

II. THE ANTITOXIC EFFECT OF IONS AS A FUNCTION OF THEIR ELECTRICAL CHARGES AND VALENCY

1. The development of an embryo from the freshly fertilized egg of the before-mentioned tish, Fundulus, served as a test for the toxic and antitoxic effects of ions. I chose this particular animal for two reasons. First, the process of development in this form is to an astonishing degree independent of the osmotic pressure of the surrounding solution. The egg will develop not only in sea-water, the osmotic

1 HARDy, Proceedings of the Royal Society, Vol. LXVI (1900), p. 110.

2 I have not altered this introduction, although I now think it probable that the ions act chemically in all these cases. [1903] 
pressure of which is about equal to that of a $\frac{5}{8} \mathrm{~m}$ sodiumchloride solution, ${ }^{1}$ but also in distilled water, or in sea-water the concentration of which has been doubled (by the addition of $\mathrm{NaCl}$ ). In the following experiments, therefore, we need not at all consider the osmotic pressure of the surrounding solution. Secondly, since enormous numbers of the eggs can be obtained, it is an easy matter to perform the experiments upon hundreds or thousands of eggs at once.

The eggs were artificially fertjlized in the laboratory by the addition of sperm, and then immediately distributed into the various solutions. The embryo Iorms in from about twenty-six to forty-eight hours - varying with the temperature - and twenty-four hours later the heart begins to beat, and the circulation is established. Usually about two hundred eggs were put into a solution, and after two or three days the developed embryos were counted and the percentage of the eggs which had developed was determined. The eggs were kept under observation as long as the embryos remained alive. Usually when an embryo was once formed, development went farther, and the circulation was established.

2. First of all the toxic effects of a pure sodium-chloride solution at various concentrations were tested. In a $\frac{m}{4} \mathrm{NaCl}$ solution every egg produced an embryo which died, however, before, or immediately after, emerging from the egg. (The embryo hatches from between twelve to twenty days after fertilization.) On the other hand, in a $\frac{3}{8} m \mathrm{NaCl}$ solution only a few of the eggs gave rise to embryos - about 1 to 5 per cent. In a $\frac{4}{8} m \mathrm{NaCl}$ solution an embryo forms but rarely, and in a $\frac{5}{8} \mathrm{~m} \mathrm{NaCl}$ solution the formation of embryos is rendered impossible. The egg goes through the first

\footnotetext{
$1 \mathrm{~m}$ represents that degree of dilution of a solution which contains one gram. molecule of the substance in one liter of the solution.
} 
stages of segmentation, but dies when it reaches the thirtytwo- or sixty-four cell stage. The concentration of a $\frac{5}{8} \mathrm{~m}$ sodium-chloride solution is indeed so high above the point of the fatal concentration of sodium chloride that a slight decrease in the degree of dissociation of the $\mathrm{NaCl}$ solution brought about through the addition of a small amount of another salt having a common ion, could be entirely disregarded. In the following experiments, however, salts with different ions were combined, wherever this was possible.

If to a pure sodium-chloride solution a trace of a calcium salt is added, as many eggs develop as in ordinary sea-water, as shown by Table I.

TABLE I

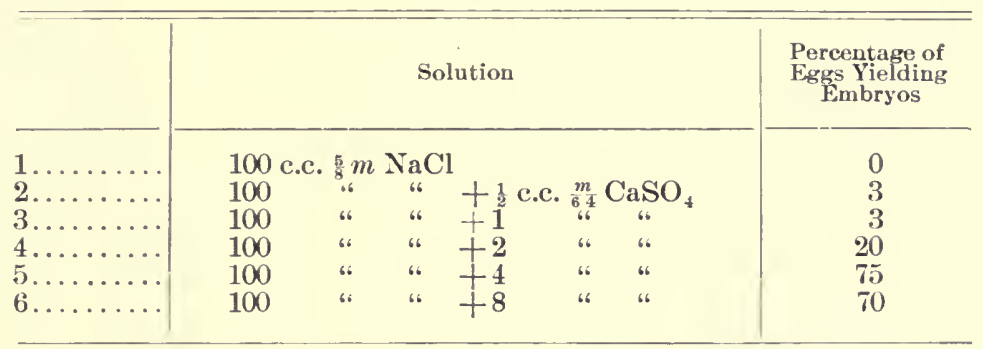

This series of experiments does not show whether it is the $\mathrm{Ca}$ or the $\mathrm{SO}_{4}$ ion that has the antitoxic effect. To determine this point the same series of experiments was twice repeated with certain modifications. In the first of these $\mathrm{Ca}\left(\mathrm{NO}_{3}\right)_{2}$ was added to the $\frac{5}{8} \mathrm{NaCl}$ solution instead of $\mathrm{CaSO}_{4}$. The result was practically that given in Table I. In the second $\mathrm{Na}_{2} \mathrm{SO}_{4}$ was added to the sodium-chloride solution. The addition of $\mathrm{Na}_{2} \mathrm{SO}_{4}$ did not inhibit the toxic action of the sodium chloride, and the eggs developed no better than in the pure sodium-chloride solution. We shall return to this point later. However, in order to eliminate entirely the effect of the anions in the antitoxic effects produced, a 
series of experiments were instituted in which the toxic and antitoxic salt both had the same anion.

TABLE II

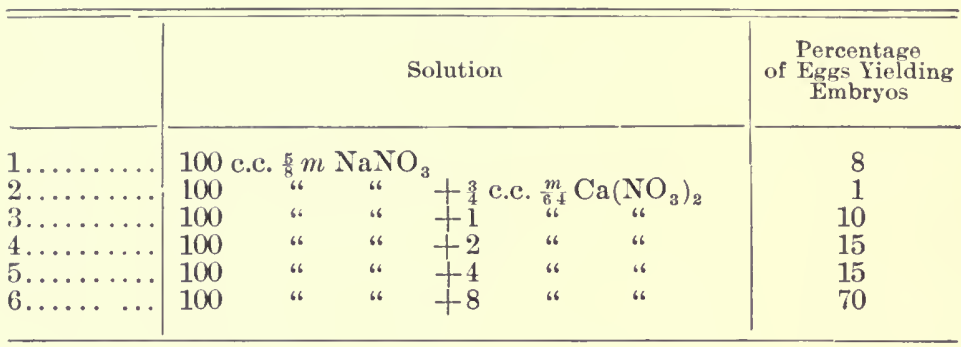

It is undoubtedly true, therefore, that the addition of even a small amount of $\mathrm{Ca}$ ions diminishes the toxic action of a pure sodium-chloride solution. It can further be shown that the concentration of the $\mathrm{Ca}$ ions necessary to abolish the poisonous effects of a sodium-chloride solution increases as the concentration of the latter increases (see Table III).

Tables II and III show clearly that the amount of calcium necessary to annihilate the poisonous effect of a solution of a sodium salt increases with the concentration of the sodium salt in the solution.

The embryos formed in these solutions, rendered harmless through the addition of calcium, developed a normal circulation and lived several weeks. As a rule, however, they did not hatch. It was further found that the addition of 5 c.c. of a $\frac{m}{6} \mathrm{CaSO}_{4}$ solution could annihilate absolutely the toxic effect of a $\frac{3}{8} m, \frac{4}{8} m$, or $\frac{5}{8} m \mathrm{NaCl}$ solution. These experiments leave no room for doubt that the presence of a trace of $\mathrm{Ca}$ ions is capable of rendering inert the poisonous effects of a pure sodium-chloride solution.

3. It was next shown that $\mathrm{Sr}, \mathrm{Ba}$, and $\mathrm{Mg}$ ions are also capable of annihilating the poisonous effects of a 
pure $\mathrm{NaCl}$ solution in a way similar to that of $\mathrm{Ca}$ ions (see Table IV).

TABLE III

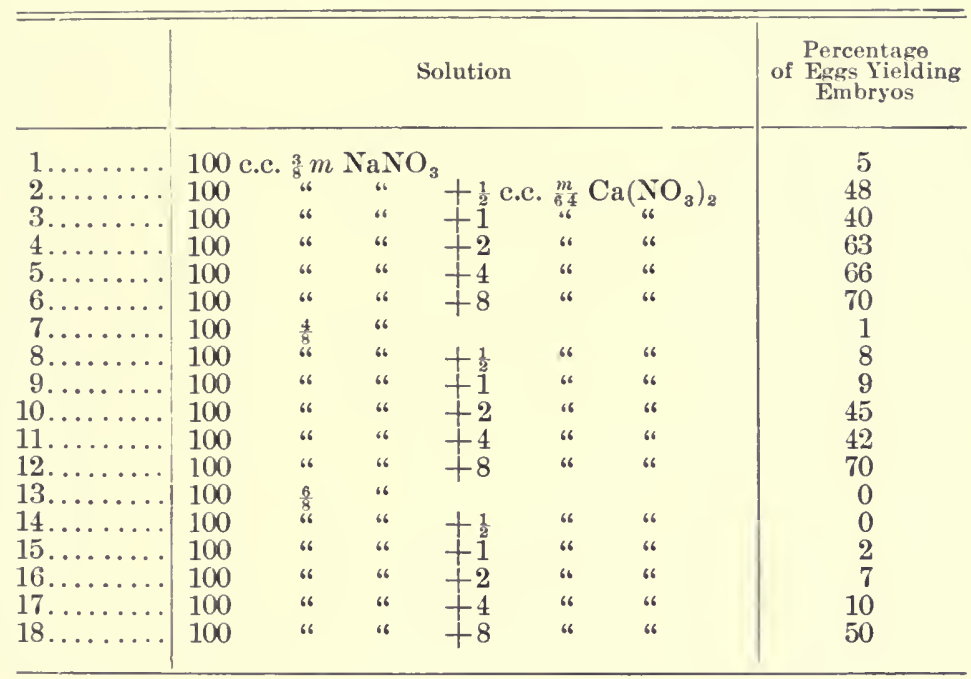

TABLE IV

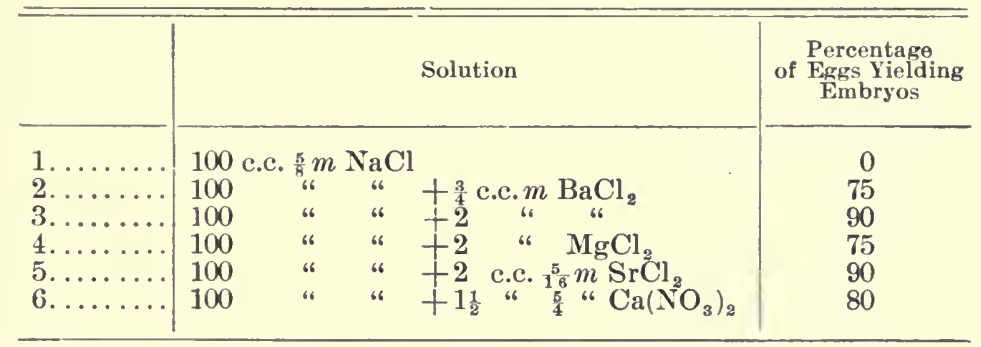

That the threshold for the antitoxic effects of $\mathrm{Ba}, \mathrm{Mg}$, $\mathrm{Sr}$ has the same magnitude as that of $\mathrm{Ca}$ may be indicated by a single experiment with $\mathrm{Ba}$ (Table $\mathrm{V}$ ).

It can be seen that the threshold of the antitoxic effect of barium is almost identical with that for $\mathrm{Ca}$ under similar conditions. 
TABLE Y

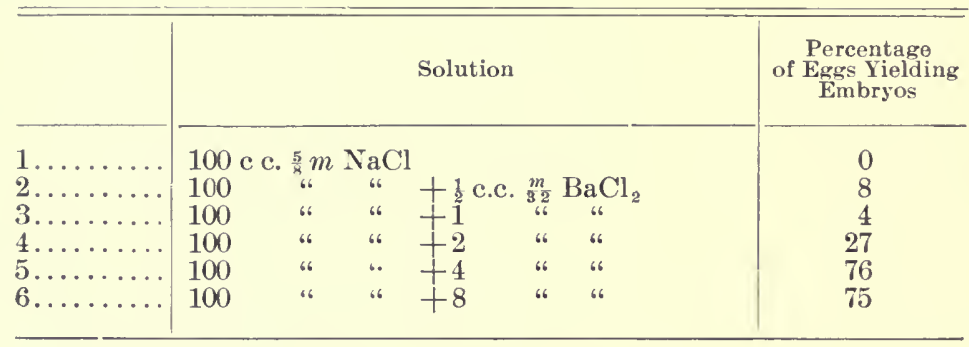

Since all these ions are related chemically, the objection was possible that we were dealing here, not with the effects of the valence or the electrical charge of the ions, but with a specific chemical effect. It was, therefore, necessary to show that the same effect can be produced by bivalent kations which lie outside of the calcium group. My first experiments failed me, since I at first employed too large amounts of the antitoxic salts. I discovered only gradually that the poisonous effects of a sodium-chloride solution may be annihilated by a bivalent kation in quantities much smaller than are given in Table IV, which presents the results of one of my first experiments. My experiments now succeeded.

4. A large number of experiments were performed with $\mathrm{ZnSO}_{4}$ as the antitoxic substance for $\mathrm{NaCl}$. The $\mathrm{NaCl}$ solution used was somewhat more concentrated than that usually employed, namely $\frac{1}{1} \frac{1}{6} \mathrm{~m}$ instead of $\frac{5}{8} \mathrm{~m}$.

TABLE VI

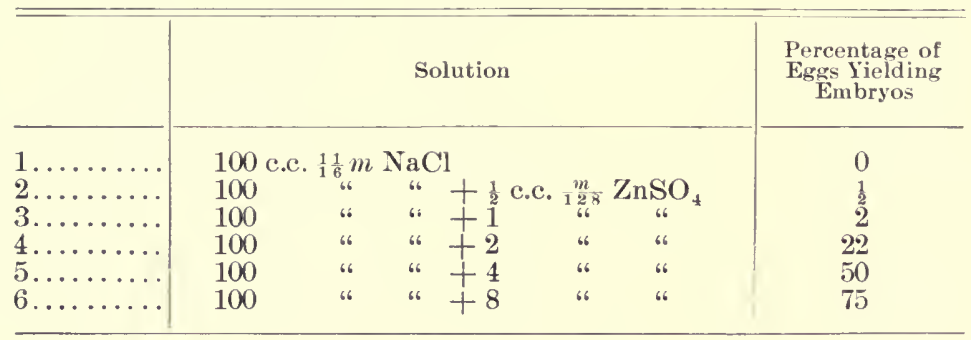


To supplement these results the following table dealing with the effects of a more concentrated $\mathrm{ZnSO}_{4}$ solution and a more dilute $\mathrm{NaCl}$ solution than that of the previous table may be given:

TABLE VII

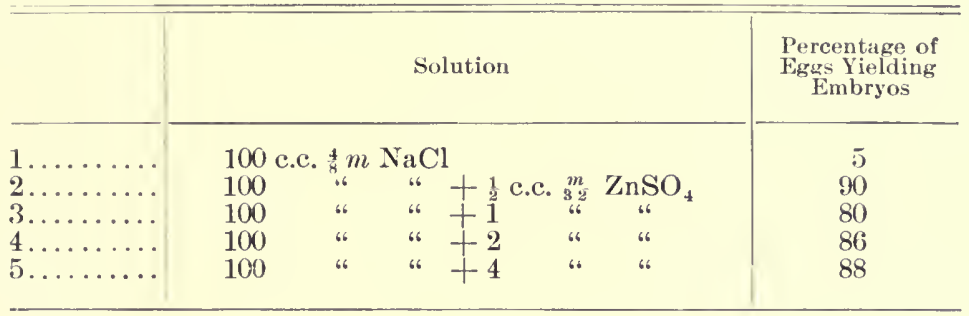

The remaining experiments showed a similar agreement in the results obtained. It is worthy of note that these embryos remained alive over a week, possessed an entirely normal circulation, and moved in the egg.

The experiments with freshly prepared $\mathrm{FeSO}_{4}$ yielded as striking results as the above. Only in these experiments the transformation of the bivalent into the trivalent $\mathrm{Fe}$ ion introduces a disturbing element. We shall see later that the ferric ion is apparently extremely poisonous. The addition of $\frac{1}{2}$ c.c. or 1 c.c. of a freshly prepared $\frac{m}{4} \mathrm{FeSO}_{4}$ solution to 100 c.c. of $\frac{5}{8} \mathrm{~m} \mathrm{NaCl}$ solution annihilates the poisonous effect of the pure sodium-chloride solution just as completely as the addition of the $\mathrm{Zn}$ ions in the previous experiment.

Then I tried whether cobalt ions are capable of annihilating the antitoxic effects of a pure sodium-chloride solution. The results were very clear indeed.

Since the amount of the bivalent kation capable of exhibiting its antitoxic properties was so extraordinarily small, I risked the attempt to amnihilate the poisonous effects of a pure sodium-chloride solution through the addition of $\mathrm{Pb}$, 
TABLE VIII

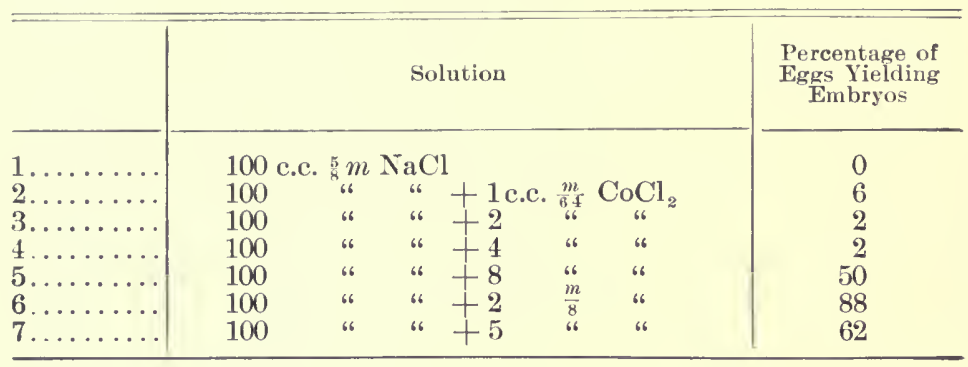

$\mathrm{Cu}$, and $\mathrm{Hg}$ ions. Had I not before demonstrated the antitoxic effects of so poisonous an ion as the zinc ion, such an attempt would have appeared to me only ridiculous. With copper acetate and mercuric chloride I obtained negative results throughout, for these two ions are so poisonous indeed that the small amount necessary to render inert the poisonous effects of a sodium-chloride solution are sufficient to kill the egg or cause its coagulation. With lead ions, however, I had a distinct success. For the antitoxic salt lead acetate was used, and for the toxic salt, sodium acetate. It was proved that the latter was slightly more toxic than $\mathrm{NaCl}$.

TABLE IX

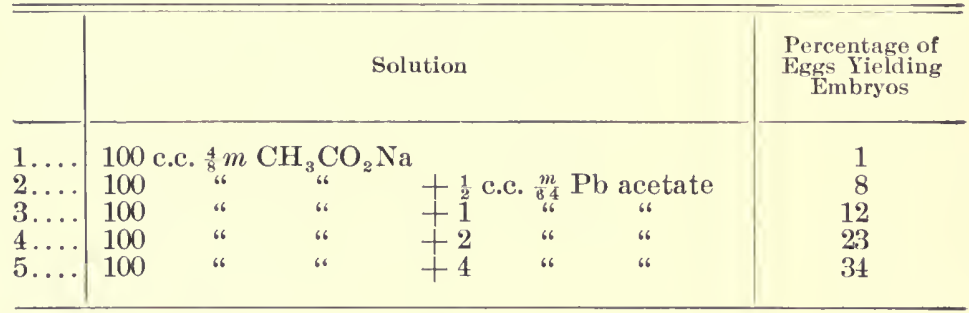

In another case 40 per cent. of the eggs formed embryos. The objection was here again at hand that the decrease in the degree of the dissociation of the sodium acetate had played a rôle. Although lead chloride is only very slightly 
soluble, I tried to see if the few lead ions that go into solution when lead acetate is added to sodium chloride would still suffice to weaken the poisonous effects of a pure $\mathrm{NaCl}$ solution. Such was indeed the case.

TABLE X

\begin{tabular}{|c|c|c|}
\hline & Solution & $\begin{array}{l}\text { Percentage of } \\
\text { Eggs Yielding } \\
\text { Embryos }\end{array}$ \\
\hline $\begin{array}{l}1 \ldots \ldots \ldots \\
2 \ldots \ldots \ldots \\
3 \ldots \ldots \ldots\end{array}$ & 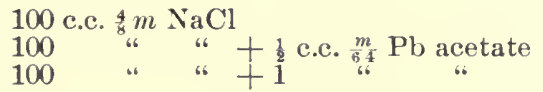 & $\begin{array}{r}3 \\
7 \\
17\end{array}$ \\
\hline
\end{tabular}

In the remaining solutions the number of embryos could not be determined, since the eggs had been rendered opaque by the precipitation of the lead salts.

5. Experiments were now made to see if it were possible to annihilate the toxic effects of a sodium-chloride solution through the addition of salts having a trivalent ion. $\mathrm{AlCl}_{3}$, $\mathrm{Cr}_{2}\left(\mathrm{SO}_{4}\right)_{3}$ and $\mathrm{FeCl}_{3}$ were used. The experiments with $\mathrm{FeCl}_{3}$ all yielded negative results. No concentration could be found at which this salt exhibited antitoxic properties. Perhaps the strongly acid character of this solution had something to do with this result. The experiments with the two other salts, however, yielded positive results.

TABLE XI

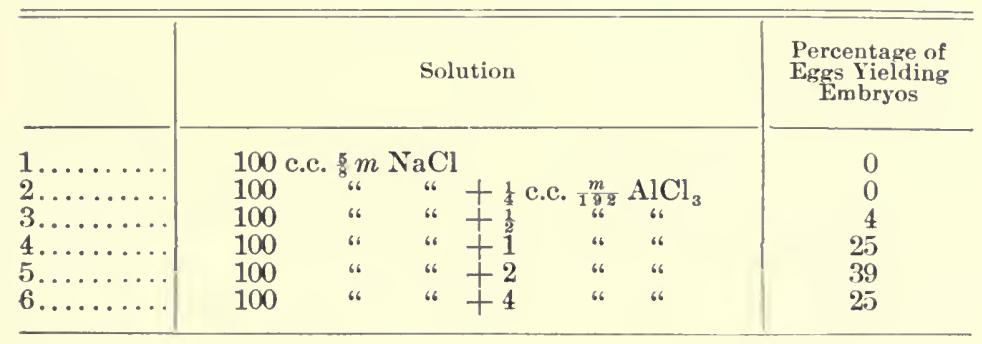


Two other series of experiments yielded the same results. It is worthy of note that the amount of a trivalent kation capable of exerting a certain antitoxic effect is considerably less than the amount of a bivalent kation necessary for the same purpose. At the same time one notices, however, that the number of eggs forming embryos is, even at the best, lower than when bivalent kations are employed. The reason for this lies, as I believe, in the fact that the trivalent ion causes readily a coagulation of the egg contents, as direct observation shows. But this coagulation is not exclusively a function of the valency of the ions, for $\mathrm{Cu}, \mathrm{Hg}$, and to a slight extent $\mathrm{Pb}$ have the same influence upon the egg. The influence of the $\mathrm{Cr}$ ion in bringing about coagulation is much more marked than is the case with $\mathrm{Al}$, and its antitoxic effects are correspondingly slight, but yet definite.

TABLE XII

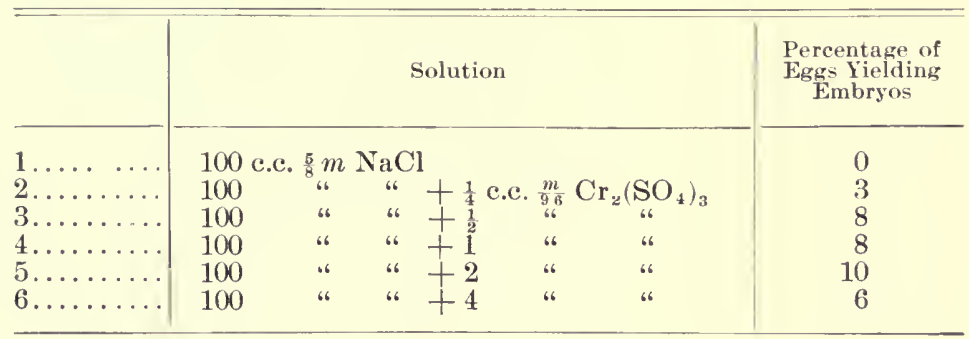

6. Since traces of trivalent kations and small amounts of bivalent kations suffice thus to amnihilate the poisonous effects of a sodium-chloride solution, experiments were made to ascertain if the same could also be brought about by monovalent kations. The experiments have thus far led to no positive results. I tried to see if the poisonous effects of a pure sodium-chloride solution could be done away with by the addition of potassium salts $\left(\mathrm{KCl}\right.$ and $\mathrm{K}_{2} \mathrm{SO}_{4}$ ). Small amounts of potassium salts were entirely without effect. 
The addition of $\frac{1}{2}$ to 2 c.c. of $m \mathrm{KCl}$ or $\mathrm{K}_{2} \mathrm{SO}_{4}$ occasionally yielded results, in that $1-5$ per cent. of the eggs formed embryos. Lithium salts showed themselves to be even less active. I occasionally obtained a slight antitoxic action by the addition of large amounts of $\mathrm{NH}_{4}$ salts. Whether hydrogen ions can yield better results must be determined through further experiments.

7. Not only can the poisonous effects of a pure sodiumchloride solution be annihilated through the addition of small amounts of bivalent or trivalent kations, but it seems as though the same holds for all salts which, like $\mathrm{NaCl}$, have a univalent kation and anion. No embryos develop in a $\frac{3}{8} \mathrm{~m} \mathrm{LiCl}$ solution. By the addition of small amounts of $\mathrm{Ca}\left(\mathrm{NO}_{3}\right)_{2}$, $\mathrm{BaCl}_{2}, \mathrm{SrCl}_{2}$, or $\mathrm{MgCl}_{2}, 50-60$ per cent. of the eggs were caused to form embryos, which developed normally. Other kations of a higher valency were not tested. I obtained entirely similar results in regard to $\mathrm{KCl}$. In a $\frac{6}{8} m$ or even a $\frac{7}{8} m \mathrm{KCl}$ solution an egg may occasionally develop. When a small quantity of $\mathrm{MgCl}_{2}, \mathrm{Ca}\left(\mathrm{NO}_{3}\right)_{2}, \mathrm{SrCl}_{2}, \mathrm{BaCl}_{2}$ or $\mathrm{FeSO}_{4}$ was added, the poisonous effects of the pure $\mathrm{KCl}$ solution were annihilated. Of salts having other bivalent kations, only $\mathrm{ZnSO}_{4}$ (a single experiment) was used. An effect was obtained in this case also, but it was less striking than in the case of the other bivalent kations.

$\mathrm{NH}_{4} \mathrm{Cl}$ seems to be the least toxic of all the salts mentioned thus far. Even in a $\frac{7}{8} m \mathrm{NH}_{4} \mathrm{Cl}$ solution an embryo could form occasionally. This immunity of the Fundulus egg against $\mathrm{NH}_{4} \mathrm{Cl}$ is perhaps related to its great immunity against urea. I cannot get rid of the suspicion that a percentage of the $\mathrm{NH}_{4}$ ions is perhaps done away with in the metabolism of the egg. I obtained striking antitoxic effects with small amounts of $\mathrm{SrCl}_{2}$ and, although less definite, of $\mathrm{FeSO}_{4} \cdot \mathrm{Ca}\left(\mathrm{NO}_{3}\right)_{2}$ increased the number of embryos formed, though not as greatly as the other salts with a 
bivalent kation, but the life of the embryos was very considerably prolonged.

The shortness of the spawning season limited the number of my experiments, so that I decided to bring my experiments upon the annihilation of the poisonous effects of a pure sodium-chloride solution to a close, and to carry the remaining experiments only far enough to decide if we are dealing here, in the main, with the same condition of affairs. That, I believe, is undoubtedly the case, so that I feel myself justified in making the following statement: The salts of monovalent kations $\left(\mathrm{Na}, \mathrm{Li}, \mathrm{K}, \mathrm{NH}_{4}\right)$ with monovalent anions $\left(\mathrm{Cl}, \mathrm{NO}_{3}, \mathrm{CH}_{3} \mathrm{COO}\right)$ exert a toxic effect at certain concentrations. This toxic effect can be amihilated through the addition of a small amount of a salt having a bivalent kation. For $\mathrm{NaCl}$, proof has been brought forward that trivalent kations exhibit even a much more energetic antitoxic effect than bivalent kations. Further experiments are yet to be made, to decide if the poisonous effects of the other salts $\left(\mathrm{LiCl}, \mathrm{KCl}, \mathrm{NH}_{4} \mathrm{Cl}\right.$ ) can also be done away with through the addition of such small amounts of trivalent kations as suffice for $\mathrm{NaCl}$.

8. While the preceding experiments show an undoubted influence of the valency of the ions upon their antitoxic effects, it was now necessary to prove that the sign of the electrical charge was the second determining variable. I instituted a large number of experiments in which I attempted to annihilate the poisonous effects of a $\frac{5}{8} \mathrm{~m} \mathrm{NaCl}$ and a $\frac{7}{8} m \mathrm{KCl}$ solution by the addition of salts having a univalent or bi- or trivalent anion. The antitoxic effects of the following salts are investigated; $\mathrm{KOH}, \mathrm{NaBr}$, NaI, $\mathrm{NaHCO}_{3}, \mathrm{Na}_{2} \mathrm{CO}_{3}, \mathrm{NaSO}_{4}, \mathrm{Na}_{2} \mathrm{HPO}_{4}$, sodium eitrate, $\mathrm{K}_{2} \mathrm{SO}_{4}$. Extensive quantitative experiments were made with $\mathrm{Na}_{2} \mathrm{SO}_{4}, \mathrm{~K}_{2} \mathrm{SO}_{4}, \mathrm{NaHCO}_{3}$ and $\mathrm{Na}_{2} \mathrm{HPO}_{4}$. The results were negative throughout. In the best cases 1 per 
cent. of the eggs formed embryos. It followed from these experiments that the toxic effects of salts with a monovalent kation and a monovalent anion can be annihilated only by bi-or trivalent kations, but not by mono-, bi-, or trivalent anions. If we correlate this fact with that previously found, that spontaneous, rhythmical contractions of muscles, Medusæ, and hearts are possible only in solutions of electrolytes, then the idea can certainly not be repudiated that the antitoxic effect of salts in the above-mentioned experiments may be a function of the magnitude and the sign of the electrical charges of the ions.

9. If the toxicity of a pure $\mathrm{CaCl}_{2}, \mathrm{MgCl}_{2}, \mathrm{BaCl}_{2}$ or $\mathrm{SrCl}_{2}$ solution is compared with the toxicity of a solution of a chloride of a monovalent kation, then it is found that the former are the more poisonous. In a $\frac{m}{8} \mathrm{Ca}\left(\mathrm{NO}_{3}\right)_{2}$ solution no embryo develops. This same toxic concentration is reached in a $\mathrm{MgCl}_{2}$ solution at the dilution of $\frac{m}{2}$. Can the toxic effects of these solutions also be overcome? One can indeed easily overcome the poisonous effects of a $\frac{m}{8}$ $\mathrm{Ca}\left(\mathrm{NO}_{3}\right)_{2}$ solution by adding large amounts of a $\mathrm{KCl}$ or $\mathrm{NH}_{4} \mathrm{Cl}$ solution. $\mathrm{NaCl}$ and $\mathrm{LiCl}$ solutions are almost without effect.

TABLE XIII

\begin{tabular}{|c|c|c|c|}
\hline & \multicolumn{2}{|c|}{ Solution } & $\begin{array}{l}\text { Percentage of } \\
\text { Eggs Yielding } \\
\text { Embryos }\end{array}$ \\
\hline $\begin{array}{l}1 \ldots \ldots \ldots \\
2 \ldots \ldots \\
3 \ldots \ldots \cdots \\
4 \ldots \ldots \\
5 \ldots \ldots \cdots \\
6 \ldots \ldots \ldots\end{array}$ & \begin{tabular}{lll}
100 c.c. & \multicolumn{8}{c}{$\mathrm{Ca}\left(\mathrm{NO}_{3}\right)_{2}$} \\
100 & " & 6 \\
100 & " & 6 \\
100 & " & " \\
100 & “ & " \\
100 & &
\end{tabular} & $\begin{array}{cc}\text { c.c. } 2 \frac{1}{2} m & \mathrm{KCl} \\
\text { "6 } & \text { "6 } \\
6 & 4 \\
\text { "6 } & \text { "6 }\end{array}$ & $\begin{array}{r}0 \\
15 \\
34 \\
40 \\
55 \\
67\end{array}$ \\
\hline
\end{tabular}

As one can see, the number of embryos formed shows a definite increase with an increase in the concentration of the $\mathrm{KCl}$. I tried still stronger solutions of $\mathrm{KCl}$ in further 
experiments, and found that in a mixture of 100 c.c. $\frac{m}{8} \mathrm{Ca}$ $\left(\mathrm{NO}_{3}\right)_{2}+20$ c.c. $2 \frac{1}{2} \mathrm{~m} \mathrm{KCl}$ a still larger number of eggs formed embryos than in the preceding experiments. On the other hand, it could be shown that the addition of small amounts of $\mathrm{KCl}$ was without effect.

TABLE XIV

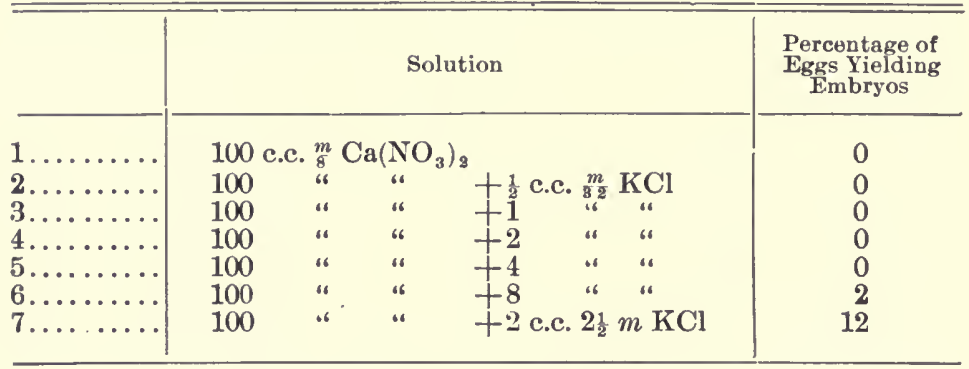

The size of the antitoxic dose of $\mathrm{KCl}$ in $\mathrm{Ca}\left(\mathrm{NO}_{3}\right)_{2}$ poisoning is, in fact, extraordinarily larger than the antitoxic dose of $\mathrm{Ca}\left(\mathrm{NO}_{3}\right)_{2}$ in the case of $\mathrm{KCl}$ poisoning. Similar relations exist for the antitoxic effect of $\mathrm{NH}_{4} \mathrm{Cl}$ upon $\mathrm{CaCl}_{2}$ poisoning.

TABLE XV

\begin{tabular}{|c|c|c|c|}
\hline & Solu & ution & $\begin{array}{l}\text { Percentage of } \\
\text { Eggs Yielding }\end{array}$ \\
\hline $\begin{array}{l}1 \ldots \ldots \ldots \\
2 \ldots \ldots \ldots \\
3 \ldots \ldots \\
4 \ldots \ldots \\
5 \ldots \ldots \ldots \\
6 \ldots \ldots \ldots\end{array}$ & $\begin{array}{ccc}100 \text { c.c. } \frac{m}{8} & \mathrm{Ca}\left(\mathrm{NO}_{3}\right)_{2} \\
100 & \text { "، } \\
100 & \text { "6 } \\
100 & \text { "، } \\
100 & \text { " } \\
100 & \text { " } & \text { "6 }\end{array}$ & 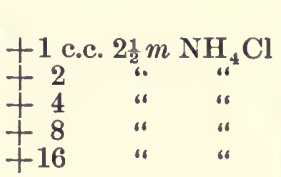 & $\begin{array}{r}0 \\
9 \\
8 \\
16 \\
21 \\
16\end{array}$ \\
\hline
\end{tabular}

The antitoxic effects of $\mathrm{NH}_{4} \mathrm{Cl}$ are not as great as those of $\mathrm{KCl}$. Similar experiments with $\mathrm{NaCl}$ and $\mathrm{LiCl}$ as antitoxic substances were without positive result.

Similar experiments were then performed with $\mathrm{MgCl}_{2}$. 
By the addition of $\mathrm{MgSO}_{4}$ the toxic effects of $\mathrm{MgCl}_{2}$ could not be done away with. But through the addition of large amounts of $\mathrm{KCl}, \mathrm{NH}_{4} \mathrm{Cl}$, or small amounts of $\mathrm{SrCl}_{2}$ this was possible, as also - to a slight extent - through the addition of $\mathrm{Ca}\left(\mathrm{NO}_{3}\right)_{2}$. The dilution at which a $\mathbf{M g C l}_{2}$ solution hinders the development of an embryo is ${ }_{16}^{5} m \mathrm{MgCl}_{2}$. Table XVI shows a series of antitoxic experiments. $\mathrm{NaCl}$ and $\mathrm{LiCl}$ were just as unable to annihilate the toxic effects of the $\mathrm{MgCl}_{2}$ solution as they were unable to annihilate the poisonous effects of $a \mathrm{Ca}\left(\mathrm{NO}_{3}\right)_{2}$ solution. When less than $\frac{1}{2}$ c.c. of a $\frac{m}{16} \mathrm{SrCl}_{2}$ solution was added, not a single egg could develop.

10. If, in these experiments, only the kations have an antitoxic effect, and this the greater, the greater their electrical charge; and if in these antitoxic effects we are dealing only with electrical effects, then it is to be logically expected that the toxic effects which are inhibited in these cases are also electrical effects, and indeed the effects of the negative electrons. If the antitoxic ions are the strongly charged positive ions, then the toxic ions in the sodium-chloride solution must be the $\mathrm{Cl}$ ions. But in a pure sodium-chloride solution we have just as many kations as anions, and in consequence just as many positive as negative electrical units. It is therefore not at once intelligible why the negative charges of the chlorine ions should be able to call forth poisonous effects in a sodium-chloride solution. If it is necessary for us to accept the fact that we are here dealing with electrical effects, then we are forced further to conclude that, for some reason or other, the negative charges of the chlorine ions attain a greater activity than the positive charges of the sodium ions. Nernst has pointed out the fact that the metallic ions tend to bind their electrical charges more strongly than the anions, and he brings this into connection with the fact that we are acquainted with kathode 
TABLE XVI

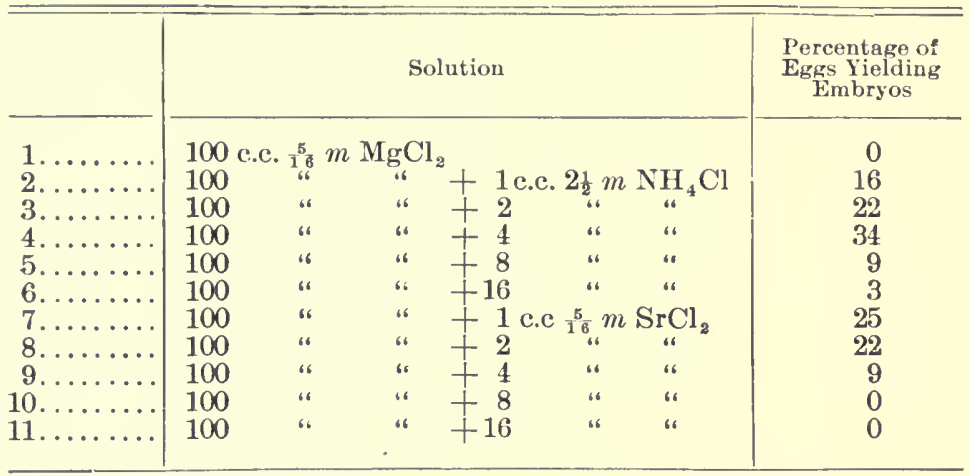

rays, but not with anode rays. Another possibility may be thought of. The egg-and all protoplasm-is a system with various phases; we have solid parts (membranes), and liquid parts which are either rich or poor in colloids. It is conceivable that the coefficient of distribution for the positive and negative ions is unequal in the various phases, and that this fact leads to the toxic effects of the negative ions which can be annihilated by the addition of a small number of positive ions holding a double or triple charge.

I was long inclined to look upon the sodium ions as the toxic ions in a pure sodium-chloride solution, and I have upheld this view in my preliminary communication concerning these experiments. What led me to this conclusion was the following experiment: I tested the relative toxicity of $\mathrm{H}$ and $\mathrm{OH}$ ions for the eggs of Fundulus. As was to be expected, it came to light that the hydrogen and hydroxyl ions differ in their toxicity. In $a_{\frac{2}{200}} \mathrm{KOH}$ solution the eggs developed and formed embryos, while a $\frac{n}{1000} \mathrm{HCl}$ solution killed the eggs almost immediately. The hydrogen ions are therefore at least as much as five times as poisonous as the hydroxyl ions. But I do not believe that we are forced to conclude from this that the poisonous effects of a 
sodium-chloride solution necessarily originate from the positively charged ions. Besides the electrical charge other fac.. tors may have to be considered in the toxicity of ions for the determination of which physical chemistry and physics must first furnish us the data. In this category belongs, for example, the fact that the toxic effects of the sodium salts of the halogens upon fish eggs (perhaps upon protoplasm in general) increase in the following order: $\mathrm{NaCl}, \mathrm{NaBr}$, Nal, $\mathrm{NaF}$. In addition we find that the bivalent anions are in general more poisonous than the monovalent, and the trivalent more poisonous than either. The same also holds true to a certain extent for the poisonous effects of kations.

In order to make the bulk of this paper no greater than it is already, I shall discuss my experiments on the toxic effects of ions no further at this point. 


\section{XXYVI}

MATURATION, NATURAL DEATH, AND THE PROLONGATION OF THE LIFE OF UNFERTILIZED STARFISH EGGS (ASTERIAS FORBESII) AND THEIR SIGNIFICANCE FOR THE THEORY OF FERTILIZATION 1

\section{INTRODUCTION}

I HAvE pointed out in my earlier publications that fertilization of the egg serves to prolong the life of the egg."

The mature unfertilized egg dies in a comparatively short time. Because of this fact the egg becomes of importance as an object of experiment, to study the question of natural death and the prolongation of life. For by no means has it been decided that there is a "natural" death. We only know that with an increase in age a critical period is reached in which every living organism dies under the influence of conditions which do not affect a younger organism. It may, therefore, be of interest that we are able to show, as I believe, that a critical period exists in the life of many eggs in which they die a "natural" death, and that the life of the eggs can, during this period, be saved or lengthened only through various external conditions.

The egg of the starfish (Asterias Forbesii) serves as a very favorable object of experiment in the study of this question. When removed from the ovary this egg is generally "immature," but as soon as it comes in contact with sea-water it begins to "maturate."

Morphologically, the immature state is characterized by

1 Biological Bulletin, Vol. III (1902), p. 295.

2 Part II, p. 689; LoEB AxD Lewis, American Journal of Physiology, Vol. VI (1902), p. 305. 
a very large plainly visible nucleus. ${ }^{1} \quad$ The process of maturation consists morphologically in this, that the nucleus becomes invisible and the polar bodies are thrown out.

This process is completed within one or two hours after the eggs are removed from the ovaries and placed in seawater. Only when maturation is complete is it possible to cause the egg to develop through the addition of sperm or through the physical and chemical agencies that have been described by me, Delage, Mathews, and Greeley.

\section{THE NATURAL DEATH OF THE MATURE UNFERTILIZED STARFISH EGGS}

The living eggs of Asterias are light yellow in color and homogeneous. They retain this appearance during the process of maturation as long as they are alive. They retain this appearance also when they are made to develop through the entrance of a spermatozoon or through the proper chemical or physical means.

If, however, the mature eggs are not fertilized or do not develop, they die in the course of four to twelve hours, and this process of dying is accompanied by a characteristic change in the color of the egg. The egg becomes at first opaque, then almost black, and the homogeneous structure of the protoplasm becomes granular. If such a culture of unfertilized eggs is examined under the microscope after twenty-four hours, two kinds of eggs are found, first, the just-described dark, dead eggs which are mature, and secondly, living, normally colored, but immature, eggs. For usually not all the eggs that are removed from the ovaries of a starfish mature at once; many mature very late, others not at all. It is readily seen that the immature eggs remain

1 The recent beautiful experiments of Delage have shown that, besides these visible changes in the nucleus, chemical, but morphologically invisible, changes also occur in the protoplasm. DELAGE, "Etudes expérimentales sur la maturation cytoplasmique et sur la parthénogenese artificielle chez les Échinodermes," Arch. de zoologie expériment., Vol. IX (1901). 
alive for several days until they finally become the prey of bacteria; while the mature eggs become opaque and die in from four to twelve hours after maturation has been completed.

Is the death of the mature but undeveloped egg brought about through internal conditions, or through the bacteria contained in the sea-water?

A trustworthy way of determining this consists in making sterile culture of the eggs in sea-water. This is a relatively simple procedure in the case of starfish. Eight flasks were sterilized, filled with sterilized sea-water, and again heated for twenty minutes on three successive days to $100^{\circ} \mathrm{C}$. A female starfish was thoroughly washed externally, an arm was opened, and one of the ovaries removed with sterilized forceps and placed in sterilized sea-water. From the thick stream of eggs which at once flowed out of the ovary, a few drops were quickly introduced with a sterilized pipette into each of the sterilized flasks. A second series of eight flasks contained normal, unsterilized sea-water, and a fewdrops of the same eggs were introduced into these flasks also. A third series of flasks were filled with sea-water, to each of which were added 2 c.c. of a putrid, foul-smelling culture of old starfish eggs in order to bring about a rapid development of bacteria from the beginning. Each of these flasks also contained eggs from the same culture as those in the sterilized flasks.

That perfect sterilization had been attained in the first eight flasks was proved by the fact that all the flasks remained absolutely clear and cloudless during the course of the experiment, and that three of the flasks which had not been opened are even today (after six weeks) absolutely clear, and every egg can be individually recognized. The flasks containing the unsterilized sea-water became cloudy within as short a time as twenty-four hours, and after two days the eggs had become the prey of bacteria and no individual egg could be 
recognized. The sterilized flasks which were opened were at all times free from foul odor, while the unsterilized flasks gave off a penetrating stench, often after one, invariably after two, days. The microscopic examination of the seawater for bacteria was always negative in the sterilized flasks, always positive in the other flasks. In those flasks to which 2 c.c. of the putrid culture of starfish eggs had been added, bacteria and infusoria were exceedingly numerous from the beginning.

Six hours after the beginning of the experiment one flask of each of the three series was opened, and the eggs examined microscopically. The picture was the same in all three flasks. Nearly all the eggs were mature, and a small number of them were opaque or black. But what is of the greatest importance to us is the fact that the percentage of opaque dead eggs was just as great in the sterile culture (if not greater) than in the unsterilized or the infected seawater.

Twelve hours later, that is to say eighteen hours afier the beginning of the experiment, one of the flasks of each of the three cultures was again opened. At this time nearly all the eggs of the sterile culture were opaque or black, and a few were already granular. In the two other cultures an equal percentage of the eggs were opaque. The eggs, therefore, die just as rapidly in the sterilized flasks which are absolutely free from bacteria as in the flasks containing bacteria. Death follows from internal causes, and so rapidly that the few bacteria in the sea-water are scarcely able to accelerate the death of the eggs. The eggs have already died from internal causes before the bacteria can attack them in sufficient numbers to threaten their existence.

The flasks which were opened later served only to corroborate what has been said. The experiment was repeated with the same result. Each of the flasks that were opened 
during the first few days also contained a small number of living transparent eggs. The latter were, without exception, immature. The experiment, therefore, shows that the mature eggs of starfish die in the course of a few hours, and that the cause of this death cannot be sought in the bacteria of the sea-water; and further, that under exactly the same conditions the immature eggs remain alive.

III. THE CHEMICAL CONDITIONS NECESSARY FOR MATURATION IN STARFISH EGGS

Since the eggs of Asterias are usually immature in the ovary, but, in part, at least, maturate in the course of one or two hours when introduced into sea-water, the suspicion was aroused that some of the substances contained in the seawater brought about the maturation. In order to determine which substance this might be, a series of solutions were prepared having approximately the osmotic pressure of the sea-water. The result was so simple that it is not necessary to describe all the experiments here. For it was found that when the eggs are introduced into solutions which contain free hydroxyl ions, maturation soon follows, but that this does not occur in solutions containing no hydroxyl ions. So, for example, the eggs retain their nucleus in a $\frac{5}{8} m \mathrm{NaCl}$ solution, or in $\mathrm{NaCl}$ solutions to which some potassium or calcium has been added. If, however, 0.5 to 2 c.c. $\frac{n}{10}$ - $\mathrm{NaOH}$ is added to each 100 c.c. of such solutions, maturation soon follows: that is to say, the nucleus becomes invisible. Since sea-water contains free hydroxyl ions the conclusion is justified that these are one of the causes for the maturation of the starfish egg. It was possible to prove this assumption through further experiments. If a small amount of acid is added to sea-water, the free $\mathrm{OH}$ ions disappear, and the water becomes acid in reaction (through the addition of 1.5 c.c. or more $\frac{n}{10} \mathrm{HCl}$ to 100 c.c. sea-water). 
Immature eggs were introduced directly into sea-water to which $1,2,3$ and 4 c.c. of a $\frac{n}{10} \mathrm{HNO}_{3}$ solution had been added to each 100 c.c. of sea-water. While, as is usual, a large percentage of eggs soon maturated in the normal seawater, maturation did not occur at all in the vast majority or in all the eggs contained in the sea-water to which 2 or more c.c. acid had been added. The addition of even 1 c.c. of acid diminishes the number of eggs that maturate. But it is not eren necessary to keep the eggs permanently in neutral or acid sea-water in order to inhibit maturation. If 4 or 5 c.c. of a ${ }_{10}^{n} \mathrm{HNO}_{3}$ solution are added to 100 c.c. sea-water, and immature eggs are introduced into such a solution for only about fifteen minutes, relatively few eggs maturate when they are returned to normal sea-water. Such acidified seawater does not kill the starfish eggs.

We shall see later that the procedure described here which, when used upon immature eggs, prevents maturation, brings about artificial parthenogenesis when used on mature eggs. ${ }^{1}$

I have, moreover, been able to convince myself of the fact that the eggs which are introduced into acidified seawater in an immature state, can be fertilized by sperm if they finally maturate. It is possibly in harmony with what has just been said that the addition of $\mathrm{NaHCO}_{3}$, or larger amounts of sodium citrate to the sea-water accelerates the process of maturation. Free hydroxyl ions are present in the solutions of both substances, and it is possible that their addition to the sea-water increases the concentration of the free hydroxyl ious in the sea-water.

But the hydroxyl ions are certainly not the only substances in the sea-water which favor or cause the maturation of the starfish egg. I soon found that when different specimens of eggs are taken from the same culture, and the per-

1 Loeb, Frscher, Axd Nerlsox, Pflugers Archiv, Vol. LXXXVII (1901), p. 594. 
centage of mature eggs is determined, this percentage is subject to the greatest variations. The cause of these variations was soon discovered. For it was found where the eggs lie together in a heap maturation occurs slowly, but where they lie in a thin layer, maturation occurs quickly. This fact suggested the importance of oxygen for maturation. Where the eggs lie in a heap the appropriation of the oxygen by the superficial layers of eggs prevents the diffusion of the oxygen to those lying deeper.

Experiments were now made in which the oxygen of a small flask containing a small amount of sea-water was replaced by hydrogen. When, in such experiments, all the oxygen was entirely removed maturation did not occur in any, or at least the majority of the eggs, in spite of the presence of the hydroxyl ions in the sea-water. There are, therefore, at least two substances in sea-water which cause or accelerate maturation, oxygen and hydroxyl ions. Possibly other constituents of the sea-water are also concerned in the process, but $\mathrm{NaCl}, \mathrm{Ca}$, and $\mathrm{K}$ have apparently no beneficial effect upon maturation. ${ }^{1}$

It seems, therefore, that the absence of oxygen and hydroxyl ions in the ovaries belongs to the conditions which inhibit maturation of the eggs in the ovary.

IV. THE PROLONGATION OF THE LIFE OF THE UNFERTILIZED STARFISH EGG BY THE PREVENTION OF MATURATION

We have shown above that the mature eggs of a culture of unfertilized starfish eggs die within a short time (which decreases with an increase in temperature), while the immature eggs remain alive a relatively long time. It was necessary now to show that when the maturation of a culture of unfertilized egg of Asterias is prevented artificially, the

1 Professor Whitman informs me that the maturation of the eggs of Clepsine does not begin until after they are laid. Possibly the oxygen contained in the water is in this case also a necessary condition for maturation. 
eggs live longer. We begin with the experiment which is technically most simple. The eggs streaming from the ovary are divided into two portions. One portion of eggs is carefully distributed without mechanical agitation, by carefully tipping the vessel, in a thin layer over the bottom of the vessel. The vessel must be low and the layer of seawater covering the eggs not too deep, so that the diffusion of oxygen to the eggs can occur with ease. A second portion is introduced with just as great care into a small-calibered glass tube sealed at one end. This glass tube is half filled with eggs so that one is certain that the lower layers of the eggs in the pipette receive little or no oxygen. It is selfevident that the eggs must be introduced into the tube immediately after being laid. When, after twenty-four hours, the eggs which are distributed over the bottom of the glass dish and which receive a large amount of oxygen are compared with those at the bottom of the glass tube, a striking difference is found between them. The eggs richly supplied with oxygen contain a much larger percentage of mature dead and black eggs than those kept in the lack of oxygen. In the latter the living immature eggs are in the majority, and a part of these maturate when spread out in a thin layer over the bottom of a vessel. These experiments are also well adapted to show that the rapid death of the mature unfertilized sea-urchin eggs is determined through internal conditions and not by the bacteria contained in the sea-water. I will cite an example.

One portion of a lot of eggs was spread out in a thin layer over the bottom of a dish; another was heaped in a mass in the same dish. The sea-water was the same in both cases. The first portion of eggs matured in a few hours and were, in less than twelve hours, opaque and dead, while the water was still absolutely clear and without odor of putrefaction. After twenty-four hours the water became putrid and 
contained many bacteria. Even after three days, when the water was exceedingly foul and cloudy, a portion of the eggs which had lain in a heap, that is to say, without oxygen, were immature and living. They were introduced into fresh water and spread out into a thin layer. They maturated and developed into swimming larvæ upon the addition of sperm. It is self-evident of course that even immature eggs finally become the prey of bacteria, and so go to pieces in the seawater.

The same experiment can be made in a somewhat more complicated way with pure oxygen and hydrogen. The freshly laid eggs of a starfish were distributed into two series of eight flasks. The one series of flasks was connected with a hydrogen generator; the other with a tank containing pure oxygen. Before the beginning of the experiment all the air in one of the series of flasks was driven out by the current of hydrogen. During the course of the experiment a vigorous current of hydrogen was maintained. Both series of flasks contained freshly laid immature eggs of Asterias. The experiment lasted three days, and from time to time a flask was removed and its contents examined. The eggs which had been exposed to the current of oxygen maturated just as rapidly and as numerously as those in ordinary sea-water, and the mature eggs soon died. In the current of hydrogen maturation did not occur in the majority of the eggs, and these remained alive. In the hydrogen cultures a rapid development of bacteria occurred, while in the oxygen cultures this occurred to a small degree. ${ }^{1}$

Treatment with acids which, as we have shown above, prevents the maturation of the eggs (without killing them) also prevents their death and disintegration.

Eggs which, without having been in contact with pure

- 1 Care must be taken in these experiments that the air is thoroughly removed from the sea-water in the hydrogen flasks before the eggs are introduced into them. Of course the hydrogen apparatus must also be free from air. 
sea-water are introduced for ten or fifteen minutes into 100 c.c. sea-water plus 4 c.c. ${ }_{10}^{n} \mathrm{HCl}$ maturate very slowly or not at all when they are returned to normal sea-water. They also retain, as long as they are immature, the transparent, normal appearance of living eggs until they become the prey of bacteria.

It seems to follow from these experiments that the same processes which underlie the maturation of starfish eggs also lead to their death (if they are not inhibited through circumstances which we designate by the term fertilization). I tried to see, now, whether it was also possible to maintain the life of the mature egg through lack of oxygen. I indeed obtained in a few cases positive results in this direction. The eggs of a starfish were spread in a thin layer over the bottom of a dish. After three hours 75 per cent. of the eggs were maturated. A portion of the mature eggs was carefully introduced into the glass tube described above, in which the deeper layers suffered from lack of oxygen. A second portion was introduced into a small flask through which a steady stream of pure oxygen was passed. On the following morning, that is to say, fifteen hours after the eggs were brought into the atmosphere of pure oxygen, the various portions of the eggs were examined. The eggs introduced into the current of oxygen showed in one vessel 98 per cent. mature and dark, dead eggs and 2 per cent. immature living eggs. The eggs which had remained in normal sea-water contained, as before, about 75 per cent. mature eggs, all of which, however, were black and dead, with the exception of a few eggs which had begun to divide, and were living.

The immature eggs were also still living. Upon the other hand, the eggs which had been left in the glass tube in

1 This cleavage was possibly brought about through mechanical agitation; I had repeatedly shaken the dish to facilitate the introduction of oxygen into the sea-water. 
absolute or relatively high lack of oxygen, were nearly all living! This observation seems to show that the same processes which lead to the maturation of the egg bring about its death if they are not inhibited at the right time. In this way the process of fertilization becomes a life-saving or life-prolonging act.

\section{v. DO THESE FACTS HOLD FOR OTHER FORMS?}

The question of the relation between maturation and natural death can be studied most beautifully in the starfish egg because it is possible to obtain it in an immature condition, and because maturation follows very rapidly. With sea-urchin eggs conditions are much less favorable since the egg maturates within the ovary, and since it is difficult to obtain immature eggs during the spawning season. I have, therefore, been unable to discover which chemical factors determine the maturation of the sea-urchin egg, and to decide whether the same circumstances cause the death of the seaurchin egg that bring about the death of the starfish egg; and whether the life of the sea-urchin egg can be prolonged through a prevention of these circumstances. In an indirect way Lewis and I attempted to answer this question last year when we assumed that the destructive processes which bring about the death of the unfertilized egg are enzymatic (autolytic?) processes which can be inhibited through poisons such as KCN.'

We did in fact succeed in showing that the addition of a small amount of KCN to the unfertilized sea-urchin eggs markedly lengthens their life. Even after seven days such eggs can be fertilized as soon as they are returned to normal seawater. We also pointed out that, because of the well-known bactericidal properties of potassium cyanide, the experiments on sea-urchin eggs were not in themselves decisive, and so

\footnotetext{
1 Loeb and Lewis, American Journal of Physiology, Vol. VI (1902). p. 305.
} 
began experiments on starfish eggs ${ }^{1}$ which, however, we were not able to complete at that time. In dealing with eggs which are as long lived as sea-urchin eggs a great development of bacteria in normal sea-water cannot be prevented, since a few of the eggs always die and so serve as an excellent culture medium for the further development of bacteria. It need, therefore, surprise no one that the unfertilized eggs of sea-urchins, as I was able to show this year, live in sterile sea-water for five days, or possibly longer, while they die much earlier in ordinary sea-water (about two days). The very fact that the eggs of sea-urchins are found mature in the ovary indicates that they are able to live a considerable time after maturation and that they differ in this respect from the starfish egg.

It is, however, a fact that in the same sea-water the fertilized and developing sea-urchin eggs live longer than the unfertilized eggs.

It almost seems as if in certain of the higher animals there are eggs which develop only when they are fertilized immediately after leaving the ovary. Under the direction of Professor C. O. Whitman, Harper has shown that the eggs of pigeons are fertilized the moment they leave the ovary. The sperm lives in a gelatinous mass upon the surface of the ovaries, ${ }^{2}$ so that provision is made for the necessary contact between sperm and egg. This also does away with the difficulty which many have found in explaining how the spermatozoon finds its way to the egg in animals in which fertilization occurs within the body. Definite directive forces are clearly not necessary, since a portion of the spermatozoa must reach the ovary, through their ciliary motion, by way of the uterus and Fallopian tubes. Experiments similar to

\section{Ibid.}

2 Spermatozoa are in general much longer lived than mature eggs, even though great differences exist in this regard in different animals. In the spermatic vesicles of the queen bee spermatozoa are believed to remain alive more than a year after copulation. 
those made by Harper upon pigeons must yet be made upon mammals. Yet there seems to be no doubt that the mam. malian egg of many species is also fertilized before it reaches the uterus. Cases of extra-uterine pregnancy also point to the possibility that fertilization may occur at the surface of the ovary.

\section{THE PROLONGATION OF LIFE AND THE THEORY OF FERTILIZATION}

Our experiments seem to have proved that the mature unfertilized starfish egg dies within a few hours through internal changes, but that the process of fertilization saves the life of the egg. This is true, not only of the fertilization of the starfish egg by spermatozoa, but also for the chemical fertilization through hydrogen ions. Mr. Neilson succeeded this year in keeping the parthenogenetic larve of starfish alive much longer than has thus far been the case (over thirty days), and Dr. Fischer was able to accomplish the same for the larva produced osmotically from unfertilized sea-urchin eggs. It is therefore possible that the chemical or osmotic fertilization of these eggs can give rise to as long-lived larvæ as the fertilization of the egg through sperm.

But how does the spermatozoon, or the physical and chemical means substituted for it, save the life of the egg, and why does the mature egg die when it is not fertilized by sperm or artificial means? I believe that the answer lies in this, that the fertilizing agencies accelerate metabolic processes in the egg which, before fertilization, went on only slowly. After fertilization by sperm or by the chemical or physical means substituted for it, the egg divides and grows which it did not do before fertilization occurred. Growth is inconceivable without a preponderance of synthetical over hydrolytical processes. I believe it possible that the deter- 
mining factor in the chemical forces set in motion within the egg through fertilization consists in this that the synthetical processes in the egg are accelerated. If these processes are not inaugurated or accelerated the egg dies. The wasting of the body in old age also indicates a decrease in synthetical processes. Whether the second critical period occurring in old age is similar to the critical period of the egg cannot yet be determined. Yet it is not impossible that the question of the prolongation of life at this period should pass over into the question of the possibility of accelerating synthetical processes.

We, therefore, come to the conclusion that fertilization accelerates a series of chemical changes (syntheses?) in the eggs which do not occur sufficiently rapidly without spermatic, chemical, or osmotic fertilization in the eggs of the majority of animals. But why does the mature egg die when these processes are not accelerated, and why does it remain alive before it maturates? The egg must often exist for years in the immature condition in the ovary. In answer I can only suggest that the processes underlying maturation are at least in some form of a destructive nature (one might think of autolytic processes) which the egg cannot withstand for an indefinite length of time without dying. In many eggs the velocity of these destructive (autolytic?) processes may be greater than in others and this may determine the differences in the velocity with which the mature, unfertilized egg dies. It is in harmony with this view that when maturation is prevented, or the mature egg is put under conditions which inhibit the process of maturation or the chemical processes underlying it, the life of the egg is lengthened. Lack of oxygen or the addition of an acid works in this way in the case of starfish eggs; a slight addition of potassium cyanide, in the case of starfish and seaurchin eggs. But since all of these substances injure the 
eggs indirectly and do not entirely do away with the destructive (autolytic?) processes occurring within the egg, life is not prolonged to the same extent by these means as by fertilization in which case life is prolonged not only through an inhibition of the destructive but also through an acceleration of the synthetical processes.

That the chemical processes which underlie maturation are not identical with those which bring about fertilization seems to be supported by the observation made above, that the same means - the treatment with acid-which causes the mature egg to develop and live beyond the bipinnarian stage, inhibits the maturation of the immature egg. When the mature unfertilized eggs of a starfish are introduced for fifteen to sixty minutes into a mixture of 100 c.c. seawater plus 3 c.c. $\frac{n}{10} \mathrm{HCl} 90$ per cent. of the eggs can, under favorable conditions, develop into larvæ. If, however, the eggs are introduced into such a solution for the same length of time before maturation, the maturation of the eggs is prevented either permanently or for a long time. ${ }^{1}$ The difference is still more striking when the eggs are kept for a shorter time in a mixture of 100 c.c. sea-water and 5 c.c. $\frac{n}{10} \mathrm{HCl}$. This shows that acid affects the process of development and the process of maturation in opposite or at least different ways.

We must now raise the question, How does the behavior of naturally parthenogenetic eggs, such as the eggs of bees, harmonize with these ideas?

In naturally parthenogenetic eggs it seems as if the processes which underlie maturation pass over into those underlying development. But it is possible that this is only apparently the case, and that in reality it so happens that in the processes underlying maturation a metabolic product is

1 The eggs which finally maturate in spite of the previous treatment with acid often begin to cleave when maturation is complete and develop into la:vø, while the control eggs kept in normal sea-water do not develop. 
formed in the parthenogenetic animals which favors the processes of derelopment. We know that an exceedingly small amount of hydrogen ions suffices to bring about development in unfertilized starfish eggs; that an exceedingly small amount of calcium causes the unfertilized eggs of Amphitrite to develop; and that a trace of potassium ions brings about the development of unfertilized Chætopterus eggs. ${ }^{1} \quad$ It is entirely possible that the specific ions or other substances necessary to start the development of the eggs of the bee are formed within the egg itself through the chemical changes taking place during or after maturation, and that without the formation of these substances development is impossible. In the case of sea-urchins and starfish eggs one might also believe that the processes of maturation and the processes of development pass over into each other. For it has often been observed that the unfertilized eggs of these forms after having resided in "normal" sea-water for about twenty-four hours begin to cleave shortly before death. This cleavage, however, never goes beyond the two- or fourcelled stage. This might be explained by the fact that the eggs begin to die at this time. After I had found this year that the eggs of sea-urchins can still be fertilized after a residence of five days in sterilized sea-water (at summer temperature), I decided to study this question of spontaneous cleavage somewhat more closely. If it were true that individual sea-urchin eggs begin to cleave in ordinary sea-water after about twenty hours, and cease to develop any further only because they soon die, it would be expected that many or all should cleave when kept alive four or five days, and that a number of them should reach a fairly advanced stage of development. A lot of sea-urchin eggs were distributed into a series of flasks containing sterile sea-water. One of the flasks was opened every morning and a careful search was made for developed eggs.

I Loeb, Fischer, ANd Neilsos, loc. cit, 
In the course of five days I never found a single divided egg, either in the two-celled stage or in later stages of development. It is possible that during the last days of the experiment a few eggs divided, and that the cleavage cells fell apart. Lewis and I found last year that when eggs are fertilized forty-eight or more hours after their removal from the ovaries they form no membrane and the cleavage cells fall apart. I have corroborated this fact this year. Usually more than one embryo develops from such an egg, because the cells drop apart. I kept this fact in mind and will not deny that a few small eggs were present, which perhaps represented only half the mass of an ordinary egg. But nearly all the eggs were of normal size, and since small eggs are occasionally found even under normal conditions, the experiment shows that in sea-urchin eggs also the processes of maturation are not continuous with those of cleavage, and that entirely different conditions which we can bring about through the abstraction of water or the entrance of a spermatozoon are necessary that division may occur. It cannot be urged that the sterilized water perhaps prevented the cleavage. When at the conclusion of the experiment these same eggs were fertilized in sterilized water by adding a drop of sperm, they developed to the pluteus stage in sterile sea-water. I, therefore, consider it possible that where authors describe a cleavage of the unfertilized seaurchin eggs in "normal" sea-water, the sea-water or the egg had in reality suffered some change which had escaped the notice of the observers. One might think of evaporation and increase in the osmotic pressure of the sea-water. A very slight increase in the osmotic pressure of the sea-water is sufficient to cause the sea-urchin egg to divide into two cells in the course of twenty hours. One might also think of a change in the sea-water brought about by the putrefaction of the dead eggs. Finally it is possible that a sub- 
stance is perhaps formed (for example, an acid) in the dying eggs which brings about a single cleavage.

The relations which exist between maturation and natural death upon the one hand, and fertilization and prolongation of life upon the other, lead us to the conclusion that a "fertilization" must perhaps come to pass in every egg, even in those naturally parthenogenetic. Only, according to our idea, the act of fertilization is not identical with the morphological process which is designated fertilization. It is rather a chemical or a physico-chemical act which accelerates certain (synthetical?) metabolic changes in the egg, which occur in the egg under ordinary conditions also, only much too slowly, The difference between naturally parthenogenetic eggs and the eggs which must be fertilized before they can develop consists perhaps in this, that to the latter the catalytically working substance or complexus of conditions must be added from the outside in order to accelerate the synthetical (?) processes, while in the naturally parthenogenetic eggs these substances are formed within the eggs (possibly in conjunction with the processes of maturation).

The connection between the prolongation of life and fertilization clearly points out that every purely morphological theory of fertilization is incomplete and that a correct theory of this process must have a physico-chemical basis. The means of reaching this basis $I$ see in further attempts at causing development of unfertilized eggs through unequivocal physical and chemical means.

\section{CONCLUSIONS}

1. Our observations and experiments seem to show that in the same sea-water and under otherwise identical conditions, mature but unfertilized starfish eggs soon die, while immature as well as mature but fertilized eggs live longer.

2. It seems certain that the rapid death of the mature 
unfertilized starfish eggs is determined by internal conditions connected with maturation and not by the bacteria contained in the sea-water. The proofs for this are: First, mature eggs die just as rapidly in sterilized sea-water free from bacteria as in unsterilized water, and secondly, when maturation is prevented artificially the eggs may continue to live in water containing many bacteria.

3. We have shown that oxygen and free hydroxyl ions accelerate the maturation of starfish eggs; that lack of oxygen and a neutral or faintly acid reaction of the seawater inhibit or prevent maturation. The fact that the eggs which remain immature in the ovaries of the starfish maturate when brought into sea-water seems to find its explanation in part at least through this.

4. When the maturation of starfish eggs is prevented artificially through lack of oxygen, or the addition of an acid to the sea-water, they remain alive much longer than when they maturate. The eggs in which maturation has already begun, or has just been completed, seem also to be saved from rapid death by these means.

5. It seems to follow from these facts that the same chemical processes do not necessarily underlie the process of maturation and the process of fertilization. Fertilization by spermatozoa, chemical or physical agencies, lengthens the life of the egg, while the changes following the maturation of the egg lead, sooner or later, to death (through autolysis?). It is in harmony with what has been said that the same treatment with acid which brings about artificial - parthenogenesis in mature starfish eggs inhibits the process of maturation when used upon immature starfish eggs.

6. These facts corroborate a suggestion which I have made before, that the fertilizing action of the spermatozoon consists in this, that it carries into the eggs substances which accelerate the course of certain (synthetical?) processes in 
the egg. Such an acceleration might, for example, be brought about through certain ions (for example, the hydrogen ions of nucleic acid), yet the possibility that such catalytic effects might also be brought about through enzymes or other substances is of course not shut out. Yet this fact must be considered: that we have been able to produce artificially normal embryos capable of development through ions, while the careful experiments of Gies conducted in my laboratory, in which he attempted to find the same to hold for enzymes, have thus far failed.

In conclusion I wish to thank my assistant, Mr. Neilson, for the assistance which he rendered me in these experiments. 


\section{XXXVII}

ON THE PRODUCTION AND SUPPRESSION OF MUSCULAR TWITCHINGS AND HYPERSENSITIVENESS OF THE SKIN BY ELECTROLYTES ${ }^{1}$

IT has been shown in former publications that a slight variation in the proportion and character of the electrolytes in a tissue is capable of imparting to that tissue properties which it does not possess ordinarily, and it has been suggested that this fact might help us in recognizing the nature of a number of nervous and muscular diseases, and also possibly furnish a means of curing or mitigating them. This paper contains some further contributions to the same subject. It deals with the determination of electrolytes which are liable to produce and inhibit hyperactivity of muscles and hypersensitiveness of the nerves of the skin; and tries to answer the question whether or not the stimulating and inhibiting effects of ions are a function of their valency and electrical charge.

I. THE PRODUCTION AND SUPPRESSION OF MUSCULAR TWITCHINGS BY ELECTROLYTES

1. Our muscles do not normally contract or twitch rhythmically, but they do so in certain diseases. The main electrolyte in our blood is sodium chloride. When we put a muscle into a pure sodium-chloride solution of the right osmotic pressure (i.e., isotonic with the muscle), the muscle soon begins to twitch rhytlımically, and these twitchings may last for several days, or about as long as the muscle lives. But when we add a very small, though definite, amount of a

1 University of Chicago Decennial Publications (1902), Vol. X, p. 3.

2 Part II, pp. 544, 559, and 692; Pfügers Archiv, Vol. LXXXVIII (1901), p. 68. 
soluble calcium salt, the twitchings will not occur, though the muscle lives longer in such a solution than in a pure sodium-chloride solution. I concluded from this that we owe it to the calcium. ions in the blood that our muscles do not twitch or beat rhythmically like our heart. ${ }^{1}$

To test this idea further, Mr. W. E. Garrey and I undertook, in 1889, a series of experiments, not yet published, on the behavior of muscles in solutions of sodium salts whose anions precipitate calcium. The muscle itself contains calcium salts, and we considered it likely that these calcium salts might help in preventing contractions. We therefore thought that by putting the muscle into solutions of sodium salts, which, by entering the muscle, precipitate the calcium contained in it, we might produce still more powerful rhythmical contractions than in a pure sodium-chloride solution. This was found to be true. In solutions of sodium-fluoride, -oxalate, -carbonate, -phosphate, etc., of the proper concentration ( 1 gram-molecule in 8 liters of the solution), we obtained similar, but more powerful, rhythmical contractions than in sodium-chloride solutions of the same osmotic pressure. Another series of observations confirms the idea that it is due to the calcium salts in our body that our muscles do not show any rhythmical contractions or twitchings. When we inject into the body of an animal any salts that are liable to precipitate calcium, we notice almost immediately twitchings of all the muscles. ${ }^{2}$ It seems, therefore, rational that in the pathology of muscular twitchings the concentration of the calcium ions in the blood should be taken into consideration. It is quite possible that abnormal conditions may arise in the body which lead to an increase of such acids in the circulation as diminish the amount of calcium ions in the

1 Part II, p. 518. See also S. Rrva ER, Journal of Physiology, Vol. VII (1886), p. 291 In this paper Ringer also mentions briefly the fact that Ba differs in its action from Ca and Sr.

2 Friedexthal, Engelmann's Archiv, 1901, p. 145. 
body, e.g., oxalic acid, or others. The necessary outcome would be muscular twitchings. In that case the administration of calcium salts might cure the disease.

2. In a recent paper I have shown that the antitoxic effects calcium produces when added to a pure $\mathrm{NaCl}$ solution are a function of its valency and the sign of its charge, inasmuch as similar effects can be produced by other bivalent or trivalent kations (e.g., $\mathrm{Mg}, \mathrm{Sr}, \mathrm{Ba}, \mathrm{Zn}, \mathrm{Fe}, \mathrm{Co}, \mathrm{Pb}, \mathrm{Al}, \mathrm{Cr}$ ), but not by bivalent or trivalent anions. ${ }^{1} \quad$ The question arises whether or not the inhibiting effects of $\mathrm{Ca}$ ions in the case of rhythmical contractions of muscles are also a function of the valency and electrical charge of the Ca ion. My earlier experiments were not opposed to such a conclusion. I had found that in $\frac{m}{8}$ solutions ${ }^{2}$ of $\mathrm{LiCl}, \mathrm{NaCl}, \mathrm{RbCl}$, and $\mathrm{CsCl}$ rhythmical contractions occur, while small amounts of the chlorides of $\mathrm{Ca}, \mathrm{Mg}, \mathrm{Sr}$ inhibit these contractions. I have since continued these experiments, with the following results: When we put a muscle (the gastrocnemius of the frog was used in these experiments) into a $\frac{m}{8}$ sodium-acetate solution, the twitchings of the muscle begin at once. The addition of from 3 to 4 c.c. of a $m \mathrm{CaCl}_{2}$ solution to 100 c.c. of a $\frac{m}{8}$ sodium-acetate solution absolutely suppresses all twitchings. But even half the amount suffices for practical purposes, inasmuch as in this case only a few beats occur at the beginning. $\mathrm{MgCl}_{2}$ and $\mathrm{SrCl}_{2}$ act like $\mathrm{CaCl}_{2}$. But $\mathrm{BaCl}_{2}$ acts altogether differently. An addition of 5 c.c. of a $m$ solution of $\mathrm{BaCl}_{2}$ to 10 c.c. $\frac{m}{8}$ sodium-acetate solution not only does not stop the rhythmical contractions, but makes them more powerful. Instead of the rapid and rather weak fibrillary twitchings which occur in a $\frac{m}{8}$ sodium-acetate solution, more tetanic and energetic contractions occur when $\mathrm{BaCl}_{2}$ is added. I then tried whether the muscle is able to

1 Part II, p. 708.

$2 \mathrm{By}$ a ${ }_{8}^{m}$ solution is meant a solution which contains 1 gram-molecule in 8 liters. 
beat in a pure $\mathrm{BaCl}_{2}$ solution. It goes without saying that in pure solutions of $\mathrm{MgCl}_{2}, \mathrm{CaCl}_{2}$, and $\mathrm{SrCl}_{2}$ a muscle does not show any rhythmical contraction. In a $\frac{m}{8} \mathrm{BaCl}_{2}$ solution, however, the muscle beat for forty minutes; in a $\frac{m}{16}$ solution, for one and a lialf hours; in a $\frac{m}{32} \mathrm{BaCl}_{2}$ solution, for over an hour; and in a $\frac{m}{6 \mp} \mathrm{BaCl}_{2}$ solution, for about half an hour. The beats showed the same tetanic form characteristic of the presence of barium. The fact that the beats stop sooner in a $\frac{m}{8} \mathrm{BaCl}_{2}$ solution than in a $\frac{m}{16}$ solution is due to the poisonous effects of barium. The fact that the beats stop also very soon in a $\frac{m}{64} \mathrm{BaCl}_{2}$ solution is due to the enormous absorption of water which occurs in such weak solutions. ${ }^{1}$

Similar facts were found for $\mathrm{Ba}\left(\mathrm{NO}_{3}\right)_{2}$ and $\mathrm{Ba}(\mathrm{HO})_{2}$. The most striking fact is that the stimulating power of $\mathrm{Ba}$ salts is greater than that of the corresponding $\mathrm{Na}$ salts. In a $\frac{m}{64} \mathrm{BaCl}_{2}$ solution the muscle may begin to beat in a few minutes and may continue to do so for half an hour. I have even occasionally noticed rhythmical contractions in a $\frac{m}{128} \mathrm{BaCl}_{2}$ solution. But I have never noticed any rhythmical contractions of muscle in a $\frac{m}{32} \mathrm{NaCl}$ solution, and as a rule even in a $\frac{m}{16} \mathrm{NaCl}$ solution the twitchings begin only after a long latent period and last but a short time.

Barium is, however, not the only bivalent kation whose chloride possesses a higher stimulating power than that of the chloride of univalent kations. It was found that the chlorides of the heavy metals are also capable of producing rhythmical twitchings or beats of muscles in much lower concentrations than those found effective in the case of $\mathrm{NaCl}$ or LiCl. In $\frac{m}{10 \overline{0}}$ solutions of $\mathrm{ZnCl}_{2}$ strong beats occurred, which, however, did not last long on account of the rapid imbibition of the muscle with water, as well as on account

1 The beats in $\mathrm{BaCl}_{3}$ solntion often do not begin at once, but after a latent period of from two to fiftecn minutes. 
of the poisonous effects of Zn. In stronger solutions than

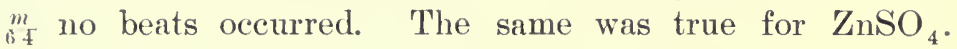
Solutions of $\mathrm{CdCl}_{2}$ and $\mathrm{Pb}\left(\mathrm{No}_{3}\right)_{2}$ also gave rise to a few contractions in the concentration of about $\frac{m}{128}$ to $\frac{m}{150}$.

The fact that the more concentrated solutions of the salts of heavy metals did not act is probably due to their poisonous effect. It is, therefore, evident that there are a number of chlorides with bivalent kations which are able to produce rhythmical contractions at a lower concentration than $\mathrm{NaCl}$. It would, therefore, be wrong to ascribe the inhibiting effect of Ca salts upon rhythmical contractions to the double valency and the positive charge of the $\mathrm{Ca}$ ions.

3. Does the effectiveness of salts for the production of rhythmical muscular contractions increase with the valency of the anion? This is decidedly not the case, as the following table shows. In this table are given the minimal concentrations of the solutions of various sodium salts in which rhythmical contractions occur:

\begin{tabular}{|c|c|c|}
\hline & Salt & $\underset{\text { Concentration }}{\text { Minimal Effective }}$ \\
\hline \multirow{6}{*}{ Univalent anions } & $\mathrm{NaCl}$ & $m$ \\
\hline & $\mathrm{NaBr}$ & $\frac{16}{16}-{ }_{32}^{m}$ \\
\hline & $\mathrm{NaJ}$ & $\begin{array}{l}16 \\
m \\
32\end{array}$ \\
\hline & $\mathrm{Na}$ acetate & $\frac{1}{m}-\frac{m}{32}-64$ \\
\hline & $\mathrm{NaF}$ & $\frac{m}{64}-\frac{m}{96}$ \\
\hline & $\mathrm{Na}$ formiate & $\frac{m}{80}-\frac{0}{160}$ \\
\hline & $\mathrm{Na}_{2}$ succinate & $\frac{m}{16}$ \\
\hline Bivalent anions & $\mathrm{Na}_{2} \mathrm{SO}_{4}$ & \\
\hline & $\begin{array}{l}\mathrm{NaHCO}_{3} \\
\mathrm{Na}_{2} \text { oxalate }\end{array}$ & $\begin{array}{l}\frac{m}{16}-{ }_{32}^{m} \\
16 \\
\frac{3}{2}-\frac{m}{300} \\
260\end{array}$ \\
\hline Trivalent anions & $\left\{\begin{array}{l}\mathrm{Na}_{2} \mathrm{HPO}_{4} \\
\mathrm{Na}_{3} \text { citrate }\end{array}\right.$ & $\begin{array}{l}\frac{m}{128}-\frac{m}{256} \\
\frac{m}{200}\end{array}$ \\
\hline
\end{tabular}

It is obvious that the power of favoring rhythmical contractions in muscles is not an unequivocal function of the valency of the anion. It is likewise obvious that the sodium salts whose anions precipitate calcium powerfully, like sodium fluorides, sodium oxalate, and sodium phosphate, are among 
the most farorable salts to produce rhythmical twitchings. Sodium citrate does not precipitate calcium in the tissues, but prevents its precipitating other compounds, and therefore practically makes calcium inactive. ${ }^{1}$ But that the precipitation and inactivation of calcium is perhaps not the only factor involved is shown by the efficiency of sodium formiate. It may be, however, that sodium formiate undergoes further changes in the tissues, and that one of the products formed acts upon calcium.

All these facts suggest that it might be worth while to test the idea whether or not the pathological cases of muscular hyperactivity and twitching are due to a lack of calciurn in the muscles (or blood), and whether the evil can be mitigated by giving calcium salts to such patients. Experiments must be made in animals to find out whether or not such a treatment would do any harm before any therapeutical experiments on patients should be attempted. It is our intention to take up these experiments in the laboratory.

\section{THE DIFFERENT EFFECTS OF CALCIUM IN THE CASE OF MYOGENIC AND NEUROGENIC RHYTHMICAL CONTRACTIONS}

1. While it seems easy to suppress, by the addition of $\mathrm{Ca}, \mathrm{Sr}$, and $\mathrm{Mg}$, rhythmical twitchings which originate in the muscle itself, the question arises whether the same means allow us to suppress, with equal ease, muscular twitchings which originate through the central nervous system. The simplest organism in which this can be tested is probably the jelly-fish. These animals contract rhythmically. Their central nervous system is contained in the margin of the swimming-bell, while the center of the animal is said to contain no nerve-elements except scattered neurons. By a cut

1 SABBATANI has shown that although sodium citrate does not precipitate cal. cium, it renders it inactive. In the presence of a sufficient quantity of sodium citrate, calcium loses, e. g., its coagulating effect: Archives Italiennes de Biologie, Vol. XXXVI (1901), p. 397 . 
parallel to the edge we can divide the animal into a marginal part, which contains the central nervous system, and a central part, without a central nervous system.

When this operation is performed, the margin will go on beating in sea-water, while the center will not beat. Romanes, who was (as I believe) the first to make this experiment, drew the conclusion that the central nervous system was the originator of the automatic contractions of this animal. From previous experiments of Aubert, ${ }^{1}$ Howell, ${ }^{2}$ and Greene ${ }^{3}$ on the heart, and my own experiments on the muscles, I concluded that the center of a jelly-fish (Gonionemus) did not beat in sea-water on account of the presence of certain ions in sea-water, especially calcium, and I showed that the center of a Medusa will beat rhythmically in pure $\mathrm{NaCl}$ or $\mathrm{NaBr}$ solution." The center of a Medusa whose margin is cut off seems then to behave, to a certain extent, like the striped muscle. It was of some importance to find out how far this analogy goes. The following six solutions were prepared:

1. 100 c.c. $\frac{m}{2} \mathrm{NaCl}$

2. 100 c.c. ${ }_{2}^{m} \mathrm{NaCl}+\frac{1}{2}$ c.c. $1_{16}^{\frac{5}{6}} \mathrm{Ca}\left(\mathrm{No}_{3}\right)_{2}$

3. 100 c.c. $\frac{m}{2} \mathrm{NaCl}+1$ c.c. $\frac{5}{16} \mathrm{Ca}\left(\mathrm{No}_{3}\right)_{2}$

4. 100 c.c. ${ }_{2}^{m} \mathrm{NaCl}+2$ c.c. $\frac{5}{16} \mathrm{Ca}\left(\mathrm{No}_{3}\right)_{2}$

5. 100 c.c. ${ }_{2}^{m} \mathrm{NaCl}+4$ c.c. ${ }_{16}^{\frac{5}{6}} \mathrm{Ca}\left(\mathrm{No}_{3}\right)_{2}$

6. 100 c.c. ${ }_{2}^{m} \mathrm{NaCl}+8$ c.c. ${ }_{12}^{\frac{5}{6}} \mathrm{Ca}\left(\mathrm{NO}_{3}\right)_{2}$

In solution 1 the center of a Medusa begins at once to contract very rapidly. The velocity of contractions steadily increases and very soon it becomes impossible to count the contractions. Occasionally the same happens in solution 2 . But in the solutions 3 to 6 the center at first remains perfectly quiet. After a latent period of about ten minutes, often, but not always, contractions begin in solutions 3 to 5 ,

1 AUbert, Pflügers Archiv, Vol. XXIV (1881), p. 361.

2 Howell, American Journal of Physiology, Vol. II (1898), p. 47.

3 Greene, ibid., p. 82.

4 Part II, p. 559. 
or even in 6 , which last sometimes as long as fifteen minutes. These contractions are not as rapid as those observed in a pure $\mathrm{NaCl}$ solution, and resemble more the normal contractions of a Medusa in sea-water. A series of experiments was undertaken to find out the minimal amount of $\mathrm{Ca}$ required to prevent completely all contractions in a pure $\mathrm{NaCl}$ solution. In a mixture of 100 c.c. of a $\frac{m}{2} \mathrm{NaCl}$ solution +3 c.c. of a $\frac{5}{4} m \mathrm{Ca}\left(\mathrm{NO}_{3}\right)_{2}$ solution no contractions occurred. A series of experiments with a slightly greater amount of $\mathrm{CaCl}_{2}$ were made with the same result.

The same inhibitory effect can be produced if, instead of $\mathrm{Ca}, \mathrm{Sr}$ or $\mathrm{Mg}$ is used. But $\mathrm{Ba}$ behaves altogether differently. The following solutions were tested:

$$
\begin{aligned}
& 100 \text { c.c. } \frac{m}{2} \mathrm{NaNo}_{3} \\
& 100 \text { c.c. }{ }_{2}^{m} \mathrm{NaNo}_{3}+1 \text { c.c. } m \mathrm{BaCl}_{2} \\
& 100 \text { c.c. }{ }_{2}^{m} \mathrm{NaNo}_{3}+2 \text { c.c. } m \mathrm{BaCl}_{2} \\
& 100 \text { c.c. }{ }_{2}^{m} \mathrm{NaNo}_{3}+4 \text { c.c. } m \mathrm{BaCl}_{2} \\
& 100 \text { c.c. }{ }_{2}^{m} \mathrm{NaNo}_{3}+8 \text { c.c. } m \mathrm{BaCl}_{2} \\
& 100 \text { c.c. }{ }_{2}^{m} \mathrm{NaNo}_{3}+16 \text { c.c. } m \mathrm{BaCl}_{2}
\end{aligned}
$$

When the center of a Medusa was thrown into any of these solutions, the rhythmical contractions began at once. The center behaved as if the $\mathrm{Ba}$ ion had not been present, with this difference, however, that the solutions with a larger amount of barium were more poisonous than a pure $\mathrm{NaCl}$ solution. $\mathrm{Ba}$ has, therefore, little or no inhibitory effect upon the center of a Medusa. ${ }^{1}$

The analogy between the effect of ions upon muscle and the center of a Medusa goes still farther. I pointed out that possibly the $\mathrm{Ca}$ ions in the sea-water and the tissues of the Medusa prevent the isolated center from beating in sea-

1 Since this was written $I$ have received, through the kindness of Professor Sabbatani in Cagliari, a paper published by his assistant, Dr. Regoli, in which the latter shows that, while $\mathrm{Ca}$ and $\mathrm{Sr}$ diminish the irritability of the cerebral cortex, Ba has the opposite effect : REGOLI, "Azione dei metalli alcalino-terrosi sulla eccitabilità elettrica della corteccia cerebrale," Bollentino d. Societate tra $i$ Cultori delle Scienze etc. in Cagliari, Torino, 1901. 
water in the same way as the presence of $\mathrm{Ca}$ in the blood seems to prevent our muscles from beating. In order to test this idea, I added to the sea-water various salts which precipitate $\mathrm{Ca}, e . g ., \mathrm{NaF}$ and $\mathrm{Na}_{2} \mathrm{HPO}_{4}$. I found that when a little more of these salts had been added than required to precipitate all the $\mathrm{Ca}$ in the sea-water, the center behaved indeed in the same way as if it had been put into a pure $\mathrm{NaCl}$ solution. When a little less $\mathrm{Na}_{2} \mathrm{HPO}_{4}$ was added, the beats began after a latent period, which varied according to the amount of $\mathrm{Na}_{2} \mathrm{HPO}_{4}$ added. Rapid contractions began at once when 32 c.c. of a $\frac{m}{8} \mathrm{Na}_{2} \mathrm{HPO}_{4}$ solution was added to 68 c.c of sea-water. The same result was obtained when 16 c.c. of a normal $\mathrm{NaF}$ solution was added to 100 c.c. of sea-water.

The addition of about 13 c.c. of $m$ sodium-citrate solution to 100 c.c. of sea-water also brought about immediate contraction of the isolated center. This salt does not bring about a precipitation of $\mathrm{Ca}$ in the sea-water or the tissues, but excludes the action of $\mathrm{Ca}$ ions in another way.

I did not succeed in bringing about such results with the addition of $\mathrm{Na}_{2} \mathrm{SO}_{4}$ to sea-water. Even the addition of 32 c.c of $m \mathrm{Na}_{2} \mathrm{SO}_{4}$ to 100 c.c. of sea-water did not give rise to contractions, although the irritability of the center was increased. Experiments with the addition of $\mathrm{NaHCO}_{3}$ remained also negative. But as only a few experiments were made with $\mathrm{Na}_{2} \mathrm{SO}_{4}$ and $\mathrm{NaCHO}_{3}$, it is possible that a continuation of the work might lead to positive results.

It is, therefore, obvious that the centers can be caused to beat through a diminution of the amount of $\mathrm{Ca}$ they contain, and it may be further argued that the presence of $\mathrm{Ca}$ in the sea-water is the cause, or at least one of the causes, that prevent the centers from beating in sea-water.

It should, however, be added that, while a certain diminution of $\mathrm{Ca}$ in the center is necessary for the development of 
rhythmical contractions, the diminution has its limit. It appears that, if too much $\mathrm{Ca}$ is removed from the tissues, the beats will also cease. This is demonstrated by the following facts: When we put the center of a Medusa into sea-water to which enough sodium citrate has been added, beats begin at once, last for a certain time, and then cease. If at this time the centers are put back into sea-water with less or no sodium citrate, beats will begin again. The explanation of this phenomenon seems to be as follows: The normal center of a Medusa contains too much $\mathrm{Ca}$ for spontaneous rhythmical contractions. If we put a center into seawater to which a large amount of $\mathrm{NaF}, \mathrm{Na}_{2} \mathrm{HPO}_{4}$, or sodium citrate has been added, so much of the salt will diffuse at once into the organism that at least in the superficial cells enough $\mathrm{Ca}$ will be eliminated from the field of action to allow the spontaneous contractions to begin. Subsequently the same will happen in the deeper cells. The process of elimination of calcium in the cell proceeds, and very soon a period comes when the loss of $\mathrm{Ca}$ in all the cells will be too great for the contractions to go on. If, as soon as this occurs, the center is thrown into normal sea-water, or seawater with only a little sodium citrate or phosphate, citrate and phosphate anions will diffuse back from the tissues into the sea-water, or Ca ions will diffuse into the cells, or both phenomena will occur, and beats will again begin. The same reasoning applies probably to the rhythmical contractions of muscles and the apex of the heart.

2. When we put the margin containing the central nervous system into a pure $\mathrm{NaCl}$ solution, it behaves very much like the center, e.g., it begins to beat very rapidly, and the rapidity of the beats increases, at first steadily, until the poisonous effects of the pure $\mathrm{NaCl}$ solutions make themselves felt. But even the addition of large quantities of Ca does not inhibit these contractions. For instance, when we 
add from 2 to $\tilde{e}$ c.c. of a $\frac{5}{4} \mathrm{~m}$ solution of $\mathrm{Ca}\left(\mathrm{NO}_{3}\right)_{2}$ to 100 c.c. of $\frac{m}{2} \mathrm{NaCl}$ solution, the margin at once begins its rapid beats. The only effect the addition of calcium has is to make the rate of the beats a little slower than without calcium. I thought at first that the stimulus of the wound caused by the cutting off of the margin might be responsible for these contractions in the presence of calcium. But this is not the case, for if we put a whole Gonionemus intact into any of these solutions, it behaves like the isolated margin. The only possible inference is that the margin is much more immune toward the inhibiting effects of calcium than the center, a fact which I have pointed out already in a former paper. ${ }^{1}$ In a pure $\mathrm{CaCl}_{2}$ solution the margin will not beat.

Inasmuch as the essential difference between center and margin which accounts for this difference in the effect of calcium is the presence of the central nervous system in the margin, it may follow from these observations that for the supression of twitchings of a nervous origin larger doses of calcium might be required than for the suppression of twitchings of muscular origin. Preliminary experiments on the motor nerves of frogs seem to harmonize with this idea. This suggests the possibility that, while a calcium treatment might be advisable for the cure of myogenic twitchings, for the suppression of neurogenic twitchings so much calcium might be required as to exclude the use of this remedy. This, too, is a point which further experiments on animals must decide before the matter may be tried in patients.

\section{THE PRODUCTION OF HYPERSENSITIVENESS OF THE SKIN BY ELECTROLYTES}

1. In a former paper I have shown that, aside from the rhythmical twitchings, the salts whose anions precipitate or inactivate calcium also make muscles and motor nerves sensi-

1 Part II, p. 692. 
tive to stimuli which normally would not affect these organs. For example, when we put a fresh muscle for one or more minutes into a $\frac{m}{8}$ solution of sodium citrate, a peculiar form of irritability arises (contact-irritability). ${ }^{1} \quad$ Whenever the muscle is taken out of the solution it goes into powerful tetanic contractions, which cease at once and give way to relaxation of the muscle as soon as the latter is put back'into the solution. When this hypersensitive condition is once established, the contractions can be produced whenever the muscle is changed from any aqueous solution to any other non-aqueous medium, while the contractions cease when the muscle is put back into an aqueous medium, no matter whether the latter be a solution of an electrolyte or a non-conductor. It is rather striking that these phenomena do not occur when the above-mentioned solutions call forth at once the rhythmical contractions mentioned in the previous part of this paper. It almost looks as if there existed two allotropic states of the muscle substance, the one giving rise to rhythmical twitchings, the other to the peculiar tetanic contractions (contact-reactions) just referred to. ${ }^{2} \quad$ Ultimately, however, in all cases, rhythmical twitchings are produced.

As far as motor nerves are concerned, I have shown in the same paper that the same salts which produce this contact-reaction produce hypersensitiveness of the nerve and ultimately rhythmical contractions of the muscle when acting upon the nerve alone.

It might be mentioned here in parenthesis that these facts may throw some light upon the action of catharties. All the salts which give rise to the above-mentioned contact-reaction or hypersensitiveness act as cathartics when introduced into the intestine. The common explanation of their action is

1 Part II, p. 692.

${ }^{2}$ This difference is emphasized by the fact, found by my pupil, Dr. Zoethout that an addition of potassium favors the contact-reaction. As far as rhythmical contractions a re concerned, $K$ has an inhibiting effect. 
the one which, I believe, was first suggested by Schmiedeberg, namely, that these salts prevent the absorption of liquids from the intestine, and that this retention of liquids causes the cathartic effect. I will not deny the effect of these salts upon the phenomena of absorption of water from the intestine, ${ }^{1}$ but it is obvious from our experiments that the same salts must increase the irritability of the nerves and muscles of the intestine, and that this must facilitate the production of peristatic motions, possibly through the mechanical or contact-stimuli of the fæces upon the nerve-endings or the muscular wall of the intestine.

2. These experiments suggested the idea whether or not electrolytes are capable of producing also a hypersensitiveness of the skin and conditions that may be comparable to the conditions of hyperæsthesia or hyperalgesia. It is well known that when we suspend a pithed frog vertically so that its legs hang down, the latter will be lifted at once when they are dipped into an acid or alkali of a certain concentration, while no such reaction occurs when they are dipped into water. The reaction of the animal to acid may be so violent as to suggest to a layman the idea that it is suffering intense pain. I wondered whether by an alteration of the nature and proportion of ions in the skin the sensitiveness could be increased or varied in such a way as to make the skin as sensitive to the contact with pure water as it naturally is to strong acid. The experiments resulted in my finding certain solutions of electrolytes which did not seem to affect the animal directly, but yet made it extremely sensitive toward contact with water. The best solutions for this purpose are, as far as my present experiments go, $\mathrm{AlCl}_{3}$, and sodium-citrate solutions. The way of proceeding is as follows: A number of solutions, say $\mathrm{AlCl}_{3}$, are prepared, namely, $\frac{m}{32}, \frac{m}{16}, \frac{n}{8}, \frac{m}{4}$, and possibly $\frac{m}{2}$. Then the weakest 1 Cushry and Wallace, American Journal of Physiulogy, Vol. I (1899). 
of the solutions is first brought in contact with the feet of the frog. If the feet are not withdrawn, the next stronger solution is used, and, if no reaction occurs, the next stronger. If one thus succeeds in keeping the feet of the animal for one minute or more in the $\mathrm{AlCl}_{3}$ solution, subsequent contact of the feet with common tap-water or distilled water makes the animal act as if the water caused the most excruciating pain. The feet are violently withdrawn, rubbed against each other in a way that one notices otherwise only when the feet are dipped into strong acids. If the $\mathrm{AlCl}_{3}$ solution chosen is too strong, the animal will not leave his feet in the solution, but will try to withdraw them. But in that case its attempts at withdrawing its feet from the solution are never as violent as the subsequent attempts at withdrawing the feet when brought into contact with common water. The stronger the solution of $\mathrm{AlCl}_{3}$ is in which the feet had been kept, and the longer they had been kept in the solution, the stronger their sensitiveness toward water will become.

Sodium citrate acts very similarly to aluminium chloride. As the latter is slightly acid and sodium citrate slightly alkaline, the possibility was suggested that the $\mathrm{H}$ and $\mathrm{HO}$ ions are responsible for the hypersensitiveness. While it is possible to produce occasionally a slight hypersensitiveness toward common water by a pure solution of $\mathrm{NaOH}$ or $\mathrm{HCl}$, the results are very unreliable. It is practically the same if one tries to use $\mathrm{NaCl}$ solutions to which slight and varying quantities of $\mathrm{HCl}$ or $\mathrm{NaOH}$ have been added. Better results can be obtained with solutions of oxalates, sulphates, carbonates, and phosphates. The sodium salts are preferable to the potassium salts, for the animal withdraws its feet much more rapidly from the solution of a potassium salt than from the solution of the corresponding sodium salt. This makes it difficult in the case of potassium salts to 
saturate the foot with the sufficient number of ions to induce the hypersensitiveness.

It goes without saying that the hypersensitiveness which can be produced by $\mathrm{AlCl}_{3}$ and sodium citrate does not make itself felt toward water alone, but to salt solutions also. One can find a minimal concentration for each solution of an electrolyte at which a pithed frog almost instantly withdraws its feet when they come in contact with the solution. This minimal concentration is considerably lowered after a treatment of the foot with an $\mathrm{AlCl}_{3}$ or sodium-citrate solution.

The production of hypersensitiveness is only one side of the problem. The mitigation of the hypersensitiveness is the other side. The violent reactions of a frog when its feet are dipped in tap-water after a treatment with $\mathrm{AlCl}_{3}$ can be stopped instantly when the feet are put into a normal solution of cane-sugar. When weaker solutions of canesugar are used the feet are withdrawn, and the attempts at withdrawing become more noticeable and violent the weaker the sugar solution is. Very concentrated solutions of urea, $e . g ., 2 n$ solutions, act similarly, but not so powerfully as cane-sugar. Glycerin solutions gave no such results; neither have I been able to find as yet any solution of an electrolyte which acted this way. The fact that only very concentrated solutions of cane-sugar or urea inhibited the hypersensitiveness gave rise to the idea that the diffusion of water out of the foot might be the inhibiting factor, and that a stream of diffusion in the opposite direction, namely, from the outside into the skin, might give rise to a withdrawal of the foot. The latter idea could be tested. When the feet of a pithed frog are dipped into a normal solution of cane-sugar, they are not withdrawn, no matter how long they remain in the solution. But if subsequently (after several minutes) the feet are put into pure water, after a few (five to ten) seconds the feet are energetically withdrawn. 
In this case, obviously, water diffuses into the skin, which previously had lost water.

There may be electrolytes which act similarly to canesugar, but I have not yet found them. Every solution of an electrolyte causes, above a certain concentration, an immediate withdrawal of the feet, and this withdrawal is the more energetic the more concentrated the solution. This differs from the behavior of sugar and urea, which above a certain concentration have the opposite effect.

The lowest concentration at which the solutions of various electrolytes will cause a pithed frog to withdraw its feet instantly or in from five to ten seconds, is about as follows:

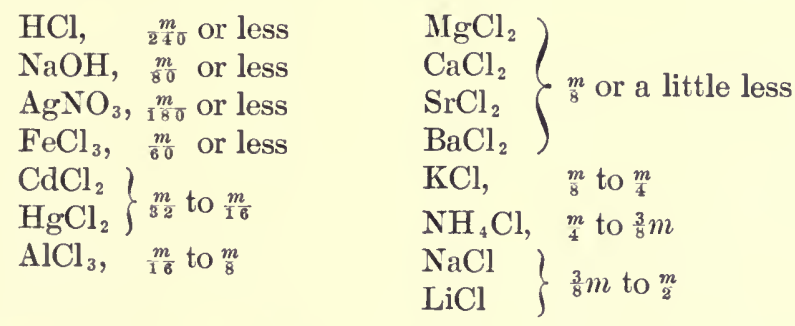

It almost looks as if the coagulating effect of the kations upon proteids was of some importance. The powerful effects of $\mathrm{Ag}, \mathrm{Cd}$, and $\mathrm{Hg}$ interfere somewhat with the conclusion that we are dealing with a pure valency effect, which otherwise seems to makeitself felt. If, instead of the chlorides, the nitrates or sulphates of the same metals are chosen, the order of efficiency seems to remain practically the same, as far as can be judged from an as yet incomplete series of experiments.

As far as the anions are concerned, the order of efficiency is for the sodium salts about as follows:

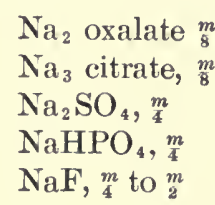

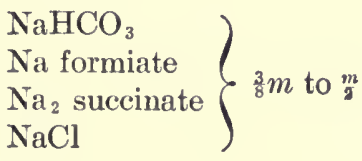


In this case, as in the case of rhythmical contractions, the oxalates and citrates are the most powerful anions of this series. It is clear that, in the determination of the lowest concentration of a salt which is still able to cause the immediate withdrawal of the foot, one must remember that a number of solutions (e.g., $\mathrm{AgNO}_{3}, \mathrm{AlCl}_{3}, \mathrm{FeCl}_{3}, \mathrm{HCl}$, $\mathrm{NaOH}, \mathrm{Na}_{3}$ citrate, etc.) have an after-effect which makes itself felt in an increase of irritability. Other solutions (e. $g$, those of calcium salts) may possibly have the opposite effect, namely, to raise the threshold of stimulation for subsequent tests.

It was of some interest to ascertain whether the results in these experiments were produced through an action of the electrolytes upon the nerve-endings, or upon the nerves themselves. In experiments upon frogs whose skin had been removed from the feet, the results described in this paper could not be produced. The experiment of putting the nerves themselves into the above-mentioned solutions remained practically without effect. It is possible that with solutions of much greater concentration results may be obtained. It is, therefore, certain that the results observed in our experiments are due to an action of the electrolytes upon the nerve-endings in the skin, and not to an action upon the sensory nerves. ${ }^{1}$

\section{CONCLUSIONS}

The experiments mentioned in this paper were undertaken with two aims in view, a practical and a theoretical one. As far as the former is concerned, it follows from our investigations that abnormal muscular twitchings and contractions may be brought about in an organism by a reduction in the proportion of calcium (or magnesium) in the muscles or the blood, or an increase in the proportion of $\mathrm{Na}$ and other

1 The chemical irritability of muscles is, as far as electrolytes are concerned, also greater than that of motor nerves. The reverse is true for electrical stimulation. 
kations. In view of the fact that thus far no explanation has been found for pathological phenomena of this kind, it becomes of some importance to see whether or not in certain of these diseases the relative amount of calcium ions in the blood is diminished. If this should be the case, the administration of calcium would be the cure for these diseases, which thus far have been beyond medical control. It is also apparent from our experiments that for the suppression of neurogenic twitchings or contractions more calcium may possibly be required than for the suppression of myogenic twitchings. There has thus far been no clue as to the origin of hypersensitiveness or hyperalgesia of the skin. Our experiments show that slight variations in the proportion of certain ions in the skin can cause an enormous hypersensitiveness.

As far as the theoretical side of the paper is concerned, it was our aim to test the idea whether or not the "stimulating" and inhibiting effects of ions are an unequivocal function of their electrical charge or valency. Over a year ago I tested the same idea without being able to obtain positive results, and nothing was said about the subject in the paper in which the results were published. ${ }^{1}$ The test was continued in the above-mentioned experiments, with results which, in my opinion, are equally questionable, if not altogether negative.

${ }^{1}$ Part II, p. 692. 


\section{XXXVIII}

ON THE METHODS AND SOURCES OF ERROR IN THE EXPERIMENTS ON ARTIFICIAL PARTHENOGENESIS ${ }^{1}$

1. Because of various papers by European authors who have encountered difficulties in repeating or continuing my experiments on artificial parthenogenesis I wish to make a few remarks on the methods and the sources of error in these experiments. I do not need to dwell upon the importance of sterilizing the sea-water, the instruments, the hands, and the animals themselves; it is self-evident. I wish in this connection to mention only the greatest sources of error, namely, the tendency of males, especially ripe seaurchins, to fill the sea-water in the pail in which they are brought into the laboratory with sperm. It is therefore advisable to keep the females isolated for twenty-four hours or if possible even longer in sea-water free from sperm before using them in the experiments on artificial parthenogenesis. If one has taken the necessary precautions against infection with sperm, the next step is to bring the unfertilized eggs to development. In the eggs of sea-urchins the only effective method which is known thus far by which they can be made to develop parthenogenetically consists in keeping the eggs for about one and one-half hours in seawater the osmotic pressure of which has been increased a definite amount. In general it is immaterial how this increase in osmotic pressure is brought about, whether through evaporation of the sea-water or through the addition of salt or sugar or urea to the sea-water. If we wish to obtain many and, as nearly as possible, normal larvæ, the choice of methods is somewhat more limited. I find after

1 Archiv für Entwickelungsmechanik der Organismen, Vol. XIII (1902), p. 481. 
all my experience that the addition of potassium or sodium salts, especially potassium chloride and sodium chloride, is perhaps the best. The degree of increase in concentration is of great importance. If the correct concentration is not struck, failure will result, and it is remarkable how greatly the necessary concentration varies in different series of experiments. Whether the variations are exclusively of an individual character and correspond to the different states of maturation of the eggs I will not endearor to say. Possibly temperature also has some effect. In order to meet all these possibilities I always work with a series of solutions. In this way I am certain to obtain good results in at least one of the solutions. I use as a stock solution a $2 \frac{1}{2}$ normal $\mathrm{NaCl}$ or $\mathrm{KCl}$ solution; that is, a solution which contains about $186 \mathrm{~g}$. of $\mathrm{KCl}$ in the liter of solution. In my experiments the solutions were accurately titrated, but this is superfluous for most purposes. I take six dishes, each containing 100 c.c. sea-water, and add to these six dishes the series of $8,10,12,14,16,18$ c.c. of the above $2 \frac{1}{2}$ normal $\mathrm{NaCl}$ solution. The unfertilized eggs of the sea-urchin are then distributed into these six dishes (and in addition into a control dish containing pure sea-water).

Differences also exist regarding the time during which the eggs must remain in these solutions. It is therefore necessary to remove, not all the eggs at once, but at various intervals after about one-half, one, one and one-half, and two hours. In this way one will certainly strike the optimal concentration and time of experiment. Potassium chloride has the advantage that it leads usually to the formation of a single embryo from each egg, while when sodium chloride is used more than one embryo is usually formed from an egg. The formation of the skeleton, however, probably occurs somewhat better when sodium salts are employed than when potassium salts are used. Mr. Hunter obtained very satis- 
factory parthenogenetic plutei by using sea-water the concentration of which had been increased 30 per cent. to 40 per cent. by evaporation. When the eggs were introduced for one to two hours into this concentrated sea-water they developed beautifully when returned to normal sea-water.

A second important circumstance which perhaps plays a rôle in these experiments is the temperature. The experiments at Woods Hole (as well as Wilson's experiments in Beaufort) were all made at summer temperature when the temperature of the water was $20^{\circ} \mathrm{C}$. or higher. In California the temperature varied considerably in my experiments. It was often pretty low and I was occasionally unsuccessful in bringing about artificial parthenogenesis. I attributed this at that time to the immaturity of the eggs. Possibly this was right, and possibly this explains the negative results of most of the European investigators who worked in winter. Since then, however, I have thought that perhaps the temperature affects the results of the experiments in such a way that below a certain temperature artificial parthenogenesis does not occur, or at least only with difficulty. This idea is strengthened by a letter from Mr. Doncaster who has worked in Naples, and who informs me that he at first obtained only negative results, that he then suspected, however, that the temperature of the water in Naples was too low, and so made experiments in water of the temperature of about $20^{\circ} \mathrm{C}$. In the latter case be obtained positive results.

2. What has been said thus far refers only to experiments on sea-urchin eggs, especially Arbacia. Especial care is necessary when working with starfish eggs. A. Mathews has observed that the unfertilized eggs of starfish (Asterias) after maturation in sea-water can be made to develop by shaking, and that a time exists at which the agitation connected with transferring the eggs from one dish to another 
is sufficient to obtain larvæ.' $\quad$ Eggs as sensitive as chis must be carefully handled in two directions if one does not wish to obtain deceptive results. First it is necessary to transfer the eggs from one dish to another in such a way that every mechanical agitation is done away with. This is best done by using pipettes with a wide opening for sucking up and transferring the eggs. The latter manipulations must then be made with the greatest care. The second precaution consists in this, that whenever the experimental eggs are transferred from one solution to another or into sea-water the same mechanical manipulation must be repeated in exactly the same way with the control eggs. In this way it can be determined whether the parthenogenetic development in individual cases is attributable to mechanical agitation, or to other agents which one employs. With these precautions we have made a series of experiments this summer on Asterias eggs and have found up to the present time that, independently of mechanical agitation, only two methods lead to artificial parthenogenesis in starfish eggs. First, the introduction of the eggs for from three to twenty minutes into sea-water to which 3 to 5 c.c. of a $\frac{1}{10}$ normal $\mathrm{HCl}$ or some other inorganic acid has been added to each 100 c.c. of seawater. The second method which was discovered by my pupil, Mr. A. W. Greeley, consists in keeping the eggs, after lying for a certain time in sea-water, on ice for a number of hours. Other methods all gave negative results, especially heating the eggs which Mr. Greeley also tried. Neither did we succeed in obtaining clear results through the abstraction of water from the egg, so that I suspect that in my earlier experiments perhaps, in which I found starfish eggs to develop through an increase in the concentration of the seawater, mechanical agitation really caused the development.

1 I have since found that the eggs of the starflsh can derelop without any notice. able external cause. [1903] 
I believe also that Delage has in part been led into error by this circumstance when he asserts that about every physical and chemical factor brings about artificial parthenogenesis. I do not believe that such an assertion could be made on the basis of experiments on sea-urchin eggs. In sea-urchin eggs agitation does not act this way and this source of error which is so inconvenient in working with starfish eggs does not exist here. Nevertheless, I made it a rule from the first to expose the control eggs to the same mechanical agitation in the experiments with sea-urchin eggs as the experimental eggs themselves.

3. The precautions necessary for the experiments on starfish eggs must also be used in the experiments on the eggs of Annelids, Chætopterus, and Amphitrite. In both these forms it has been possible this summer to bring about artificial parthenogenesis through shaking and mechanical agitation of the eggs. In Chætopterus, however, this result is less certain than in Amphitrite. If the unfertilized eggs of Annelids are allowed to remain in ordinary sea-water without jarring the vessel, the eggs do not develop into larvæ any more than do starfish eggs. We cannot speak of a "natural" parthenogenesis of these forms. If, however, they are allowed to remain for thirty minutes in the sea-water the unfertilized eggs of Amphitrite can be made to develop into larvæ by squirting them from one vessel into another by means of a pipette. This does not succeed with every culture, but still very frequently." It is possible, however, to cause the unfertilized eggs of Amphitrite to develop every time without agitation, when they are introduced into sea-water to which a small but definite amount of a soluble calcium salt has been added. It is not necessary to return the Amphitrite eggs from such a solution to sea-water. They develop

1 I suspect that the skaking affects the development of the egg only in an indirect way. [1903] 
in such a solution to swimming larvæ. Just as hydrogen ions bring about the development of larvæ from starfish eggs calcium ions bring about the development of Amphitrite eggs. The addition of 2 to 5 c.c. of a normal calcium-nitrate or calcium-chloride solution to 100 c.c. of sea-water is sufficient for this purpose.

I repeated and confirmed this year my earlier experiments on the specific effects of potassium ions on the development of unfertilized Chætopterus eggs. These eggs develop when a small but definite amount of any soluble potassium salt $\left(\mathrm{KCl}, \mathrm{KNO}_{3}, \mathrm{~K}_{2} \mathrm{SO}_{4}\right.$ ) is added (about 1 to 2 c.c. of a $2 \frac{1}{2}$ normal solution of one of these salts to 100 c.c.) to sea-water. It is not necessary to remove the eggs from this solution and to return them to normal sea-water. It may perhaps be well to emphasize especially that calcium and potassium ions have no specific effect upon starfish eggs, that potassium ions are in the same way unable to cause the development of Amphitrite eggs, and that calcium ions are ineffective in the case of Chætopterus eggs.

4. The following facts are also indirectly of importance for the methods of the experiments on artificial parthenogenesis. All the ions which bring about parthenogenesis in starfish, Amphitrite, and Chætopterus, also bring about at the same time agglutination of these eggs and the formation of giant embryos. The problem at which Driesch once worked, and which in sea-urchins is beset with great difficulties, namely, to bring about the coalescence of the contents of several eggs, succeeds beautifully in these experiments, and to a large extent especially in the eggs of starfish. I need scarcely emphasize the fact that it is of great theoretical importance that the ions which bring about artificial parthenogenesis also in a definite sense and at the same time alter the physical state of the egg. I have not yet succeeded in finding a specific ion which brings about the development of 
the unfertilized eggs of sea-urchins. It would be of interest to determine whether such an ion when it is found also brings about an agglutination of the sea-urchin eggs.

In other forms, Nereis, Podarke, and Phascolosoma, the experiments have been carried far enough so that we can say that artificial parthenogenesis (swimming larvæ) is possible in these. The experiments, however, have not yet been worked out sufficiently in order to allow them to be published.

We can say with certainty of the methods given here that they lead to successful results in the American forms on the Atlantic ocean. In the attempt to discover new methods it may perhaps be well to keep the following (theoretical) considerations in view, which I have discussed in greater detail in various earlier papers. The artificial methods for obtaining parthenogenesis must be able, first of all, to favor the liquefaction or other destruction of the nuclear membrane. Secondly, they must also alter in a definite way the physical properties of the protoplasm (viscosity, etc.). It seems that in the eggs in which artificial parthenogenesis has succeeded thus far (and possibly in many, if not all, other eggs) chemical changes take place under natural circumstances in the unfertilized egg, which endeavor to alter the egg in the two directions mentioned above; that these, however, under ordinary conditions occur so slowly that the egg dies before it undergoes actual cell-division. Those circumstances which are able to accelerate these natural processes will also bring about the development of the unfertilized egg. 
INDICES 



\section{AUTHORS' INDEX}

Allman, 116, 117, 118, 128, 129.

Andrews, E. A., 289.

Araki, 372.

Arrhenius, 450.

d'Arsonval, 496.

Aubert, 187, 371. 404, 754.

Baer, 345.

Bardeen, 363.

Béclard, 426 .

Bemmelen, van, 466.

Bert, Paul, 9, 378.

Berthold, 506.

Bickford, E., 336.

Bickford, Miss, 629.

Biedermann, 420, 518 .

Birukoff, 449 .

Bonnet, Charles, 118, 119, 228, 250, 627.

Boveri, 325, 331.

Breuer, 186, 189.

Budgett, j07, 636 .

Bumpus, 282, 597.

Bunge, 310, 370.

Bunsen, 236.

Castell, 404.

Chauveau, 496.

Chun, 290.

Claus, 356.

Conklin, Dr., 576.

Contarini, N., $167,171$.

Cooke, Miss, $450,469$.

Cremer, 499.

Cunningham, J. T., 190.

Cushny, 511, 760 .

Dalyell, 116, 117, 127, 128, 129, 136, 175, 250, 627.

Danilewsky, 482, 491.

Darwin, 77, 81, 286, 3\%8.

Delage, 187, 729, 770 .

Demoor, 384.

De Vries, 231.

Dewitz, J., 23, 111, 580.

Diquemare, 167 .

Dohrn, A., 338.

Doncaster, 768 .

Driesch, 589, 629, 676, 771.

Driesch, Hans, 105, 143, 306, 307, 323, 332.

Dubrochet, 378 .
Duclaux, 635.

Duhamel, 119.

Dutrochet, 426 .

Edwards, 126.

Engelmann, 14, 15, 73, 7i.

Faraday, 489, 496.

Farkas, 53).

Fernet, 236.

Fischer, 597, 733, 740.

Forchhammer, 225, 242.

Fraenckel, 535.

Friedenthal, 535, 749.

Friedlander, 438 .

Friedlånder, B., 221, $357 \mathrm{ff}$.

Galileo, 81 .

Garrey, W. E., 708, 749.

Gemmill, 597.

Geppert, 479.

Giard, A., 686.

Gleichen-Russwurm, 88 .

Goltz, 189, 368, 437, 438.

Graber, 12, 13, 16, 358 .

Greely, 729.

Greeley, A. W., 769.

Greene, 530, 535, 754.

Groom and Loeb, 89, 180, 272, 290.

Gruber, 508 .

Hardy, 711.

Hammarsten, 623.

Harper, 739.

Hegel, 38.

Heider, A. von, 201, 250.

Hempel, 310.

Herbst, 205, 307, 575, 589, 590, 595, 627, 686 .

Hermann, 370.

Hertwig, 25\%, 325, 580, 595.

Hertwig, O., 684.

Hertwig, R., 581 .

Hilger, 229.

Hoeber, 535.

Hoek, 340.

Hoff, Van 't, $450,496,499$.

Hoffmeister, 77, 78, 378, 513.

Hogies, 88.

Hoppe-Seyler, 225, 244, 245, 371, 644.

Howell, .513, 519, .533, 7..54.

Huxley, 286. 
Jacobsen, 241.

Janósik, 543.

Kahlenberg, 451, 452, 474.

Kohlrausch, 456.

Külne, $372,440,448$.

Kulagin, 580 .

Lewis. 728, 738.

Lingle, D. J., 708.

Locke, 526. 533, 549.

Lubbock, 10, 11, 5.5.

Ludwig, 238.

Lyon, 87 .

Mach, Ernst, 69, 81, 87, 88, 187, 189, 202, 499.

Marshall, W., 117, 283.

Massart, 283.

Mathews, 579, 729, 768 .

Maxwell, 47 .

Mead, 540, 591, 656.

Metschnikoff, 637 .

Miescher, 637.

Mingazzini, P., 217, 222.

Moore, A., 708.

Moore, Miss, 696.

Morgan, 577, 591, 607, 618, 644, 676.

Mäller, Johannes, 9.

Maller, Wilhelm, 43.

Neilson, 733, 740 .

Noll, 202, 203.

Norman, 540, 577, 578, 607, 618, 644 .

Norman, W. W., 399 ,

Nussbaum, 117, 205, 321, 322, 323, 336, 341, 508,580 .

Ostwald, 450, 456, $459,476,490$.

Ostwald, Wolfgang, 292.

Pasteur, 636, 689.

Pauli, Dr. W., 5 $48,622$.

Pemsel, 547.

Pfluger, 202, 323, 371, 404.

Plateau, 110.

Pleasanton, General, 126.

Preyer, 184, 185.

Prowazek, Dr. S., 686.

Rádl, $69,87$.

Ranke, 450.

Réaumur, 7, 37, 38, 41, 56.

\section{Regoli, 75.5.}

Ringer, 513, 519, 533, 549, 749 .

Romanes, 37, 80, 81, 541, 560 .

Roth, 2:6.

Roux, 448.

Sabbatani, 753, 75.j.

Sachs, 2, 4, 5, 6. 7, 14, 42, 73, 80, 89, 96, 97, $102,176,179,207,211,212,215,249,342,343$, 34.

Saussure, 378 .

Schrader, 88, 186, 347.

Schmankewitsch, 237, 238, 239, 240.

Schwann, 378.

Semper, 56, 229, 230, 248.

Sewall, 186.

Spallanzani, 370, 378, 627.

Spencer, Herbert, 229.

Spiro, 546, 517.

Spitzer, 506.

Stahl, 6, 14, 73, 75.

Steiner, 187, 345, 346.

Stieglitz, 546.

Strasburger, 5, 73, 283.

Strassen, zur, 676, 678.

Tichomirof, 580.

Tiedemann, 404.

Tornier, Gustav, 436.

Torrey, 167.

Traube, 506.

Trembley, 7. 8, 73, 116, 118.

True, 451, 452, 534 .

Verworn, 506, 507, 508.

Vignier, 684.

Voit, 499.

Wallace, 511, 760 .

Weismann, 319.

Wilson, E. B., 686, 768 .

Winkler, Hans, 686, 688.

Wheeler, 287, 288.

Whitman, C, O., 734, 739.

Wortmann, 6, 212, 231.

Wüllner, 238.

Young, Emil, 427.

Zoethout, 694, 759 .

Zuntz, 236, 237, 309. 


\section{SUBJECT INDEX}

ABsorption OF WATER: relation of, to regeneration, $223 \mathrm{lf}$; a basis for judging effects of ions, 453; effect of $\hat{H}$. and $\mathrm{OH}$. ions on, $164 \mathrm{ff}$; by muscles and soaps, $510 \mathrm{tr}$.

Acins: physiological effects of, $453 \mathrm{HF}$., 501 if.

ACTINIA CARA: heteromorphosis in, 166.

ACTIXIA diAPIENA : heteromorplosis in, 171.

ACTINIA EQUINA: heteromorphusis in, 166 ff.; stcreotropism in, 170 .

ACTINIA MEsEMBRYAxTHEMUM: geotropism in, 183; basal end preferred in new growth, 201 .

Actixospherium: exception to Pflüger's law, 4t0; liquefaction of protoplasm of, 448.

ADAMSIA RONDELETTI: heteromorphosis in, 166.

ADVENTITIOUS ROOTS: stereotropism of, 136.

AglaOphenia PLCIA: heteromorphosis in, 115, 130; morphology of, 130; determinants of heteromorphosis in, 132; stereotropism in, 135; longitudinal growth of, 136; larve of, 137; geotropism in, 176.

ALGE: influence of direction of rays of light on, 5, 89; heliotropism of swarmspores of, 283 .

Amblystoma : influence of central nervous system on devclopment of, $436 \mathrm{ff}$.; galvanotropism in, $440 \mathrm{ff}$.

AMMONIUM CHLORIDE: effects on regeneration and growth, $2 \downarrow 6$.

AммотнЕA: segmentation in, 340.

АмоевА : spontaneity in, 321.

AMPHIPYRA : heliotropism in, 21 ; stereotropism in, 21 ; gcotropism in, 44 .

AMPHITRITE: artificial parthenogenesis in, 770 .

ANEMONIA SULCATA: heteromorphosis i11, 166 .

ANISOTROPY : influence of intense light on, 62 .

ANTENNULARIA: heteromorphosis in, $628 \mathrm{ff}$.

ANTENNULARIA ANTENNINA : geotropism in, 177; growth in, devendent on geotropism, I91-204; variation in, 204; irritability and growth in, 213; heteromorpliosis in, 249.

ANTs: influence of less refrangible rays of light on wingless form, 11; heliotropism of winged form, 19,113 ; relation between heliotropism and sexu. ality of, 52, 113: factors detcrmining nuptial fliglit of, 53.
ARBACIA (SFA-URCHIN) : effect of change of concentration of sea-watcr on cleavage of eggs of, $253 \mathrm{ff}$; t twin production in, $303 \mathrm{ff}$.; limit of divisibility of em. bryo of, 323 ff, ; lack of oxygen and scgmentation of egrs of, $400 \mathrm{Hf}$.: effect of ions on unfertilized egrs of, 576 ff.: on fertilized eggs of, $581 \mathrm{ff}$; ; a rtificial parthenogenesis in, $624 \mathrm{ff}$.

Artevia MülhaUsexiI: artiflcial conversion into Branclipus, $237 \mathrm{ff}$.

Artemia s.lLiNa: conversion into Mülhausenii, 237 ff.

ARTISTIC IMPULSE: anthropomorphic conception of, 165 .

Ascaris: agglutination of eggs of, 678 .

AssOCIATIVE MEMORY : definition of, 36i.).

Asterias (STAR-FISH): gentropism in 183 ff., 291 ; artificial par thenogenesis by shaking eggs of, 768 .

Asterias Forbesir : artificial parthenogenesis in, 644 ; prolongation of life of unfertilized eggs of, 728 ff.

Asterina gibbosa: geotropism in, 183.

AsTERINA TENUISPINA: heliotropism in 183.

AUDITORY NERVEs: relation of, to orientation, 188.

AURELIA AURITA: relation of concentration of water to contractions of, 561 .

BACTERIA: heliotropism of, 15; oricntation influenced by assimilation, 15 .

BALANUS PERFORATUS: negative stereotropism in, 111; change of scnse of hcliotropism in, 113, 272, 417: depthmigrations of, 290

BARANA CASTELLI: regeneration of, 338.

BAsEs: physiological effects of, 461.

BATHOMETRIC DISTRIBUTION : of pelagic animals, 178: physiological conditions determining, $289 \mathrm{ff}$.

BEETLES : heliotropism of, $56,70,85$.

BLOOD-VEssels: devclopment of, $297 \mathrm{ff}$.

Вомвхх : parthenogenesis in, 580 .

BOMBYX LANESTRIS: heliotropism in, 38.

BOMBYX NEUSTRA : geotropism in, 85.

BraIN : regeneration of, 251; physiology of, in worms, $34 \mathrm{i}$ ) $\mathrm{ft}$.

Branchiomma: explanation of eye oll gill of, 97 .

Braxchipcs: Schmankcwitsch's experiment on, 237.

Bryopsis: organization coutrolled by exterual forces, $20^{\circ}$.

BURSARIA : heliotropism in, 15.

BUTtERfles: sleep of, 37 ; lieliot ropism in, 20,37. 
CAMPANLLARIA : heteromorphosis in. 629.

CATALYTC substaxces: importance in oxidation, 505 .

Caterpillars: heliotropism in, 20,42, 74.

CErL-division: mechanics of, 389.

Cereactis A URANTIACA: heteromorphosis in, 166.

Cerebratules margixates: brain physiology of, $3: 6 \mathrm{ff}$.

CERIANTHLS MEMBRAxACELS: secretion of, due to friction, 99 ; lack of heteromorphosis in, 116: formation of tentactes of, 145; heteromorphosis in. 150; relation between form and irritability of, 152 ; life phenomena of, 159 ; importance of turgor in, $162 \mathrm{ff}$; external conditions in formation of tubes of, 16.).

Chetoptercs: artificial parthenogenesis in, $540,779,646,674,770$; specific effects of $\mathrm{h}$ ions on, 6.56 .

CHemical stimeli: orientation of Musca toward, 66.

Chlorophyll-Bearisg Plasts: influence of light on movements of protoplasm of, 6 .

Chromatophores: distribution in Fun. dulus, :200.

Ciosa INTEstinalis: organization of, 215; regeneration of nervous system of, 217 ; th reshold of stimulation of. 219 .

Cladocora : geotropism in, 201 ; heteromorphosis in, 250.

Cleavage: general remarks, 253 ff.; lack of ixygen and, $373 \mathrm{ff}$ : carbon dioxide and, $393 \mathrm{ff}$.; pure oxygen and, 394.

Clepsine: oxygen necessary for maturation of eggs of, $73+$.

Coccisella : geotropism in, 85, 179

CоскRоAсн : geotropism in, $86,182$.

Color Preference: anthropomorphic idea of, 16.

CoMPENSATORY MOVEMENTs: influence of inner ear on, 186 .

CostaCt-stimeli : effect on orientation, 193; effect on organization of, 214.

COPEPODS : heliotropism of, 282; change of sense of heliotropism, $283 \mathrm{ff}, 411$.

CRTPtops: stereotropism in. 110.

CTENolabrus: influence of lack of oxygen on, $378 \mathrm{ff}$.; influence of carbon dioxide on, $393 \mathrm{ff}$.

Cucumaria cucumis: geotropism in, $180 \mathrm{ff}$.

CoMA RATHKII : heliotropism in, $73 \mathrm{ff}$.

Crclas: effect of hydrogen on heart-beat of, $41 \%$.

DAPHNia PULEx: Bert's anthropomorphic idea of, 9; Lubbock's idea of "preference" in, 10.

DEPTH DISTRIBUTION AND MIGRATION: conditions determining, $289 \mathrm{ff}$.
DEYELOPMENT OF ORGASS: influence of liglit on, 4?iff.

DIVISIBILITY OF MATTER: orientation of particles, 117; limits of, $321 \mathrm{ff}$.

DROSERA : reactions of, 286 .

EArthworms: heliotropism in, 73, 77; brain physiologs of, $3.57 \mathrm{ff}$.

Ecrixus: segmentation not influenced by light, $t_{2} i$.

Electrical Waves: physiological effects of, 482 if.

Embryosic tissue: effects of ions on, 56.) $\mathrm{ff}$.

Epheneridex: geotropism in, 44.

ECDENDRJCM RACEMOSUM : heliotropism in. 106: heteromorphosis in. 140,172; influence of light on growth of, $42 x$.

EvGLExA: influence of direction of rays on, 14; influence of refrangibility of rays on, 14 ; sensitive spot of, 77 .

Eres: relation between irritability and, 56 .

Fertilizatiox: nature of, 539, 620, 638 , 646 ; theory of, 683,740 .

FLY (LARYA): heliotropism of, 20,6s, 158.

Forficula acriçLariA : heliotropism of, 22 ; stereotropism of, 110,158.

FrEEZING: effects of, 225.

Friction: a cause of movement, $107,110$.

Fuxpulus: development of embryo of, $295 \mathrm{ff}$.; sensitiveness to lack of oxygen, 309,397 ; effects of lack of oxygen on cardiac activity of embryos, 404 ; influence of light on embryos of, 434 ; effects of ions on, 2.50 ff.; parthenogenesis in, 682 .

Fusios: of cleavage cells through lack of oxygen, 383 .

Galvaxotropism: of Amblystoma, 40 $\mathrm{ff}$.; theory of, $410 \mathrm{ff}$.; of Crustaceans, 447.

Gammares Locesta: leliotropism in, 73.

Gastrostyla : divisibility of, 321 .

GEOMETRA PINIARIA : lieliotropism in, 40.

Geotropism: in Porthesia chrysorrhoea, 33; in Lepidoptera, 43 ; in Amphipyra, 44 ; in Bombyx, 85; theory of, $10^{2}$; in Hydroids, 17t $\mathrm{ff}$; ; in free-swimming animals, 178; in Asterina, 183; dependence on imner ear, 185; influence of, on axis of eves, 186; in Antemularia antennina, 251; relation of, to heliotropism, 28j; in Loligo, 292; in star-fish, 292.

Goxionevus : effects of ions on 553, 559; parthenogenesis in, $68^{*}, 7.54$.

GoxothyrEA LOVExII : abnormality of growth in, 14; heteromorphosis in, 173.

Gravitatios: relation to light, 95, 105 effects of, on Cerianthus, 107, 109, 15t ff. ; effect of, on orientation of body, 
186 ; effect on position of eyes, 186 ; relation to heteromorphosis in Antennularia, $191 \mathrm{ff}$.

Greex slipper aximalcelde: heliotropism of, $\mathbf{1 5}$.

Growth: phenomena of importance in, 17i): de pendence of, on geotropism, 191 ; relation between concentration of seawater and, $228 \mathrm{ff}$, ; relation of, to quantity of wator, 247 ; and regeneration, 252.

HeMATococcus: heliotropism in, 11, 283.

HEART: action of potassium salts on, 296.

HeLIOTROPISM : identity of, in animals and plants, $1 \mathrm{ff}$., 89 ; influence of direction of rays on , 2, 4, 5, 16,53,91, 108, 26.5; in plants, 4; in Hydra, 8; in Euglena, 14; iu Infusoria, 14; in bacteria, 15 in Bursaria, 15: methods of experimentation, 17 ; negative form of, 17,56 positive form of, 17, 24; effect of colored rays oll, 18, 29 ff.; in ants, 19, 52. iu caterpillars, $20,42,74$; in fly larve 20 ; inversion of sense of, $20,68,26 \% \mathrm{ff}$.' $417 \mathrm{ff}$.; in Amphipyra, 21 ; in Forficula auricularia, 22; effect of temperature on 37 ; in butterflies, 37 ; in Bombyx lanestris, 38; in Moths, 38; in Sphinx euphorbia, 38; in Geometra piniaria, 40; periodic variations in, 40 ; in $\mathrm{Papi}$ lio machaon, 42 ; in plant lice, $45 ;$ in beetles, $56,70,85$; in Mesocarpus, 56 , 113; character of protoplasm in. 57; in Musca, 57 ; in Tenebrio molitor, 70 ; in June bugs, 71 ; iu Melolontha vulgaris, 71 ; in Cuma rathkii, 73 ff.; in earthworms, 73, 77; in Gammarus locusta, 73; in leeches, 73 ; in planaria, 73; in snails, 73 ; distribution of, in animal kingdom, 73 ; variations of, according to pole of animal, 79,83 ; not dependeut on central nervous systcm, 84,221 ; in sessile auimals, 89 ; in Spirographis Spallanzanii, 90-110; Sach's theory of, 102; in hydroids, 103; in sertularia, 103,266; relation of, to instinct, 109 ; sexuality in relation to, 113: in Balanus perforatus, $113,272,417$; lack of, in Tubularia mesembryanthemum, 126; in Eudendria, 141; effect of, on heteromorphosis, 174; iu Asterina tcuuispina, 183; in Ciona, 221 ; in Limulus polyphemus, 267 ; theory of, 270 ; in Polygordius, 273; intensty of, 273 ; effect of concentration of sea-water on, 279 , 282 ; in Temora longicornis, 282 ; in Covepods. 283; difference in locomotion under influence of, 284 ; liberation of encrgy in, 286; in Loligo, 291; lack of oxygen in, 417 .

HEREDITY : theory of, 319 .

Heteromorphosis: in Aglaophenia pluma, 115, 130; definition, 120; in 'Tubularia nesembryantlemum. $120 \mathrm{ff}$.; in Plımularia pinnata, 137 ; in Eudendrium, 138, 140, 172; effects of aeration on, 140, 141; in Sertularia, 142; in (to. nothyrea lovenii, 144, 173; ill Ceriall- thus membranaceus, 1.50 ; in Actinia cara, 166; in Actinia eruina, 166; in Adlamsia roncleletti. 166: in Inemonia sulcata, 166: in Cereactis anrantiaca, 166; in Actinia diaplena, 171; law grov erning, 173; influence of geotropism on, $191 \mathrm{ff}$; in uninjured organs, 1945; casuistic ideas of, 249 ; in Intenuularia antennina, 249; in Cladocora, 250: in horse-shoe crab, 267; in Hirudina, 341 ; in Hirudo, 343; in Crustaceans, 627; in Hydroids, 627 ff.; in Antennularia, 628 ff.; in Campanularia, 6:9.

HYBRIDIZATIOx : possibility of, between Chætopterus and Echinoderns, 678 .

HYDRA : heliotropism of, 8,73 ; theory of polarity in, 117, 118, 216; regeneration in, $149,150,173,205$; amount of substance necessary for regeneration of, 336 .

HYDroIDs : heliotropism iu, 103-5; stereotropism in, 111; heteromorphosis in, $115,116,627 \mathrm{ff}$.; geotropism in, 177 .

Hydromeduse: influence of jons on contractiou of, 541 ; Romanes's ideas of, 5.11 .

HYDROSTATIC PRESSURE: importance of, for growth of tentacles of Cerianthus, 17.); relation to geotropism, $181 \mathrm{ff}$.

Hydrotropism : in Plasmodia, 179, 18:.

HyPERSENSITIVENESS OF SKIN : production and suppression of, by electrolytes, $748 \mathrm{ff}$.

IxFUSORIA: heliotropism in, 14, 73; regeneration in 205: importance of nucleus in, 321; influence of lack of oxygen, 636 .

Ixsтinct: inherited, 61; movements called instinctive due to physical laws, 107; physical laws in, 107-110; antlıropomorphic iclea of, 16.

ION-PROTEIDs: importance in absorption of water by muscles, 510 ff.; rôlc in life-phenomena, 544 ff.; relation to ciliary movements, 5i, $\mathrm{ff}$; ; in parthenogenesis, $646 \mathrm{ff}$.

Ioxs: physiological etfects of, 4.0 ff., 501 If.; in relation to absorption of water by muscles, $464 \mathrm{ff}$; ; velocity of nigration of in relation to toxicity of, $47 t$ if.; and rhythmical contractions of muscles, 518, 5.59; effects of, on devel. opmient of muscle, 56.5 $\mathrm{fr}$; ; effect of, on undifferentiated embryonic tissuc, $56^{\circ}$ tf.; in artificial parthenogenesis, 576 ff.; effect of, on fertilized eggs of $\mathrm{Ar}$ bacia, $581 \mathrm{Hf}$.; effects of, in artificial partlenogenesis of giant and dwarf embryos of Arbacia and Chetopterus, $674 \mathrm{tf}$,; effect of, on nerves, 703 ff.; toxic anci antitoxic effects of. $708 \mathrm{fr}$.

IRRITABILITY : a function of temperature, 36 ; sex-ditferences iu, 56; relation between structure of body and, 76 : distribution of, 80 ; and form, 152; and organization, 213; depcudence of, on concentration of medium, $26^{\circ}$.

Isopons: cliange of scuse of lieliotropisill of, 419 . 
JUNE-BUG LARVE: heliotropism of, 20,71.

LACK of OXYGEx: influence of, on fish embryos, 309 tf.; and Perca flnviatilis, $3: 0$; physiological effects of, $370 \mathrm{ff}$.; and Copcpods. 373; and Ctenolabrus egus, 37t; influence of, on Fundulus eggs, 375,397 ; and segmentation of $\mathrm{egR}$. $400 \mathrm{tf}$.; and cardiac activity of fish embrvo4, 404; and (yclas larve, 417 ; and heliotropism, 417; and pigment cells, 420.

LEECHES : heliotropism in, 73: oral end more sensitive to light, 78 ; stereotroJism in, 79 ; lack of regeneration in, 341 ff.; brain physiolngy of, 361 .

LEPIDOPTERA: heliotropism in, $7,37,40$, 54, 56, 61, 74. 86; chemotropism in, 112 .

Levcocrtes: migration of, due to stereotropism, 111.

LIGHT: effect of direction of ray on movements, $2,4,5,16,53,91,105,265$; effective rays of $, 3,5$; effect of change in intensity of , $3,82.276$; effect of, on swarm-spores of algre, 5; effect of, on Lepidoptera, 7 ; effect of, on Protozoa, $\tau$; mechanical cffects of, $\tau$; effect of, oll water fleas, 8 ; effect of, on Daphnia, $9 ;$ influencing "instinctive" movements, $10 i, 109$; effect of, on development of organs, $42 ;$ ff.: effect of, on Fundulus embryos, 434 ff.

LIMULUS POLYPHEMUS: heliotropism in, 267. 28x; locomotion dependent on sense of heliotropism of, 284.

LOLIGO: heliotropism in, 291; gcotropism in, 292.

Loss OF WATER: effect of, on cleavage, 253: influence of, on embryos, 309, 314.

LUMBRICUS FETIDUs: brain physiology of, 359 .

LYMNEUS STAGNALIS : growth in, 229.

Macherites: blindness of, as rclated to sex, 56

MARgelis: heteromorphosis in, $628 \mathrm{ff}$.

Maturation: of unfertilized cggs of star-fish, $728 \mathrm{ff}$.

MedesA : periodic migration of, 366 ; ionproteids in, 544; locomotiou of, 553; effects of Ca ions on, 753 .

MELOLONTHA VULGARIS: heliotropism in, 71.

Mesocarpes: influence of light on, 6 .

Metamorphosis: influence of central nervous sy'stem on, 436 .

MICELLA : conceptions of, 334.

Migrations of Aximals: influence of geotropism on, 180; physiological conditions determining, $289 \mathrm{ff}$.

Mотнs: heliotropism in, $7,38$.

Multiple Embryos : development of, 303.

Musca vomitorid: helitropism in, 56, 113; stereotropism in, 64, 68; effect of heat on orientation of, 65 : relation of orientation of, to chemical stimuli, 66 : movements due to sum of stimuli, 112.
MUsCLE: absorption of water by, ,j10 ff.; rhythmical contrictions of, 518 ff: contact-irritability of, 692 ff.: production and suppression of twitchings of, by electrolytes, 740 ff.

MySID.E: stereotropism in, $\mathbf{1 1 0}$

Nemertises : brain physiology of, $356 \mathrm{ff}$.

NereIs: brain physiology of, 358; artificial parthenogenesis in, 772 .

Nerve: regeneration of, 217,252 ; effects of fluorides on, 703 ff.

Nucleus: effect of, on growth. $321 \mathrm{ff}$.; the organ of oxidation, 508 .

OCELLA: formation of, in Ciona, 216.

EDema: influence of osmotic pressure on, 471 ; increase in osmotic pressure of muscle causing, 515 .

Oral Plates: in Cerianthus, 159, 160.

Orbitolites: changes of enucleated pieces of, 506,507 .

Orgaxization: dependent on orientation, 191, 192; relationship of, to growth, 191, 251; internal canses of. 205 ; Sach's theory of, $207,211,212,215$; Loeb's theory of, 208; relationship of, to irritability, 213; in Ciona, 215; embryonal, 319 .

Orientation: influence of direction of rays on, $2,4,5,16,53,91,10 \times, 265$; inflnence of temperature, 3 ; influence of intensity of light on, $3,4,33^{\circ}$; influence of physical laws on, 51; intluence of form of body on, 75; of plants, 109; composition of forces in, 112; forms of irritability influencing, 174,251 ; influence of gravitation on, 176, 177, 178; governs regeneration and heteromorphosis, 193.

Orthotropism: of organs, 2; in dorsiventral animals, 97.

Osmotic pressure: relation of, to growth, 228, 240; in bursting of eggmembrane, 306 ; relation of, to absorption by muscle, 466 ; in parthenogenesis, $640,648 \mathrm{ff}$

OToLiths: relation of, to geotropism, $16 \overline{7}, 189$.

Oxygex (see Lack of Oxygen): rolc of, in heliotropism, 15 ; relation of, to regeneration, 240, 252; Hoppe-Seyler's theory of action of, 371 ; relation of, to cleavage, 394; relation of, to growth, 400 .

PANTopons: regeneration of, 338.

PAPILIO MACHAON : heliotropism in, 42.

Parthenogenesis: artificial, $539 \mathrm{ff}$., 638 ff.: in Arbacia, $576 \mathrm{ff}, 624 \mathrm{ff}$.; in Annelids (Chrotopterus), 646 ff.; in Fundulus, 682; in Gonionemus, 682; in Podarke, 682; in Phascolosoma. 682,772 ; in Crustaceans, 684 ; sources of error in, $765 \mathrm{ff}$.

Perca Fluviatilis: effect of lack of oxygen on, 320. 
Phascolosoma : artificial parthenogenesis in, 68\%, $77^{\circ}$.

Pнотокinetics: definition, 265; reactions influencing, $286 \mathrm{ff}$.

Phoxichilidiem MAxILLARA: regeneration of, 338 if.

Physiological problems: discussion of, $497 \mathrm{ff}$.

Physiologic Unit: idea of, 322.

Pigmext : relation of, to gravitation, 190 in Tubularia. 210; influence of lack of oxygen on, 4?0.

Plagiotropic orgaxs: definition, 2.

Plasaria: heliotropism in. 73. 77; photokinesis in, 287: heteromorphosis in, 344 ; brain physiology of, $352 \mathrm{ff}$.

PlaxorbIs: influence of light on segmentation of, 427 .

Plaxt lice: heliotropism in, 45, 49, 50, 112; geotropism in, 0 ; temperature effects on, 51, 108: flight movements of, 54; movements of, not voluntary, 109 .

Plaxula: influence of light on, 433.

Plasmodia : geotropism in, $\mathbf{1 7 9}$.

Pltyclaria pIsNata: heteromorphosis in. 137,172

PODARKE: Parthenogenesis in, 682, 772.

Polarity: heliotropism as a factor in, 76 ; Allmann's theory of, 117, 129; as $r$ gards Tubularia mesembryanthcmum, 128 ; in Cerianthus, 206,215 .

PoLYGordius; change of sense of heliotropism in, 273, 293, 417 ; locomotion in, 284.

Polyps: formation of, 124.

PoRTHEsIA CHRYsoRRHoA : heliotropism in, 19, 24-37, 112; stereotropism in, 21.

Potassicm : effects of, on regeneration, 242,252 ; effects of, on Fundulus, 296,297 .

Pressure: effects of, on so-called instinct, 110.

Protoplasm: influence of light on, 6; movem c1its of, 212; isotropy in, 334 .

Protozod: heliotropism in, 7.

Prcnogonides: regeneration of, $338 \mathrm{ff}$.

QUANTITY OF WATER: influcnce on regeneration and growth, $247,252$.

RAxA: influence of light on development of, 427 .

REFlexes : persistence of, in Ciona, 218; in Planaria, 3\% $\mathrm{ff}$.

REGENERATION : Bonnet's theory of, 119 ; definition of, 120; in Tubularia, 12: ; Ciona intestinalis, 217; influence of concentration of sea-water on, 222; necessity of oxygen for, 240; rclation of, to inorganic substances, 24*2, 245; influence of quantity of water on, 247 , $25 \%$; influcnce of magnesium on, $25 \%$ : quantitative limits of, 336; general ideas on, 338; in Pantopods, 338; in Chetopods, 341: and nucleus, 505; of organs in Hydroids, $627 \mathrm{ff}$.
RESEGMENTATION: of Ctenolabrus eggs without oxygen, $37 \times$.

RESPIRATORY ORGAx : cffect of light OH, 97.

RHEOTropism : in Eudendria, 141; in Plasmodia, 179, 182.

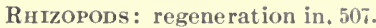

SACCharomyces Cerevisie: a ferment for glucoses, 498.

SCYLlium CaNICUla : geotropism in, dependent on inner ear. $18 \%$.

SEA-WATER: regeneration in, 222: concentration of, and influence on longitudinal growth, 228; analysis of, 242: influeuce of concentration of on segmentation, 257: effect of concent ration of, on heliotropism, 279-8\%.

SEgmextation: of nucleus without segmentation of protoplasm, 258 .

Serpela : heliotropism in, 101, 106: photokinesis in. 239 .

Sertelaria halecisa : heliotropism in. 136.

Sertularia (Polyzonias): heliotropism in. 103; heteromorphosis in. 14? $173,174,249$; change of sense of heliotropism in, 266.

Sessile animals: heliotropism in, 90-106.

SEXUALITY: relation of, to heliotropism. $52,68,113$.

SHARKs : geotropism in, 186.

SiaMese TwINs: formation of, $304 \mathrm{ff}$.

SNaILs: heliotropism in, 73.

SODICM CHLORIDE: poisonous character of solution of, 544 if.

Spermatozod: stcreotropism of, 23, 111.

SPHINx EUPHORBIA: heliotropism in. $38 \mathrm{ff}$.

Spirographis Spallaxzanif : heliotropism in, $90-100$; movements of, not instinctive, 107 ; change of sense of heliot ropism, 266.

STENTOR viridis: influence of oxygen on, 15.

Stereotropism: definition of, 23: in Porthesia chrysorrhoea, 34; in Lepidoptera, 54; in plant lice. 54; in ants, $5 i$; in June-bugs, 71 : relation of, to instinct, 109, 111: in Tubularia mesembryanthemum, 121, 124; in Aglaoplenia pluma, 13\%; in Plumularia, 138; in Sertularia, 143: in Hydroids 174: in Antennularia antennina, 251: in Lmmbricus foetidus, 360 .

Stimulation: in heteromorphosis, 140: threshold of, 219 : latent period of, 221 .

STRONGYLOCENTRATUS FRANCINCANCS: artificial parthenogenesis in, 626, 638, 644.

STRONG YLOCENTRATUS PURPUR.ITU' : artificial parthenogenesis in, 626, 638, 644 .

Suxlight: effect on Lcpidoptera, 48; effect on Polygordius, 277. 
TEMORA LONGICORxis: change of sense of heliot ropism in, $28 *$.

Temperature: effects of, on Porthesia, 36: oll Mnsca larvie, 65; on Polygordius, 274; on depth-migrations. 293 .

TEXEBRIO MOLITOR: heliotropism in, 70; stereotropism in, 71 .

TEXTACLES : formation of, in Ceriantlus, $145-152,160$

Trysixozoox BRocchil: regeneration in, 2201; brain pliysiology of, $347 \mathrm{ff}$.

Toxopxecstes: natural parthenogenesis in, 64 .

TrADEscAxtIA: influence of oxygen on formation of cell wall, 354 .

TRAxsForyATIOx OF ORGAxs: in Hylroids, $627 \mathrm{ff}$.; basis of, $634 \mathrm{ff}$.

TuBEs: formation of, in Cerianthus, 164.

TUBLLARIA: heteromorphosis in, 118, 215; stereotropism in, 174; irritability and organization of, 211 : regulation and concentration of sea-water in. 290 ff.; effect of salts on growth of, 230 , $242 \mathrm{ff}$.; regeneration of. 336 .

TUBCLARIA CROCEA : organization of, 214. TCBCLARIA INDIVISA: growth of polyps in, $12 \overline{7}$.
TUBCLARIA MESEMBRYANTHEMCM: heteromorphosis in. 120-27: morphology of, 121; laws governing reactions of, 125; conditions of growth of poly ps of, 127; internal causes of organization in. 205 ; stereotropism in, 213 .

TUxICATEs : heteromorphosis in, 627 .

TLRgOR: importance of, in growth, 162 ff., 175 .

VARIITION: in irritability. 40.

VAscular sistem: development of, 297.

VIOLET RAYs: influence of, on growth, $426 \mathrm{tf}$.

VITAL FORCE: anthropomorphic idea, 114.

Voluntary Movemexts: influence of physical laws on, 107, 109, 110.

WAsps: Lubbock's experiments oll, 11.

WITER FLEAs: effect of light on, 8.

WATER RIGOR: influence of dilute sea. water on, 327 .

WrLL: subject to physical influences, $10 \bar{T}, 109.110$.

Worss : brain physiology of, $345 \mathrm{ff}$. 




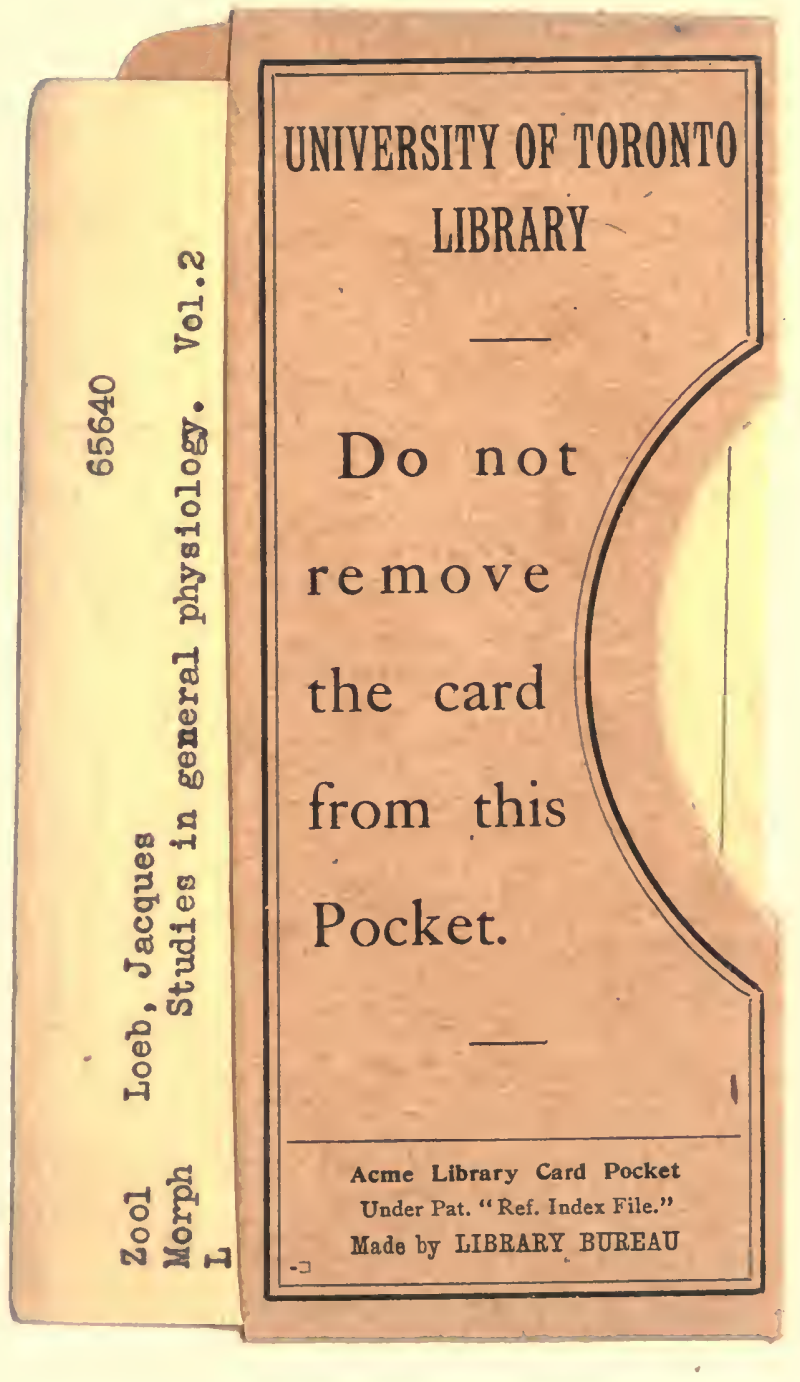


